, $10^{2}+3$

(3)

a 


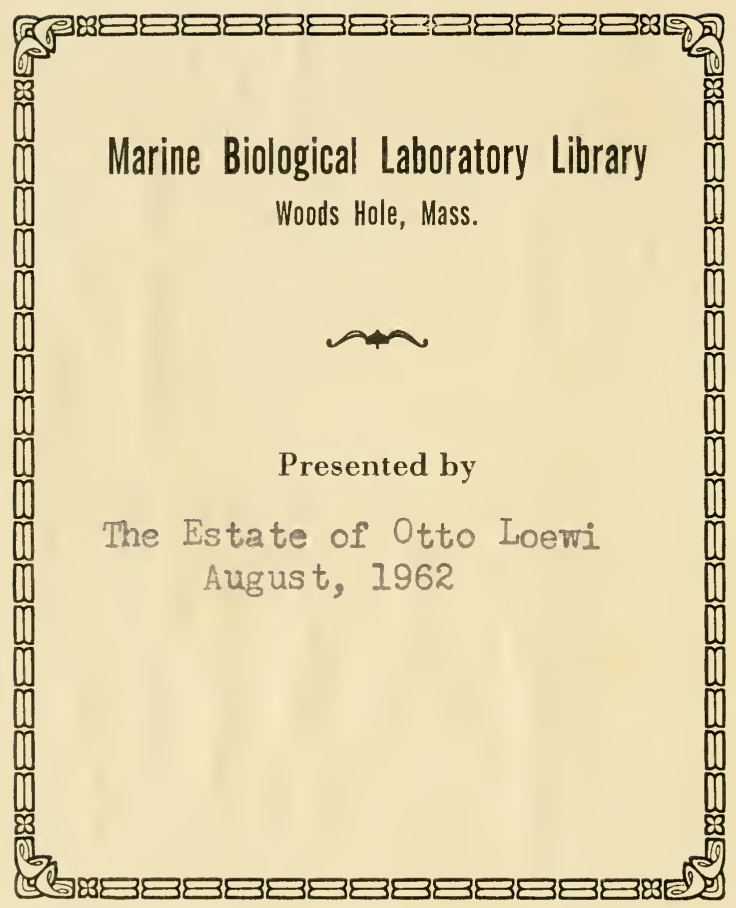


le rwfenor lito hoern,

lnit mice, admuntini cond

$$
\begin{aligned}
& \text { Lappeci- } \\
& \text { Curviel isurlo }
\end{aligned}
$$

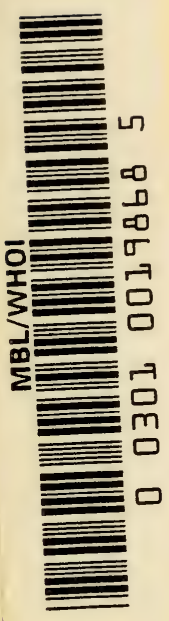



PHYSIOLOGY OF THE SALIVARY (GIANDS 
MONOGRAPHS OF THE PHYSIOLOGICAL SOCIETY

Number 8

Editors: H. Barcroft, H. Davson, W. D. M. Paton 


\title{
PHYSIOLOGY OF THE SALIVARY GLANDS
}

by

\author{
A. S. V. BURGEN \\ M.D.(Lond.), M.R.C.P.
}

Professor of Physiology, McGill University: Deputy Director, McGill University Medical Clinic, Montreal General Hospital, Canada and

\author{
N. G. EMMELIN \\ M.D.(Lund)
}

Professor of Physiology, University of Lund, Sweden

DR. OTTO LOEWL

155 EAST 93RD ST.

NEW YORK 28, N. Yd

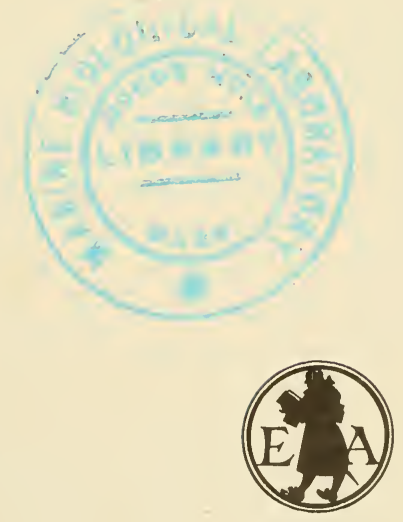

LONDON

EDWARD ARNOLD (PUBLISHERS) LTD. 
(c) A.S.V.Burgen and N. G. Emmelin $196 I$

First published I96I

Printed in Great Britain by Butler \& Tanner Ltd., Frome and London 


\section{PREFACE}

The study of the salivary glands and their secretions enjoyed greater popularity in the past than it does at the present time. Indeed, however great the importance of saliva in the mastication of food and maintenance of our health, the evidence for any unique and essential role of these secretions in the body economy is not great. In most courses of physiology, not even a single lecture is devoted to saliva secretion. On the other hand, the salivary glands are wonderful pieces of physiological machinery which provide unexcelled preparations for the study of autonomic innervation, the action of drugs, changes in blood flow and metabolism during activity, as well as the processes involved in the transport of water and electrolytes. A glance at the table of chapter headings will show that these aspects of the glands have received a great deal of space in this book, in direct relationship to the personal interest of the authors in these matters. Nevertheless, most aspects of salivary physiology have been covered, although not always exhaustively. For instance, it was not considered desirable to refer to all of the vast literature on the composition of the saliva; rather, selections have been made from the papers illustrative of the principles governing saliva composition with neglect of those offering only isolated and unrelated observations. Similarly, in the chapter on comparative physiology, material is cited for the light it throws on the modification of salivary function in different branches of the animal kingdom, but the chapter is in no way encyclopaedic.

We hope that we have laid at least as much emphasis on the present state of ignorance of many aspects of salivary physiology as upon the facts that are solidly established. The interested reader should find many problems that are waiting to be worked upon. We hope that the critical approach to some of these problems may be of special value to workers in the field of dental research.

The writing of this book was helped by the circumstance that enabled one of us (N. G. E.) to spend several months in Montreal as a visiting professor at McGill University in the fall of 1958 . We have also been aided in great measure by the library staffs of 
the McGill Medical Library and University of Lund Medical Library, as well as by our secretaries, Miss Ann Waters, Mrs. Elsa Kaunat and Miss Ursula Delfs.

We are grateful to the Acta Physiologica Scandinavica, Alcan et Cie, American Fournal of Physiology, Archives of Neurology and Psychiatry, British Fournal of Pharmacology and Chemotherapeutics, British Medical Bulletin, Canadian Fournal of Biochemistry and Physiology, Helvetica Medica Acta, Fournal of Biophysical and Biochemical Cytology, Fournal of Cellular and Comparative Physiology, Fournal of Histochemistry, Fournal of Neurophysiology, Fournal of Physiology, Quarterly Fournal of Experimental Physiology, Revue Canadienne de Biologie, and Springer-Verlag and the authors of the articles, for permission to reproduce illustrations which originally appeared in these Journals. One of us (A. S. V. B.) wishes to express his gratitude to the Associate Committees on Dental and Medical Research of the National Research Council of Canada for generous grants in support of his work in salivary secretion over the past six years.

Chapters I, II, VIII, IX, X, XI and XIV were written by A. S. V. B., and Chapters III, IV, V, VI, VII, XII and XIII by N. G. E. 


\section{CONTENTS}

Chapter

I Historical Introduction

II The Anatomy of the Salivary Glands

III Innervation of the Glandular Elements 38

IV Pharmacology of Salivary Secretion 72

V Spontaneous Secretion of Saliva 94

VI Effects of Denervation $\quad 103$

VII Blood Flow and Secretion I2I

VIII The Inorganic Components of Saliva I40

IX The Proteins and Organic Constituents of Saliva $\quad 169$

X Theories of Secretion $\quad 195$

XI Metabolism $\quad 229$

XII The Control of Salivary Secretion 237

XIII The Physiological Role of Saliva $25 \mathrm{I}$

XIV The Comparative Physiology of the Salivary Glands 267 Index

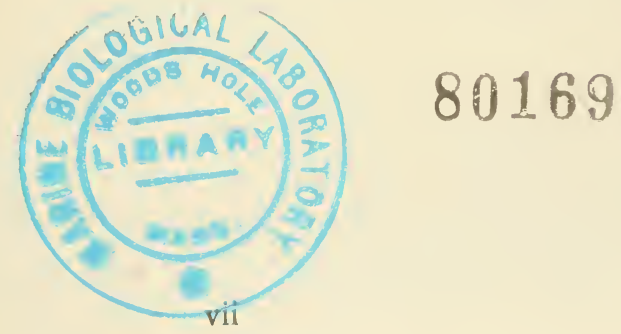





\section{HISTORICAL INTRODUC'TION}

Understanding of the function of the salivary glands has come about slowly. Of course the lubricating and cleansing actions of saliva were known since earliest times, and some details of the anatomy of the glands were known. For instance, Galen in De usu partium had indicated the positions of the major salivary glands and had even described the opening of the submaxillary duct in the mouth. With the revival of learning detailed anatomical descriptions of the glands appeared, beginning with the publication of Vesalius' de Humani corporis fabrica in I 543; other anatomists (e.g. Steno, Wharton, Rivinus, Nuck) expanded these observations, and established the existence of ducts conveying a secretion to the mouth. These anatomists were passionate disputants, greatly concerned about priority of discovery; to them the function of the structures they discovered was a subject for speculation, but not for experiment. The exception was Regner de Graaf, who published in 1677 his brilliant study of the pancreatic secretion. de Graaf prepared dogs with chronic fistulae of both the pancreatic and submaxillary ducts (Fig. I.I). In addition to observations on pancreatic juice, he must have made many on submaxillary secretion, but unfortunately these were never published and we have to be content with less than a page in which he records that salivary flow increased during mastication and swallowing as well as in response to the smell and taste of food. He emphasized the role of saliva in facilitating the swallowing of food. It is curious that such a valuable experimental method as the production of fistulae should have fallen into oblivion and not have been used again until it was revived by Bernard (I856) and Heidenhain (I 868) and later developed extensively by Pavlov (I897).

During the eighteenth century considerable progress was made in the study of gastric digestion, notably by Spallanzani (I 784), who made ingenious experiments on intragastric digestion in many species. He apparently did not consider saliva as contributing to digestion. Bordeu ( $175 \mathrm{I}$ ) in a speculative account of the physiology of the glands, recognized the main circumstances under which P.S.G.-B 
saliva secretion occurs (during speech, mastication, the sight and smell of food and in disease) and hinted at a reflex secretion due to irritation of the nerves in the mouth by food. He also noted that the saliva could be observed to emerge from the opening of the parotid duct in little spurts. Haller ( 1744 ), who attempted the classification of glandular secretions in his Physiology, suggested that secretion

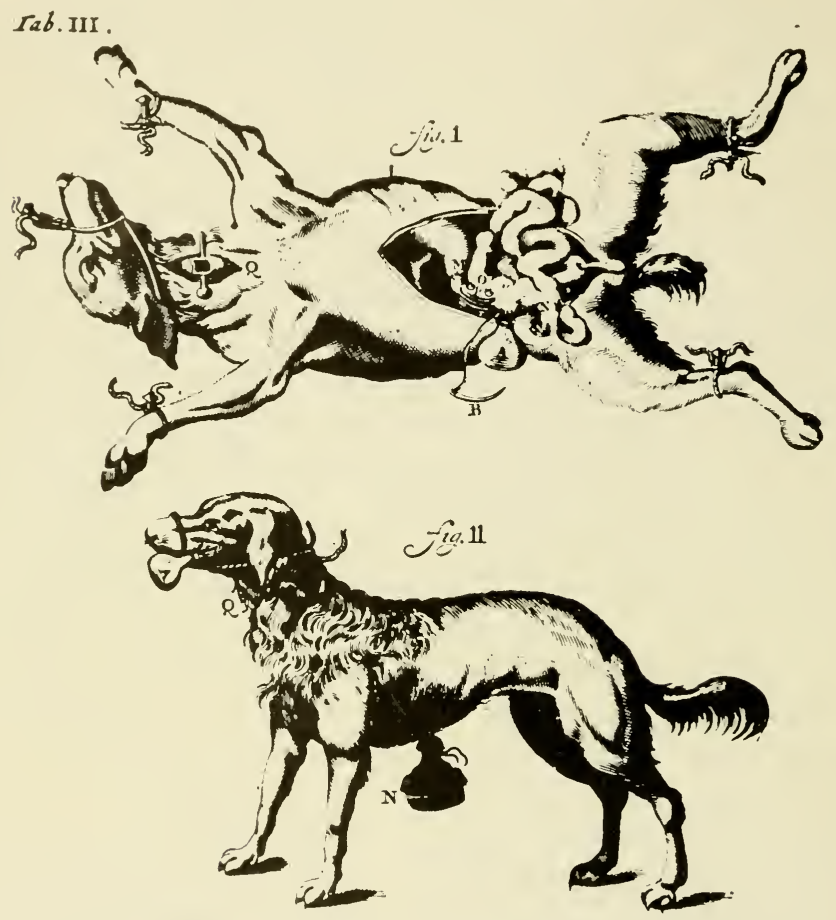

FIG. I.I (a). de Graaf's preparation of dogs with pancreatic and salivary fistulae.

(Regner de Graaf, De succo pancreatico, 1677.)

was due to ultrafiltration from the acini (discovered by Malpighi i683) which he believed to be collections of blood vessels. He suggested that an increase in the rate of secretion in a gland was due to increased blood flow and hence an increase in ultrafiltration.

These views were speculative and the development of a more critical scientific attitude in the early nineteenth century is due largely to the influence of Johannes Müller. Müller wrote a great textbook of physiology which rapidly became the standard work 
throughout Europe; in it he collected together the ideas of the time and examined them critically and sceptically. 'This scepticism threw doubt on the experimental basis of the current ideas in physiology and suggested new experimental and theoretical approaches. The modern reader of this remarkable book is struck by

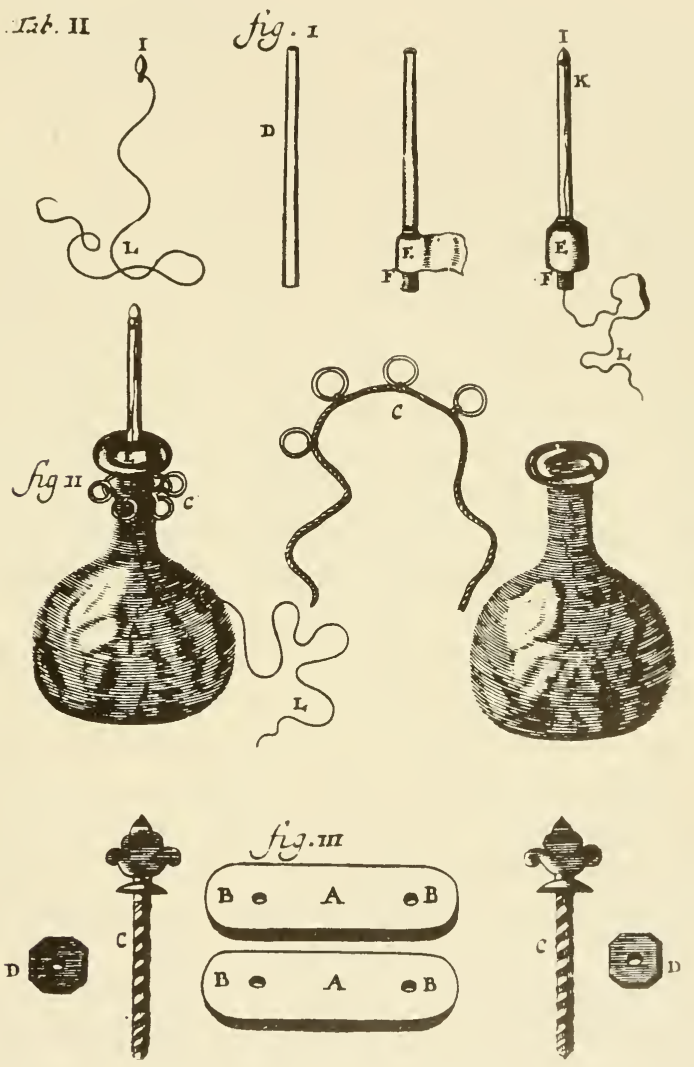

FIG. I.I (b). Cannulae and other instruments used by de Graaf.

(Regner de Graaf, De succo pancreatico, 1677.)

the similarity of its spirit to that of the comparably influential General physiology by Bayliss (1924). Müller was greatly interested in the relationship of the gland cells to their secretion. He recognized the difficulties imposed by the unidirectional character of the secretory process, and was the first to realize that efferent nerves to secretory glands might be secretomotor. He produced 
fairly convincing evidence of this in the case of the vagus and the stomach. Indeed the idea of nervous control of secretion rapidly became accepted and we can only be surprised that it was not until I 85 I that Ludwig proved experimentally the existence of nervous control of salivary secretion.

In this same period the science of biochemistry was arising. Tiedemann and Gmelin's book entitled Physiological and chemical experiments in digestion ( 1826 ) was one of the pioneers of biochemistry. Thanks to Berzelius methods of analysis had been greatly improved, and Tiedemann and Gmelin were to advance these methods further and apply them with remarkable skill and vision to the analysis of saliva and the other digestive juices. They had the perspicacity to realize that results obtained on the saliva obtained from the parotid duct in the dog might be superior for analytical purposes to the more heterogeneous mouth (mixed) saliva. It is regrettable that many contemporary workers have still to learn this lesson. Amongst many observations they proved that the red colour given by human saliva with ferric chloride (noted by Treviranus) was due to the presence of thiocyanic acid which had recently been discovered by Porett. 'They isolated the thiocyanic acid by extraction of thiocyanates from dried saliva with alcohol and distillation of the free acid whose constitution was established by oxidation to sulphate identified by precipitation as barium sulphate. They also showed that the major cation of saliva was potassium (identified as potassium sulphate and potassium chlorplatinate), that saliva was alkaline, and that there were traces of a phosphorus containing fat in it. They made a thorough study of the proteins of saliva, and showed that acetic acid precipitated mucin from saliva as a soft transparent mass. They also found that after crushed oats had been mixed with sheep saliva and left for a while they would no longer give a blue colour with iodine. This appears to be the first description of salivary amylase.

The new methods of analysis developed by Tiedemann and Gmelin were soon applied by Mitscherlich (1832) to the study of a case of parotid fistula in man. In a delightful paper Mitscherlich described the development of the parotid fistula and the circumstances under which the secretory rate changed, these included the effects of diet, mastication and sleep. He also compared the fistula saliva with mouth saliva. Mitscherlich was very impressed with the rapidity with which the saliva flow rate changed with such stimu- 
lation as food in the mouth, and suggested that a nervous pathway was involved; Müller's influence is apparent in this attitude. It was reading Mitscherlich's paper that led Ludwig ( $185 \mathrm{I}$ ) to test experimentally whether there was a secretomotor innervation of the salivary glands. Ludwig investigated the anatomy of the nerves going to the salivary gland and showed conclusively that the chorda tympani was secretomotor to the submaxillary gland. He also showed that in many cases the gland could secrete against a pressure greater than the arterial pressure and indeed that secretion could continue even when the circulation to the gland was arrested, thus disproving Haller's ultrafiltration theory. Ludwig's approach to physiological problems had a sophistication that set him apart from his contemporaries and he was the first man to attempt to apply exact measurement and physical rigour to physiological problems. Ludwig's genius soon became absorbed in other branches of physiology, but the torch was taken up by Claude Bernard, probably the greatest physiologist of the nineteenth century.

Bernard became interested in salivary secretion early in his career and sustained this interest until nearly the end. In the lectures given at the Collège de France in 1856 (Bernard, I 856 ) he collected together a wonderful amount of precise, careful observation and experimentation on the salivary glands. This included a detailed study of the chemistry of the saliva from the different glands collected under a great variety of circumstances, as well as studies on salivary proteins using the novel methods of salting out with sodium sulphate and magnesium sulphate; he also investigated the distribution of amylase in different species. In a study of the total saliva secreted by the minor as well as the major salivary glands, he revived and improved the methods of production of salivary fistulae and introduced the important technique of sham feeding, using an oesophageal fistula.

It was an investigation of the thirst that develops with salivary fistulae that led him not only to a clear appreciation of the moistening and lubricating function of the saliva, but also to the realization that the sensation of thirst was not a peripheral one due to deficient moistening of the mouth but rather to the effects of systemic dehydration. He describes how he arrived at this conclusion thus: "It is not necessary to believe that the excessive thirst after a parotid fistula is due to a great dryness of the pharynx 
giving rise to this sensation. This sensation is rather the expression of a general need created by the diminution of the total body fluid. If one divides the oesophagus in the lower part of the neck in a horse with bilateral parotid fistulae and then gives him water to drink, with each swallow water is squirted out and is not absorbed by the intestine. Under these circumstances the animal's thirst is

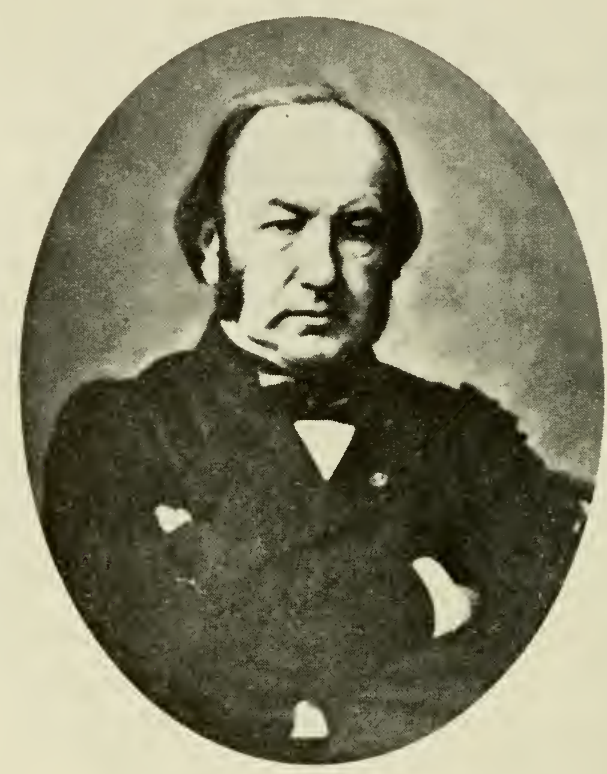

FIG. I.2. Claude Bernard in about i 860 .

(L'Eurre de Claude Bernard, Baillière, I88I.)

not satisfied although the throat is kept moist and the animal continues to drink until exhausted ... but if water is retained and absorbed in the stomach and intestine, thirst is soon satisfied just as it is by direct injection of water into the veins."

Bernard investigated the nervous mechanisms of saliva secretion, and showed that reflex secretion was produced by stimulation of the central end of the lingual, facial and vagus nerves. He also found that the secretion produced by application of sapid sub- 
stances to the tongue was abolished by section of the lingual nerve. He discovered the very striking increase in gland blood flow that accompanies secretion and noted the increased redness in the venous blood (I 858). Another subject of contemporary interest was a study on gland permeability to iodide, cyanide, dextrose, ferric iron and ferricyanide.

We have cited here only a tithe of the more important observations made by Bernard; his papers and, in particular, the 1856 lectures referred to above, should be read by all students of salivary secretion. They are a rich lode of information, much of it forgotten, and the experiments are models of how to conduct physiological investigations and, above all, are presented with charm and with style.

In the latter half of the nineteenth century, salivary secretion was a popular field of investigation especially in Germany and a great deal of detailed and precise observation accumulated, the extent of which can be seen in the masterly review by Heidenhain in Hermann's Handbook of physiology ( 1883 ). Heidenhain himself contributed greatly to this advance with studies on the cytological changes in secretion, which have only been extended in recent years by the use of the electron microscope. Heidenhain's school also did much to develop physiological surgery. Pavlov carried this technique to its extreme, studying the effects of the nervous system on digestive canal secretion with great skill and insight. During the course of these studies the conditioned reflex was discovered and became the absorbing interest of Pavlov's life. One of Pavlov's pupils, Babkin, became a lifelong student of salivary secretion and through his two books and his students, has had great influence on research on the salivary glands.

In the modern period, the rationalization of the anatomy and physiology of the autonomic nervous system brought about by Langley's systematic study of the location of autonomic synapses provided the basis on which Loewi and Dale developed the theory of chemical synaptic transmission, which has had important consequences in the understanding of salivary secretion. Langley's account of the salivary glands in Schaefer's textbook (I898) remains a model and a challenge to his successors. 


\section{REFERENCES}

BABKIN, B. P. (1928). Die äussere Sekretion der Verdauungsdrïsen. Springer, Berlin.

- (1945). Secretory mechanisms of the digestive glands. Hoeber, New York.

BAYLiss, W. M. (1924). Principles of general physiology. Longmans, London.

BERNARD, CLAUDE (1856). Leçons de physiologie expérimentale appliquée à la médecine, Tome 2. Baillière, Paris.

- (I858). De l'influence de deux ordres de nerfs qui determinent les variations de couleur du sang veineux dans les organes glandulaires. C.R. Acad. Sci., 47, 245-253.

- (I 859). De l'influence qui exercent différents nerfs sur la sécretion de la salive. Mem. Soc. de Biol., 9, 85-6.

- (I864). Du rôle des actions reflexes paralysantes dans les phenomènes des sécretions. F. Anat., Paris, I, 507-5 r 3 .

BORDEU, THÉOPHILE DE (175I). Recherches anatomiques sur la position des glandes et sur leur action. Brosson, Paris.

GaLEN ( I60 A.D.). De usu partium. (Teubner ed., Leipzig, I 907.)

gRAAF, REgNeR DE (I677). De succo pancreatico. In Opera Omnia I677, Hackiana, Amsterdam.

HALLeR, Albrecht von (I744). Physiology (trans. S. Mihles). Innys and Richardson, London.

HEIDENHain, R. (i 868). Beiträge zur Lehre von der Speichelabsonderung. Stud. physiol. Inst. Breslau, 4, I.

- (I883). Physiologie der Absonderungsvorgänge. In Handbuch der Physiologie, ed. L. Hermann. Vol. 5, Part I, pp. I4-89. Vogel, Leipzig.

LANGLEY, J. N. ( 1898 ). The salivary glands. In Textbook of physiology ed. E. A. Schaefer. Vol. I, pp. 475-530. Young J. Pentland, Edinburgh.

LUDWIG, CARL (I85I). Neue Versuche über die Beihilfe der Nerven zur Speichelabsonderung. Z. rat. Med., N.F., 1, 255-277.

MALPIGHi, MARCELli (I677). Exercitationes de Viscerum. Gollner, Jena.

Mitscherlich, C. G. (1832). Ueber den Speichel des Menschen. Magazin Ges. Heilkunde, 38, 491-521.

MÜLLER, J. (I 839). Elements of physiology (trans. Baly), and ed. Taylor and Walton, London.

PAVLOV, I. P. (1897). Lectures on the work of the principal digestive glands (trans. 1910). Griffin, London.

SPAllanzani (i784). Expériences sur la digestion de l'homme et de différentes espèces d'animaux (trans. J. Senebier). Chirol, Geneva.

TIEDEMANN, F. and L. GMELIN (I826). Récherches expérimentale physiologiques et chimiques sur la digestion (trans. Jourdan). Baillière, Paris. vesaliI, Andreae (1543). de Humani corporis fabrica, Book 6, Chapter 5. Oporinus, Basel. 


\section{CHAPTER II}

\section{THE ANATOMY OF THE SALIVARY GLANDS}

The gross anatomy of the salivary glands and their nerve supply is adequately described in the standard textbooks of anatomy, and the experimental preparation of the submaxillary and sublingual glands in Liddell and Sherrington (1923). The only description of the approach to the parotid innervation is that given by Heidenhain (1883). In the dog the postganglionic nerve (auriculo-temporal) can be reached more satisfactorily along the inner side of the ramus of the mandible after retraction of the mylohyoid and the tongue and division of both pterygoid muscles (Burgen, I955).

Histologically the salivary glands are composed of acini, a tubule system and excretory ducts. Between the acini and the main excretory ducts there are usually at least two kinds of epithelium lining the ducts. In rodents the ducts are a more prominent feature of the gland histology than are the acini. If custom had not hallowed the use of the term duct for these intermediate structures in the gland, tubule would be more descriptive, for these structures are probably at least as important in the secretory process as the acini and indeed seem analogous to the convoluted tubule in the kidney. The similarity in histology between the striated ducts of the salivary gland and the tubules in the aglomerular kidney of Lophius (Smith, I95I) is very striking indeed. Further it may well be that the somewhat derogatory term "duct" which has been responsible for the neglect from which the collecting ducts (of Bellini) have only recently been rescued, has also been responsible for a general underestimation of the functional importance of the salivary ducts.

The literature on the histology of the salivary glands is very voluminous and citations of original papers would be inappropriate to our purpose in this chapter, which is to provide a morphological basis on which a discussion of the physiology of the salivary glands can rest. The following account is taken from the reviews of Merkel (1883), Zimmerman (1927), Stormont (1932), Rawlinson (1933, 1934, 1935) and Leeson (1959).

In general the salivary glands are organized on a lobular-racemose plan with the lobules being practically independent units. 
The sublingual gland in the cat is more tubular (Lundberg, 1957) in arrangement; this offers several advantages from the point of view of experimental study.

The acinar cells are large polygonal cells arranged in the form of an alveolus, which appear tightly packed after the usual fixation procedures, intercellular spaces cannot usually be seen, nor is any lumen prominent in fixed material. The cells may take on a bluish stain with haematoxylin-eosin which may be interpreted as showing the presence of mucin or a pinker colour interpreted as serous (albuminous) or non-mucous. Stormont and others have pointed out the fallacies and difficulties of mucin staining particularly in cells apparently intermediate in type. All that can be said with confidence is that the presence of basophilic cells in a gland usually correlates with the presence of a viscous saliva (not necessarily very rich in mucoproteins).

In many glands occasional cells of a different type are seen within an alveolus, and in those glands with a consistently mixed cellular character the acidophil cells are arranged as demilunes. Recent histological interpretations agree in considering a demilune as an evagination of a group of serous cells from the main alveolus. Granulation is not always easily seen in these acinar cells. In general, the tendentious subdivision of the acinar cells into histological types previously considered of importance has not proven of value in understanding gland functions.

The acini lead into intercalated ducts formed of small cuboidal cells almost filled by a large nucleus. The scanty cytoplasm shows no striation nor as a rule any granules (Fig. 2.I). The intercalated ducts are often short and inconspicuous in histological sections, they empty into intralobular ducts which are usually known as "striated " ducts and are composed of dense-looking cells with a markedly striated appearance in their basal one-third and a centrally placed nucleus. Occasionally unusual slender cells ("compressed cells") may be seen and also basal cells. The basement membrane is often rather prominent. There is a sharp transition into the excretory ducts which are lined by a two-layered epithelium composed of a columnar superficial layer and a flattened deep layer. This structural arrangement is continued in the main ducts to near their termination where an abrupt change to a multilayered stratified squamous epithelium occurs (Fig. 2.3a). These main ducts are very richly vascularized, and Pischinger (I924) has 
pointed out that the cells in the main ducts have granules which may be extruded into the lumen. In adult rodents the proximal part of the intralobular duct is greatly developed and specialized

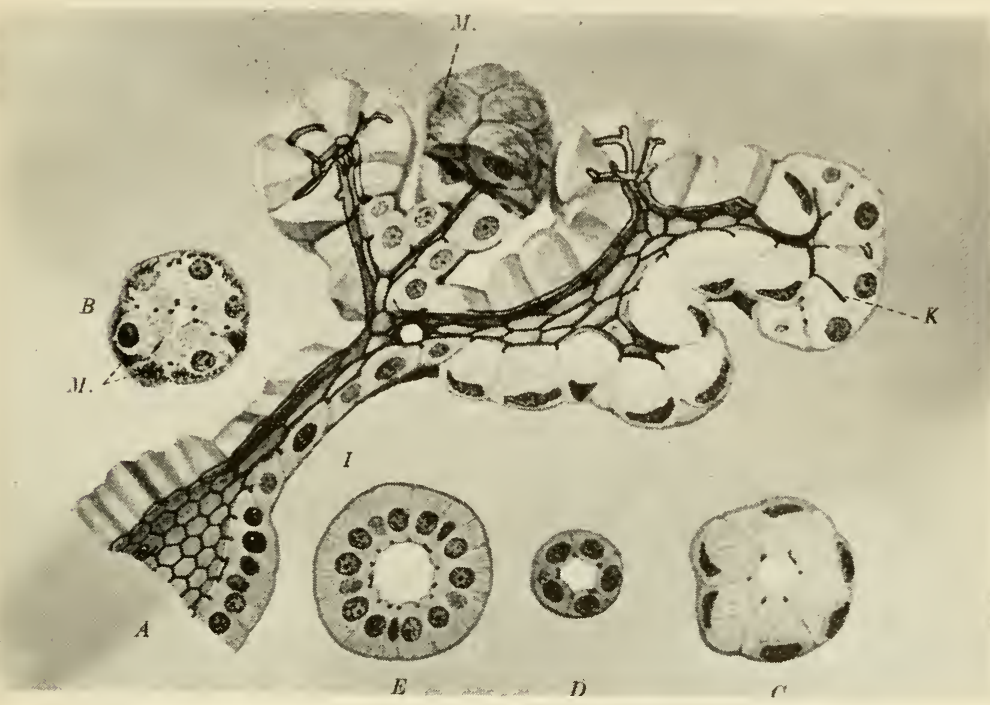

FIG. 2.I. Schematic representation of the human salivary gland.

$B$, serous acinus, note the round nucleus and the granules in the apical cytoplasm; $C$, mucous acinus, the nucleus is flattened and stretched along the base of the cell whose cytoplasm is glassy in appearance; $D, I$, intercalary ducts, the cells are small and almost filled by a round nucleus; $A, E$, intralobular (striated) duct, the cells are higher than those of the intercalary ducts and show basal striations; $M$, myoepithelial cells: $K$, canaliculus between acinar cells (Zimmermann, I027).

and may be convoluted. This segment is known as the granular tubule and is composed of cells that are large and very heavily granulated (Fig. 2.2).

In some glands basal or myoepithelial cells are found in the basal layer of alveoli and ducts. They are band-shaped flattened cells or star-shaped with long processes (Fig. 2.3b). They may be seen very clearly when stained by Gomori's alkaline phosphatase procedure (Leeson, 1956). The evidence that they are contractile in function is largely presumptive. However, in the mammary gland where myoepithelial cells are well developed their relationship to "let down", that is, the expulsion of preformed secretion, is well established (Linzell, I959).

In different glands the extent of the development of cell types 


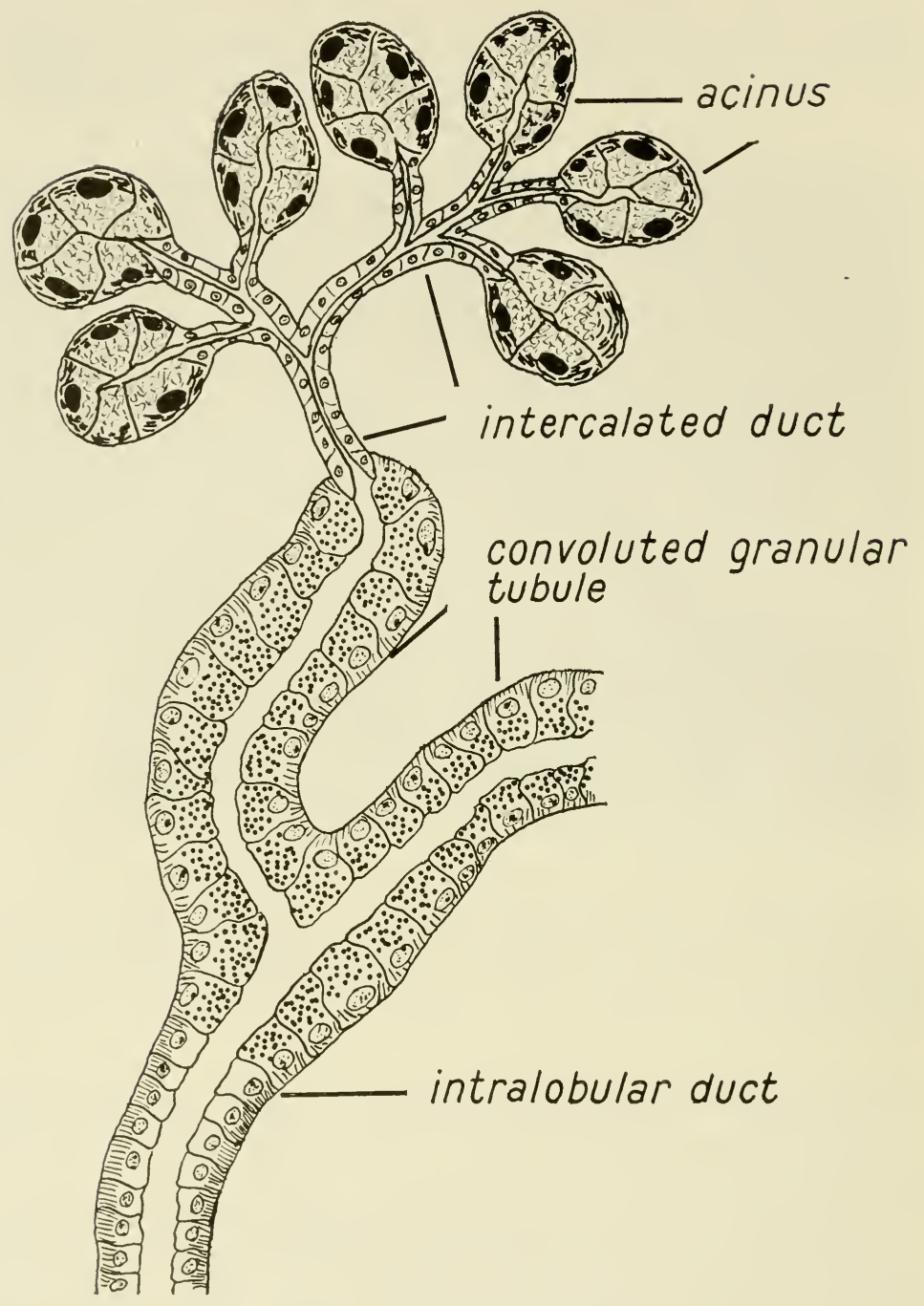

FIG. 2.2. Adult submaxillary gland of the rat.

Between the well-developed intercalated duct and the intralobular duct, the granular tubule is interposed (Leeson, 1959).

in the intercalary and intralobular ducts differs considerably (Fig. 2.4). It is natural that many authors from Merkel onward should have attempted to correlate the histological pattern with the composition of the saliva secreted by the gland (Babkin, I944; Thay- 


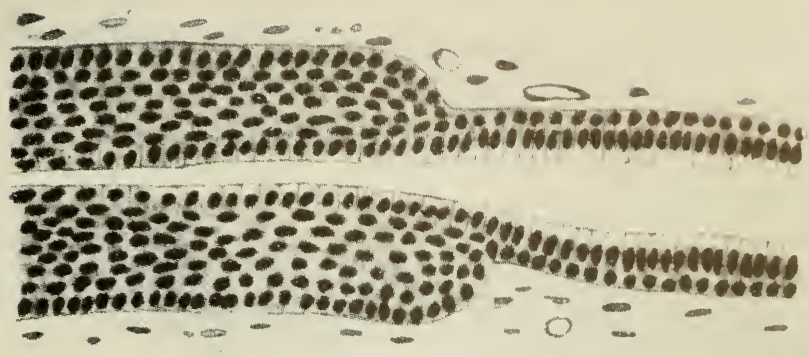

(a)

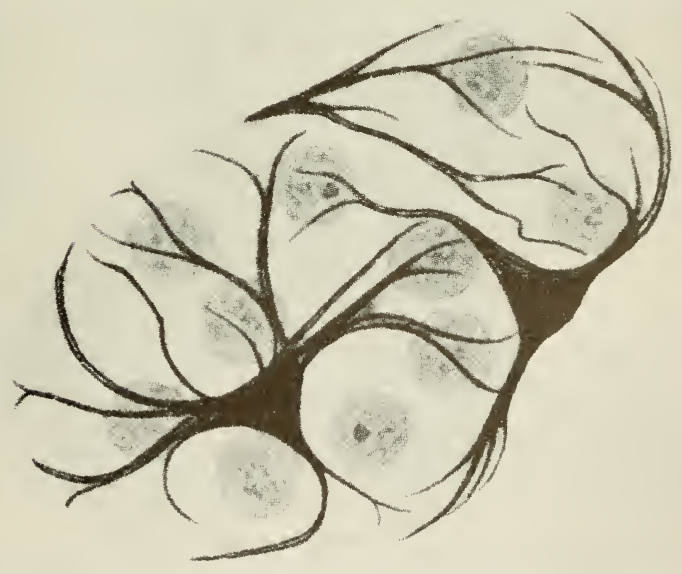

(b)

FIG. 2.3. (a) Termination of the main excretory duct of the human sublingual gland showing the transition from two-layered to multi-layered

(b) Branched basket cells from human submaxillary gland.

(Zimmermann, 1927.)

sen, I955; Bro-Rasmussen, Killman and Thaysen, 1956). This approach has met with only limited success for a number of reasons, the first of which is that the physiological information has 
been too scanty for an adequate test of the hypothesis. Secondly, the hypotheses applied have been too simple and limited in scope. As the salivary glands produce a secretion of very complicated composition, it is not at all likely that a simple hypothesis involving secretion or reabsorption of a single ion will account for this secretion (see Chapter X). It may be that more sophisticated arguments with statistical evaluation of the cell population may be more
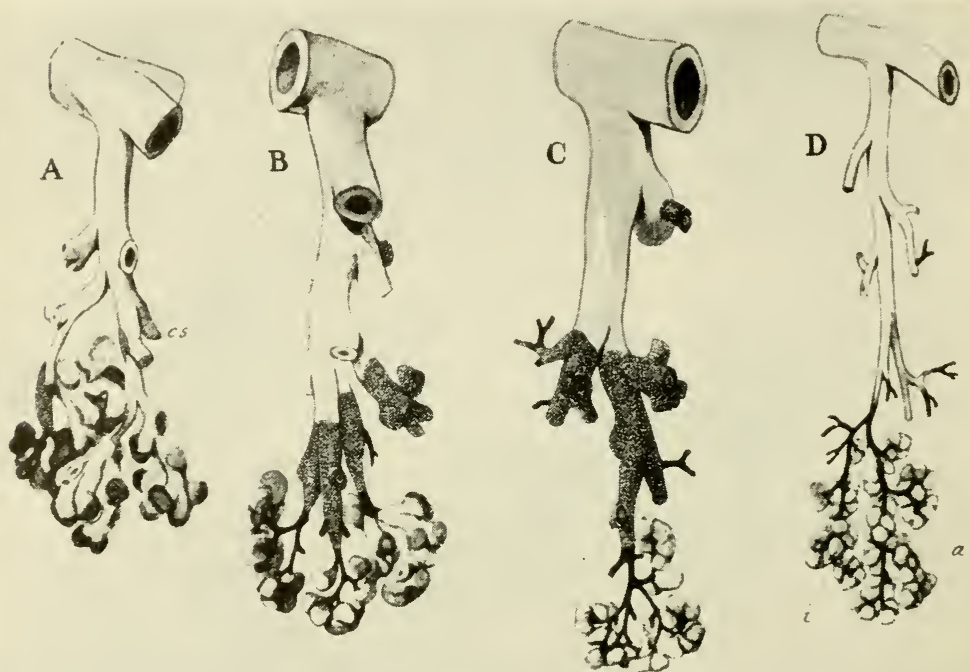

FIG. 2.4. Distribution of different duct epithelia in human salivary and pancreatic glands.

Intercalary ducts, black: striated ducts, stippled: excretory ducts, light grey.

$A$, sublingual; $B$, submaxillary; $C$, parotid; $D$, pancreatic (Bouin, P. (I932), Elements d'Histologie, Alcan, Paris).

illuminating, but in the kidney, for instance, a study of the complex histology has proven to be no help in aiding the understanding of physiological events. Caution must also be used in interpreting cytological changes in gland cells as evidence of a particular secretory activity. Degranulation after stimulation does correlate quite well with a decline in protein output (p. I 82), but we may not assume that this correlates in any way with the secretion of water or electrolytes, since there is no evidence at the present time of cytological correlation of these secretions. Indeed in the pancreas a dualism between the effects of secretin on water and electrolyte 
secretion and pancreozymin on zymogen release is widely accepted; in the salivary glands a similar dualism is operating even though the effector agent may be common to the two processes.

\section{BLOOD SUPPLY}

The vascular architecture of the salivary glands presents many unusual features whose physiological significance is enigmatic, but may provide clues to the equally strange behaviour of the gland blood flow during activity (see Chapter VII).

The main arteries to the submaxillary and sublingual glands enter at the hilus although additional minor arteries may enter on

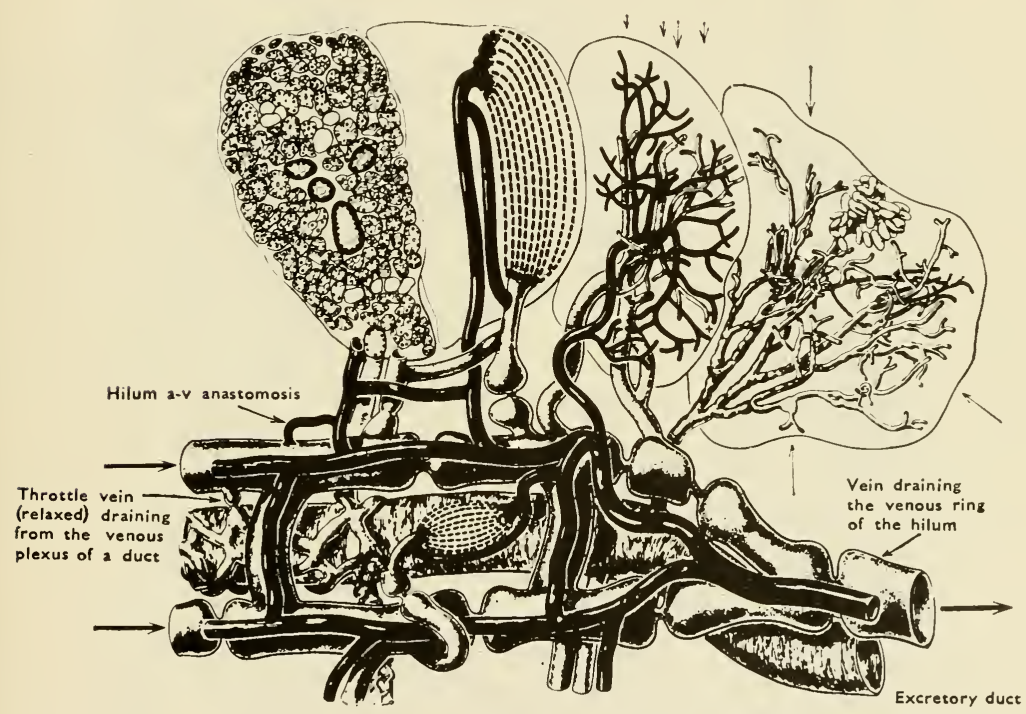

Fig. 2.5. General arrangement of vessels in the submaxillary gland, based on injection preparations of the human and guinea-pig glands.

Note the throttle vein leaving the venous plexus around the duct and entering the ring vein.

Note also the arteriovenous anastomoses in the hilus and in the lobules (Spanner, 1937).

the gland convexity. In the case of the parotid the "hilus" is not such a well-defined entity nor is the position of entry of the arteries. In all the glands the main vessels travel in company with the interlobular ducts into the lobules. The vascular territories of the lobules are quite distinct (Fig. 2.5). Within the lobules the arteries continue to travel with the ducts and break up into a very rich capillary plexus around the ducts (Fig. 2.6) (Kowalevsky, I885; 
Flint, I902; Spanner, 1937). Near the termination of the intralobular ducts ring-shaped arterial arcades are formed from which branches come off to supply the alveoli (Fig. 2.5). Embryologically

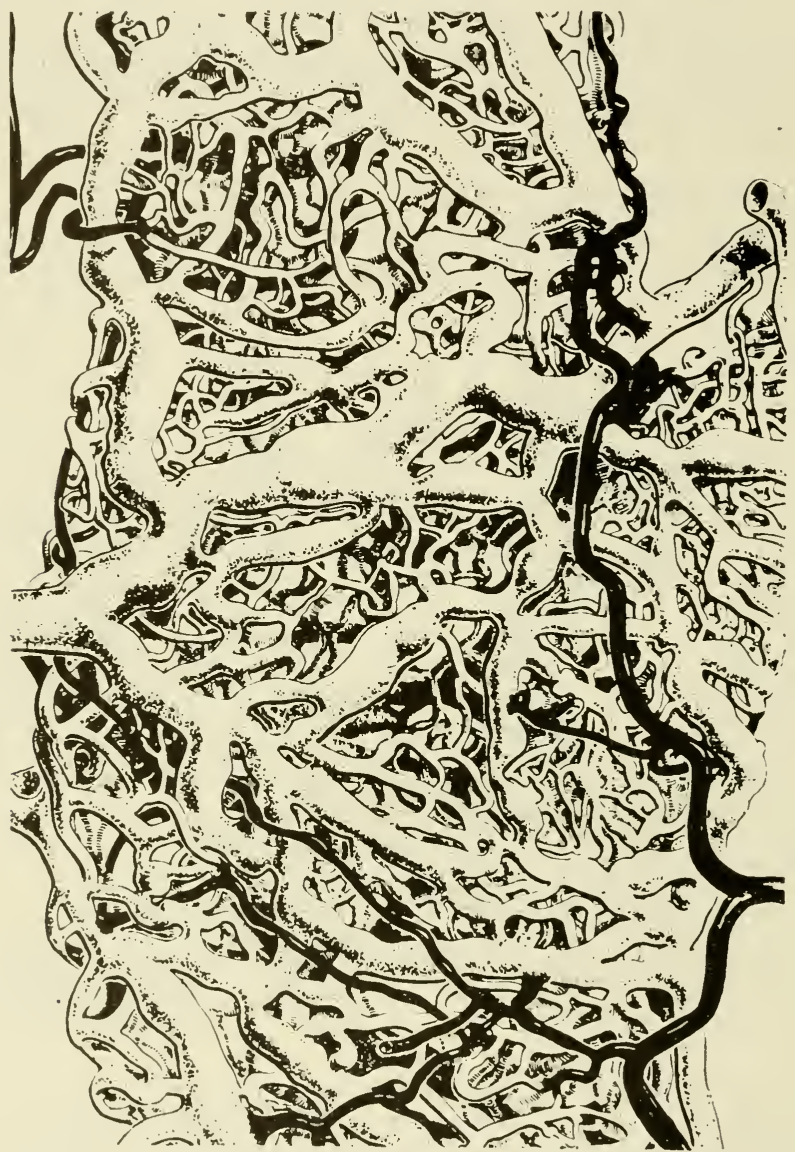

FIG. 2.6. Double injection preparation of the vascular plexus around a duct of the guinea-pig submaxillary gland.

Arterics, black; vcins, dotted; capillaries, hatched. Note the richness of the vascularisation of the duct (Spanner, 1937).

the ducts and their vessels develop before the alveoli and the vessels of the alveoli. The capillary plexus around the acini is not very dense compared with the rich vascularization of the ducts. The formation of veins within the lobules follows the same general pattern as that of the small arteries but the larger veins tend to drain 
to the periphery of the gland. There are, however, "venae comites" running back along the ducts. In injected preparations Spanner (1937) was impressed by the prominence of arteriovenous anastomoses throughout the lobule (Figs. 2.5 and 2.6). They are most

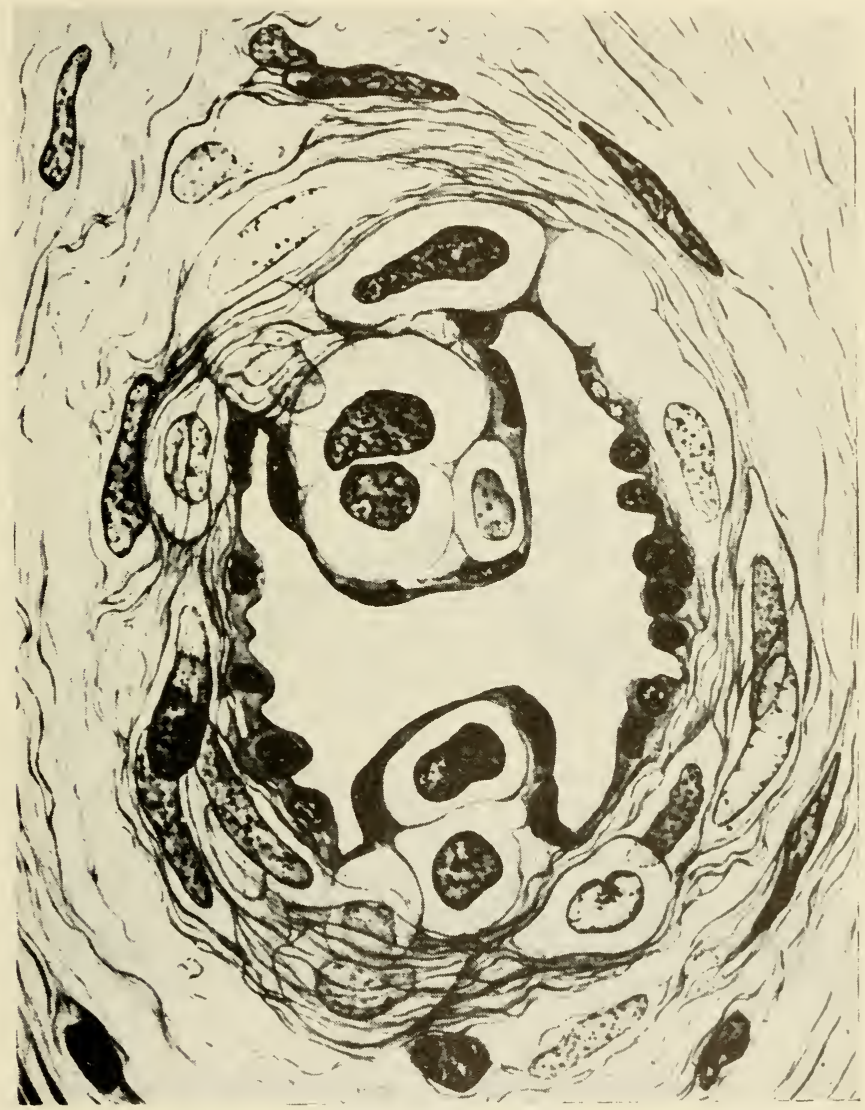

FIG. 2.7. (a) Epithelioid cells in the wall of a small arteriole in the human parotid gland.

(Spanner, 1942.)

prominent in the region of the ring vessels and are not very frequent in the duct wall. Some of these anastomoses are of considerable size. In many of the small arteries of the gland an extraordinary appearance of large epithelioid cells is seen in the wall of the vessels (Spanner, 1942, Fig. 2.7). These arteries are found most 
numerously in the region around the ducts and may be highly developed. Spanner has also found these structures in the pancreas. The appearances are reminiscent of the juxta-glomerular vessels in the kidney. A further unusual vascular feature of the gland is the

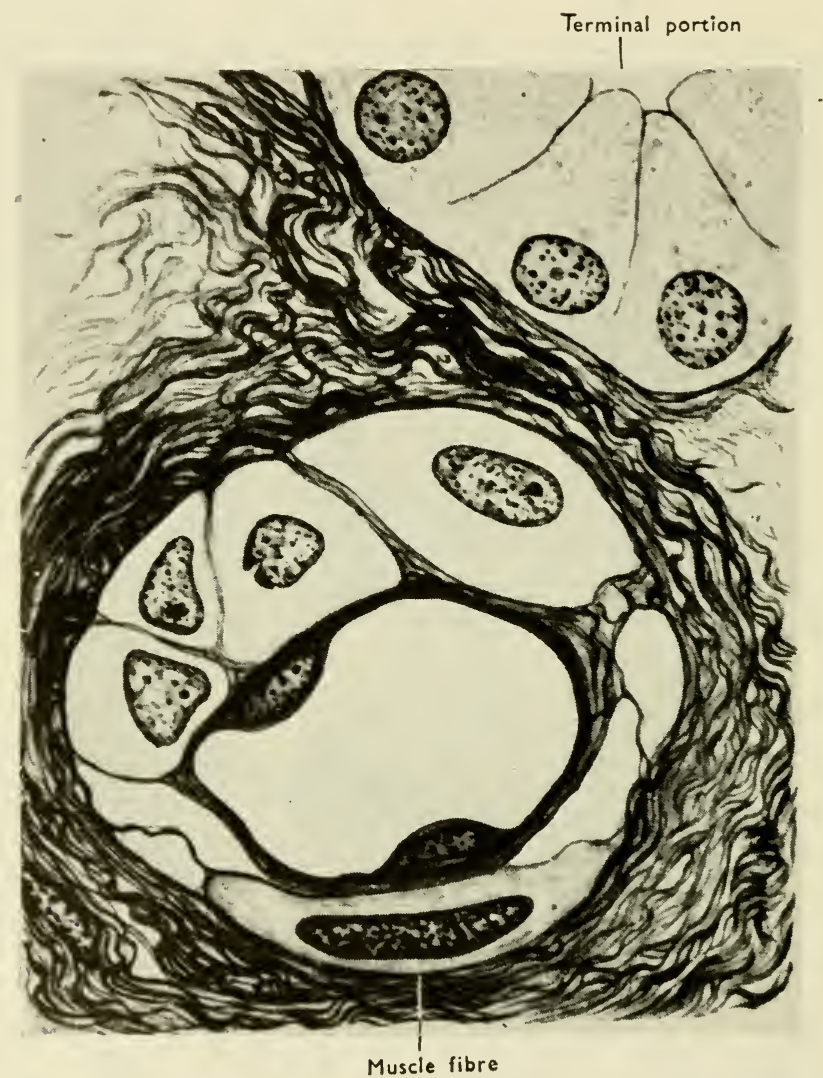

FIG. 2.7. (b) Epithelioid cells in the wall of a small arteriole in the human parotid gland.

(Spanner, 1942.)

presence of large sacculated veins (Spanner's Drosselvene or throttle veins) which occur especially in the hilar region (Fig. 2.5). These veins often appear as a saccular pocket developed in the side of a small vein. Similar veins are found in a number of organs including the penis (Clara, 1939). Spanner suggests that these veins serve a reservoir function and also serve to back up pressure in the 
capillary circulation during activity. Such studies as have been made of the living circulation in the glands do not greatly clarify the issues. Holtzlöhner and Niessing (r936a and $b$ ) saw a rather sluggish circulation in capillaries around the acini in the resting gland that was greatly slowed or arrested during activity, despite the increased total blood flow through the gland. Brücke and Zwiauer (1938), on the other hand, saw a consistent increase in flow in the acinar capillaries during activity and claimed that a decreased flow was seen only if the digastric muscle was contracted and obstructed secretory outflow. Burgen and Seeman (1958), on the basis of tracer experiments, came to the conclusion that most of the blood perfusing the gland went to capillaries in the duct system and that the flow in these was mainly countercurrent to the flow of saliva. They also give reasons for supposing that there might be serial perfusing of the ducts and acini. These observations are consistent with Kowalevsky's preparations but are not supported by Spanner. It is difficult to see how an active secretion of water by the acini (if this occurs, see p. r95) could be supported in the face of the arrested circulation found by Holtzlöhner and Niessing (1936 $a$ and $b$ ).

Further, the observations of Burgen and Seeman do not allow for a very extensive circulation through arteriovenous anastomoses, since this blood would not be available for exchange of solute with the gland parenchyma. It is hard to see how such a circulation can serve a physiological function unless the arteriovenous systems are in line with endocrine cells within the gland. It is possible that the epithelioid cells found by Spanner (1942) are of this type. In any case all observations agree in emphasizing the richness of the vascularization of the duct system both anatomically and functionally.

\section{LYMPHATICS}

Little is known of the lymphatics of the salivary glands. Klein (I882) found richly intercommunicating lymphatic channels mainly running along the ducts and surrounding the blood vessels. Extensive lymph spaces are found around the alveoli with interconnections to adjoining lymph spaces. In the central part of the gland drainage seems to run into the ducts, in the more peripheral part to lymph vessels at the margin of the lobules. 


\section{THE ULTRASTRUCTURE OF THE SALIVARY GLANDS}

The introduction of the electron microscope has already revolutionized our ideas of the structure of cells and has placed an entirely new set of facts at our disposal which must be made to harmonize with the physiology of the secretory process. Up till the present few satisfactory studies of the salivary glands have appeared, but a great deal of detailed study has been made of the pancreas. In all essential details the ultrastructure of the salivary cells of the rat appear to resemble the pancreatic cells. The differences are merely of degree. We will therefore draw heavily on the description of the pancreatic cell, adding such details as are known of the salivary glands.

The plasma membranes of both apical and basal faces of secreting cells have a three-layered structure with a total thickness of 60-70 A (Sjöstrand, 1956; Robertson, 1959). In material fixed in $\mathrm{OsO}_{4}$ this appears as two dark bands separated by a light band about $25-30 \AA$ wide. It is still uncertain which structures are stained by $\mathrm{OsO}_{4}$, but the consensus of opinion is that this reagent has a strong affinity for spread protein layers and a rather poor affinity for lipids. The three layers may therefore be considered as a lipoid layer sandwiched between spread protein layers. This morphological interpretation agrees well with the physiological concept of a cell membrane built up from studies on cell permeability, and the physicochemical and electrical properties of the cell membrane (see Danielli and Davson, I943). At the areas of contact between adjacent cells the membranes are distinct and may follow a relatively straight path as in the pancreas (Sjöstrand and Hanzon, I954a) or be tortuous and interlocking as in the rat submaxillary acini (Leeson and Jacoby, I959). In the striated ducts of the rat submaxillary an intermediate picture is seen, the adjacent membranes interlock in the basal one-third of the cells and then run straight towards the apical poles.

At both free surfaces of the cell foldings of the cell membrane occur. At the apical surface these are mainly seen as microvilli protruding into the lumen of the acinus (Sjöstrand and Hanzon, I954a; Pease, 1956; Siekevitz and Palade, r958; Leeson and Jacoby, $1959 b$ ). These microvilli are found in all stages of development between simple protrusions of the plasma membrane and the pinching off of droplets of "secretion" (Fig. 2.8). 


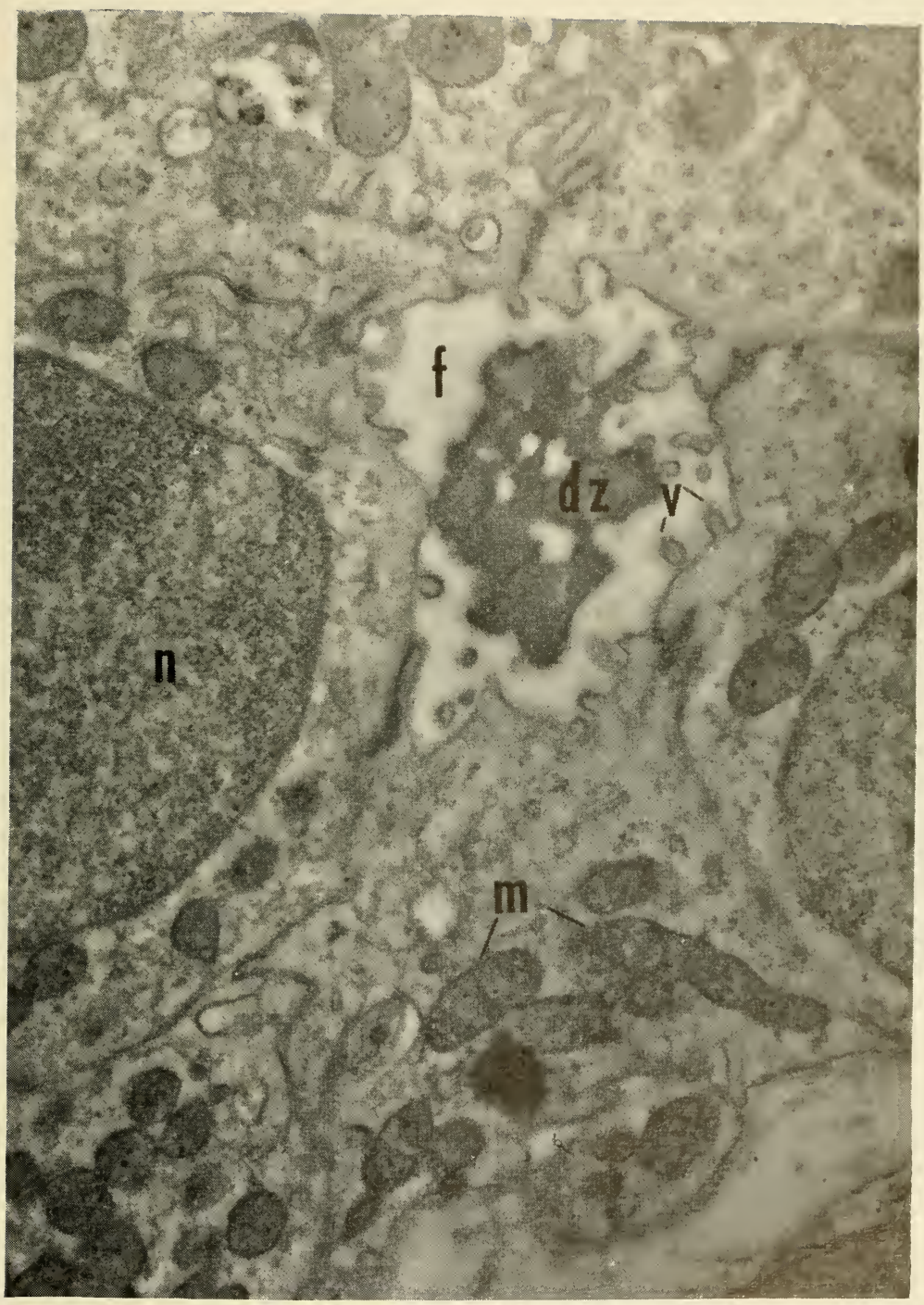

FIG. 2.8. Small pancreatic duct lumen.

Five epithelial cells surround the duct lumen which contains light and dense material $(f, d z)$. The apical surfaces of the cells bear microvilli $(v)$ which can be seen in various stages of pinching off. Mitochondria $(m)$, cell nucleus $(n)$ (Siekevitz and Palade, 1956). 
On the basal aspect of the cells infolding of the plasma membrane may be exteinsive and produce $\mathrm{S}$-shaped patterns of parallel layers of the membranes (Fig. 2.9). These correspond to the basal striations seen in the light microscope. This kind of basal infolding is only seen in cells which may be regarded as having secretory properties, and has led to the suggestion (Pease, 1956) that this arrangement is concerned with water transport. There seems no reason to tie this appearance specifically to water transport, it is

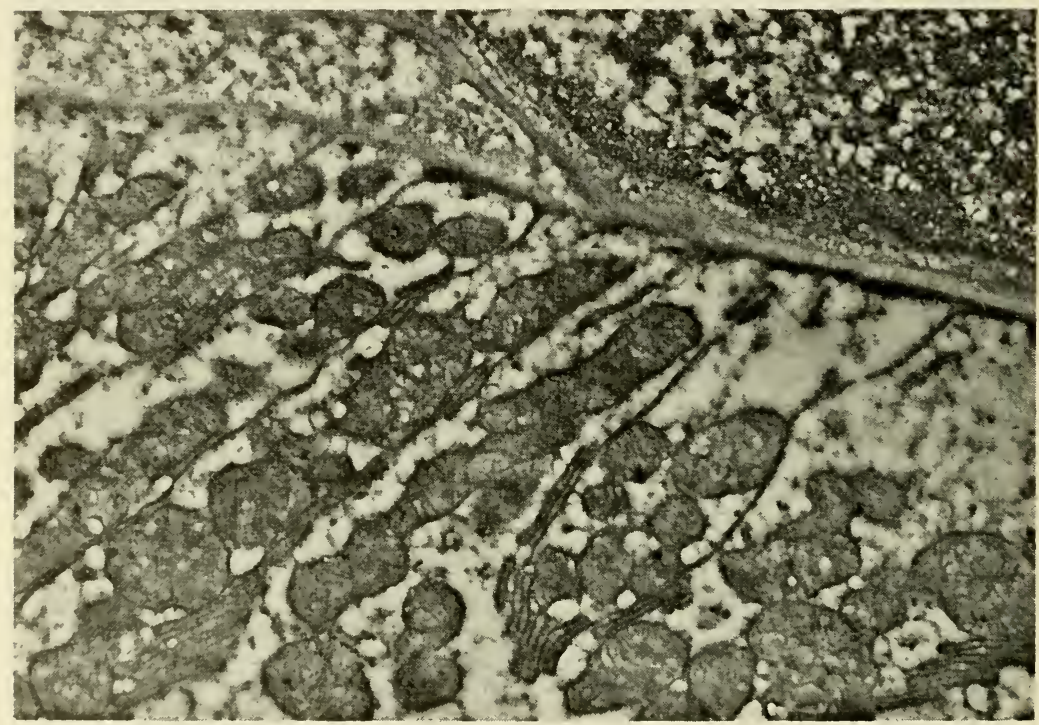

Fig. 2.9. Intralobular striated duct cell from the rat submaxillary gland.

Note basal parallel rows of mitochondria with infolding of the basal cell membrane between them (Leeson, 1959).

probable that the infolding provides a greatly augmented surface area for transport of many substances. If this is the correct explanation it is very interesting that it should involve the basal surface of the cell-implying that transport into the cell is in greater need of assistance than is expulsion from the cell into the secretion (cp. secretion of iodide, p. I 55). According to Leeson and Jacoby $(1959 b)$ the striated duct cells in the rat submaxillary gland show very marked basal infolding, the granular tubules show much less, while Pease (1956) shows pronounced basal infolding in acinar cells in the same gland, but in a later paper found basal infolding 
to be marked only in the duct cells (Scott and Pease, 1957). Pease emphasizes that mitochondria are normally very prominent in these cells (v. infra) whereas others find relatively few mitochondria in these cells. This discrepancy may perhaps be accounted for by regional variations within the gland since Pease selected hilar tissue for his study, or perhaps Pease incorrectly identified the cells since duct cells predominate in the hilar region. The intercalated ducts show relatively little basal infolding. The relationship of the basement membrane and blood capillaries to these cells is illdefined. Sjöstrand and Hanzon (1954a) in the pancreas illustrate an irregular rough basement membrane lying very close to a cell of a blood vessel. Porter (1954) shows a similar arrangement in the rat parotid. Since the extracellular space is the immediate source of fluid and solutes for secretion the state of this space is of great interest and merits careful study in the electron microscope.

Within the cells a more or less extensive system of parallel double membranes exists (Palade, 1956; Sjöstrand and Hanzon, 1954a; Porter, 1956; Gautier and Diomede-Fresa, 1953; Bernhard, Haguenau, Gautier and Oberling, 1952; Palade and Porter, 1954) which is generally called the endoplasmic reticulum (e.r.). These membranes have the same thickness as the plasma membrane, and it is indeed not settled whether the e.r. is not also an extension of the surface membrane (for discussion see Robertson, 1959). These membranes may show two other properties: $(a)$ the presence of numerous small dense particles $130-150 \AA$ diameter adherent to the outer surface of the double membranes. These particles are rich in RNA and correspond to the microsome fraction in cell homogenates (Palade, 1955) and are now generally referred to as Palade granules and are believed to account for the major part of the cytoplasmic RNA (Palade and Siekevitz, r956). In Palade's paper these are shown to be quite profuse in the acinar cells of the rat parotid (Fig. 2.10). (b) The double membranes of the e.r. may become separated to form round or ovoid vesicles known as cisternae. In pancreatic cells cisternae are well developed, as they are also in rat submaxillary and parotid acinar cells (Gautier and Diomede-Fresa, I953; Bernhard, Haguenau, Gautier and Oberling, 1952; Palade and Porter, 1954; Palade, 1955; Leeson and Jacoby, $1959 b$ ). On the other hand, in the striated duct cells the e.r. is not extensive and both granules and cisternae are scarce (Leeson and Jacoby, I959b; Pease, 1956). 
In the electron microscope mitochondria are found diverse in size, but generally are sausage-shaped bodies with an outer double membrane of the same thickness as the e.r. membranes. The inner membrane may be thrown into complicated folds (cristae mitochondriales), which increase the available internal surfaces. In the acinar cells the mitochondria are not very numerous (Leeson and Jacoby, 1959 $b$; Hill and Bourne, 1954) (but compare Pease (1 956), who states: "The basal half or two-thirds of the serous cells is ordinarily so jammed with mitochondria that there is hardly room for other components"). In the striated duct cells mitochondria are much more frequent and are characteristically found packed in parallel rows between the areas of membrane infolding. In no cells up till the present has continuity between mitochondria and any other cell membranes been demonstrated, although Robertson (1959) speculates that these occur and proposes a scheme for formation of mitochondria from the plasma membrane.

Studies with isolated mitochondria have established that these are the major site of cell respiration (for reviews and bibliography see Lindberg and Ernster, 1954; Ernster, 1959) and contain the whole of the cell cytochrome oxidase and the major part of the enzymes of the citric acid cycle. Roughly speaking the density of mitochondria in a cell corresponds to its respiratory activity.

Secretory granules appear in the resting cell as dense round bodies $0.5^{-2} \mu$ diameter congregated at the cell apex (Siekevitz and Palade, 1956). In this state it is difficult to be certain that they are enclosed in a cytoplasmic membrane, but in the active cell the granules can clearly be seen lying within membrane-lined cavities within which they undergo more or less complete dissolution. These granule-containing cisternae appear to undergo extrusion into the acinar lumen (Fig. 2.8). Granules of this type are seen especially in the granular tubules of the rat submaxillary, less prominently in the acinar cells and are rare in the striated ducts (Leeson and Jacoby, 1959b). In the lamb parotid acinar cells granules appear to be scarce (Manni, Grillo and Ambrosino, 1957). A comparison of serous and mucous acinar cells by this technique would be of considerable interest.

Hokin (1955) isolated zymogen granules from homogenates of dog pancreas in a sucrose medium at $\mathrm{pH} 5^{-6}$. The granules were rich in protein but contained much less phospholipid or RNA than other cell fractions. The granules underwent rapid dissolution 
when the $\mathrm{pH}$ of the medium exceeded $6 \cdot 8$. Hokin suggested that dissolution of the granules occurred after ejection into the alkaline pancreatic juice, but the observations of Siekevitz and Palade (1958) do not support this.

The Golgi apparatus known from supravital staining in the light microscope has turned out to have a well-defined although enigmatic appearance in the electron microscope. It consists of one or a series of vacuoles with concentrically arranged membranes embedded in the perinuclear ground substance (Sjöstrand and Hanzon, 1954 $b$; Dalton and Felix, 1956; Lacy and Challice, r957) giving a quite characteristic appearance. The neutral red bodies studied extensively by Hirsch (1932) and others are not in the true Golgi apparatus, but are artefacts due to the cytotoxic action of this substance (Weiss, I955).

Sjöstrand and Hanzon (1954b) found all stages of evolution of zymogen granules apparently occurring in relationship to the Golgi apparatus of pancreatic acinar cells. This supports the many observations made with the light microscope suggesting a relationship between the Golgi system and secretory granules (see Junqueira and Hirsch, 1956). There was no apparent connection between the Golgi system and the mitochondria, but presumably the Golgi system is continuous with the e.r. The Golgi apparatus in salivary cells is very similar to that found in other secreting cells (Leeson and Jacoby, I959b). Schneider and Kuff (1954) have isolated a highly purified suspension of the Golgi system from homogenates of epididymis and found a very high content of lipid phosphorus $(200 \mu \mathrm{g} / \mathrm{mg} \mathrm{N})$ and a high content of RNA and alkaline phosphatase, but other enzyme activities tested were low and, in particular, there was no detectable cytochrome oxidase or desoxyribonuclease.

The nucleus in secreting cells does not have any specific features, but appears as a rather uniform granular sphere surrounded by a coarsely pored double membrane.

Scott and Pease (1957) identified nerve fibres penetrating the basement membrane of salivary acini and ending as fine filaments directly applied to the basal and intercellular surfaces of the acinar cells. No nerve fibres were seen ending on duct cells.

Myoepithelial cells in the electron microscope (Fig. 2.10) resemble quite closely smooth muscle; this may be taken to support the theory that they are contractile in function. 
Changes during activity. Siekevitz and Palade (1958) have reported striking changes in the e.r. in pancreatic cells after feeding. Large cisternae developed around the apical secretory granules and small free granules appeared in the wall of the cavities (Palade,

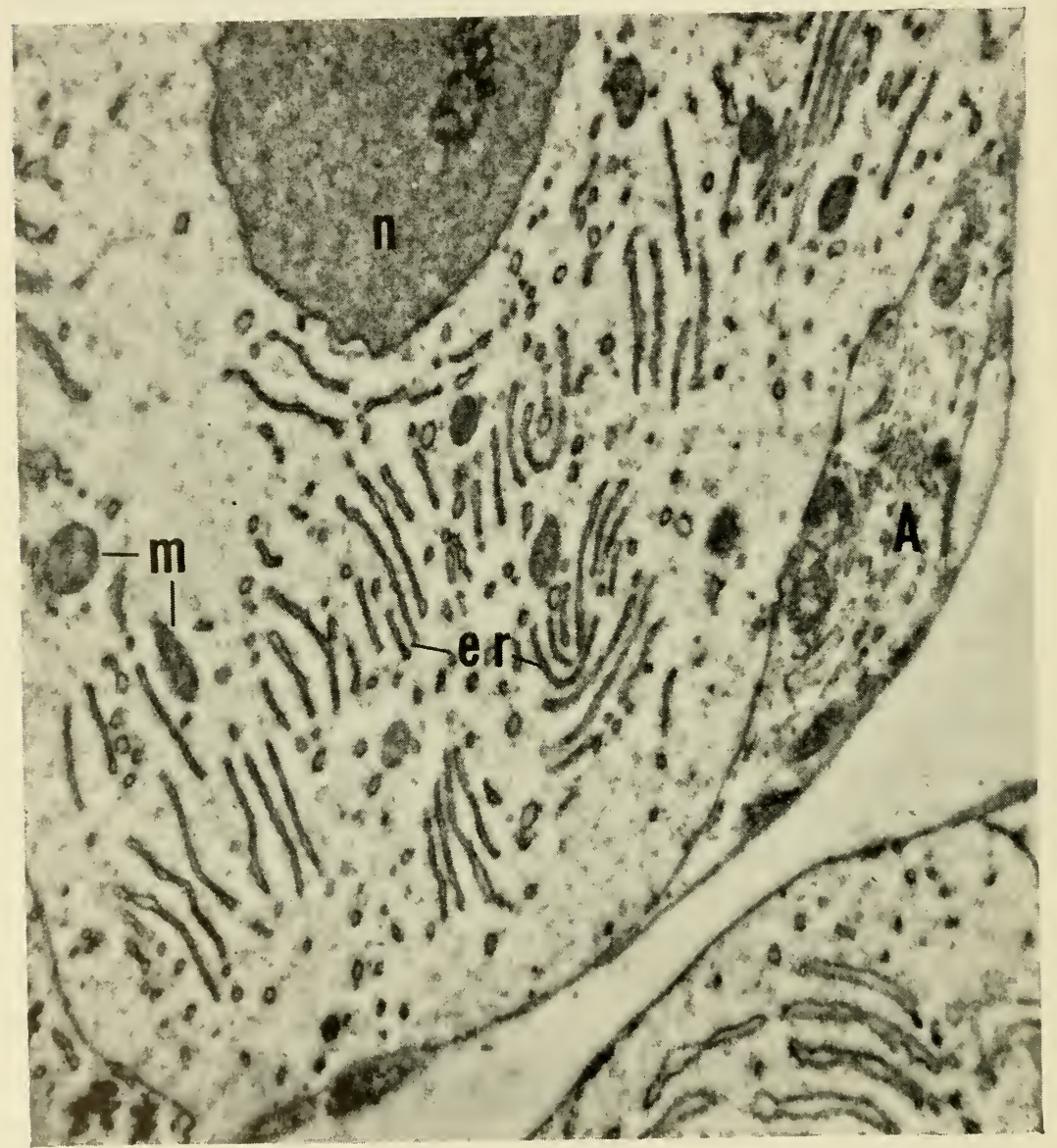

FIG. 2.10. Electron micrograph of mucous cell of the rat parotid.

Endoplasmic reticulum (er) shown as long slender profiles which are transverse sections of flattened cisternae. Mitochondria $(m)$, nucleus $(n) . A$ is part of a myoepithelial cell (Porter, 1954).

I956b). Gautier and Diomede-Fresa (1953) and Manni (1957) have reported changes in the e.r., mitochondria and cell nuclei following stimulation, but Sjöstrand and Hanzon (1954a) consider these to be artefacts due to inadequate fixation. The latter found no changes 
whatsoever in the e.r. or mitochondria of the pancreas after starvation or pilocarpine administration. It should be remembered, however, that pilocarpine is not always a very effective stimulator of acinar secretion. Daly and Mirsky (1952-3) found feeding to be a

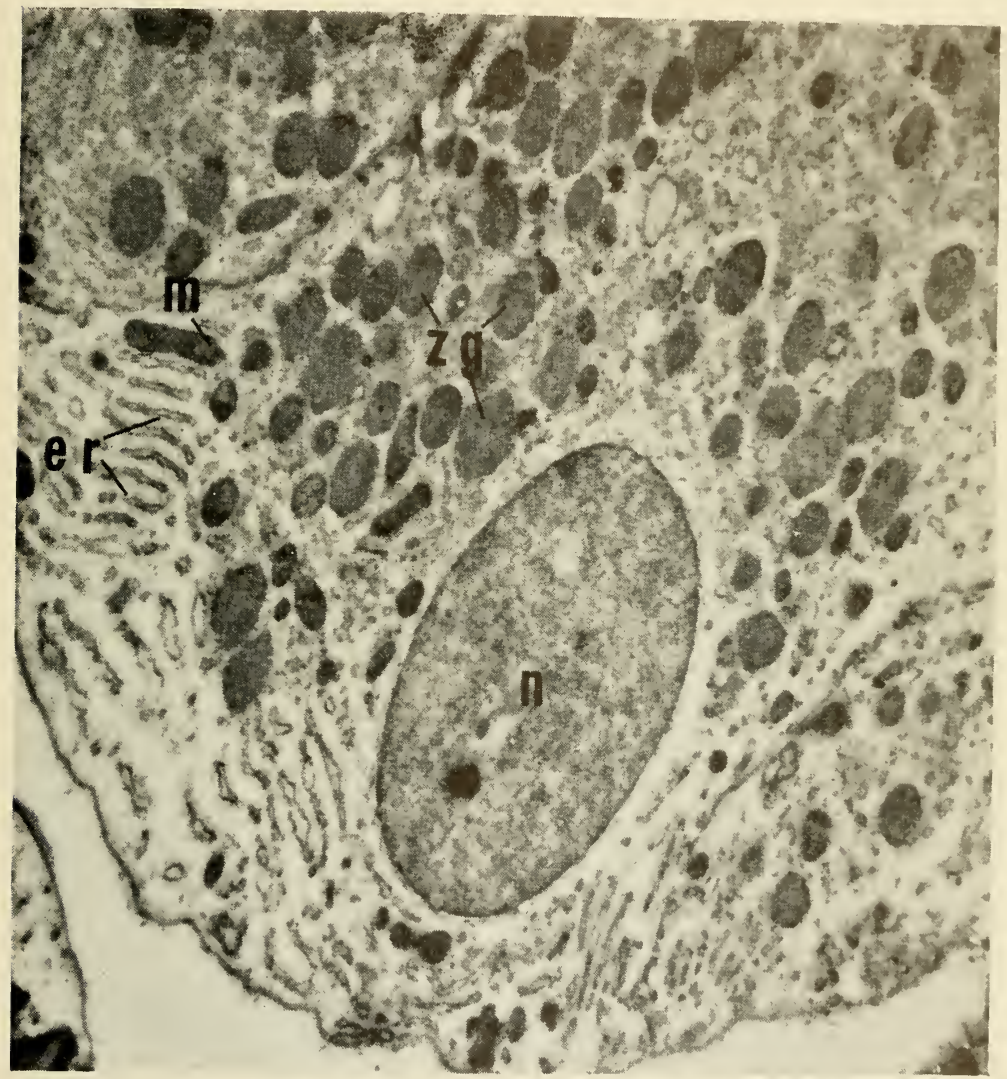

FIG. 2.II. (a) Section through serous cell of rat parotid in the resting state.

The basal membrane is to the lower left. Note the numerous zymogen granules $(z g)$ and rather sparse er.

much more satisfactory way of depleting the mouse pancreas of enzymes than was pilocarpine. However, Porter (1954) produced complete degranulation of the mouse parotid with pilocarpine, and found a considerable increase in the development of the e.r. to result (Fig. 2.I I).

Repeatedly the recent literature on ultrastructure of cells has 
referred back to the observations of Lewis (I93I, I937) on the phenomenon of pinocytosis or cell drinking. This was described in tissue cultures of macrophages and malignant cells in which fluid from the medium was apparently engulfed by ruffle-shaped

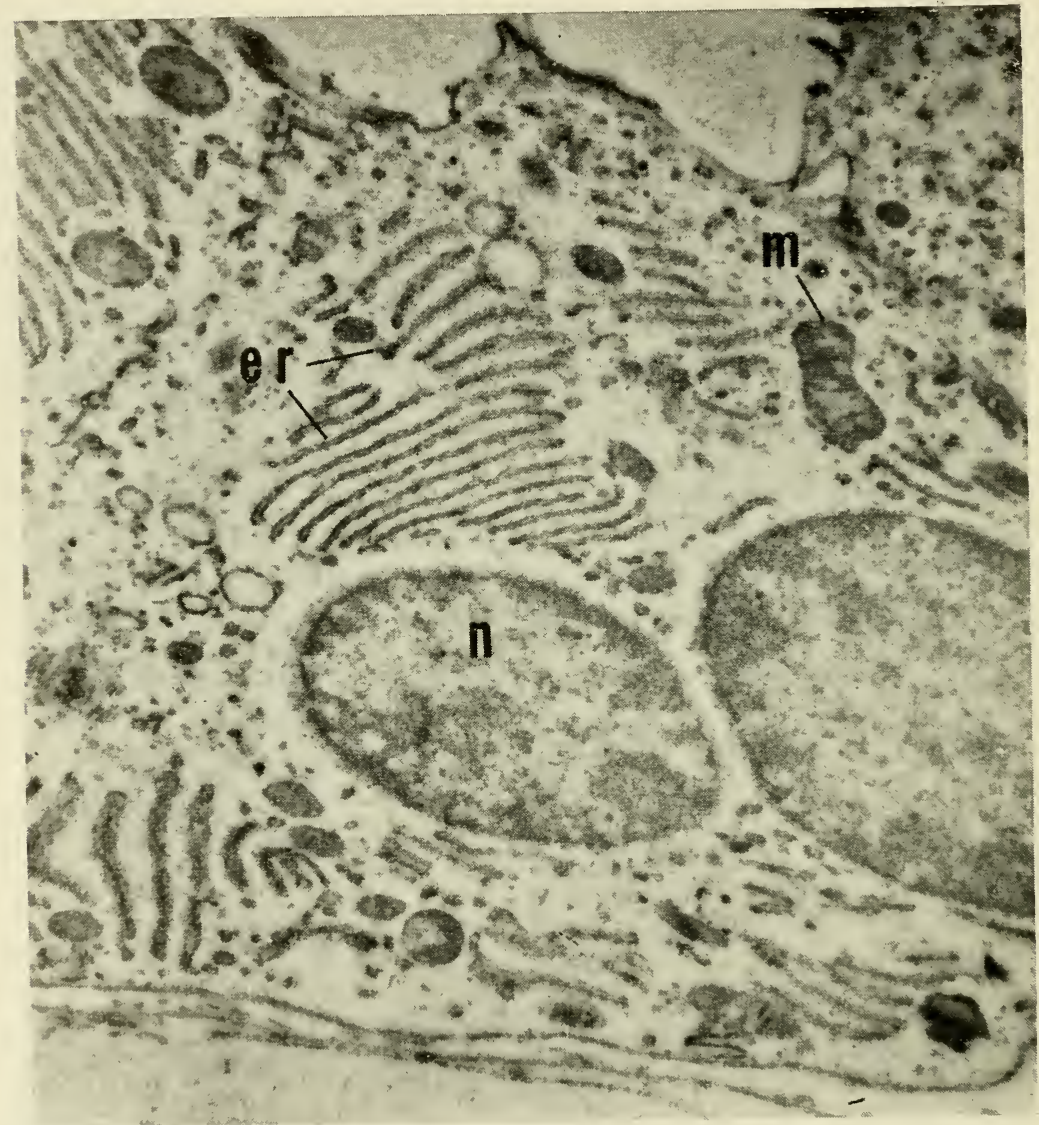

FIG. 2.I I. (b) Serous cell from rat parotid, removed 90 minutes after the injection of pilocarpine into the animal.

Zymogen granules are not prominent, but the er is very evident (Porter, 1954).

pseudopodia put out by the cell. Bennett (1956), in particular, has proposed invagination of the cell membrane as a mechanism for active transport and ion pumping into cells. It is quite possible that such a process does occur and might explain situations where all the constituents of a bathing fluid seem to be transferred across 
a cell proportionately, and in any case some such mechanism must be present to allow the entry of macromolecules (e.g. antibodies) into cells. However, a process of this kind cannot explain the highly selective transfer of ions into and out of cells. On the other hand, the reverse process of granule and vacuole extrusion at the apex of the cell seems to be a quite general and fundamental phenomenon in secreting cells.

\section{HISTOCHEMISTRY}

$P A S$-Schiff reaction. In all species so far examined amylaseresistant PAS positive material is present in the acinar cells. This is often present in higher concentration in cells classified as mucous than serous, although for instance the "special" serous cells of the mouse submaxillary gland are stained more strongly than the serous cells of the parotid. Staining is not prominent in the ducts but in the apical region of the intralobular ducts small intensely staining granules are present (mouse), some of these being seen in the cell margin and in the lumen either free or attached to the cell membrane. The duct cells contain much glycogen (i.e. PAS material removed by amylase) (Junqueira, Fajer, Rabinovitch and Frankenthal, I949; Hill and Bourne, I954; Lewke and Müller, I956; Shklar, Glickman and Turesky, I958).

Phosphatases. Alkaline phosphatase is present irregularly in the salivary glands (Noback and Montagna, I947; Deane, I947; Junqueira et al., I949; Hill and Bourne, 1954). Leeson (1956) found the alkaline phosphatase reaction of rat salivary glands (Gomori's technique) localized almost exclusively to the myoepithelial cells, otherwise only irregular appearance of alkaline phosphatase was found. Acid phosphatase was found in both duct and acinar cells in the rabbit, but was scanty in the mouse, rat and cat. In the guinea pig parotid there was a strong concentration of the enzyme at the apical surface of the striated duct cells.

Esterases. Cholinesterase is found mainly in the nerve fibres of the salivary glands. These are particularly seen surrounding the main ducts. The enzyme also appears as a fine network around the base of the acinar cells. Small amounts were also seen in the nuclei and cytoplasm of the duct cells. The density of stained nerve fibres was much less in the sublingual than in the submaxillary gland (Snell and Garrett, 1957).

Esterases detected with naphthyl acetate and naphthyl AS acetate 
were invariably found in the duct cells of different glands and species, but the acinar reaction was very variable in different glands but nearly always much weaker than in the ducts (Burstone, I956; Hill and Bourne, 1954; Noback and Montagna, I947). Lipase was found by Martin (I953) in the interlobular ducts of the dog submaxillary glands. The acini were negative as were all cells in the parotid. The serous acini of the guinea pig submaxillary gland were positive. Hill and Bourne (1954) did not find positive reactions in the cat, guinea pig, mouse or rat.

Amino peptidase has been demonstrated in the interlobular ducts of the human parotid and submaxillary glands (Burstone and Folk, I 956).

Dehydrogenases. High concentrations of succinic dehydrogenase have been found in the duct cells of the rat, guinea pig and rabbit with much less enzyme in the acinar cells (Padykula, r952; Stier, 1952; Neumann, 1952; Hill and Bourne, 1954). It is interesting that Stier also found a high concentration of this enzyme in the pancreatic ducts.

\section{EMBRYOLOGY AND MATURATION}

The salivary glands develop as groove-like outgrowths of the oral epithelium which subsequently becomes a solid rod of epithelium budding to form lobules. The rod develops a lumen and becomes a tube as a result of degeneration of the most centrally placed cells (Chievitz, I885; Schulte, I9I3; Borghese, I950). The ducts at this stage are lined by a multi-layered epithelium similar to that found in the adult main ducts. The general form of the glands is established at this stage although the epithelium is still relatively undifferentiated. In man the parotid anlage appears at 8-I2 $\mathrm{mm}$, the submaxillary at $\mathrm{I} 2-\mathrm{I} 4 \mathrm{~mm}$ and the sublingual at 20-24 mm, the parotid and submaxillary ducts begin to ramify after $20 \mathrm{~mm}$ is reached (Bujard, I9I I). The acini are later developments which bud off the terminal tubules to give first of all simple alveoli which then may become differentiated into serous and mucous cells and finally to demilunes (in those glands possessing them). In man it appears that primitive acini are already formed in the $138 \mathrm{~mm}$ (4th month) foetus and presumably are mature at birth (de Plessis, 1957); in the cat on the other hand the submaxillary gland is incompletely differentiated at birth and reaches maturity a few weeks after birth ('Takagi, 1925). In the rat no acini are 
present at birth and full development of the gland awaits maturity of the animal (3-6 months) (Leeson and Jacoby, I 959a; Screebny, Meyer, Bachem and Weinman, I955; Leeson, 1959).

This extreme case illustrates the general conclusion that acinar cells are a late development of the gland, and at least in the rat and probably other rodents very active saliva secretion can occur in the absence of acini. Little use has been made of a developmental approach to attempt to dissect the secretory function of the salivary gland, but it might well be a fruitful one. Leeson and Jacoby (1959 $a$ and $b$ ) and Leeson (1959) describe the development of the rat submaxillary gland in great detail and find that at birth the large interlobular ducts already show basal striation (and infoldings), the intralobular ducts are small and merge into a rudimentary intercalated duct or terminal tubule. These terminal tubules are formed of columnar cells with basal nuclei, extensive cytoplasmic granulation and a well-developed endoplasmic reticulum. 'Two weeks after birth crescent-shaped buds of the terminal tubules form the primordia of the acini which begin to appear shortly afterwards. At six weeks acini are well developed, as are the intercalated ducts. 'The early development of the duct system is accompanied by ingrowth of blood vessels (Flint, 1902-3) and this pattern persists in the mature gland (see p. I5), the vascular tree of the acini appearing to have grown out of that of the ducts.

In rodents the subsequent development of the gland is complicated by hormonal effects. In prepubertal mice the tubules consist of cubical cells with central nuclei and clear cytoplasm. In adult females the cells are more columnar, some are vacuolated and others show dark granules in the apical cytoplasm. On the other hand, in adult males the tubules are comprised of large cells with basal nuclei and mitochondria and the cytoplasm is packed with granules (Lacassagne, I940; Junqueira, Fajer, Rabinovitch and Frankenthal, 1949). This interesting dimorphism has been the subject of numerous investigations, which have shown an atrophy of the tubules in castrated males (Shafer and Muhler, I953; Junqueira, 1949) corrected by testosterone, and a depression of the size of the female tubules by stilboestrol. These tubules are also affected by thyroid hormones (Grad and Leblond, I949; Bixler, Webster and Muhler, I957; Raynaud, 1950) and atrophy after hypophysectomy (Screebny, Meyer and Bachem, I953; Lacassagne and Chamorro, I940). The atrophy after hypophysectomy is 
only partly corrected by thyroxin and testosterone. Studies on enzyme content of the glands show that the protease and phosphatase content of the glands is strongly affected by the development of the granular tubules, but amylase and arginase is little changed (Junqueira, Fajer, Rabinovitch and Frankenthal, I949; Kochakian, Endahl and Hall, I955). Little work has been done on changes in salivary glands in senescence. Kurtz (1954) found in the rat that the mitochondria changed from the plump forms found in young adults to long rather irregular forms in the senile rat and he also found irregularities in the Golgi apparatus.

Atrophy of the salivary glands occurs after duct ligation. This is a rapid process and is complete within a week. The most marked changes occur in the acini which decrease in size, the cells become vacuolated and almost completely disappear. The ducts remain as a skeleton of the gland structure and indeed undergo hyperplasia so that a multi-layered duct epithelium becomes the rule. There is also a proliferation of connective tissue (Junqueira and Rabinovitch, I954; Dietz, I955; Bhaskar, Borden and Weinman, I956; Standish and Shafer, I957). On removal of the duct ligature the histology and biochemistry of the gland slowly returns more or less to normal even if the ligature had remained on the ducts for as long as a year. Partial regeneration of the rat submaxillary gland has been reported after subtotal resection (Milstein, I950). The first changes are a thickening in the duct epithelium with numerous mitoses, and the formation of branch ducts; subsequently acini bud off these new ducts.

\section{REFERENCES}

BABKIN, B. P. (1944). Secretory mechanisms of the digestive glands. Hoeber, New York.

BENNETT, H. S. (1956). The concepts of membrane flow and membrane vesiculation as mechanisms for active transport and ion pumping. F. Biophys. Biochem. Cytol., 2, Suppl., 99-103.

BERNHARD, W., F. HAGUENAU, A. GAUTIER and C. OBERLING (I952). La structure submicroscopique des éléments basophiles cytoplasmiques dans le foie, le pancreas, et les glands salivaires. Z. Zellforsch., 37, 28 I-300. BHASKAR, S. N., T. E. BORDEN and J. P. WEINMAN (1956). Experimental obstructive adenitis in the mouse. $\mathcal{F}$. dent. Res., 35,852 .

BIXLER, D., R. C. WEBSTER and J. C. MUHLER (I957). The effect of testosterone, thyroxine, and cortisone on the salivary glands of the hypophysectomized rat. $\mathcal{F}$. dent. Res., 36, 566-570. 
BORGHESE, E. (I950). L'azione dei processi morfogenetici nella sviluppo di ghiandola salivari, in condizioni normali e nelle culture in vitro. Arch. Ital. Anat., 55, I82-2 I4.

BRO-RASMUSSEN, F., S. A. KILLMAN and J. H. THAYSEN (I956). The composition of pancreatic juice as compared to sweat, parotid saliva, and tears. Acta physiol. scand., 37, 99-I I3.

BRÜCKE, E. T. and A. ZWIAUER (I938). Über den Blutstrom in den Capillaren der ruhenden und tätigen Speicheldrüse. Fiziol. Zhur., 24, 78-85 (see abstract in Ber. ges. Physiol., 107, 582, 1938).

BUJARD, E. (I9II). Reconstructions plastiques des glandes d'un foetus humain de 10 semaines environ. Anat. Anz., 38, i I 5-127.

BURGEN, A. S. V. (I955). The osmotic work of salivary secretion in the dog. F. cell. comp. Physiol., 45, 465-478.

BURGEN, A. S. V. and P. SEEMAN (1958). The role of the salivary duct system in the formation of the saliva. Can. F. Biochem. Physiol., 36, I I9142.

BURSTONE, M. S. (I956). Esterase of the salivary glands. F. Histochem., 4, I30-I39.

BURSTONE, M. S. and J. E. FOLK (I956). Histochemical demonstration of amino-peptidase. $\mathcal{F}$. Histochem., 4, $217-226$.

CHIEvitz, J. H. (I885). Beiträge zur Entwicklungsgeschichte der Speicheldrüsen. Arch. Anat. Entwick., 40 I-436.

ClarA, M. (1939). Die arteriovenösen Anastomosen. Leipzig.

DALTON, A. J. and M. D. FELix (I956). A comparative study of the Golgi complex. F. Biophys. Biochem. Cytol., 2, Suppl., 79-83.

DALY, M. M. and A. E. MIRSKY (1952-53). Formation of protein in the pancreas. F. gen. Physiol., 36, 243-254.

DANIELLI, J. F. and H. DAVSON (I943). The permeability of natural membranes. Cambridge University Press.

DEANE, H. W. (I 947). A cytochemical survey of phosphatases in mammalian liver, pancreas, and salivary glands. Amer. F. Anat., 8o, 32 I-359.

DiETZ, H. (I 955). Das Verhalten der grossen Kopfspeicheldrüsen des Kaninchens nach Unterbindung ihres Ausführungsganges und nach Transplantation. Frankf. Z. f. Path., 66, 416-425.

ERNSTER, L. (I 959). Distribution and interaction of enzymes within animal cells. Biochem. Soc. Symp., I6, 54-7 I. Cambridge University Press.

FLINT, J. M. (I902-3). The angiology, angiogenesis and organogenesis of the submaxillary gland. Amer. F. Anat., 7, 4 I 7-444.

GAUTIER, A. and V. DIOMEDE-FRESA (I953). Étude au microscope electronique de l'ergastoplasme des glandes salivaires du rat. Mikroskopie, 8, 23-3I.

GRAD, B. and C. P. LEBLOND (I949). The necessity of testes and thyroid hormones for the maintenance of the serous tubules of the submaxillary gland of the rat. Endocrinology, 45, 250-266.

HEIDENHAIN, R. (1883). Physiologie der Absonderungsvorgänge. In Handbuch der Physiologie ed. Hermann. Vol. 5. Vogel, Leipzig.

HILL, C. R. and G. H. BOURNE (I954). The histochemistry and cytology of the salivary gland duct cells. Acta anat., 20, I I6-I28.

HiRsCH, G. C. (I932). Die wechselnde Permeabilität der Pancreaszelle als limitierender Faktor der vitalen Neutralrotfärbung. Z. Zellforsch., I4, 5 I 7-543.

HOKIN, L. E. (I955). Isolation of the zymogen granules of dog pancreas and a study of their properties. Biochim. biophys. Acta, r8, 379-388. 
HOLTZLÖHNER, E. and C. NIESSING (1936a). Über Kapillardrosselung bei vermehrter Organdurchblutung. Z. Biol., 97, ro8-1 12.

— - (1936b). Die Drüsentätigkeit bei Nervenreizung 5. Lebendbeobachtungen an Zellen, Lymphspalten und Kapillaren der Unterkieferdrüse. $Z$. Biol., 97, 563-572.

junqueira, L. C. U. (I949). Estudo Histologico, Histoquimico, Bioquimico, e Experimental da glandula submaxillar do Camondongo (Mus musculus L). Arch. brasil. Med., 39, 581-584.

JUNQUEIRA, L. C., A. FAJER, M. RABINOVITCH and L. FRANKENTHAL (I949). Biochemical and histochemical observations on the sexual dimorphism of mice submaxillary glands. F. cell. comp. Physiol., 34, 129I 58 .

JUNQUEIRA, L. C. and M. RABINOVITCH (1954). Reversibility of the phenomena induced by excretory duct ligation in the rat submaxillary gland. Texas Rep. Biol. Med., 12, 94-97.

JUNQUeIRA, L. C. U. and G. C. HIRSCH (1956). Cell secretion; A study of pancreas and salivary glands. Int. rev. cytol., 5, 323-364.

KLEIN, E. (I 882). On the lymphatic system and the minute structure of the salivary glands and pancreas. Quart. F. micr. sci., N.S., 22, 154I75.

KOCHAKIAN, C. D., B. R. ENDAHL and H. D. HALL (1955). Arginase activity of the salivary glands and its regulation by androgens. Proc. Soc. exp. Biol., N.Y., 89, 289-291.

Kowalevsky, N. (1885). Über das Blutgefässsystem der Speicheldrüse. Arch. Anat. Physiol., 385-395.

KURTZ, S. M. (1954). Cytologic studies on the salivary glands of the rat in reference to the ageing process. F. Geront., 9, 42I-428.

LACASSAGNE, A. (I940). Dimorphisme sexuel de la glande sousmaxillaire chez la souris. C.R. Soc. Biol., Paris, 133, 180-18r.

LACASSAGNE, A. AND A. CHAMORRO (I940). Reaction à la testosterone de la glande sousmaxillaire atrophée consécutivement a l'hypophysectomie chez la souris. C.R. Soc. Biol., Paris, 134, 223-224.

LACY, D. and C. E. CHALliCE (I957). The structure of the Golgi apparatus in vertebral cells examined by light and electron microscopy. Symp. Soc. exp. biol., 10, 62-88.

LEESON, C. R. (1956). Localization of alkaline phosphatase in the submaxillary gland of the rat. Nature, $\mathbf{I} 78,858-859$.

- (1959). Histological, histochemical and electron microscopic studies on the rat submaxillary gland with special reference to its post-natal development. M.D. Thesis, Cambridge.

LEESON, C. R. and F. JACOBY (I959a). The post-natal development of the rat submaxillary gland. $\mathcal{F}$. Anat., Lond., 93, $20 \mathrm{I}-2 \mathrm{I} 6$.

- - (1959b). An electron microscopic study of the rat submaxillary gland during its post-natal development and in the adult. F. Anat., Lond., 93, 287-295.

Lewis, w. H. (I 93I). Pinocytosis. Fohns Hopkins Hosp. Bull., 49, 17-27. - (1 937). Pinocytosis by malignant cells. Amer. F. Cancer, 29, 666-679. LEWKE, J. and G. MÜLLER (1956). Über den Nachweis PAS-positiven Substanzen in den Speicheldrüsen beim Meerschweinchen. Acta histochem., 2, 216-221.

LIDDELL, E. G. T. and C. SHERRINGTON (1923). Mammalian physiology. Clarendon, Oxford.

LINDBERG, O. and L. ERNSTER (1954). Chemistry and physiology of mito- 
chondria and microsomes. Handbuch der Protoplasmaforschung. Springer, Vienna.

Linzell, J. L. (I959). Physiology of the mammary glands. Physiol. Rev., 39, $534-576$.

LUNDBERG, A. (1957). Secretory potentials in the sublingual gland of the cat. Acta physiol. scand., 40, 21-34.

MANNI, E. (1957). Sugli effetti della stimolazione dei nervi parasimpatici della parotide ricerche al microscopic elettronico. Arch. fisiol. Fir., $\mathbf{5 7}, 339-350$.

MANNI, E., M. A. GRILLO and C. AMBRosino (I957). Sulla struttura submicroscopica e su alcune attivita enzimatiche (succinico deidrogenasi e adenosin-trifosfatasi) dei mitocondri dell ghiandola parotide. Arch. fisiol. Fir., 57, I-13.

MARTIN, B. F. (1953). Lipase in gland duct epithelium and in mucus secreting cells. Nature, 172, 1048-1049.

MERKel, F. (1883). Die Speichelröhre. Vogel, Leipzig.

MILSTEIN, B. B. (I950). Regeneration in the submaxillary gland of the rat. Brit. F. exp. Path., 31, 664-669.

NeUmanN, K. H. (1952). Eine neue Methode zur histochemischen Lokalisation des Bernsteinsäure dehydrierenden Fermentes Succinodehydrase. Klin. Wschr., 30, 605-606.

NOBACK, C. R. and W. MONTAGNA (I947). Histochemical studies of the basophilia, lipase and phosphatases in the mammalian pancreas and salivary glands. Amer. F. Anat., 81, 343-367.

PADYKUla, H. A. (1952). Localization of succinic dehydrogenase in tissue sections of rat. Amer. F. Anat., 9r, 107-145.

PALADE, G. E. (1955). A small particulate component of the cytoplasm. F. Biophys. Biochem. Cytol., 1, 59-68.

- (1956a). The endoplasmic reticulum. F. Biophys. Biochem. Cytol., 2, $85-98$.

- (1956b). Intracisternal granules in the exocrine cells of the pancreas. F. Biophys. Biochem. Cytol., 2, 41 7-422.

PALADE, G. E. and K. R. PORTER (I954). Studies on the endoplasmic reticulum I. Its identification in cells in situ. F. exp. Med., 100, 641-656.

PALAdE, G. E. and P. Siekevitz (I956). Pancreatic microsomes. $\mathcal{F}$. Biophys. Biochem. Cytol., 2, 671-690.

PEASE, D. C. (1956). Infolded basal plasma membranes found in epithelia noted for their water transport. F. Biophys. Biochem. Cytol., 2, Suppl., 203-208.

PISCHINGER, A. (1924). Beiträge zur Kenntnis der Speicheldrüsen, besonders der Glandula sublingualis und submaxillaris des Menschen. Z. mikr.-anat. Forsch., r, 437-489.

DE PLESSIS, D. J. (1957). Some important features in the development and function of the parotid salivary glands. S. Afr. med. F., 31, 773-780.

PORTER, K. R. (I954). Electron microscopy of basophilic components of cytoplasm. F. Histochem., 2, 346-373.

- (1956). The submicroscopic morphology of protoplasm. Harvey Lect., 1955-56, Series 51, 175-228. Academic Press, New York.

RAWlinson, H. E. (I933). Cytological changes after autonomic and adrenalin stimulation of the cat's submaxillary gland. Anat. Rec., 57, 289-301.

- (1934). Certain histophysiological aspects of gland secretion. Ph.D. Thesis, McGill University. 
RAWLIN ON, H. E. (I935). The changes in the cells of the striated ducts of the cat's submaxillary gland after autonomic stimulation and nerve section. Anat. Rec., 63, 295-313.

RAYNAUD, J. (I950). Action de la thyroxine sur la glande sous-maxillaire de la souris castrée. C.R. Soc. Biol., Paris, 144, 245-248.

RoBERTSON, J. D. (1959). The ultrastructure of cell membranes and their derivatives in The structure and function of subcellular components. Biochem. Soc. Symp., 16, 3-43. Cambridge University Press.

SCHNEIDER, W. C. and E. L. KUFF (I954). On the isolation and some biochemical properties of the Golgi substance. Amer. F. Anat., 94, 209-224.

SCHUlTE, H. W. (I9I3). The development of the salivary gland in man and cat. Studies in cancer, Vol. 4. Columbia University Press, New York. SCOTT, B. L. and D. C. PEASE (1957). Electron microscopy of the major salivary glands of the rat. Anat. Rec., 127, 364.

SCREEBNY, L. M., J. MEYER and E. BACHEM (I 953). Histologic and enzymatic differences in the submaxillary glands of normal and hypophysectomised male and female white rats. F. dent. Res., 32, 686.

SCREEBNy, L. M., J. MEYeR, E. BACHEM and J. P. WEINMAN (1955). Post-natal changes in proteolytic activity and in the morphology of the submaxillary gland in male and female albino rats. Growth, 19, 57-73. SHAFER, W. G. and J. C. MUHLER (1953). Effect of gonadectomy and sex hormones on the structure of the rat salivary glands. F. dent. Res., $32,262-268$.

SHKLAR, G., I. GLICKMAN and S. TURESKY (1958). A histochemical study of the salivary glands in normal and cortisone injected white mice. F. dent. Res., 37, I $19-124$.

SIEKEVITZ, P. and G. E. PALADE (I958). A cytochemical study on the pancreas of the guinea pig. II. Functional variations in the enzymatic activity of the microsomes. F. Biophys. Biochem. Cytol., 4, 3093 I8.

SJÖSTRAND, F. S. (1956). The ultrastructure of cells as revealed by the electron microscope. Int. rev. cytol., 5, 455-533.

SJÖSTRAND, F. S. and v. HANZON (I954a). Membrane structures of cytoplasm and mitochondria in exocrine cells of mouse pancreas as revealed by high resolution electron microscopy. Exp. Cell Res., 7, 393-414.

- - (1954b). Ultrastructure of Golgi apparatus of exocrine cells of mouse pancreas. Exp. Cell Res., 7, 41 5-429.

Smith, H. W. (195I). The Kidney. Oxford University Press, New York.

SNELL, R. S. and J. R. GARRETT (I 957). The distribution of cholinesterase in the submaxillary and sublingual salivary glands of the rat. F. Histochem., 5, 236-245.

SPANNER, R. (I937). Der Abkürzungskreislauf der Glandula submaxillaris. Z. Anat. Entwick., 107, 124-153.

- (1942). Besonderheiten an der Gefässwand der grossen Mundspeicheldrüsen, sowie der Bauchspeicheldrüse. Morph. $\mathfrak{F} b ., 87,193^{-2}$ I 5 .

STANDISH, S. M. and W. G. SHAFER (1957). Serial histologic effects on rat submaxillary and sublingual salivary gland of duct and blood vessel ligation. F. dent. Res., 36, 866-879.

STIER, A. (1952). Über den Nachweis von Reduktionsorten mittels Tetrazol in Mundspeicheldrüsen und Pancreas des Meerschweinchens. Z. Anat. Entruick., I16, 399-4I8. 
Stormont, D. L. (1932). The salivary glands. In Special cytology ed. Cowdry, Vol. I. Hoeber, New York.

TAKAGI, K. (I 925). Untersuchungen über die Unterkieferdrüse der Katze mit besonderer Berücksichtigung des Chondrioms. Z. mikr.-anat. Forsch., 2, 254-323.

thaysen, J. H. (I955). Sekretionsstudier. Jorgenson, Copenhagen.

WEISS, J. M. (1955). Intracellular changes due to neutral red as revealed in the pancreas and kidney of the mouse by the electron microscope. F. exp. Med., ror, 213-223.

zimmermanN, k. W. (1927). Die Speicheldrüsen der Mundhöhle und die Bauchspeicheldrüse. In Handbuch der mikroskopischen Anatomie des Menschen ed. Mollendorff, Vol. 5. Springer, Berlin. 


\section{CHAPTER III \\ INNERVATION OF THE GLANDULAR \\ ELEMENTS}

Saliva may flow from a salivary gland because the secretory cells have an inherent ability to secrete spontaneously or because they are stimulated to activity by extracellular agents carried to the gland by the blood or liberated from nerve endings. Examples of spontaneous activity and of secretion induced by hormones will be given in later chapters. The flow controlled by nerves, which is undoubtedly the most important, will be considered in the present chapter.

In a discussion of the innervation of the salivary glands the following complicating factors must be taken into account:

I. 'The glands receive nerve fibres both from the parasympathetic and the sympathetic nervous system. Both sets of nerves, electrically stimulated, are able to affect the secretory process, but the physiological significance of the double innervation of the glands is not altogether clear.

2. There is some uncertainty as to the route by which the nerves reach some of the glands. Evidence suggests that secretory fibres may arrive at some glands through unknown channels. This may invalidate inferences drawn from denervation experiments.

3. The saliva poured into the mouth results from activity in different types of cells. It may be produced, for instance, both in serous and mucous cells and its composition modified by the cells of the ducts. An important problem, which has been the subject of many investigations, is whether the single secretory cell is innervated both by parasympathetic and sympathetic fibres. Little is known about the innervation of the ducts. Histological and electrical changes in their cells have been produced by stimulation of nerves, but they may be indirect, due to activity evoked in the secretory cells. On the other hand, the presence of true cholinesterase in the duct cells of the rat's submaxillary and sublingual glands (Snell and Garrett, 1957) may suggest that these cells are supplied with cholinergic nerve fibres.

4. The nerves control structures in the glands other than the 
secretory cells, and may thereby modify the secretion. An accelerated flow of saliva may be due to contractions of myoepithelial cells. Vascular changes, caused by impulses in vasomotor nerves, may affect the secretion. Conversely, it is conceivable that secretory activity may change the flow of blood through the gland. The possibility of a complicated interaction between secretory, motor and vasomotor processes has rendered investigations on the different types of fibres present in the nerves difficult.

\section{THE EFFERENT NERVE FIBRES OF THE GLANDS}

Ludwig ( $185 \mathrm{I}$ ) discovered that saliva flowed from the submaxillary gland on stimulation of the chorda-lingual nerve even if the nerve had been cut centrally to the electrode; and although it had been fully accepted, for more than a century, that salivary secretion is caused by the brain acting in some way on the glands through nerves, this experiment by Ludwig has been regarded as the first definite proof of the existence of special secretory nerve fibres. The discovery of vasodilator nerve fibres was made in the same preparation (Claude Bernard, 1858). The hyperaemia in the gland, caused by stimulation of the chorda-lingual nerve, was, indeed, so impressive that an old hypothesis was revived according to which the flow of saliva is due to increased filtration pressure in the gland.

It has, on the other hand, been repeatedly suggested that the vasodilation following stimulation of the parasympathetic nerve might result from excitation of secretory, and not vasodilator fibres, the increased blood flow being due to agents released from the activated secretory cells (Barcroft, I9I4; Hilton and Lewis, I955).

When the sympathetic innervation of the salivary glands is considered, similar lines of thought are encountered. On stimulation of the cervical sympathetic trunk Ludwig (I85I) observed a flow of saliva from the submaxillary gland and Claude Bernard ( 1858 ) an intense vasoconstriction. Later investigators have noticed periods of vasodilation, alternating with constriction or following it when the stimulation is discontinued. These findings have not, however, been taken as evidence by all investigators that secretory, vasoconstrictor and vasodilator fibres are present in the sympathetic innervation of the gland. Most, but not all, workers seem to agree that the vasodilation is secondary to the secretion and not due to activation of separate vasodilator fibres. The hypothesis has been proposed that there are no secretory fibres in the sympathetic 
trunk. The flow of saliva observed on stimulation of the trunk may be due to excitation of motor fibres innervating contractile elements in the gland which expel saliva already present in the ducts (Mathews, I898). Alternatively, a flow of saliva seen during stimulation of the sympathetic nerve may be caused by sympathin diffusing from the vasoconstrictor nerve terminals to the secretory cells (Richins and Kuntz, I953).

The enumeration of the different types of fibres which may supply the salivary glands is not limited to those so far described. Several investigators have suggested that the parasympathetic nerve contains vasoconstrictor fibres (e.g. Fröhlich and Loewi, I906). The fact that a flow of saliva induced by parasympathetic stimulation may be diminished by sympathetic stimulation has led to the suggestion that the sympathetic trunk carries inhibitory secretory fibres for the gland (Czermak, I857). Claude Bernard ( 1862 ) and Bradford (I888), in attempts to explain the "paralytic secretion" seen after section of the chorda-lingual nerve, postulated the presence of such inhibitory fibres in the parasympathetic nerve. Histological investigations led Kuntz and Richins (1946) to the conclusion that the parasympathetic, and not the sympathetic, nerve contains motor fibres for the contractile elements of the salivary glands, the myoepithelial cells. Finally, it should be recalled that it was as a result of investigations on the salivary glands that Heidenhain ( 1878 ) advanced the hypothesis of trophic and secretory fibres, further elaborated by Babkin and extensively discussed in his monograph (1950).

An investigation by Graham and Stavraky (1953) is of particular interest. The experiments of these authors indicate that whereas low concentrations of acetylcholine have the well-known secretory and vasodilator effects, higher concentrations tend to cause vasoconstriction and reduce the flow of saliva. Acetylcholine was supplied either by intra-arterial injections of small and big doses of the drug or by stimulation of the chorda tympani; in some experiments eserine was given. The usual vasodilatation caused by stimulation of the chorda tympani could for instance be replaced by constriction if big doses of eserine or acetylcholine were given, and with this the flow of saliva diminished.

To sum up:

I. From the experiments of Graham and Stavraky it can be inferred that nerve fibres, which ordinarily cause vasodilation or 
secretion, may under special experimental conditions act as constrictor or inhibitory fibres.

2. Nerve fibres in contact with certain structures may under special conditions affect other structures as well, through diffusion of chemical mediators. Secretory nerves may thus influence the vascular bed, and vasomotor fibres the secretory cells. It is not unreasonable to suppose a diffusion of the chemical transmitters. A piece of cotton-wool, soaked in a solution of acetylcholine and placed on the surface of a salivary gland, causes a lively secretion; that this is not due to absorption of the drug into the general circulation is shown by the fact that the other salivary glands do not respond. Such a diffusion has in fact been assumed to take place by Cannon and Rosenblueth (1937) when considering the possibility that only certain "key cells" are supplied by nerve fibres. It is, however, not known whether under physiological conditions the transmitters are able to influence distant effectors.

3. Stimulation of secretory fibres may indirectly lead to vasodilatation because vasodilator agents are released from the activated secretory cells.

4. Stimulation of vasoconstrictor fibres may reduce the supply of blood to such an extent that a secretion is diminished or stopped.

5. Stimulation of motor nerve fibres may lead to expulsion of saliva, thereby simulating a secretory effect.

At our present state of knowledge it seems safe to state that the parasympathetic nerves supply the salivary glands with fibres which under ordinary conditions are secretory, and that the sympathetic nerves carry vasoconstrictor fibres. Whether motor and secretory sympathetic fibres exist will be discussed below, whereas problems concerning vasomotor fibres will be dealt with in Chapter VII.

The parasympathetic secretory innervation. All the salivary glands, both the three big pairs and the small glands in the oral mucosa, seem to receive their main secretory innervation from the parasympathetic system. A single electrical shock applied to the parasympathetic nerve affects the secretory cells. This had already been seen in the external electrogram of the submaxillary gland by Bradford (1888); Rosenblueth, Forbes and Lambert (1933), using concentric needle electrodes, made the same observation. In his recent experiments with microelectrodes inserted from the surface of the submaxillary gland into single cells Lundberg (1955, 1958) has been able to show that single shock stimulation of the chorda 
increases the resting membrane potential; this occurs both in his "type I" and "type 2" responses, which he assumes to originate from alveolar and demilune cells, respectively. According to Gayda ( 1925$)$ it is even possible to demonstrate a secretory response to a single shock applied to the chorda; other investigators have found this to be the case in some experiments only (Beznák and Farkas, I 936-37).

On repetitive stimulation the rate of salivary flow increases with the increasing rate of stimulation, as analysed by Beznák and Farkas (1936-37). When trying to estimate the frequency needed to obtain a maximal response different results have been obtained, for instance 40 (Wedensky, I892), ro-30 (Kupalov and Skipin, I934), 36 (Rosenblueth, I932), 30-40 (Bruner and Kozak, I957), 3 (Beznák and Farkas, I936-37), 9 (Wills, I941), ro per second (Diamant, Enfors and Holmstedt, 1959). At least in the submaxillary gland of the cat 10-20 stimuli per second give a maximal secretory response. With this frequency, the high rate of flow can be almost maintained, for hours ("die Geduld des Beobachters erschöpft sich früher als die Erregbarkeit des Nerven und der Drüse", according to Heidenhain), the gland delivering an amount of saliva as big as its own weight in a few minutes.

Lundberg's experiments indicate that the parasympathetic fibres excite both the alveolar and the demilune cells. It is, in fact, not possible to obtain a higher rate of salivary flow with any chemical or nervous stimuli than that elicited by stimulation of the chorda (Emmelin, I955a). It seems reasonable to assume that the chorda fibres are able to excite all the secretory elements of the submaxillary gland to maximal activity. After destruction of some of the parasympathetic fibres, stimulation of the remaining ones causes cytological signs of secretory activity in some acini, whereas other neighbouring acini seem to be at rest (Mansfeld, Hecht and Kovács, I93 I ; Hillarp, I949). There is thus no spread of stimulation from some nerve fibres to all the glandular elements. The results have been taken as evidence to show that diffusion of the chemical mediator from its site of liberation in contact with one cell to adjacent cells does not play a major role (Hillarp, I949). Under certain experimental conditions such a spread may of course take place; after the administration of a cholinesterase inhibitor, for instance, stimulation of the chorda may even evoke a secretion in the contralateral submaxillary gland and a fall in the 
systemic blood pressure (Babkin, Alley and Stavraky, 1932). Physiologically, however, a salivary cell does not seem to have to depend for its excitation on transmitter substance from parasympathetic fibres of neighbouring cells. On the contrary, each cell seems to have a rich supply of parasympathetic fibres, several parasympathetic neurones converging on to the secretory cell. This was concluded by Lundberg (1955) from experiments of the type shown in Fig. 3.I. The membrane potential was recorded using
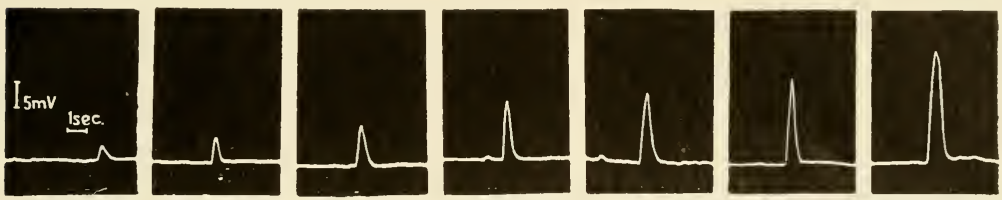

FIG. 3.I. "Type I" responses obtained with intracellular electrode from the cat's submaxillary gland.

Showing increasing response with increasing strength of single shock stimulation to chorda. Supramaximal stimulation in record to the right (Lundberg, 1955).

an intracellular electrode. It was found that with increasing strength of the single shocks, applied to the chorda, the hyperpolarization increased. Some experiments, in which the potential grew stepwise with increasing intensity of stimulation, allowed the conclusion that the secretory cell is innervated by a minimum of $5^{-10}$ neurones. The fibres stimulated were of course preganglionic, and further experiments on a preparation, in which postganglionic parasympathetic stimulation is possible, would be of great interest.

Numerous investigators have demonstrated that the transmitter of the parasympathetic nerve fibres, which cause salivary secretion, is acetylcholine. Acetylcholine can be extracted from the salivary glands. After section of the chorda tympani the amount extractable decreases, according to Chang and Gaddum (1933). Beznák (1932, I934), however, found no such reduction in the acetylcholine content. It is interesting to observe that according to Chang and Gaddum all the acetylcholine does not disappear even after section and degeneration of postganglionic fibres (in the parotid gland). This may suggest that acetylcholine has a function in the gland apart from that as a transmitter; but it should also be kept in mind that there is some evidence showing that cholinergic fibres reach the parotid gland through anatomically unknown channels. Cholinesterase, predominantly of the specific type, is present in salivary 
glands (MacIntosh, 1937; Riker and Wescoe, 1949; Koelle, 1950; Dirnhuber and Evans, 1954; Dumont, 1955; Strömblad, 1955, 1956a, 1957 $a$; Kahlson and Renvall, 1956). Histochemical observations show true cholinesterase to be present in a fine network of nerve fibres around the acini (Snell and Garrett, 1956, 1957). Experiments by Dirnhuber and Evans (1954) suggest that the true cholinesterase plays a more important role for the transmission process than pseudocholinesterase. Using inhibitors acting selectively on the true, or on the pseudocholinesterase, they found that the secretory process was particularly influenced by inhibition of the true esterase. Section of the parasympathetic fibres causes a decrease in the esterase activity of the glands; as with acetylcholine, there is not a complete loss of activity, even after postganglionic denervation, but a reduction by about 60 per cent (Strömblad, 1955, 1957a).

It is well established that parasympathetic stimulation releases acetylcholine from the submaxillary gland of cats and dogs (Babkin, Alley and Stavraky, 1932; Babkin, Gibbs and Wolff, I932; Beznák, 1932; Gibbs and Szelöczey, 1932; Feldberg, 1933; Henderson and Roepke, $1933 a$ and $b$ ). 'The liberation takes place even in the presence of atropine.

The acetylcholine set free has generally been assumed to originate from the terminals of the postganglionic neurone. In the submaxillary gland, however, most of the synapses between the preand postganglionic neurone are situated close to the gland or within it, and these synapses are unavoidably included in a perfusion experiment. In experiments on submaxillary glands perfused with eserinized plasma, acetylcholine was found to appear in the venous effluent on stimulation of the chorda (preganglionic, parasympathetic fibres). Stimulation of the postganglionic neurone, and a consequent release of acetylcholine from its endings, was then prevented by the addition of curarine to the perfusion fluid. When the chorda was again stimulated acetylcholine was still found in the perfusate, but the quantity was reduced to one-quarter to one-third of that found in the absence of curarine. It was concluded that when the plasma contained curarine, the acetylcholine obtained on chorda stimulation originated only from the preganglionic endings, whereas in the absence of curarine the acetylcholine had been liberated both from pre- and postganglionic endings (Emmelin and Muren, 1950). Fig. 3.2 shows two experiments of this kind, one in 
a dog, the other in a cat. The figure shows in addition that some acetylcholine appears in the effluent when the nerve is not stimulated; this is the case even in the presence of the curarine. Since this seemed to be the first demonstration of a release of acetylcholine in a parasympathetic ganglion, attempts were made to find further arguments supporting the view that the preganglionic chorda fibres are cholinergic. The nerves were found to contain acetylcholine in fairly high concentration. Further, it is known

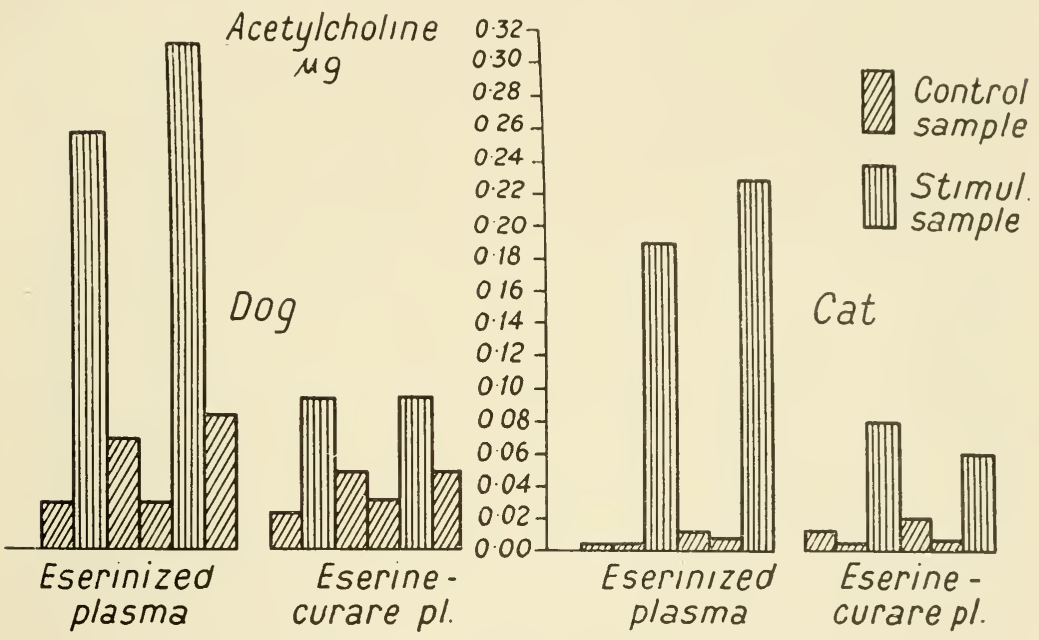

FIG. 3.2. Output of acetylcholine from the submaxillary gland of a dog and a cat.

The glands were perfused with heparinized plasma containing eserine $10^{-5}$ and in the second part of the experiment in addition curarine $10^{-4}$. Each column represents the acetylcholine content in a sample of perfusate collected during 3 minutes. Stimulation samples were collected when the chorda had been excited during the first 2 minutes of the period with 20 supramaximal shocks per sec. Assay of acetylcholine on blood pressure of eviscerated, eserinized cat (Emmelin and Muren, 1950).

from cross-suture experiments that functional union can be established between the peripheral stump of the transected chorda and the central end of some other efferent nerve, containing cholinergic fibres, for instance the hypoglossal nerve (see Emmelin, Muren and Strömblad, I $957 a$ ). Since it is generally assumed that cholinergic fibres of one nerve can functionally replace fibres of another nerve only if these are cholinergic too (Dale, I934), further support is thus given to the view that acetylcholine acts as mediator across the parasympathetic ganglion of the submaxillary gland. A clinical counterpart to the cross-suture experiments may also be quoted. 
In "the chorda tympani syndrome" (Young, 1956) unilateral sweating occurs in the submental region during meals. After a previous accidental injury to the chorda, for instance during removal of tuberculous cervical lymph glands, misdirected regenerating chorda fibres have innervated sweat glands and, when food is taken, impulses meant for the salivary gland cells reach the sweat glands instead. Since the sudomotor fibres are cholinergic (Dale and Feldberg, 1934) the inference would again be that the preganglionic chorda fibres are cholinergic too.

The average quantity of acetylcholine liberated at the preganglionic terminals for each volley in the chorda tympani was found to be about $20 \mathrm{pg}$ in the cat's submaxillary gland, perfused with plasma containing eserine and curarine, when the nerve was stimulated for two minutes at a frequency of 20 per sec (Emmelin and Muren, 1950). For comparison it may be mentioned that this figure is almost as high as that obtained under similar experimental conditions in the superior cervical ganglion of the cat (Emmelin and MacIntosh, 1956). When the gland was perfused without curarine, the average output of acetylcholine per volley was about $80 \mathrm{pg}$; the contribution of the preganglionic endings would thus be about 20 , that of the postganglionic endings about $60 \mathrm{pg}$. The ratio of preganglionic axons to ganglion cells in the chorda is not known; it is generally supposed to be low in the parasympathetic system, of the order of 3 to I or 2 to I so that the quantity of acetylcholine released per shock is probably of the same order at the pre- and postganglionic ending.

In order to be accepted as a mediator between the parasympathetic fibres and the gland cells acetylcholine must of course be able to mimic the action of nerve stimulation; further, the quantity of the agent set free must be big enough to excite the gland cells. It is well known that acetylcholine evokes a secretion of saliva; and the electrical responses to acetylcholine and to chorda stimulation are identical, both in the external electrogram (Langenskiöld, I94I) and when intracellular recording is used (Lundberg, 1958). Comparisons between the composition of saliva obtained with different stimuli is always difficult, particularly because the composition varies with the rate of secretion; the literature does not, however, seem to contain any statements to the effect that there may be any fundamental difference between saliva obtained with injected acetylcholine and with parasympathetic stimulation. 
As to the quantitative aspect, the following may be pointed out. In the perfusion experiments, quoted above, about $0 \cdot 2 \mu \mathrm{g}$ of acetylcholine was obtained from the cat's submaxillary gland during a stimulation period of two minutes, of which two-thirds should originate from the postganglionic endings in contact with the secretory cells. The secretory threshold to acetylcholine injected through the lingual artery in retrograde direction, all arterial branches except that of the submaxillary gland having been tied, was found to be O.I $\mu \mathrm{g}$ (Graham and Stavraky, I953); under similar conditions Gibbs (1935) saw an effect with as little as $0.0 \mathrm{I} \mu \mathrm{g}$ of acetylcholine, and Beznák and Farkas (1936-37) with $0.00 \mathrm{I}-0 . \mathrm{I} \mu \mathrm{g}$. When acetylcholine was injected through the submaxillary duct towards the gland the threshold dose was $0.5^{-1} \mu \mathrm{g}$, or $0.1-0.5 \mu \mathrm{g}$ after previous section of the chorda (Emmelin, Muren and Strömblad, 1954). Considering the unfavourable conditions of these various experiments, which probably allowed only a small fraction of the administered drug to reach the gland cells (for instance, no anticholinesterase was given), it seems safe to conclude that the amounts of the drug released on chorda stimulation are big enough to excite the gland cells.

It is, in fact, probable that acetylcholine is liberated with a big margin of safety, in the synapse, at the postganglionic endings, or at both sites. This is suggested by the following observation (Emmelin, Muren and Strömblad, I957a). After section of the chorda, the cut nerve fibres were allowed to regenerate, or hypoglossal fibres were directed towards the synapses. In some cases seemingly fairly normal conditions were restored; stimulation of the regenerated fibres caused a lively secretion of saliva, the gland was not as atrophied as a denervated gland and the supersensitivity to chemical agents, characteristic of denervation, had decreased. However, on continued stimulation the rate of secretion tended to decline, and hexamethonium had an abnormally high blocking effect.

The safety factor is apparently high in another step of the transmission mechanism as well; cholinesterase activity can be greatly inhibited without seriously affecting transmission (Riker and Wescoe, I949; Dirnhuber and Evans, I954; Strömblad, I957a).

The supposition that acetylcholine normally appears in saliva (Secker, I 934) is apparently erroneous (Feldberg and Guimarais, 1935; Gibbs, I935; Larson, I935; Winterstein and Özer, I948). Acetylcholine is obviously very effectively dealt with by the esterase 
of the gland when it has acted on the gland cells. In addition, cholinesterase has been found in saliva (McCance, Brown, Comline and Titchen, 195I). For the understanding of the mode of action of acetylcholine on the gland cell it would be interesting to know whether the transmitter can reach the inner membrane of the secretory cell, and whether it has any action on it. However, neither the fact that acetylcholine causes a secretion when injected through the duct (Emmelin, Muren and Strömblad, I954), nor the finding that acetylcholine might possibly appear in saliva on stimulation of the chorda in the presence of eserine (Feldberg and Guimarais, I935) seems to throw any light on that problem.

In man stimulation of the chorda tympani has been found to produce a flow of saliva from the submaxillary gland (Diamant, Enfors and Homstedt, I959).

The sympathetic secretory and motor innervation. The salivary response to sympathetic stimulation is much more variable and usually much smaller than that obtained on stimulation of the parasympathetic. Marked differences in the effect are found between different species and also between the various glands of the same species. General conclusions as regards the existence and distribution of sympathetic secretory and motor fibres should therefore be made with some caution. In the cat, for instance, sympathetic stimulation usually causes a lively flow of saliva from the submaxillary gland, but only a scanty flow from the parotid gland; in some cats, however, the response of the submaxillary gland is very small, or in exceptional cases, completely lacking. In the dog, saliva is obtained from the submaxillary gland, but scarcely any from the parotid gland. In rabbits, the response of the parotid is more marked than that of the submaxillary gland (Nordenfelt and Ohlin, i957).

A common finding is that the flow of saliva, whether rapid or slow, is short-lasting; it diminishes quickly and often ceases wholly in spite of continued stimulation of the sympathetic fibres. This is very likely one of the observations that has led to the conception that the effect of the stimulation is to expel saliva already present in the ducts of the gland. Mathews (1898), for instance, suggested that the flow of saliva from the submaxillary glands of cats and dogs evoked by stimulation of the cervical sympathetic trunk is due solely to the activation of a contractile mechanism. For an effect to be obtained, the ducts should consequently have to con- 
tain fluid; the arguments for a motor innervation have been of the following type: the responses often decrease on repeated stimulation of the sympathetic fibres, and can be increased by blowing fluid backwards through the duct towards the gland or by previous stimulation of the parasympathetic fibres. Through the last-mentioned observation the problem of the motor innervation has been linked with that of "augmented salivary secretion". Experiments by Bradford (1888) and Langley (1889) showed that the response to sympathetic stimulation could be increased by previous excitation of the parasympathetic fibres. Langley's explanation was that the first stimulation left the gland cells in a state of heightened excitability, which persisted for a short period. Numerous later investigators have accepted this mechanism as responsible for the "augmented secretion", others have emphasized the importance of a contractile mechanism, activated by the sympathetic fibres and usually presumed to be identical with the myoepithelial "basket cells". Babkin (1950), who with co-workers has contributed much to the solution of the problem of the "augmented secretion", has given an exhaustive review of the literature. From this it is apparent that both mechanisms may be at work. The sympathetic nerves of the salivary glands obviously contain motor fibres acting on contractile elements. These may also be activated by injected adrenaline or histamine. Most investigators, collecting saliva from a cannula in a salivary duct, have probably noticed that if some saliva, secreted after sympathetic stimulation or injection of adrenaline, is left on the tip of the cannula, it will slowly disappear, sucked back into the gland. A reasonable explanation seems to be that this occurs because the contracted elements slowly relax, although it could be due to reabsorption in the ducts.

The effect of the sympathetic fibres on the contractile elements has been well illustrated in experiments on the sheep's parotid gland. Histological investigations have shown this gland to contain myoepithelial cells (Silver, 1954), and stimulation experimen's have made it likely that these can be excited by sympathetic stimulation or injection of oxytocin (Kay, 1954). In the experiment of Fig. $3 \cdot 3$ (Coats, Denton, Goding and Wright, 1956) the effect of sympathetic stimulation is demonstrated. The parotid gland of the sheep is in permanent activity even if denervated, presenting an example of spontaneous secretion. This process continuously fills the ducts of the gland, and saliva is discharged at a constant rate, 
as shown by the straight line of the figure (a cumulative drop record). Sympathetic stimulation increases the rate of flow; but this is followed by a compensatory decrease in the rate. Experiments by these authors showed that the total amount of saliva collected over a $30-\mathrm{min}$ period with stimulation for $20 \mathrm{sec}$ of every 2 min was not bigger than that discharged during the same period without stimulation.

Kuntz and Richins (1946) examined histologically the question of the innervation of the myoepithelial cells of the parotid and sub-

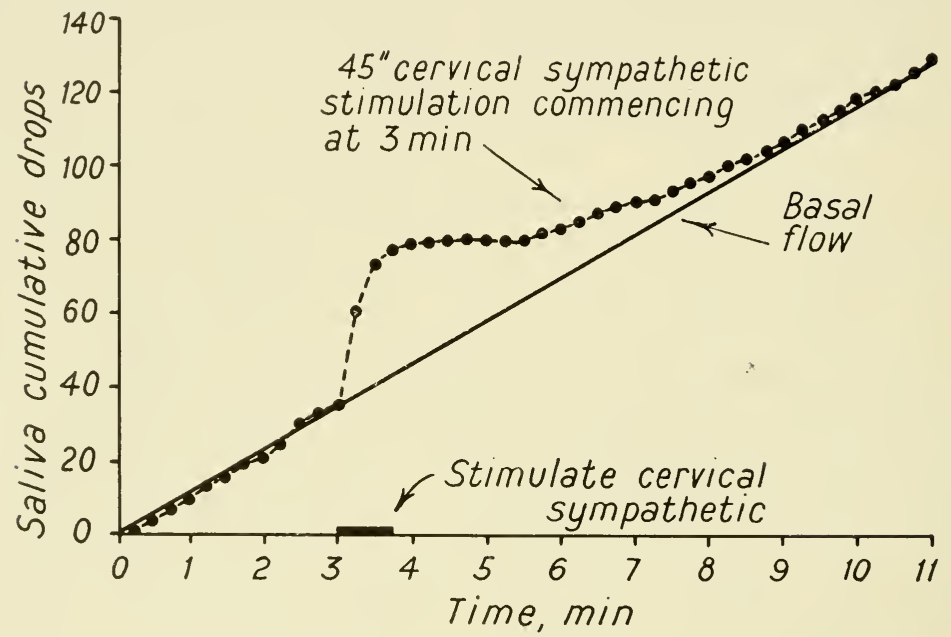

FIG. 3.3. The effect of cervical sympathetic stimulation upon the basal flow of saliva in a parotid gland of a sheep.

Parasympathetic fibres divided. The gush of saliva obtained on sympathetic stimulation is compensated for in the subsequent pause (Coats, Denton, Goding and Wright, 1956).

maxillary glands of cats, dogs and monkeys; the different nerves of the glands were cut and left to degenerate. From this investigation it was concluded that the myoepithelial cells are innervated exclusively through the parasympathetic nerves. The discrepancy between these observations and those described above has not been explained. The physiological evidence surely strongly supports the view that there are sympathetic motor fibres which are able to activate some kind of contractile mechanism in the salivary glands.

Such motor fibres may alone be responsible for a flow of saliva following sympathetic stimulation in some types of glands (or an accelerated flow, as in the sheep's parotid gland, for instance). In 
most glands, however, sympathetic stimulation has some further effect on the gland apart from the vascular effect (discussed in Chapter VII). Such an effect, apparently exerted on the secretory cells, has been demonstrated in different ways.

I. In some glands, such as the parotid gland of the dog, microscopical changes have been seen in the gland cells.

2. It can further be seen as an "augmented secretion" in Langley's sense, in which sympathetic stimulation has a real secretory effect, increased because the excitability of the gland cells has been

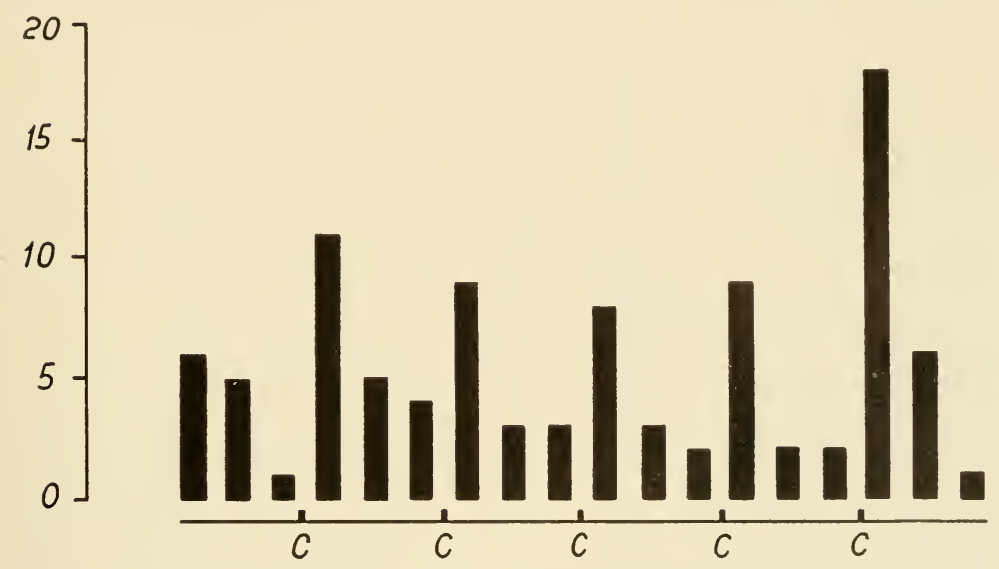

FIG. 3.4. Augmented secretion in a cat in dial anaesthesia.

Atropine had been given in a dose which abolished the secretory effect of chorda stimulation. The sympathetic nerve was stimulated for periods of 1 minute at 6 -minute intervals. The vertical columns represent the submaxillary secretion in divisions of the graduated tube ( $I$ division $=4.5 \mu \mathrm{l}$.). The points marked $c$ on the lower line indicate that the chorda, which alone produced no secretion, was stimulated for the 60 seconds just preceding the sympathetic stimulation (MacIntosh and Rawlinson, 1935).

raised, for instance by a previous stimulation of the parasympathetic fibres. The existence of such a "true augmented secretion" (Babkin) was well demonstrated in the following way (MacIntosh and Rawlinson, I935), illustrated in Fig. 3.4. A small dose of atropine had been given, just big enough to abolish the secretory effect of the chorda tympani on the submaxillary gland of the cat. Stimulation of the chorda was nevertheless found to increase the secretory effect of subsequent stimulation of the sympathetic fibres. The effect of the chorda stimulation could obviously not be to fill the ducts with saliva for a contractile mechanism activated by sympathetic stimulation to exert an expulsive action on; the augmented effect was not due to vasodilatation in the gland caused by the 
chorda even in the presence of atropine, for it persisted when the dilatation had passed off. The reasonable explanation was that the parasympathetic transmitter, although unable to cause a secretion, had increased, for some time, the excitability of the gland cells. It has, in fact, been shown that acetylcholine in such quantities as can be liberated from the chorda endings raises the excitability of the submaxillary cells (Beznák and Farkas, r936-37).

Making use of the "true augmented secretion" it may be possible to demonstrate a secretory effect of the sympathetic fibres even in
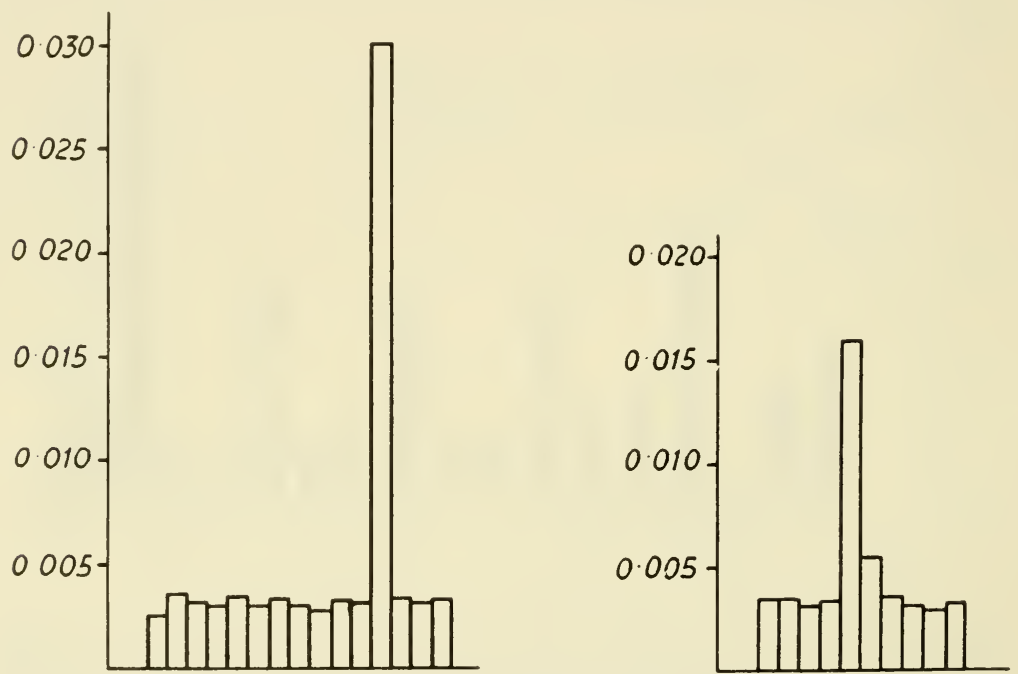

FIG. 3.5. Secretion from the sublingual glands of two cats in chloralose anaesthesia.

Each column represents the amount of saliva in ml. collected over a 10 -minute period. The high columns correspond to samples collected during nerve stimulation. In the experiment to the left the chorda was excited during the first 30 seconds of a 10-minute period. To the right: in the fifth period the sympathetic was stimulated during the first minute (Emmelin, 1953).

glands in which it is difficult to detect such an effect merely by stimulating the nerve.

3. The sympathetic stimulation, even if it does not cause a flow of saliva, can change the composition of saliva secreted in response to excitation of the parasympathetic fibres, but it may be necessary to ascertain that this effect is not secondary to sympathetic vasoconstriction.

4. In glands showing a spontaneous secretion a real secretory effect of the sympathetic fibres may manifest itself in the way shown in Fig. 3.5. The sublingual gland of the cat secretes spon- 
taneously. Stimulation of the chorda accelerates the flow. Stimulation of the sympathetic, likewise, increases the rate of flow; and there is no compensatory decrease after the stimulation, as seen in the sheep's parotid.

5. In some glands, such as the submaxillary gland of the cat, the flow of saliva seen during sympathetic stimulation is usually so rapid and persists for such a long time that it can only be due to a real secretory effect. That the gland cells are affected by the stimulation is further evidenced by the fact that their membrane potential changes, as seen with intracellular recording (Lundberg, I955); in exceptional submaxillary glands, which do not secrete on sympathetic stimulation, no electrical responses are found.

Although the secretory effect of sympathetic stimulation on most submaxillary glands of cats is unmistakable, the existence of secretory sympathetic fibres has been denied. In the histological investigation by Kuntz and Richins (1946), quoted above, it was inferred that the innervation of the glandular elements is mainly, perhaps exclusively, parasympathetic. In a later paper (Richins and Kuntz, I 953) the same authors express the view that the secretion from the cat's submaxillary and parotid glands which follows sympathetic stimulation, is caused by the transmitter released from the endings of vasomotor fibres, diffusing from the vascular bed to the gland cells. This theory was based on the observation that the secretory effect of sympathetic, but not of parasympathetic stimulation, was abolished by occlusion of the external carotid artery.

Such a theory might perhaps explain the variability in the secretory responses to sympathetic stimulation. As shown by Lundberg (I955) the electrical responses of the single gland cell appear with a longer latency after sympathetic than after chorda stimulation; further, whereas single shocks to the chorda cause the response, repetitive stimulation of the sympathetic is required. These facts might be in agreement with the theory of Richins and Kuntz. It is certainly easier to accept effects as due to diffusion of the relatively stable sympathetic transmitter than to acetylcholine.

In order to prove that secretory fibres for the salivary glands are really present in the sympathetic trunk it would be desirable to be able to excite the various types of fibres separately. The different effects of the stimulation can be separated. After a suitable dose of chlorpromazine, for instance, the secretory effect of sympathetic stimulation is abolished but the vasoconstriction retained; after 
priscol, on the other hand, the constriction is lost but the secretion preserved (Emmelin, I $955 b$ ). Of course, these observations cannot be used as arguments to show the presence of special secretory fibres. It does not seem likely that it would be possible to stimulate secretory fibres electively near the exit from the spinal cord. Langley (I 892), stimulating different spinal nerves, concluded that "the origin of the secretory fibres in the Cat and Dog bears, then, a very close resemblance to the origin of the vaso-motor fibres in these animals". Some light may be thrown on the problem under discussion by experiments on the degenerating sympathetic fibres. In the cat, it is true, the secretory and vascular effects seem to disappear at about the same time after section of the sympathetic trunk (Jurist and Rabinovich, I 924); but in dogs Sinelnikoff (I92 I) was able to obtain a secretory effect unaccompanied by vasoconstriction between the third and the sixth day after the nerve had been cut. The secretory effect was apparently mostly demonstrated as an "augmented secretion" after chorda stimulation. Similar experiments led Stavraky (I93I) to the conclusion that such an "augmented secretion", obtained about 90 hours after the operation, is not a "true augmented secretion" but a mechanical phenomenon, due to stimulation of surviving motor fibres. In some experiments, however, Sinelnikoff obtained a flow of saliva on rhythmical stimulation of the degenerating nerve even without previous chorda stimulation, and not accompanied by vasoconstriction. It might be that this effect was due to stimulation of real secretory fibres.

An indication of an influence, exerted under physiological conditions by the sympathetic fibres on the secretory cells may be that removal of the superior cervical ganglion is followed by the development of a supersensitivity of the gland cells to chemical agents (Simeone and Maes, 1939; Emmelin and Muren, I951). This does not prove, however, that there are separate secretory fibres, but it shows that the sympathetic fibres normally have some kind of action on the secretory cells, even if it may be exercised by sympathin diffusing from the vasomotor nerve endings. Actions on the gland cells, observed in an experiment during stimulation of the sympathetic fibres, are not merely due to abnormal conditions, for instance the use of unphysiologically high frequency of stimulation.

Claude Bernard (1858) found that a permanent flow of impulses 
in the sympathetic trunk keeps the vessels of the submaxillary gland in a state of contraction. If the flow of blood through the submaxillary gland of the cat is recorded in an acute experiment it can be shown that section of the cervical sympathetic trunk considerably increases the blood flow. Now, it can often be demonstrated that to restore the preoperative level of vascular tone it is necessary to stimulate the peripheral stump of the sectioned trunk using an impulse rate, which causes a slow flow of saliva (Emmelin and Engström, I960a). Since the same degree of tone was maintained physiologically, presumably by impulses of the same rate, without any secretion, this observation may suggest that separate secretory fibres are present in the trunk. The physiological discharge rate in vasoconstrictor fibres seems to be of the order of I to 3 impulses per second under "resting conditions" (see Folkow, I955). Impulses of such a rate, artificially applied to the cervical sympathetic trunk will fairly regularly evoke a flow of saliva; a very slow secretion has even been observed in one cat on stimulation of the sympathetic trunk at a frequency of ro per minute (Emmelin and Engström, I960a). It would be interesting to know the lowest rate of sympathetic stimulation causing a change in the membrane potential of the single gland cell. It also seems desirable to see whether an intense vasoconstriction can be elicited reflexly in a salivary gland without any secretion. In a series of experiments on cats the sympathetic vasoconstrictors were activated by bleeding. In order to avoid interference from blood-carried adrenaline and the mechanical effect of the bleeding the submaxillary gland was perfused separately by blood from the carotid artery of another cat. Bleeding was found to cause a pronounced vasoconstriction in the gland, but no secretion. Electrical stimulation of the sympathetic trunk using a frequency which gave a similar constriction invariably evoked a flow of saliva (Emmelin and Engström, I959 and $1960 a$ ).

More work may be required to settle the question raised by the investigations of Kuntz and Richins. It seems safe, however, to conclude that sympathetic fibres under fairly physiological conditions may stimulate the secretory cells of many salivary glands, even if no fibres end in anatomical contact with these cells. The fact that the maximal rate of secretion obtainable on sympathetic stimulation in the cat's submaxillary gland is about as big as that caused by injected adrenaline or noradrenaline suggests that the 
sympathetic impulses are able to reach all the secretory cells susceptible to the sympathetic mediator (Emmelin, I955a).

Which gland cells then have a sympathetic innervation? (In the following the cells will be called "innervated" even if the effect is an indirect one, as discussed above.) The problem whether the individual gland cell is controlled both by parasympathetic and sympathetic fibres has been a matter of dispute since the days of Heidenhain and Langley. 'Through the work of Babkin and his school it has been generally accepted that the gland cell is not innervated by both sets of fibres, but that the alveolar cells have a parasympathetic, the demilune cells a sympathetic supply. The experimental evidence supporting this conception has been surveyed by Babkin (1950). Recently, however, this view has been contested by several investigators.

Langenskiöld (I94I) analysed the external electrograms obtained from the submaxillary gland on stimulation of the different nerves and on injection of drugs, and came to the conclusion that "all secretory cells in the submaxillary gland that are innervated by the sympathetic are also innervated by the chorda".

From histological investigations Glimstedt and Hillarp (I942) concluded that the separate secretory cells of the rat's submaxillary gland very likely have a double innervation.

Experiments on the maximal rate of secretion under various conditions have supported the view expressed by Langenskiöld (Emmelin, I 955a). Stimulation of the cervical sympathetic trunk usually causes an abundant flow of saliva from the submaxillary gland of the cat. Nevertheless, when chorda stimulation elicits its maximal rate of salivary flow, an added sympathetic stimulation is unable to accelerate the flow further; provided that the sympathetic fibres were able to throw into activity cells not already activated by the mediator released at the chorda endings, one would expect the flow of saliva to increase. Fig. 3.6 shows such an experiment. The maximal rate of flow obtained on chorda stimulation is shown in the first section, that obtained on sympathetic stimulation in the second. In the last part sympathetic stimulation was superimposed upon the chorda stimulation; the rate of flow did not increase, but after a short period it started to decrease. This latter effect is due to sympathetic vasoconstriction. When the gland is secreting at a maximal rate it is very susceptible to a reduction of the blood supply. The vasoconstriction could be almost abolished by pre- 


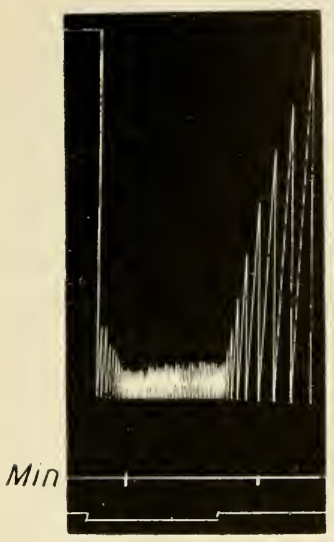

C

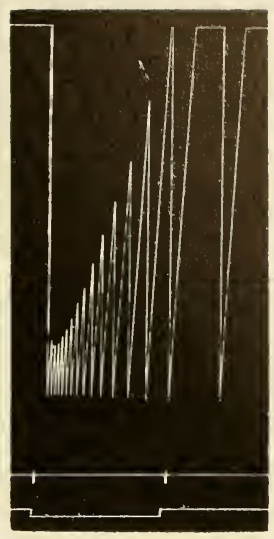

$S$

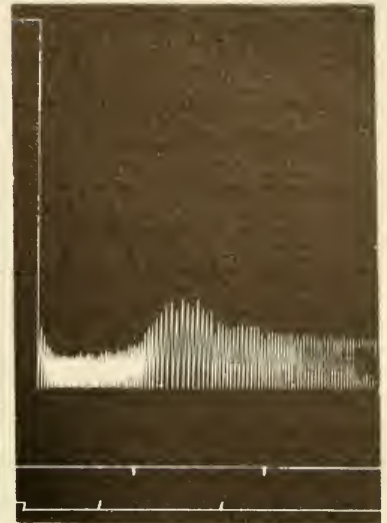

C S

FIG. 3.6. Secretion from a submaxillary gland of a cat. Chloralose anaesthesia.

Records from above: rate of secretion; time in minutes; signal. Left tracing: $C$, chorda stimulated; middle tracing: $S$, sympathetic stimulated; right tracing: $C$, chorda stimulated throughout, $S$, sympathetic stimulated between vertical lines (Emmelin, 1955a).
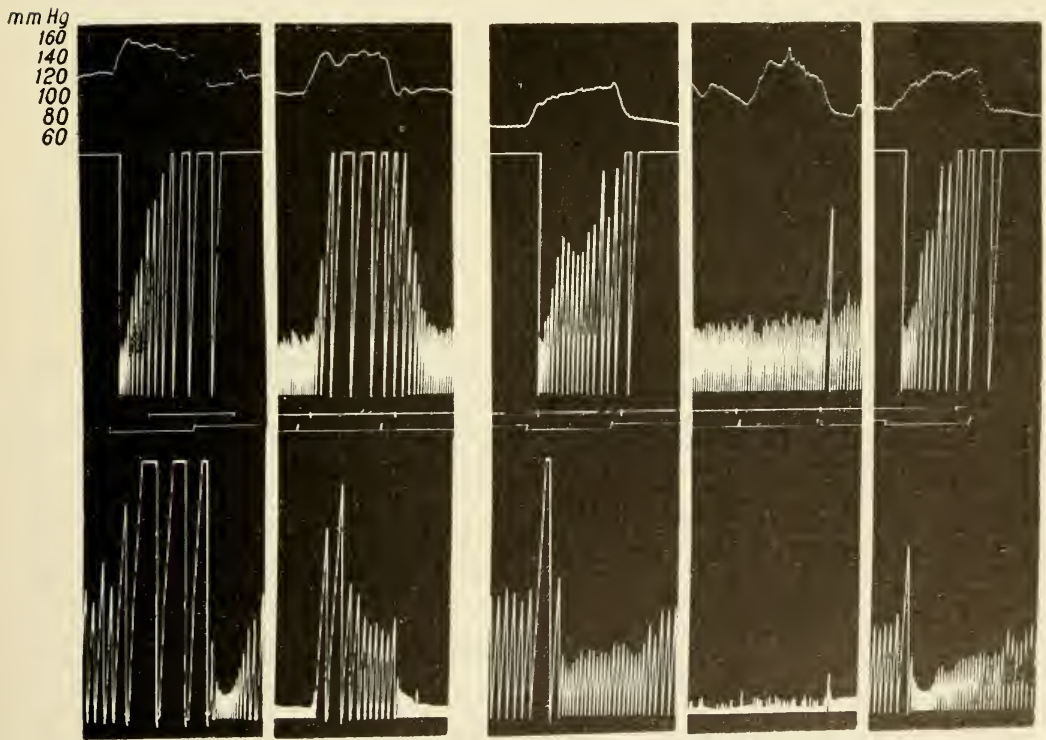

FIG. 3.7. Submaxillary secretion and blood flow in a cat, both recorded using ordinate recorders.

Records from above: blood pressure; secretion; time in minutes; signal; blood flow through Records from above: blood pressure; secretion; time in minutes; signal; blood fow the second the gland. First section: sympathetic stim maximal secretion, and between the two marks of the section the chorda was stimulated to cause maximal secretion, and betwion, 20 minutes after intravenous injection of $5 \mathrm{mg} / \mathrm{kg}$ priscol, shows effect of sympathetic stimulation. Fourth section repeats section two (at the end of the sympathetic stimulation period the chorda stimulation was discontinued for some seconds by mistake). Section five: sympathetic stimulation (Emmelin, 1955a), 
vious administration of priscol, without decreasing the secretory sympathetic response. This is shown in Fig. 3.7 in which both secretion and blood flow were recorded. It can be seen that sympathetic stimulation, after priscol, neither decreased the blood flow nor the secretion during chorda stimulation. But it did not increase the salivary flow either; the fact that this did not occur in the absence of priscol, therefore, was not due to a sympathetic vasoconstriction.

Strong evidence for a double innervation of the gland cells was obtained when the nerves were stimulated during intracellular electrical recording (Lundberg, I955). In the microelectrode "type I" response of submaxillary glands, supposed to originate from alveolar cells, the resting membrane potential of the cell could be increased both by chorda and sympathetic stimulation. In the "type 2" response, probably from demilune cells, chorda stimulation gave hyperpolarization, but sympathetic stimulation depolarization. In the sublingual gland of the cat only one type of response was found; both nerves affected the potential, both raising the potential over the outer membrane above the resting level (Lundberg, I957).

Experiments by Strömblad (1957b) indicate that the two chemical mediators act on the same cells. The oxygen consumption of chopped submaxillary glands of cats was measured manometrically. Acetylcholine, adrenaline and noradrenaline increased the respiration. When one of the drugs was given in a dose causing its maximal effect, another of the drugs could not further increase the response.

Hokin and Sherwin (1957) found that acetylcholine and adrenaline stimulate the secretion of amylase and the incorporation of ${ }^{32} \mathrm{P}$ into the phospholipids in slices of parotid glands of rabbits. The effects of maximal concentrations of the drugs were not additive, suggesting that the two drugs acted on the same cells of this gland also.

Section of the chorda tympani is followed by a pronounced supersensitivity of the gland cells to adrenaline (and acetylcholine). It seems unlikely that cells not normally excitable by adrenaline should become susceptible to this agent through denervation; for instance, it may be pointed out that the maximal rate of secretion on adrenaline injection is not higher in the denervated than in the normal gland (Emmelin and Muren, I95I). As the sympathetic seems to be able to affect all the cells sensitive to adrenaline, it is 
probable that section of the chorda affects cells which can be influenced by the sympathetic also, i.e. cells with a double innervation. Similarly, removal of the superior cervical ganglion sensitizes the gland cells to acetylcholine and to impulses of low frequency in the chorda. Cross-suture experiments have, likewise, pointed to the existence of a double innervation (Emmelin, Muren and Strömblad, I957 $a$ and $b$ ). When hypoglossal fibres were made to innervate the submaxillary gland through the chorda, the supersensitivity to drugs which developed when the chorda was cut was found to decrease. When, instead, the hypoglossal nerve was connected to the cervical sympathetic trunk and the chorda cut, the supersensitivity was also found to decrease when there was evidence of a functional union, for instance when swallowing movements were accompanied by dilatation of the pupil, retraction of the nictitating membrane and secretion of saliva. The hypoglossal nerve is thus not only able to counteract the supersensitivity, following section of the chorda, when connected to the chorda, but to the sympathetic as well. This surely suggests that the chorda and the sympathetic act on the same gland cells.

There are thus several very different types of experiments supporting the view that the gland cells of at least many salivary glands have a double innervation. On these particular structures the two divisions of the autonomic nervous system have consequently not an antagonistic function; in the salivary glands the antagonism is exerted on the vascular bed only. The two sets of nerves act rather synergistically, as seen in the "true augmented secretion". This does by no means imply that the nerves have identical effects on the secretory cells. Saliva secreted under the influence of one nerve may differ very much in its composition from a sample collected during stimulation of the other nerve, and the difference cannot be due to vascular factors alone. Furthermore, the electrical responses to the two types of nerves are very different, in the "type 2" responses of Lundberg even of different sign.

The picture of a salivary cell is thus that of a cell which can be excited by two different transmitters, both causing graded responses according to their concentration; the action of one substance is specifically antagonized by drugs like atropine, that of the other by drugs like ergotamine; and the response of the cell to one transmitter can be very different from that to the other one.

The chemical transmitter responsible for the secretory effects of 
sympathetic stimulation has been much less studied than the mediator of the parasympathetic fibres. Since the investigations by Cattell, Wolff and Clark (I934) the sympathetic fibres of the salivary glands have been supposed to be adrenergic. These workers showed that stimulation of the sympathetic fibres of the gland caused a contraction of the sensitized contralateral nictitating membrane; this effect could not be induced if the venous effluent from the gland had been stopped by a clamp. The effect could, of course, be due to sympathin from the vasoconstrictor endings in the gland, and it probably was in part. It was, however, further demonstrated that the secretory effects of sympathetic stimulation were increased by cocaine, which indicated an adrenergic transmitter at work. The fact that the electrical responses to adrenaline are identical with those obtained on sympathetic stimulation may further speak in favour of the view that the transmission is adrenergic. Whether the transmitter is adrenaline, noradrenaline or both, is not known, and probably difficult to establish in view of the fact that the nerve seems to contain not only secretory, but motor and vasomotor fibres as well. Oborin (1954) perfused the submaxillary gland of the cat and found that both adrenaline and noradrenaline appeared in the perfusate on sympathetic stimulation. The greater part of the sympathin was noradrenaline, but at least io per cent was adrenaline. Smaller doses of adrenaline are needed to produce a secretion than of noradrenaline; in many cats the secretory effect of adrenaline is but little increased by cocaine, but that of noradrenaline markedly, and in these animals cocaine has only a small effect on the secretory response to sympathetic stimulation (Emmelin and Emmelin, 1953). These observations may centre the interest on adrenaline as a transmitter for the secretory process : but further work on this problem is certainly required.

Very little is known, likewise, about the destruction of the secretory mediator in the salivary glands. It may be mentioned here that amine oxidase has been shown to be present. The submaxillary gland of the cat shows a higher activity than the parotid gland; in that connection it is pointed out that the sympathetic secretory innervation is much more pronounced in the former gland than in the latter. Removal of the superior cervical ganglion does not cause a fall in the amine oxidase activity in the submaxillary gland, and in the parotid gland there is even an increased activity (Strömblad, I956b). 
The secretory response to sympathetic stimulation differs from that to parasympathetic stimulation in being more or less shortlasting. This is well illustrated in Figs. 3.6 and 3.7. During constant stimulation of the sympathetic the flow of saliva decreases; sometimes the rate may temporarily increase again, but on the whole it tends to decline and often to stop completely. This is obviously not because the secretory cells (or their receptive mechanism) are exhausted, for a long-lasting, regular flow can be maintained by continuous injection of adrenaline or noradrenaline. Nor is this decrease in rate due to failure of synaptic transmission, for it is seen when the postganglionic fibres are stimulated also. The pronounced vasoconstriction evoked by stimulation may play a role; the temporary increase in secretion sometimes seen always accompanies a vasodilatation, which for a short period replaces the constriction. The experiment of Fig. 3.7 may point in the same direction. It shows that after priscol the sympathetic constriction is almost abolished, and now the secretory response is somewhat bigger than before priscol. The figure shows also, however, that even with priscol the sympathetic secretion is not well maintained; consequently the decrease in rate cannot wholly be due to constriction. Probably the stores of the adrenergic transmitter get used up more quickly than they can be replaced; it should be noticed that the experiments are usually carried out with unphysiologically high stimulation frequencies. With a low rate of stimulation the secretion can, in fact, often be well maintained for a long time (Emmelin and Engström, I $960 a$ ). A factor contributing to the initial rapid flow may be the simultaneous stimulation of sympathetic motor fibres.

In man, stimulation of the sympathetic trunk in the neck causes a secretion of saliva from the submaxillary, but not from the parotid gland (Folkow and Laage-Hellman, r 960). Similarly, adrenaline injected into a salivary duct in man, evokes a flow of saliva from the submaxillary, but not from the parotid gland (Emmelin and Strömblad, 1954). In human salivary glands the amine oxidase activity is remarkably high (Strömblad, I959).

THE POSTGANGLIONIC NEURONES OF THE SECRETORY

\section{NERVES}

Recent experiments suggest that the postganglionic neurones may have an action on the secretory cells apart from the one due to impulses from the central nervous system relayed across the 
ganglionic synapses. There is evidence to show that acetylcholine is continuously released from the postganglionic, parasympathetic endings in the salivary glands, and it may exert some kind of action on the gland cells (Emmelin, i960).

In perfusion experiments with eserinized solutions acetylcholine has been detected in the effluent when no nerves have been stimulated (Henderson and Roepke, I933 b, Emmelin and Muren, I950). This can be seen in Fig. 3.2. In these experiments impulses from the central nervous system were excluded by section of the (preganglionic) chorda fibres. Acetylcholine was obtained even when curarine was present in the perfusion fluid, as shown in the figure, and this could therefore not be due to impulses from the cut end, for instance, or set up in the postganglionic cell body by the eserine.

Anticholinesterases are known to cause secretion of saliva. This is the case even when the drugs are given into the artery of the gland (Dirnhuber and Evans, 1954) or through the salivary duct towards the gland (Emmelin, Muren and Strömblad, I954); with suitable doses the effect will remain local in the gland. The effect is abolished by atropine. It can be elicited when the chorda fibres have been cut, and is thus not dependent on impulses from the central nervous system. It can even be evoked when the postganglionic fibres have been sectioned acutely (Emmelin and Strömblad, I958a); this was shown by section of the auriculo-temporal fibres of the parotid gland. Consequently, the secretory effect of anticholinesterases is not dependent on impulses from the postganglionic cell body either. When the postganglionic fibres have been cut in advance and been allowed to degenerate, on the other hand, the effect of anticholinesterases is very small, in spite of the fact that the gland cells, because of the denervation, are highly supersensitive to acetylcholine. Fig. 3.8 shows the effect of eserine

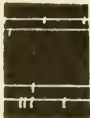

$A$

\section{(1)} ${ }_{E}^{L R}$

FIG. 3.8. Secretion from the normally innervated, right parotid gland of a cat (Nor) and from the left parotid (Post); the left auriculo-temporal fibres had been cut i 8 days previously.

Time in minutes. The signal (Sig) marks the injection of acetylcholine, $2 \mu \mathrm{g} / \mathrm{kg}$, intravenously at $A$; and the injection into the right $(R)$ and left $(L)$ parotid duct of $50 \mu \mathrm{g}$ eserine $(E)$ (after Emmelin and Strömblad, 1958). 
on the normal gland and on the gland previously postganglionically denervated, and sensitized to acetylcholine. 'The eserine was injected through the ducts so as to make it possible to treat the glands separately.

The most reasonable explanation of these experiments seems to be that there is a small continuous release of acetylcholine from the postganglionic, parasympathetic nerve endings, similar to the leakage from the motor nerve terminals, sufficient to cause a secretion only when the cholinesterase has been inhibited.

That an effect is obtained at all after the auriculo-temporal nerves have degenerated presents in itself a problem. It probably indicates that some cholinergic fibres are still present in the parotid gland; some auriculo-temporal fibres may have been left, or some fibres may reach the gland by other channels, as discussed in the next section of this chapter.

During the period in which the auriculo-temporal fibres are degenerating a curious phenomenon, a "paroxysmal salivary secretion", can be seen (Emmelin and Strömblad, 1958b). Attacks of secretory activity occur, alternating with periods of rest. The flow, as will be discussed later in Chapter VI, is probably due to bursts of acetylcholine released from the endings of the degenerating fibres. Normally, however, the continuous release is apparently not large enough to cause a secretion when acetylcholine is not preserved by a cholinesterase inhibitor. The question naturally arises whether the acetylcholine released has any effect. Dirnhuber and Evans (1954) suggest that this acetylcholine may perhaps keep the gland in a condition of constant subliminal excitation.

Investigations in quite a different field may give some indication that continuously released acetylcholine normally exerts some action on the gland cells. When the chorda tympani has been cut, the secretory cells of the submaxillary gland acquire a supersensitivity to chemical agents, which develops progressively and reaches a maximum within three weeks. In order to study whether the same would happen when the gland cells were deprived of chorda impulses in some other way, cats were treated with repeated injections of atropine over some weeks. A supersensitivity was found to ensue, and like the one following section of the chorda it was unspecific; therefore, a substance like adrenaline could be used for testing the level of sensitivity, even in the presence of atropine (Emmelin and Muren, I95I). Further examination disclosed 
that the level of supersensitivity attained by treatment with parasympatholytic agents was higher than that created by cutting the chorda (Emmelin and Strömblad, 1957). The drug had obviously excluded chorda impulses from acting on the gland, but must also have had some further effect. Since the agent used (piperidinoethyl-diphenyl-acetamide) was found to be highly specific as a parasympatholytic agent it was concluded that the additional sensitization, above the chorda level, indicated that the drug had prevented some acetylcholine, unconnected with preganglionic chorda impulses, from acting on the gland. It is reasonable to assume this to be the acetylcholine supposed to leak continuously from the endings of the postganglionic, parasympathetic neurones. If this be true, the experiments described would demonstrate that this acetylcholine normally exerts some action on the gland cells, the elimination of which would manifest itself in a supersensitivity. The postganglionic neurones of the submaxillary gland cannot be completely eliminated surgically since some of them are situated within the gland; but if the chorda is dissected towards the hilum of the gland and removed as thoroughly as possible, a supersensitivity is found to follow which surpasses that obtained by section of the chorda but is not quite as high as that found after treatment with parasympatholytic agents (Emmelin, 1960). This affords additional evidence of some influence exerted by the postganglionic neurone on the gland.

The sympathetic, postganglionic neurone seems to have some similar action on the gland cells, for whereas removal of that neurone causes a supersensitivity, preganglionic sympathetic denervation does not (Emmelin and Engström, 1960b).

\section{SECRETORY FIBRES THROUGH LESS-KNOWN CHANNELS}

Several investigators have concluded that some of the salivary glands may receive secretory fibres by other routes than those generally accepted. Seo (I934) cut the chorda tympani and removed the superior cervical ganglion in dogs supplied with a permanent fistula of the submaxillary and sublingual glands. In spite of these operations secretory responses were obtained on feeding and even when food was shown. The effects were small shortly after the nerves had been cut but increased somewhat in the course of time. Various procedures, such as cutting other nerves in the neighbourhood, were tried in order to eliminate the effects, but 
without success. The conditioned responses obtained, very quickly elicited, surely suggest the existence of some nervous pathway. Koropow (1939) found the salivary reflex of the parotid gland of dogs to reappear some time after parasympathetic denervation; sympathetic denervation did not abolish the response. Similar results were described by Emmelin and Strömblad (1953), working on dogs with permanent fistulae of the submaxillary glands. Conditioned reflexes were obtained from the "denervated" glands; they were initially very small but increased gradually in the course of time; after some weeks when they had fully developed on one side, the contralateral gland gave as big a response only a few days after "denervation". Babkin (1950) suggests that "reserve paths" may exist which after section of the usual secretory nerves gradually take over their function.

Some observations in man may be further quoted. In three patients Reichert and Poth (1933) observed that the flow of saliva diminished not only from the parotid, but from the submaxillary and sublingual glands as well after intracranial section of the glossopharyngeal nerve; this was followed by some recovery. Similarly, section of the chorda in the middle ear decreased the secrecion from all three glands. The authors concluded that all the glands receive secretory fibres from the seventh and the ninth nerves. In anatomical investigations in man Guerrier and Bolönÿi (1948) have found nerve fibres from a cervical branch of the facial nerve entering the submaxillary gland, and fibres from the hypoglossal nerve which enter the sublingual gland. Recently, Laage-Hellman and Strömblad (1960) have observed that no pronounced supersensitivity develops in the submaxillary gland after section of the chorda in the middle ear in patients. When searching for an explanation for this they have found that a profuse reflex secretion can still be obtained in these cases; the effect can be abolished by injecting local anaesthetics with the aim of blocking the hypoglossal or glossopharyngeal nerves.

There are apparently great species differences in this respect. Stimulation of the hypoglossal nerve in cats does not cause any submaxillary secretion, even if the chorda has been cut in advance; this operation would otherwise in two ways favour the unveiling of secretory fibres in the hypoglossal: by mobilizing the "reserve path" and by sensitizing the gland cells to secretory impulses (Emmelin, Muren and Strömblad, I957a). 
THE AFFERENT NERVES OF THE SALIVARY GLANDS

Various observations indicate that the salivary glands have a supply of fibres carrying pain impulses. Claude Bernard (I 858) observed that direct stimulation of the submaxillary gland of a non-anaesthetized dog caused evidence of pain. It is well known that swelling of the gland is painful. When the salivary duct is obstructed secretion of saliva during meals produces pain in the gland. Similarly, pain is experienced when fluid is injected through the duct towards the gland to elicit secretion (Emmelin and Strömblad, 1954). An interesting phenomenon has been described by Gardner and Abdullah (1955). In patients in which the superior cervical ganglion had been excised, pain appeared in the parotid region on eating. It was first seen during the second week after the operation; it occurred just at the beginning of the meal and remained for a few seconds. Sometimes it became milder over a period of some months, but did not disappear. It was described as similar to the pain experienced in mumps and was therefore supposed to be the result of sudden increase in intracapsular tension occurring as a reflex response to the gustatory stimulus. Since it was not abolished by atropine it could not be due to a sudden production of saliva. Instead, an excessive vasodilatation was thought to be the cause of the pain; as atropine does not antagonize the reflex vascular response but only the secretion it would not be expected to have any effect. After a ganglionic blocking agent, or after section of the glossopharyngeal nerve, no pain was obtained on eating. The authors' explanation is that the pain arises because on eating a vasodilation is elicited, which becomes abnormally big when not antagonized by the sympathetic nerves; since patients in which the preganglionic sympathetic had been cut did not show the phenomenon it was assumed that the decentralized postganglionic sympathetic neurone was able to hold within physiological bounds the vasodilatation on eating.

A related phenomenon is probably the pain sometimes experienced at meal times by hypertensive patients receiving bretylium.

The hypothesis has been put forward that the chorda tympani contains afferent fibres which transmit inieroceptive impulses arising in the secreting gland to regions in the central nervous system, from which the secretory activity can be modified (Galperin, 1936). 


\section{REFERENCES}

BABKin, B. P. (1950). Secretory mechanism of the digestive glands, 2nd ed. Hoeber, New York.

BABKIN, B. P., A. ALLEY and G. W. STAVRAKY (I932). Humoral transmission of chorda tympani effect. Trans. Roy. Soc. Can., 26, 89-107.

BABKIN, B. P., O. S. GIBBS and H. G. WOLFF (1932). Die humorale Uebertragung der Chorda-tympani-Reizung. I. Mitt. Arch. exp. Path. Pharmak., 168, 32-37.

BARCROFT, J. (1914). The respiratory function of the blood. Cambridge.

BERNARD, C. ( 1858 ). De l'influence de deux ordres de nerfs qui déterminent les variations de couleur du sang veineux dans les organes glandulaires. C.R. Acad. Sci., 47, 245-253.

- (1 859). Leçons sur les propriétés physiologiques et les alterations pathologiques des liquides de l'organisme, Vol. 2. Baillière, Paris.

- (1862). Recherches expérimentales sur les ganglions du grand sympathique. C.R. Acad. Sci., 55, 34I-350.

BEZnÁk, A. (1932). Die autacoide Aktivität des venösen Blutes von sezernierenden Submaxillardrüsen. Arch. ges. Physiol., 229, 7 $19-729$.

- (1934). On the mechanism of the autacoid function of parasympathetic nerves. F. Physiol., 82, 129-1 53.

BEZNÁK, M. and E. FARKAS (1936-37). The interpretation of some phenomena of salivary secretion caused by direct electrical stimulation of the effector nerve, in terms of the present knowledge of the nervous impulse and of its chemical transmission. Quart. F. exp. Physiol., $26,265^{-283}$.

BRADFORD, J. R. (I 888). Some points in the physiology of gland nerves. f. Physiol., 9, 287-316.

BRUNER, J. and W. KOZAK (I957). Salivary secretion to single and rhythmical volleys of impulses. Acta physiol. polon., 3, 291-293.

CANNon, w. B. and A. ROSENBlueth (1937). Autonomic neuro-effector systems. New York, Macmillan.

CATTELl, M., H. G. WOLFF and D. CLARK (1934). The liberation of adrenergic and cholinergic substances in the submaxillary gland. Amer. $\mathcal{F}$. Physiol., ro9, 375-385.

Chang, H. C. and J. H. GADDUM (1933). Choline esters in tissue extracts. F. Physiol., 79, 255-285.

COATS, D. A., D. A. DENTON, J. R. GODING and R. D. WRIGHT (I956). Secretion by the parotid gland of the sheep. F. Physiol., I3I, I3-3I.

CZermak, w. (1857). Wien. Sitzungsb. Math. ntw. Cl., Bd. XXV. Quoted from Langley, 1 878. F. Physiol., r, 96-103.

Dale, H. H. (1934). Pharmacology and nerve-endings. Proc. R. Soc. Med., 28, 319-332.

DALE, H. H. and W. FELDBERG (1934). The chemical transmission of secretory impulses to the sweat glands of the cat. $\mathcal{F}$. Physiol., 82, I2 I-1 28.

DIAMANT, H., B. ENFORS and B. HOLMSTEDT (I959). Salivary secretion in man elicited by means of stimulation of the chorda tympani. Acta physiol. scand., 45, 293-299.

DIRNHUBER, P. and C. L. EVANS (I 954). The effects of anticholinesterases on humoral transmission in the submaxillary gland. Brit. F. Pharmacol., 9, $44 \mathrm{I}-45^{8}$.

DUMONT, L. (1955). Innervation cholinergique des glandes salivaires. C.R. Acad. Sci., Paris, 240, 240-242. 
EMMELIN, K. and N. EMMELIN (1953). Unpublished observations.

EMMELIN, N. (I955a). On the innervation of the submaxillary gland cells in cats. Acta physiol. scand., 34, I I-2 I.

- $(1955 b)$. Sympathicolytic agents used to separate secretory and vascular effects of sympathetic stimulation in the submaxillary gland. Acta physiol. scand., 34, 29-37.

- (1960). Is there a leakage of acetylcholine from postganglionic parasympathetic nerve endings? Nature, $\mathbf{1 8 5}, 297-298$.

EMMELIN, N. and J. ENGSTRöm (I 959). Sympathetic secretory fibres for the cat's submaxillary gland. $\mathcal{F}$. Physiol., r49, 67-68P.

- ( $1960 a)$. On the existence of specific secretory sympathetic fibres for the cat's submaxillary gland. F. Physiol., r53, I-8.

- - (1 $960 b)$. Effect of sympathetic denervation on the sensitivity of the submaxillary gland to stimulating agents. F. Physiol., I53, 9-16.

EMMELIN, N. and F. C. MACINTOSH ( 1956$)$. The release of acetylcholine from perfused sympathetic ganglia and skeletal muscles. F. Physiol., r3r, 477-496.

EMMELIN, N. and A. MUREN (I950). Acetylcholine release at parasympathetic synapses. Acta physiol. scand., 20, I3-32.

- - (I95 I). Sensitization of the submaxillary gland to chemical stimuli. Acta physiol. scand., 24, I03-127.

EMmelin, N., A. MUREN and R. STRÖMBLAd (I954). Secretory and vascular effects of various drugs injected into the submaxillary duct. Acta physiol. scand., 32, 325-338.

- - (1957a). Effect of anastomosis between the hypoglossal and chorda-lingual nerves on the supersensitivity of the denervated submaxillary gland. Acta physiol. scand., 41, I 8-34.

- - - (1957b). Effect of anastomosis between the hypoglossal and sympathetic nerves on the supersensitivity of the denervated submaxillary gland. Acta physiol. scand., 4I, 35-48.

EMIMELIN, N. and R. STRÖMBLAD (I 953). Salivary secretion after section of the chorda tympani in non-anaesthetized dogs. Acta physiol. scand., 30, Suppl. I I I, 65-74.

- (I954). A method of stimulating and inhibiting salivary secretion in man. Acta physiol. scand., 31, Suppl. I I 4, I 2-I3.

EMMELIN, N. and B. C. R. STRömblad (1957). Sensitization of the submaxillary gland above the level reached after section of the chorda tympani. Acta physiol. scand., 38, 319-330.

- - (1958a). The effect of anticholinesterases on the parotid gland after parasympathetic decentralization or denervation. Brit. F. Pharmacol., I3, 193- I96.

- - (1958b). A "paroxysmal" secretion of saliva following parasympathetic denervation of the parotid gland. F. Physiol., r43, 506-5 I4.

FELDBERG, w. (I933). Die blutdrucksenkende Wirkung der ChordaLingualisreizung und ihre Beeinflussung durch Atropin. Arch. exp. Path. Pharmak., r70, 560-570.

FELDBERG, W. and J. A. GUIMARAIS (I935). Some observations on salivary secretion. F. Physiol., 85, I 5-36.

Folkow, B. (I955). Nervous control of the blood vessels. Physiol. Rev., $35,629-663$.

FOlkow, B. and J.-E. LaAge-hellman (i 960). Personal communication. FRÖHLICH, A. and O. LOEWI (I 906). Ueber vasokonstriktorische Fasern in der Chorda tympani. Zbl. Physiol., XX, 229-233. 
GALPERIN, S. I. (I936). Interoceptive impulses of the salivary glands. Bull. Biol. et Méd. exp. U.R.S.S., r, 420-421. Quoted from Physiol. Abstr., 1937, XXII, 925, and Ber. ges. Physiol., I937, I00, 582583 .

GARDNER, W. J. and A. F. ABDULlaH (1955). Parotid pain following superior cervical ganglionectomy; A clinical example of the antagonistic action of the parasympathetic and sympathetic systems. Amer. $\mathcal{F}$. med. Sci., 230, 65-69.

GAYDA, T. (1925). Arch. di science biol., 7, 177. Quoted from Babkin (1928); Die äussere Sekretion der Verdauungsdrïsen, 2nd ed. Springer, Berlin.

GIBBS, O. S. (I935). On the alleged occurrence of acetylcholine in the saliva. F. Physiol., 84, 33-40.

GiBBS, O. S. and J. SzELÖCZEY (I932). Die humorale Uebertragung der Chorda tympani-Reizung. Arch. exp. Path. Pharmak., r68, 64-88.

GLIMSTEDT, G. and N.-A. HILLARP (I942). Ueber die Innervationsgebiete des Sympathikus und des Parasympathikus bei der Glandula submandibularis. Kungl. Fysiogr. Sällsk. Handl., N.F., 53, I-38.

GRAHAM, A. R. and G. W. STAVRAKY (I 953). Reversal of the effects of chorda tympani stimulation, and of acetylcholine and adrenaline, as seen in the submaxillary salivary gland of the cat. Rev. canad. Biol., II, 446-470.

GUERRIER, Y. and F. BOLÖNŸI (r 948). A propos de l'innervation des glandes salivaires sous-maxillaire et sub-linguale. Ann. d'Oto-laryng. Paris, I04-IO5.

HEIDENHAIN, R. (I 878$)$. Ueber sekretorische und trophische Drüsennerven. Arch. ges. Physiol., I7, I-67.

HENDERSON, V. E. and M. H. ROEPKE (1933a). On the mechanism of salivary secretion. F. Pharmacol., 47, 193-207.

- - (1933b). Ueber den lokalen hormonalen Mechanismus der Parasympathikusreizung. Arch. exp. Path. Pharmak., 172, 314-324.

HILLARP, N.-A. (I 949). The functional organization of the peripheral autonomic innervation. Acta physiol. scand., I7, I 20-1 29.

HILTON, S. M. and G. P. LEWIS (I955). The cause of the vasodilatation accompanying activity in the submandibular salivary gland. $\mathcal{F}$. Physiol., r28, 235-248.

HOKIN, L. E. and A. L. SHERWIN (I957). Protein secretion and phosphate turnover in the phospholipids in salivary glands in vitro. $\mathscr{F}$. Physiol., I35, $18-29$.

JURIST, P. M. and B. A. RABINOVICH (1924). Some peculiarities of the sympathetic innervation of the submaxillary gland of the cat. $\mathcal{F}$. Physiol., 58, 274-275.

KAHLSON, G. and S. RENVALL (1956). The distribution of cholinesterases in cats and changes caused by hypophysectomy, adrenalectomy, undernutrition and DOCA. Acta physiol. scand., 37, I 59-1 76.

KAY, R. N. B. (I954). The effect of sympathetic stimulation on the flow of parotid saliva in the sheep. $\mathcal{F}$. Physiol., r25, 24-25 $P$.

KOELLE, G. B. (1950). The histochemical differentiation of types of cholinesterases and their localizations in tissues of the cat. $\mathcal{F}$. Pharmacol., roo, I $58-$ I 79 .

KOROPOW, W. M. (1939). Einfluss der Entfernung des N. Jacobsoni und des oberen sympathischen Halsganglions auf die Parotissekretion beim Hund. F. Physiol. U.S.S.R., 27, I 56-165. Quoted from Ber. ges. Physiol., (1940), Ir9, 426. 
KUNTZ, A. and C. A. RICHINS (I 946). Components and distribution of the nerves of the parotid and submandibular glands. F. comp. Neurol., $85,2 \mathrm{I}-32$.

KUPALOV, P. S. and G. V. SKIPIN (1934). The relations between the frequency of the stimulation and the volume of secretion of the submaxillary gland. F. Physiol. U.S.S.R., I7, I 301. Quoted from Babkin, I 950.

LAAGE-HELlmAN, J.-E. and B. C. R. STRÖMBLAD (1960). Secretion from human submaxillary gland after section of the chorda tympani. F. appl. Physiol., I5, 295-297.

LANGENSKIÖLD, A. (I94I). Component potentials of the submaxillary gland electrogram and their relation to innervation and secretion. Acta physiol. scand., Suppl. VI, 2, I-109.

LANGLEY, J. N. (I 889). On the physiology of the salivary secretion. V. 'The effect of stimulating the cerebral secretory nerves upon the amount of saliva obtained by stimulating the sympathetic nerve. F. Physiol., I 0, $29 \mathrm{I}-328$.

- (1892). On the origin from the spinal cord of the cervical and upper thoracic sympathetic fibres, with some observations on white and grey rami communicantes. Philos. Trans., I83, 85-124.

I.ARSON, P. S. (1935). On the alleged occurrence of acetylcholine and adrenalin in cat's saliva. F. Pharmacol., 54, 341-345.

Ludwig, c. (I85i). Neue Versuche über die Beihilfe der Nerven zur Speichelabsonderung. Z. rat. Med., N.F., I, $255^{-277}$.

LUNDBERG, A. (I955). The electrophysiology of the submaxillary gland of the cat. Acta physiol. scand., 35, I-25.

- (1957). Secretory potentials in the sublingual gland of the cat. Acta physiol. scand., 40, $2 \mathrm{I}-34$.

- (1958). Electrophysiology of salivary glands. Physiol. Rer., 38, 2 I-40.

MCCANCE, R. A., L. M. BROWN, R. S. COMLINE and D. A. TITCHEN (I95I). Cholinesterase activity in the secretions of the pancreas of the dog and parotid of the pig. Nature, $\mathbf{1 6 8 , 7 8 8 - 7 8 9 .}$

Macintosh, F. C. (I937). Choline-esterase content of normal and denervated submaxillary gland of the cat. Proc. Soc. exp. Biol., N.Y., 37, 248-25I.

MACINTOSH, F. C. and H. E. RAWLINSON (I935). The effect of atropine on the augmented salivary secretion in the cat. Quart. F. exp. Physiol., 25, I 99-205.

MANSFELD, G., K. HECHT and A. Kovács (I931). Ueber die Gültigkeit des Alles-oder-nichts-Gesetzes der Erregung. Arch. ges. Physiol., 227, 797-806.

mathews, A. (1898). The physiology of secretion. Ann. N.Y.Acad. Sci., $\mathrm{XI}, 293-368$.

NORDENFELT, I. and P. OHLIN (I 957). Supersensitivity of salivary glands of rabbits. Acta physiol. scand., 4I, I 2-I 7.

OBORIN, P. E. (I954). A study on the role of the sympathomimetic vasomotor innervation of the cat's submaxillary gland. M.Sc. Thesis, McGill University.

REICHERT, F. L. and E. J. POTH (I 933). Pathways for the secretory fibres of the salivary glands in man. Proc. Soc. exp. Biol., N.Y., 30, 973977.

RICHINS, C. A. and A. KUNTZ (1953). Role of sympathetic nerves in the regulation of salivary secretion. Amer. F. Physiol., 173, 471-473. 
RIKER, W. F. and W. C. WESCOE (I949). The relationship between cholinesterase inhibition and function in a neuroeffector system. $\mathcal{F}$. Pharmacol., 95, 51 5-527.

ROSENBLUETH, A. (1932). The chemical mediation of autonomic nervous impulses as evidenced by summation of responses. Amer. F. Physiol., 102, $12-38$.

ROSENBLUETH, A., A. FORBES and E. LAMBERT (1933). Electric responses in the submaxillary gland. Amer. F. Physiol., 105, 508-517.

SECKER, J. (I934). The humoral control of the secretion by the submaxillary gland of the cat following sympathetic stimulation. F. Physiol., 82, 293-304.

SEO, M. (I 934). Observations on the salivary secretion from the denervated submaxillary gland. Tohoku F. exp. Med., 22, 563-608.

SILVER, I. A. (1954). Myoepithelial cells in the mammary and parotid glands. F. Physiol., r25, 8-9P.

SIMEONE, F. A. and J. P. MAES (I939). Sensitization of submaxillary gland by sympathetic denervation. Amer. F. Physiol., 125, 674-679.

SINELNIKOFF, E. I. (192I). Secretory and vaso-motor innervation of the submaxillary gland in the dog. F. Physiol. U.S.S.R., 3, 97-113. Quoted from Babkin, 1950.

SNELL, R. S. and J. R. GARRETT (1956). Histochemical appearances of cholinesterase in the submaxillary and sublingual salivary glands of the rat. Nature, 178, I I77-I 178 .

- - (1957). The distribution of cholinesterase in the submaxillary and sublingual salivary glands of the rat. F. Histochem. Cytochem., 5, $236-245$.

STAVRAKY, G. W. (I93I). The effect on the submaxillary gland of stimulation of the partly degenerated sympathetic nerve. Quart. F. exp. Physiol., 21, 123-134.

STRÖMBLAD, R. (1955). Acetylcholine inactivation and acetylcholine sensitivity in denervated salivary glands. Acta physiol. scand., 34, 38-58.

STRÖMBLAD, B. C. R. (I956a). Acetylcholine splitting enzymes in salivary glands after prolonged treatment with pilocarpine and an atropinelike substance. Acta physiol. scand., 36, 47-65.

- $(1956 b)$. Supersensitivity and amine oxidase activity in denervated salivary glands. Acta physiol. scand., 36, I37-1 53 .

- (1957a). Supersensitivity caused by denervation and by cholinesterase inhibitors. Acta physiol. scand., 4I, I I 8-138.

- (1957b). Oxygen consumption of the normal and denervated submaxillary gland in vitro. Acta physiol. scand., 40, I30-I 45.

- (1959). Observations on amine oxidase in human salivary glands. $\mathcal{F}$. Physiol., r47, 639-643.

Wedensky, N. (I892), Sécrétion salivaire et excitation électrique. C.R. Acad. Sci., Paris, II5, $1103-1106$.

Wills, J. H. (194I). Some factors in secretion by submaxillary glands of the cat. Amer. F. Physiol., I34, 44 I-449.

WINTERSTEIN, H. and F. ÖZER (I948). Enthält menschlicher Speichel Acetylcholin? Arch. int. Pharmacodyn., 76, 335-340.

young, A. G. (1956). Unilateral sweating of the submental region after eating. Brit. med. F., 976-979. 


\section{CHAPTER IV}

\section{PHARMACOLOGY OF SALIVARY SECRETION}

It would seem that the only way of activating the secretory mechanism of the salivary gland cell is to apply an agent which imitates the action of parasympathetic or sympathetic nerve fibres. As early as 1859 , Claude Bernard had shown that the salivary gland cells cannot be excited electrically. It is true that various agents, ordinarily not classified as autonomic drugs, such as potassium, barium and mercury ions, histamine and some other imidazole derivatives, tetramethylammonium, and an unidentified compound present in saliva, may excite secretion. Common to these substances, however, is that their secretory actions, like that of parasympathetic stimulation, can be abolished by atropine. The only doubtful case may be the secretion caused by some nitrogen mustards, which cannot be interrupted by the administration of atropine; and it has, in fact, been assumed by some investigators that such agents have a "direct" effect on the secretory mechanism. Nevertheless, if atropine has been given prior to the injection of the nitrogen mustard no secretion is evoked. 'The general statement that no agents can cause a secretion of saliva after the administration of a sympatholytic or parasympatholytic drug therefore seems to hold good.

Apart from the various agents, acting within the salivary glands, numerous drugs may of course provoke a flow of saliva by causing a discharge of impulses in the secretory nerves. Such agents may act on receptors from which a salivary reflex can be elicited or on central or ganglionic structures. Correspondingly, salivary secretion can, under such circumstances, be abolished not only by sympatholytic or parasympatholytic agents but by drugs with ganglionic blocking or central depressant action as well. Generally, it seems to be true that salivary secretion is very susceptible to a blocking action, exerted peripherally, ganglionically or centrally. It is a common experience that dryness of the mouth is one of the more frequent side effects of therapeutic agents. Henderson (I923) studied the sensitivity to atropine of various structures supplied with nerves from the bulbosacral outflow and found the following 
order of sensitivity: "nasal, chorda secretory, cardiac vagus, tonus of pyloric sphincter, and small intestine, bladder, oculomotor to pupil, salivary vasodilator, vagus to intestine for rhythmic and peristaltic movements". After a dose of a sympatholytic agent such as dihydroergotamine, chlorpromazine or regitine which abolishes the salivary secretory effect of stimulation of the cervical sympathetic trunk contraction of the nictitating membrane, dilatation of the pupil and a rise of blood pressure can still be obtained. The order of decreasing sensitivity to the ganglionic blocking action of hexamethonium is given as follows: parasympathetic salivary ganglia, sympathetic superior cervical ganglion, sympathetic vasomotor and parasympathetic intestinal ganglia and vagal cardiac ganglia (Goodman and Gilman, 1955). Investigators of salivary secretion in animals have often observed that in most types of anaesthesia there is no flow of saliva and it is difficult or impossible to elicit a salivary reflex, whereas various other reflexes are readily evoked.

\section{DRUGS THAT ELICIT SECRETION REFLEXLY}

The literature dealing with the effect of various gustatory stimuli on the secretion of saliva has been extensively reviewed by Babkin (1928). The effect of agents exciting the taste buds to evoke secretion of saliva has been studied particularly in human beings and in dogs. Chemical agents apparently play a minor role as stimulants of salivary secretion in horses, cattle and sheep; in these animals the physical properties of the food are of particular importance, as shown for instance by Scheunert and Trautmann (I92I). Nevertheless, it is sometimes possible to evoke a secretion from the parotid gland of sheep by applying acetic acid or sucrose on the tongue (Coats, Denton, Goding and Wright, 1956). When studying species differences as to gustatory stimuli, it is necessary to bear in mind investigations on various animals on action potentials in the taste fibres after application of different substances to the tongue. It is known, for instance, that the tongue of the cat lacks receptors sensitive to sugar (Zotterman, 1935).

Substances irritating the oral mucosa stimulate secretion of saliva. The excessive salivation characteristic of mercury poisoning is thus probably in part secondary to the stomatitis caused by mercury excreted by the saliva. Smoking usually increases the flow of saliva by irritating the mucosa; the amount of nicotine absorbed 
after a few cigarettes is insufficient to cause secretion (Schnedorf and Ivy, 1939).

The secretion caused by ether, chloroform or cyclopropane is likewise of reflex origin. Robbins (1935) examined the effect of various anaesthetics on the parotid secretion in dogs. With the agents mentioned he observed a lively flow of saliva when they were first administered; in deep anaesthesia the flow ceased, to return during recovery. No secretion was obtained if the agents were supplied directly via a tracheal cannula, or if the upper respiratory tract had been cocainized; the site of action was, therefore, assumed to be on nerve endings in the upper respiratory mucosa. During surgical anaesthesia, the reflex was suppressed by the action of the anaesthetics on the medullary centres.

A reflex which may be related to the one just described has been observed by Elsberg, Spotnitz and Strongin (1940, 1942). Flow of saliva elicited from the nasal mucosa by odorous substances is generally assumed to be due to a conditioned reflex; these authors, however, studied a response which they called the olfactoryparotid reflex and supposed to be unconditioned. When a stream of air containing menthol or phenylethyl alcohol was blown into the nose, saliva was found to flow from the parotid glands, particularly ipsilaterally. The response was obtained even in patients with complete anosmia and was therefore assumed to be elicited from endings of trigeminal fibres. This is in agreement with the conclusions reached by Lashley (1916) according to whom there is no unconditioned reflex secretion to olfactory stimulation, whereas odorous substances, which irritate the mucosa, like amyl alcohol or oil of peppermint, may stimulate salivary secretion.

Numerous early investigators have stated that a solution of atropine can cause a flow of saliva when dropped into the eye. This effect is, however, not elicited from the conjunctiva as once supposed but from the oral mucosa (Metzner, I912; Blume, I928).

\section{DRUGS WITH CENTRAL ACTIONS}

Salivary secretion may be one of the effects caused by drugs that excite the central nervous system. For instance, picrotoxin in a dose which gives convulsions and stimulates the medullary respiratory and circulatory centres evokes a flow of saliva as well (Grünwald, 1909). After bulbocapnine in sublethal or lethal doses, salivary secretion was observed (Amadon and Craige, 1935). Tournade and 
Malméjac (I930) found a secretion after intravenous injection of coramin and pyridin; they inferred the effect to be central since it was obtained in a submaxillary gland of a dog even when the gland was perfused with blood from another dog. After administration of cocaine to a cat, Blume (1928) observed a profuse salivation lasting for hours.

Of greater interest than these drugs with more or less generalized central effects are those which activate a physiological mechanism to produce a syndrome in which salivary secretion is one component. Two instances of drugs causing such effects may be mentioned: drugs affecting thermoregulation and drugs eliciting nausea and vomiting.

In dogs, salivation and panting play an important part in the thermoregulatory process. It has been shown that when the body temperature is raised in dogs by the subcutaneous injection of $\beta$-tetrahydronaphthylamine, the submaxillary and sublingual, but not the parotid glands, enter into activity and there is a clear parallelism between the increase in temperature and the rate of salivary flow (Alexandrov, I939, I955). Tainter and Cutting (1933) increased the metabolism and the body temperature in different species by injecting dinitrophenol. All the animals were found to make efforts to dissipate heat; the respiration was accelerated and dogs reacted by panting and pouring out large amounts of saliva over the tongue.

In the nausea syndrome hypersalivation is a conspicuous feature. Drugs with an emetic action therefore cause salivary secretion whether they act reflexly, on the medullary vomiting centre or on the chemoceptive emetic trigger zone of the area postrema. Salivation caused by apomorphine, morphine and related alkaloids (Eddy and Reid, I 934), digitalis glucosides (Wallace and Van Dyke, I933), quinidine (Ernstene and Lowis, I933) and veratrum preparations (Borison and Fairbanks, I952) therefore occurs, not as a separate effect, but as part of the nausea syndrome.

Numerous drugs have been seen to produce secretion of saliva when injected into the ventricular system of the brain. This effect has been combined with a variety of other symptoms; the effects have usually been supposed to be elicited from the cells surrounding the third ventricle. Well known are the investigations by Cushing (I93 I), according to which, pituitrin and pilocarpine, injected into the lateral ventricles in man, cause vascular effects, perspiration, 
salivation, retching, vomiting and other symptoms. 'The drugs were assumed to act by direct stimulation of hypothalamic nuclei after diffusion through the ependymal lining of the third ventricle, and the observations were taken as evidence to show the existence of a "parasympathetic centre" in the diencephalon. Some salivary secretion was described by Henderson and Wilson (r936) to occur after intraventricular injection of acetylcholine in man; it was combined with nausea. In experiments on monkeys, however, no secretory effects of pituitrin or acetylcholine given into the lateral ventricles were observed; pilocarpine caused secretion (Light and Bysshe, I933). In rabbits pilocarpine was likewise found to cause a secretion of saliva when injected intraventricularly (Light, Bishop and Kendall, r933). Aird and Montgomery (r936) found pilocarpine given into a lateral ventricle of dogs to act even on a denervated salivary gland and concluded that the drug exerted its effect after absorption into the blood. This is obviously an important source of error, necessary to take into account in experiments of this type, when the drugs have a peripheral, secretory effect. In the case of pituitrin no such site of action seems to exist.

Among the effects of central excitation caused by curare salivation has been described. McGuigan ( 1916 ) observed a flow of saliva in dogs after injection of curare into the fourth ventricle. Salama and Wright (I950) saw a secretory effect in cats when $d$-tubocurarine had been injected into a lateral ventricle and regarded this experiment as support for the view expressed by McIntyre (1947), according to which salivation occurring after rapid intravenous injection of curare is of central origin; it is associated with retching and often with vomiting.

In their chronic experiments on unanaesthetized cats, Feldberg and Sherwood have found salivation to occur after the injection into the lateral ventricle of doses of $d$-tubocurarine as small as $30 \mu \mathrm{g}$. Flow of saliva and defaecation appear as initial symptoms in a syndrome characterized by convulsions and electrical changes in the brain resembling those of grand mal epilepsy (Feldberg and Sherwood, I954; Feldberg, I957). Various other drugs applied in the same way, histamine, 5-hydroxytryptamine, hexamethonium, decamethonium, banthine and atropine were also found to cause a profuse secretion of saliva. It is interesting to observe that these drugs all caused tachypnoea with or without panting; most of them caused retching and vomiting as well. 
Central inhibition of salivary secretion caused by general anaesthetics has already been mentioned. Some of these drugs, for instance, certain barbiturates, may in addition exert an inhibitory action on ganglia and more peripheral structures, as will be discussed below. Salivation as a component of the nausea syndrome will be counteracted by antiemetic drugs, such as the antihistamines; some of these may further decrease the flow of saliva by virtue of a parasympatholytic action.

\section{DRUGS WITH GANGLIONIC ACTIONS}

Drugs exciting ganglion cells may cause a secretion both via the parasympathetic and the sympathetic postganglionic neurones; the biggest effects are obviously elicited via the former system. Similarly, drugs interfering with synaptic transmission may do so in both systems, but since secretion elicited from the central nervous system is mainly mediated by the parasympathetic nerves, the most important effect will be exerted on the synapse of that pathway. For example, xerostomia during treatment of hypertension with a ganglionic blocking compound will be due to an action of the drug exerted on the parasympathetic ganglion.

The ganglionic synapse in both the sympathetic and the parasympathetic system is cholinergic and both types of ganglia can be excited by acetylcholine. The muscarinic effect of this agent on the salivary glands is, however, so pronounced that when ordinary doses of acetylcholine are used to produce secretion, the concentration required for a nicotinic effect is scarcely attained. This is evidenced by the fact that the secretory effect of acetylcholine in doses commonly used is not lowered by a ganglionic blocking agent. The same seems to be true for tetramethylammonium. Burn and Dale (I9I5) found this compound to cause a marked secretion of saliva in cats after intravenous injection. It was shown on various structures to possess both muscarinic properties and to excite ganglion cells; but doses of nicotine sufficient to paralyse all ganglion cells hardly affected its action on the submaxillary gland.

Nicotine injected intravenously was found by Heidenhain (1872) to cause a transient salivary secretion in dogs; afterwards neither stimulation of the chorda nor of the cervical sympathetic nerve caused any secretory response. Langley ( 1890 ) confirmed this finding and found that local application of nicotine to the chorda close to the submaxillary gland likewise produced a temporary secretion 
with subsequent abolishment of the action of the chorda. Usually the effect of chorda stimulation is only reduced but not completely cancelled by nicotine applied to the hilum of the cat's submaxillary gland since some synapses within the gland are not reached by the drug.

Tetraethylammonium differs from nicotine in lacking the initial stimulating effect on the ganglia of the salivary glands (Burn and Dale, 1915). The same is true for the more recent synthetic ganglionic blocking compounds. It is possible that curarine may have some excitatory effect on the ganglia before paralysing them. Sometimes curarine may cause a small secretory response, not due to a central action (Emmelin and Muren, 1950a). This may be the cause of the secretion observed by Claude Bernard (1864) on injection of curare into the artery of the submaxillary gland; he explained the effect as due to exclusion of an inhibitory influence from the central nervous system.

\section{PARASYMPATHOMIMETIC DRUGS}

Parasympathomimetic drugs cause a secretion of saliva which may be as rapid as that evoked by maximal stimulation of the parasympathetic fibres. This is best shown if the drugs are applied in such a way as not to cause any general circulatory effects, for instance, close arterially or through the salivary duct.

In its action on the gland cells acetylcholine closely imitates the action of parasympathetic stimulation; this can be seen in the electrical responses, as shown with intracellular recording by Lundberg (1955). The effect of acetylcholine is apparently not only to excite the cell but to increase its excitability to subsequent stimuli as well (Beznák and Farkas, 1936-37). This fact very likely provides the explanation of the phenomenon of "true augmented secretion" (MacIntosh and Rawlinson, 1935). When the concentration of acetylcholine is raised to a certain level the secretory response tends to decline, as demonstrated by Graham and Stavraky (1953). At such a concentration these investigators found the vascular effect of acetylcholine to change from dilatation to constriction, and this might be one of the causes of the diminished secretory response; but Graham and Stavraky think that in addition an inhibitory action on the gland cell is exerted by acetylcholine in high concentration. It would be interesting to study the microelectrode response of gland cells to such concentrations. 
The ordinary vascular effect of acetylcholine in the salivary glands is a vasodilatation. According to Hilton and Lewis (I955a and $b$ ) this dilatation is functionally secondary to the effect on the gland cells and is caused by bradykinin. In this respect the dilatation resembles that caused by stimulation of the parasympathetic fibres; but it differs in being completely abolished by atropine. It is not known whether acetylcholine in addition has a "direct" vasodilator effect on the smooth muscles of the gland vessels.

The effects of acetylcholine and other secretory agents can also be demonstrated by an increased uptake of oxygen in vitro (Deutsch and Raper, I938; Strömblad, I957a).

Acetylcholine given intravenously has been shown to evoke a secretion of saliva in man (Weiss and Ellis, r934; Kern and Almy, I952). For use in human beings, however, methacholine seems preferable and it has been given by numerous investigators (Starr, Elsom and Reisinger, r 933; Weiss and Ellis, r 934; Kern and Almy, I952; Thaysen, Thorn and Schwartz, I954; Diamant, Diamant and Holmstedt, I957). Dameshek and Feinsilver (1937) suggested that mecholyl should be used as a diagnostic test in patients suspected of having a poisoning due to belladonna alkaloids; the failure of appearance of salivation and other characteristic effects would speak in favour of such a diagnosis. Pilocarpine has, likewise, been given to human beings to evoke secretion of saliva, for instance, by Marshall (1904), Nyman (1942). Necheles and Levitsky (1936-37) injected a standard dose of pilocarpine subcutaneously and found it to cause a smaller response from the salivary glands in peptic ulcer patients than in normal subjects.

It is not possible, within a limited space, even to enumerate more than a small number of all the drugs possessing a parasympathomimetic action on the salivary glands. Mention has already been made of tetramethylammonium which causes a profuse secretion abolished by atropine (Burn and Dale, i9i5). When $\gamma$-crotonic betaine, a pharmacologically relatively inert substance present in animal tissues, is converted into the methyl ester, a substance causing profuse and prolonged salivation is obtained (Burgen and Hobbiger, I949). Bicarnesine, another betaine derivative, has also a secretory effect (Charlier, 1956). The effects of these various drugs would be classified as "muscarinic"; it is therefore gratifying to learn that even chromatographically pure, crystalline muscarine, prepared from Amanita muscaria, evokes a flow of saliva (Fraser, 
I957). This is true for synthetic muscarine also (Waser, I958). Some agents with a similar action will be discussed under the heading "miscellaneous agents" of this chapter.

Cholinesterase inhibitors increase the secretory effect of acetylcholine and parasympathetic stimulation; if the dose of acetylcholine, or the frequency of stimulation, is chosen so as to cause submaximal responses the inhibitors may increase the rate of flow of saliva; otherwise their effect is to increase the duration of action only. It is well known, however, that the anticholinesterases can evoke a flow of saliva even if the parasympathetic fibres are not stimulated and no acetylcholine injected, and this has been taken as evidence for a continuous release of acetylcholine from the postganglionic, parasympathetic terminals (see Chapter III). Two observations by Dirnhuber and Evans (I954) seem to be of particular physiological interest in this connection. It is not possible to cause an inhibition of the secretion, as can be done with large doses of injected acetylcholine, by increasing the dose of the anticholinesterase; the reasonable explanation is that the amounts of acetylcholine constantly released are not big enough for such an inhibition, even if the cholinesterase of the gland has been inactivated to a great extent. Further, when the secretion caused by an anticholinesterase has been stopped by a small dose of atropine, a secretion cannot be started again by increasing the dose of the anticholinesterase. Hence there is not the "mutual antagonism" studied by Langley (I880) which makes it possible to restart a secretion, caused by pilocarpine but stopped by atropine by giving a bigger dose of pilocarpine. This second observation further supports the view that the amount of acetylcholine released is limited.

Anticholinesterases may increase the secretory effect not only of parasympathetic, but sometimes of sympathetic stimulation also. This can, however, not be used as evidence showing that there are cholinergic sympathetic secretory fibres, as done by Secker (1934). This effect of the anticholinesterases can be regarded as analogous to the augmenting action of previous chorda stimulation (Feldberg and Guimarais, I935).

As to the action of different cholinesterase inhibitors on salivary secretion reference may be made to the following authors: Burgen, Keele and Slome (1 949); Fernandez and Vinoles (1949); Riker and Wescoe (1949); Verbeke (I949); Dirnhuber and Evans (1954); 
Emmelin, Muren and Strömblad (1954); Wills and Somers (1 956); Strömblad (1957b); Emmelin and Strömblad (1958).

\section{PARASYMPATHOLYTIC DRUGS}

It has already been emphasized that salivary secretion (caused by parasympathetic impulses or parasympathomimetic drugs) is easily blocked by atropine. Several investigators have found secretion of saliva, usually induced by injection of pilocarpine or carbachol, to be a convenient test for the assay of atropine-like drugs (Cushny, I920; Nyman, I942; Bülbring and Dawes, 1945; Brown and Quinton, 1957). In the low concentrations required to antagonize such secretion atropine has a specific parasympatholytic effect and ever since the discovery of its antisialogogue action (Heidenhain, 1872) it has been a useful tool in physiological and pharmacological experiments on salivary secretion. It has, however, certain drawbacks when used for such purposes. When the dose is increased, the specificity of action is lost. Long ago, Langley (I 878) found that atropine could prevent the sympathetic from producing a flow of saliva when the nerve was stimulated proximal to the superior cervical ganglion, whereas postganglionic sympathetic stimulation still caused secretion; but even such stimulation became ineffective if the dose of atropine was further raised. Similar observations were made by Carlson (1907). Atropine has apparently a ganglionic blocking action which has been analysed by Konzett and Rothlin (1953). In addition it has a more peripheral, sympathetic blocking action in high concentration, abolishing the secretory effect of postganglionic stimulation or injection of adrenaline.

It may further be pointed out that atropine is less well suited for chronic experiments because of the pronounced tolerance which develops to this drug. This phenomenon may be illustrated on salivary secretion in the following way. When a parasympatholytic agent is administered repeatedly to a cat over a period of some weeks, a supersensitivity to adrenaline develops in the submaxillary gland, resembling that seen after section of the chorda; if atropine is used as a blocking agent the dose has to be increased successively (Emmelin and Muren, I950b). If the same small dose of atropine is given for some weeks, the sensitivity first increases, but then decreases again almost to the pre-treatment level (Emmelin and MacIntosh, 1955). 
Numerous substitutes for atropine are available, some even more potent in parasympatholytic action or even more long-acting than atropine, some lacking the disadvantages discussed above. Scopolamine blocks secretion of saliva more strongly than atropine. $\mathrm{N}$-methylation of atropine or scopolamine further increases the blocking effect. Methylscopolamine, for instance, blocks secretion of saliva, induced by pilocarpine in man, very effectively (Nyman, r943). Judging from sensitization experiments the tendency to increasing tolerance is much less with this drug than with atropine (Emmelin, 1960). The same is true for the synthetic drug Hö-9980 (piperidinoethyldiphenylacetamide), the parasympatholytic properties of which were first investigated by Schaumann and Lindner (I95I). This agent very strongly and specifically antagonizes the effect on the salivary glands of parasympathetic stimulation (Emmelin and Henriksson, I953; Emmelin and Strömblad, I957). A great number of benzilic esters of alkamines have been studied as atropine substitutes by Ing, Dawes and Wajda (I945); the pronounced antisecretory actions of some of them have been investigated by Bülbring and Dawes (1945). Another potent inhibitor of salivary secretion is dibutoline (dimethyl-ethyl- $\beta$-hydroxyethylammonium sulphate di- $n$-butyl-carbamate), studied by Featherstone and White (I945), Peterson and Peterson (I945) and Biggins ( 1948$)$.

Many drugs used therapeutically for various purposes produce a dry mouth as a side-effect because of a more or less pronounced parasympatholytic action. This is true of Methanthelin and related substances (Zupko and Prokop, 1954) and many of the antihistamines, for instance, diphenhydramine (see Anderson and Emmelin, I947). In therapeutic doses such agents may depress salivary secretion because of this peripheral action and through a general sedative and an antiemetic effect. Barbiturates may likewise interfere with the secretion of saliva by several different actions (Stavraky, I93I; Montgomery, I935; Emmelin, I94I; Bråhammar and Emmelin, I94I ; Guimarais, Malafaya-Baptista, Garrett and Osswald, 1955). For instance, in a cat, anaesthetized with hexobarbitone, there is no flow of saliva, and the secretory response to sympathetic or parasympathetic stimulation or injected acetylcholine may be greatly reduced, whereas the response to adrenaline is unaffected. 
SYMPATHOMIMETIC AGENTS

Salivary secretion is not one of the more conspicuous effects of sympathomimetic agents. Chang (1937) compared the sensitivity of different effectors to adrenaline in cats and gave the following order of susceptibility: blood-sugar, blood pressure, denervated heart, nictitating membrane, stomach, iris, hair and salivary gland.

In general the sympathomimetic drugs are much less effective than the parasympathomimetic in producing secretion of saliva. This is probably parallel to the fact that the sympathetic innervation is much less complete than the parasympathetic one. Glands which respond well to sympathetic stimulation, such as the submaxillary gland of the cat, do so to injected sympathomimetic agents also; exceptional submaxillary glands of the cat which do not react to sympathetic stimulation are not stimulated by adrenaline either. The secretory responses of the cat parotid gland are small both when the sympathetic is stimulated and adrenaline is injected (Strömblad, I955). In rabbits, conversely, the parotid but not the submaxillary gland responds well to adrenaline and sympathetic stimulation (Nordenfelt and Ohlin, 1957). When the submaxillary gland of a cat is relatively sensitive to adrenaline, so that doses causing too disturbing vascular effects can be avoided, it can be seen that adrenaline and sympathetic stimulation cause the same maximal rate of secretion.

Adrenaline can be shown to cause a secretion from the submaxillary gland in man; the drug has to be given through the salivary duct in order not to produce any general effects (Emmelin and Strömblad, 1954).

On the gland cells adrenaline imitates the effect of sympathetic stimulation, as seen in the microelectrode responses (Lundberg, 1955). In this connection it may be mentioned that one striking difference between sympathetic and adrenaline saliva seems to exist; after injection of adrenaline, glucose appears in the saliva. This is generally not the case when the sympathetic nerve is stimulated (Hebb and Stavraky, 1936).

A series of sympathomimetic amines can be arranged, in order of decreasing secretory activity on the submaxillary gland, as follows: adrenaline, noradrenaline, synephrin, ephedrine, paredrinol, isoprenaline, amphetamine (Emmelin and Muren, I95 I). The last five drugs not only cause a secretion but also in some way increase 
the secretory effect of adrenaline and, particularly, of noradrenaline. A similar, sensitizing effect is exerted by cocaine. If a suitable dose of cocaine is injected through the salivary duct, it can be seen that the secretory effect of parasympathetic and sympathetic stimulation is abolished because of a local anaesthetic action, the effect of injected acetylcholine is unchanged but the response to injected noradrenaline increased.

Among the sympathomimetic agents, tyramine is of particular interest in this connection. It causes a secretion from the submaxillary gland of the cat which decreases with repeated doses and which is abolished by previous extirpation of the superior cervical ganglion; it is therefore assumed to act not directly on the receptors of the gland cells but through some indirect mechanism (Strömblad, 1956).

The sympathomimetic amines may also affect salivary secretion through their action on the blood vessels. In Chapter VII the inhibition of salivary secretion resulting from sympathetic vasoconstriction will be discussed. Adrenaline, for instance, decreases the flow of saliva produced by chorda stimulation, particularly if the rate of secretion is high. It has been pointed out by Dirnhuber and Evans (1954) that adrenaline may also cause anoxia and further reduce a secretion in the gland because of its metabolic effect.

\section{SYMPATHOLYTIC AGENTS}

The early investigations on the actions of ergot by Dale (1906) showed that this drug can abolish the secretory effects of adrenaline and sympathetic stimulation on the submaxillary gland of the cat while the effect of chorda stimulation is retained. The sympatholytic effect on the salivary glands exerted by ergotamine was shown by Yonkman (1933). Dibenamine, likewise, antagonizes the secretory effect of sympathetic stimulation on the submaxillary gland; the effect of chorda stimulation may in addition be slightly reduced, probably secondary to a fall in blood pressure (Uvnäs, 1948).

The motor effect of sympathetic stimulation on the salivary glands is abolished by ergotamine (Babkin, 1929). The vasodilatation, accompanying salivary secretion in response to sympathetic stimulation, is abolished by agents which annul the secretion, as discussed in Chapter VII. The sympathetic vasoconstriction is often abolished too, for instance, by dihydroergotamine or antistin. With some drugs, however, it is possible to separate constriction 
on one hand from secretion and dilatation on the other (Emmelin, 1955). A suitable dose of chlorpromazine may preferentially abolish the secretion and dilatation, one of priscol, the constriction. Breiylium abolishes the secretory and constrictor effects of sympathetic stimulation (Emmelin and Engström, I960).

\section{MISCELLANEOUS AGENTS}

Potassium. A few mg of potassium chloride injected close arterially into the submaxillary gland of a cat may have a slight secretory effect. The response is considerably increased by eserine and is due to local liberation of acetylcholine in the gland by the potassium (Feldberg and Guimarais, 1936).

Barium. When studying the contractile mechanism of the salivary glands which can be activated by sympathetic stimulation, adrenaline or histamine, Stavraky (1932) examined the action on the glands of barium. Contrary to what was expected, the action of barium was secretory in effect. This was increased by eserine and abolished by atropine. In some cases the response was not completely annulled by atropine. This might perhaps indicate that the secretory effect was partly due to adrenaline released from the suprarenals, for the doses causing secretion were apparently not far below a lethal level.

Mercury. Mercurial ptyalism is well known and many attempts have been made to reveal its mechanism. Several possibilities have to be taken into account. 'The hypersalivation may be secondary to the stomatitis and elicited reflexly from the mouth. Mering (I88I) found, however, in animal experiments that mercury can cause a flow of saliva even if no stomatitis is present and suggested an action either centrally or on the secretory nerves. As to the first possibility, it has been shown (Morgan and Johnson, I930) that injection of mercury chloride into the tuber cinereum-region in dogs causes excessive salivation. The peripheral actions of mercury on the submaxillary gland of dogs have been studied by Melville (I930). He found mercury chloride to increase the effect of chorda stimulation but not of injected pilocarpine and assumed an action on the chorda endings. In this connection it is interesting to observe that mercury compounds have been found to increase the action of vagus stimulation on the heart and the intestinal motility (Salant and Brodman, I $929 a$ and $b$ ). A reasonable hypothesis might be that mercury acts by inhibiting cholinesterase. This would be 
compatible with the fact that it increases the effect of chorda stimulation but not that of pilocarpine and with the statement in the early literature that atropine abolishes the secretion caused by mercury salts.

Histamine. Dale and Laidlaw (I910) found that histamine causes secretion of saliva in cats and dogs. This effect has been studied by many later investigators; the result of this work has been summarized by Babkin (1950). Generally it may be said that fairly big doses of the drug are required to cause a slight secretion of saliva, compared with those eliciting a fall in blood pressure, contraction of plain muscle and secretion of gastric juice. Several different mechanisms may be at work. The central effects of histamine have already been mentioned. The ability of histamine to release adrenaline should perhaps also be kept in mind. In addition, histamine has apparently a double peripheral effect. It contracts those elements which expel saliva from the glands and it has a true secretory effect on the gland cells. The latter, but not the former, action is abolished by atropine. Dale and Laidlaw described the secretory effect as being of the pilocarpine type and pointed out that both agents possess an imidazole ring; it may be added that another imidazole derivative, naphazoline (privine), has been found to have a slight secretory effect, which is abolished by atropine (Yonkman, Rennick and Schwerma, 1945).

Nitrogen mustards. Investigations during the last war, only in part published in the open literature, disclosed that protracted salivation is a prominent symptom after lethal doses of nitrogen mustards. The peculiar type of secretory response obtained after an injection of methyl-bis (2-chloroethyl) amine ( $\left.\mathrm{HN}_{2}\right)$ into the carotid artery of cats have been described by Hunt and Philips (1949), who have also quoted earlier investigations in this field. Shortly after the injection of the drug saliva starts to flow from the submaxillary gland. The secretion soon ceases and during a period of about five minutes there is no flow. Salivation is then resumed and gradually attains a maximal rate at which it continues for hours. When atropine is administered before the $\mathrm{HN}$, salivation is prevented. However, if atropine is given after the initial appearance of salivation, even as early as in the interim between the two phases of salivation, it fails to alter the delayed response.

As to the mechanism responsible for the secretion the following observations have been made. Nitrogen mustards cause a pro- 
nounced excitation of the central nervous system. They have muscarine-like actions, demonstrated on the blood pressure and the pupil, and nicotine actions on sympathetic ganglia as shown on the nictitating membrane and, after atropine, on the blood pressure. In vitro experiments show that they can inhibit acetylcholine esterase.

Esterase inhibition, however, cannot be the cause of the salivation, for a normal activity of the enzyme was found in a gland that had responded to HN2. Central or sympathetic ganglionic effects cannot be the main causes, since the flow is obtained after acute section of the chorda and removal of the superior cervical ganglion. A muscarinic action seems to be mainly responsible for the salivation. In the strange two-phase response and in the lack of atropine antagonism in the second phase (if the atropine is not given early) nitrogen mustard differs from the ordinary muscarinelike drugs. Hunt and Philips assume that even the second phase of secretion is due to a reaction between the drug and "cholinergic receptors"; this reaction, when it has once taken place, is not antagonized by atropine. Alternatively, it has been suggested that the agent excites the gland cells "directly" (Gaddum and Foss). Obviously, the mechanism of action is obscure and warrants further study (Hunt and Philips, 1949).

Secretagogue substances in saliva. According to Demoor (1913) saliva contains agents which are able to stimulate secretion from the salivary glands. Guimarais (1932, 1936a and $b, 1938$ ) and Guimarais and Tavares (1942a and $b$ ) have further studied the secretory activity of saliva. When saliva is injected into the artery of the submaxillary gland an abundant secretion is evoked. The agent causing this effect is not identical with that which on intravenous injection lowers the blood pressure, i.e., kallikrein. It has been suggested that the chemical transmitters of the secretory nerves or injected secretory drugs, cause the release of the secretory agent from an inactive state; the agent then acts on the gland cells to cause a flow of saliva. When considering this agent as a general, ultimate mediator for salivary secretion it must be kept in mind that its secretory effects are abolished by atropine. Further experiments seem required to throw light on the possible physiological role of this interesting agent. 


\section{REFERENCES}

AIRD, R. B. and M. F. MONTGOMERY (1936). Studies upon the site of stimulation of salivation by intraventricularly injected pilocarpine in dogs. F. Pharmacol., 56, 290-306.

Alexandrov, I. S. (1939). Quoted from Ber. ges. Physiol., 1940, Ir8, 576.

- (1955). Quoted from Physiol. Abstr., 1957, 6, 479.

AMIADON, R. S. and A. H. CRAIGE (1935). An investigation into the ratio between the effective and lethal doses of bulbocapnine in the cat. F. Pharmacol., 54, 334-340.

ANDERSON, D. J. and N. EMMELIN (1947). The action of $\beta$-dimethylaminoethyl benzhydryl ether hydrochloride on salivary secretion. Acta physiol. scand., 13, 72-74.

вавкIN, в. P. (1928). Die Äussere Sekretion der Verdaunngsdrüsen, 2nd ed. Springer, Berlin.

- (1929). Innervation of the salivary glands. Amer. F. Physiol., 90, 27 I.

- (1950). Secretory mechanism of the digestive glands, 2nd ed. Hoeber, New York.

BERNARD, C. ( 1859$)$. Leçons sur les propriétés physiologiques et les altérations pathologiques des liquides de l'organisme, Vol. 2. Baillière, Paris.

- (i 864). Du rôle des actions réflexes paralysantes dans les phénomènes des sécrétions. F. Anat., Paris, r, 507-513.

BEZNÁK, M. and E. FARKAS (1936-37). The interpretation of some phenomena of salivary secretion caused by direct electrical stimulation of the effector nerve, in terms of the present knowledge of the nervous impulse and of its chemical transmission. Quart. F. exp. Physiol., 26, $265-283$.

BIGGINS, C. H. (I948). The action of dibutoline on submaxillary salivary secretion. Ann. of Western Med. and Surgery, 2, 445-448.

BLume, W. (I 928). Ueber eine erregende Wirkung des Atropins auf die Speicheldrüsen. Arch. exp. Path. Pharmak., 127, I 53-164.

BORISON, H. L. and V. F. FAIRBANKS (1952). Mechanism of veratruminduced emesis in the cat. F. Pharmacol., 105, 317-325.

BROWN, D. M. and R. M. QUINTON (1957). The assay of anti-acetylcholine agents for antagonism of pilocarpine-induced salivation in rabbits. Brit. F. Pharmacol., 12, 53-60.

BRÅHAMMAR, N. S. and N. EMMELIN (I 94I). The effect of narcotics, especially barbiturates, on salivary secretion, elicited through chorda stimulation or parasympathomimetic drugs. Acta physiol. scand., 3, I $82-184$.

BC̈LBRING, E. and G. S. DAWES (I945). A method for the assay of atropine substitutes on the salivary secretion. F. Pharmacol., 84, I77-183.

BURGEN, A. S. v. and F. HOBBiger (1949). The pharmacology of the methyl and benzyl esters of $\gamma$-crotonic betaine ( $\gamma$-carboxyallyltrimethylammonium chloride). Brit. F. Pharmacol., 4, 229-233.

BI RGEN, A. S. V., C. A. KEELE and D. SLOME (1949). Pharmacological actions of tetraethylpyrophosphate and hexaethyltetraphosphate. F. Pharmacol., 96, 396-409.

BURN, J. H. and H. H. DALE (1915). The action of certain quarternary ammonium bases. F. Pharmacol., 6, 417-438.

CARLSON, A. J. (1907). Vaso-dilator fibres to the submaxillary gland in the cervical sympathetic of the cat. Amer. F. Physiol., 19, 408-4I6. 
CHANG, S. (1937). Effect of adrenaline on the blood-sugar, blood pressure, denervated heart, nictitating membrane, stomach, iris, hair and salivary gland in the cat. Chin. F. Physiol., 12, 397-404.

CHARLIER, R. (1956). A propos de la pharmacologie de la bicarnésine. Arch. int. Pharmacodyn., 106, 184-198.

COATS, D. A., D. A. DENTON, J. R. GODING and R. D. WRIGHT (I956). Secretion by the parotid gland of the sheep. F. Physiol., I31, I3-31.

Cushing, H. (1931). Proc. nat. Acad. Sci., Wash., 17, I63-180, 239264 .

Cushny, A. R. (1920). On optical isomers. F. Pharmacol., 15, 105-127.

DALE, H. H. (1906). On some physiological actions of ergot. $\mathcal{F}$. Physiol., 34, I63-206.

DALE, H. H., and P. P. LAIDLAW ( 1910 ). The physiological action of $\beta$-iminazolylethylamine. F. Physiol., 41, 318-344.

DAMESHEK, W. and O. FEINSILVER (1937). Human autonomic pharmacology. The use of acetyl-beta-methyl-choline chloride (mecholyl) as a diagnostic test for poisoning by the atropine series of drugs. $\mathcal{F}$. Amer. med. Ass., 109, 56I-564.

DEMOOR, J. (I9I3). Le mécanisme intime de la sécrétion salivaire. Arch. int. Physiol., 13, 187-206.

DEUTSCH, W. and H. S. RAPER (1938). The respiration and metabolism of submaxillary gland tissue of the cat. $\mathcal{F}$. Physiol., 92, 439-458.

DIAMANT, B., H. DIAMANT and B. HOLMSTEDT (I957). The salivary secretion in man under the influence of intravenously infused acetyl-betamethylcholine iodide. Arch. int. Pharmacodyn., I I I, 86-97.

DIRNHUBER, P. and C. L. EVANS (1954). The effects of anticholinesterases on humoral transmission in the submaxillary gland. Brit. F. Pharmacol., 9, $44 \mathrm{I}-458$.

EDDY, N. B. and J. G. REID (I934). Studies of morphine, codeine and their derivatives. F. Pharmacol., 52, 468-493.

ELSBERG, C. A., H. SPOTNITZ and E. I. STRONGIN (1940). The effect of stimulation by odorous substances upon the amount of secretion of the parotid glands. F. exp. Psychol., 27, 58-65.

$-\ldots-(1942)$. The olfactory-parotid reflex. Arch. Neurol. Psychiat., $47,707-717$.

EMmelin, N. (I94I). Evipan and the parasympathetic nervous system. Acta physiol. scand., 2, 289-310.

- (I955). Sympathicolytic agents used to separate secretory and vascular effects of sympathetic stimulation in the submaxillary gland. Acta physiol. scand., 34, 29-37.

- (1960). Supersensitivity of the submaxillary gland following exclusion of the postganglionic parasympathetic neurone. Brit. F. Pharmacol., I $5,356-360$.

EMmELIN, N. and J. ENGSTRÖM (1960). Parotid pain during treatment with bretylium. Lancet, 2, 263.

EMMELIN, N. and K. G. HENRIKSSON (1953). Depressor activity of saliva after section of the chorda tympani. Acta physiol. scand., 30, Suppl. I I I, $75^{-82}$.

EMMELIN, N. and F. C. MAcINTOSH (I955). Unpublished observation.

EMMELIN, N. and A. MUREN (1950a). Acetylcholine release at parasympathetic synapses. Acta physiol. scand., 20, 13-32.

- - $(195 \circ b)$. Supersensitivity of denervated organs to chemical stimuli. Nature, r66, 6 го. 
EMMELIN, N. and A. MUREN (I95I). Sensitization of the submaxillary gland to chemical stimuli. Acta physiol. scand., 24, 103-127.

EMMELIN, N., A. MUREN and R. STRÖMBLAD (I954). Secretory and vascular effects of various drugs injected into the submaxillary duct. Acta physiol. scand., 32, 325-338.

EMMELIN, N. and R. STRÖMBLAD (1954). A method of stimulating and inhibiting salivary secretion in man. Acta physiol. scand., 31, Suppl. I 14, I 2-13.

EMMELIN, N. and B. C. R. STRÖMBLAD (I957). Sensitization of the submaxillary gland above the level reached after section of the chorda tympani. Acta physiol. scand., 38, 319-330.

- $-\left(195^{8}\right)$. The effect of anticholinesterases on the parotid gland after parasympathetic decentralization or denervation. Brit. F. Pharmacol., 13, I $93^{-1} 96$.

ERNSTENE, A. C. and S. LOWIS (I933). The mechanism of vomiting induced by quinidine. F. Pharmacol., 48, 305-310.

FEATHERstone, R. M. and N. G. White (1945). Studies on the general pharmacology of dibutoline. F. Pharmacol., 84, $105^{-1}$ I 4.

FELDBERG, W. (1957). The action of drugs injected into the cerebral ventricles. (A contribution to the study of subcortical convulsions and impairment of consciousness.) Psychotropic drugs, 303-3I2. Proc. Internat. Symposium on Psychotropic drugs, Milan.

FELDBERG, W. and J. A. GUIMARAIS (1935). Some observations on salivary secretion. F. Physiol., 85, i 5-36.

- (1936). 'The liberation of acetylcholine by potassium. F. Physiol., 86, $306-3$ I 4 .

FELDBERG, W. and S. L. SHERWOOD (I954). Injections of drugs into the lateral ventricle of the cat. F. Physiol., 123, 148-167.

FERNANDEZ, A. and J. J. viNOLES (I 949). Sur la pharmacologie du diméthylcarbamate d'hydroxy-phényl-benzyl-triméthyl-ammonium (Nu683). IV. Influences du Nu-683 sur la sécrétion salivaire. Arch. int. Pharmacodyn., 8o, 85-88.

FRASER, P. J. (I 957). Pharmacological actions of pure muscarine chloride. Brit. F. Pharmacol., r2, 47-52.

GOODMAN, L. S. and A. GILMAN (I955). The pharmacological basis of therapeutics, 2nd ed. MacMillan, New York.

GRAHAM, A. R. and G. W. STAVRAKY (I 953). Reversal of the effects of chorda tympani stimulation, and of acetylcholine and adrenaline, as seen in the submaxillary salivary gland of the cat. Rev. canad. Biol., I I, 446-470.

GRÜNWALD, H. F. (I909). Zur Kenntnis des Pikrotoxins und seiner Beziehungen zum autonomen Nervensystem. Arch. exp. Path. Pharmak., $60,249-255$.

guimarais, J. A. ( I 932). Propriétés excitatrices de la sécrétion salivaire dans la salive sécrétée sous l'influence de l'injection de salive tympanique et de la salive obtenue par l'action de la pilocarpine. C.R. Soc. Biol., Paris, I 10, I 046-1 048.

- (1936a). 'The secretagogue and depressor substances in saliva and pancreatic juice. 7 . Physiol., 86, 95-108.

- (I936b). Further observations on the active substances in saliva. Arch. Portug. Sci. Biol., 5, I 56-162.

- (1938). Sur le mécanisme de la sécrétion salivaire. XVI Internat. Physiol. Kongr. Zürich, 2 I I-212. 
GUimarais, J. A., A. MALAFAyA-BAPTista, J. GarRetT and W. OSSWALD ( 955 ). Barbituriques et sécrétion salivaire. Arch. int. Pharmacodyn., I02, $235^{-248}$.

GUIMARAIS, J. A. and A. TAVARES (1942a). Sur la distinction des "substances actives" excito-sécrétoire et hypotensive de la salive. Arch. Portug. Sci. Biol., 6, I 84-189.

- - (1942b). Substances actives salivaires et sécrétion gastrique. Arch. Portug. Sci. Biol., 6, 209-2 I 5.

HEBB, C. O. and G. W. STAVRAKY (1936). The presence of glucose in the salivary secretion after the administration of adrenaline. Quart. $\mathcal{F}$. exp. Physiol., 26, 141-I53.

HeIdenhain, R. (1872). Ueber die Wirkung einiger Gifte auf die Nerven der glandula submaxillaris. Arch. ges. Physiol., 5, 309-3 18.

HENDERSON, V. E. (I 923 ). On the sensitivity of different nerve endings to atropine. F. Pharmacol., 2r, 99-102.

HENDERSON, W. R. and W. C. WILSON (1936). Intraventricular injection of acetylcholine and eserine in man. Quart. F. exp. Physiol., 26, 83-95.

HILTON, S. M. and G. P. LEWIS (1955a). The cause of the vasodilatation accompanying activity in the submandibular salivary gland. $\mathcal{F}$. Physiol., 128, 235-248.

- $-\left(1955^{b}\right)$. The mechanism of the functional hyperaemia in the submandibular salivary gland. F. Physiol., r29, 253-271.

HUNT, C. C. and F. S. PHILIPS (1949). The acute pharmacology of methylbis (2-chloroethyl) amine (HN2). F. Pharmacol., 95, I3 1 -144.

ING, H. R., G. S. DAWES and I. WAJDA (1945). Synthetic substitutes for atropine. $\mathcal{F}$. Pharmacol., 85, 85-102.

KERN, F. and T. P. ALMY (1952). The effects of acetylcholine and methacholine upon the human colon. $\mathcal{F}$. clin. Invest., 31, 555-560.

KONZETT, H. and E. ROTHLIN (I953). Zur ganglionär blockierenden Wirkung von Atropin. Wien. klin. Wschr., 65, 78 $1-78_{3}$.

LANGLEY, J. N. (1 878$)$. On the physiology of the salivary secretion. $\mathcal{F}$. Physiol., ז, 96-103.

- (1880). On the antagonism of poisons. F. Physiol., 3, I I-2 I.

- (1890). On the physiology of the salivary secretion. $\mathcal{F}$. Physiol., I r, I $23^{-I} 5^{8}$.

LASHLEY, K. S. (I9I6). Reflex secretion of the human parotid gland. $\mathcal{J}$. exp. Psychol., I, $46 \mathrm{I}-493$.

LIGHT, R. U., C. C. BISHOP and L. G. KENDALL (I933). The response of the rabbit to pilocarpine administered into the cerebrospinal fluid. $\mathcal{F}$. Pharmacol., 47, 37-45.

LIGHT, R. U. and S. M. BYSSHE (1933). The administration of drugs into the cerebral ventricles of monkeys; pituitrin, certain pituitary fractions, pitressin, pitocin, histamine, acetyl choline and pilocarpine. $\mathcal{F}$. Pharmacol., 47, 17-36.

LUNDBERG, A. (r955). The electrophysiology of the submaxillary gland of the cat. Acta physiol. scand., 35, 1-25.

Mcguigan, H. (I9I6). The central action of curare. $\mathcal{F}$. Pharmacol., 8, 47 I477.

MACINTOSH, F. C. and H. E. RAWLINSON (I935). The effect of atropine on the augmented salivary secretion in the cat. Quart. F. exp. Physiol., 25, I 99-205.

McINTYRE, A. R. (1947). Curare. Its history, nature and clinical use. University of Chicago Press, Chicago. 
MARSHALL, C. R. (I904). On the physiological action of the alkaloids of jaborandi leaves. F. Physiol., 31, I 20-1 56.

MELVille, K. I. (I930). Concerning the mechanism of mercurial salivation. Arch. int. Pharmacodyn., 37, I 43-1 54.

MERING, J. (I88I). Ueber die Wirkungen des Quecksilbers auf den thierischen Organismus. Arch. exp. Path. Pharmak., r3, 86-I I 2.

METZNER, R. (I912). Mitteilungen über Wirkung und Verhalten des Atropins im Organismus. Arch. exp. Path. Pharmak., 68, I Io-1 59.

MONTGOMERY, M. F. (I935). Effect of amytal upon pilocarpine-induced submaxillary and gastric secretion. Proc. Soc. exp. Biol., N:Y., 32, I 287 - I 290 .

MORGAN, L. O. and C. A. JOHNSON (1930). Experimental lesions in the tuber cinereum of the dog. Arch. Neurol. Psychiat., 24, 696-726.

NECHELES, H. and P. LEVITSKY (I936-37). Salivary secretion test in peptic ulcer patients and normal subjects. F. Lab. clin. Med., 22, 624626.

NORDENFELT, I. and P. OHLIN (I957). Supersensitivity of salivary glands of rabbits. Acta physiol. scand., 41, I2-17.

Nyman, E. ( I 942). Studien über die Atropingruppe. Acta physiol. scand., 3, Suppl. X.

- (1943). N-methylierte Skopolaminderivate. Acta physiol. scand., 6, $256-265$.

PETERSON, C. G. and D. R. PETERSON (1945). Dibutoline. I. Pharmacodynamic actions of a choline ester with atropine-like properties. $\mathcal{F}$. Pharmacol., 84, 236-253.

RIKER, W. F. and W. C. WESCOE (I 949). The relationship between cholinesterase inhibition and function in a neuroeffector system. 7 . Pharmacol., 95, 5 I 5-527.

RobBins, B. H. (I935). Effect of various anesthetics on salivary secretion. 7. Pharmacol., 54, 426-432.

SALAMA, S. and S. WRIGHT (I 950). Action of $d$-tubocurarine chloride on the central nervous system of the cat. Brit. F. Pharmacol., 5, 49-6i.

SALANT, W. and K. BRODMAN (I929a). The effect of mercury on cardiac inhibition. F. Pharmacol., 36, 195-202.

- - (1929b). The effect of mercury on intestinal motility. F. Pharmacol., $37,55^{-66}$.

SCHAUMANN, O. and E. LINDNER (I95I). Neue synthetische Verbindungen der "Polamidonreihe" mit parasympathicolytischer Wirkung. Arch. exp. Path. Pharmak., 214, 93-102.

SCHEUNERT, A. and A. TRAUTMANN (I92I). Zum Studium der Speichelsekretion. I. Mitt. Ueber die Sekretion der Parotis des Pferdes. Arch. ges. Physiol., r92, I-32.

SCHNEDORF, J. G. and A. C. IVY (I939). The effect of tobacco smoking on the alimentary tract. F. Amer. med. Ass., I I2, 898-904.

SECKER, J. (I934). The humoral control of the secretion by the submaxillary gland of the cat following chorda stimulation. $\mathcal{F}$. Physiol., $8 \mathrm{I}, 8 \mathrm{I}-92$.

STARR, I., K. A. ELSOM and J. A. REISINGER (I 933). Acetyl- $\beta$-methylcholin. The action on normal persons. Amer. F. med. Sci., I86, 313-323.

S'TAVRAKY, G. W. (I93 I). Effect of amytal on the autonomic nervous system as indicated by the salivary glands. F. Pharmacol., 43, 499-508.

- (i932). The effect of barium chloride on the salivary secretion. $\mathcal{F}$. Pharmacol., 45, 53-64. 
STRÖMBLAD, R. (1955). Sensitivity of the normal and denervated parotid gland to chemical agents. Acta physiol. scand., 33, 83-98.

STRÖMBLAD, B. C. R. (1956). Tyramine as a secretory agent in the submaxillary gland of the cat. Acta physiol. scand., 36, I 54-I 57.

- (1957a). Oxygen consumption of the normal and denervated submaxillary gland in vitro. Acta physiol. scand., 40, I30-145.

- (1957b). Supersensitivity caused by denervation and by cholinesterase inhibitors. Acta physiol. scand., 4I, I 8 - I 38 .

TAINTER, M. L. and W. C. CUTTING (I933). Febrile, respiratory and some other actions of dinitrophenol, $\mathcal{F}$. Pharmacol., 48, 410-429.

THAYSEN, J. H., N. A. THORN and I. L. SCHWARTZ (I954). Excretion of sodium, potassium, chloride and carbon dioxide in human parotid saliva. Amer. Y. Physiol., 178, 155-159.

TOURNADE, A. and J. MALMÉJAC (I 930). Contribution à l'étude de la sécrétion salivaire par la méthode de la glande sousmaxillaire "irrigée". C.R. Soc. Biol., Paris, 104, $178-180$.

UVNÄs, B. (1 948). Action of n, n-dibenzyl-chloroethylamine (Dibenamine) on the effect of sympathetic secretory impulses to the submaxillary gland of the cat. Acta physiol. scand., r5, 362-364.

VERBEKE, R. (I 949). On the pharmacology of tetraethylpyrophosphate ('TEPP). Arch. int. Pharmacodyn., 80, i 9-27.

WALLACE, E. W. and H. B. VAN DYKE (1933). Cumulative poisoning by squill derivatives and by ouabain. F. Pharmacol., 48, 430-444.

WASER, P. G. (1958). Struktur und Wirkung des Muscarins, des Muscarons und ihrer Stereoisomeren. Experientia, I4, 356-358.

WEISS, S. and L. B. ELLIS (1934). The comparative effects of the intravenous administration to man of acetylcholine and acetyl- $\beta$-methylcholine. F. Pharmacol., 52, I I 3-120.

WILLS, J. H. and L. M. SOMERS (1956). Effect of sarin upon potassium loss by the submandibular gland. F. Pharmacol., II 7, I-9.

YONKMAN, F. F. (1933). Ergotamine paralysis of sympathetic salivation. F. Pharmacol., 48, 291.

YONKMAN, F. F., B. RENNICK and H. L. SCHWERMA (1945). Pharmacologic studies of a new vasoconstrictor; 2-naphthyl-( $\left.\mathrm{I}^{\prime}\right)$-methyl-imidazoline hydrochloride (privine or naphazoline). F. Pharmacol., 84, 197-202.

zOTTERMAN, Y. (1935). Action potentials in the glossopharyngeal nerve and in the chorda tympani. Skand. Arch. Physiol., 72, 73-77.

ZUPKO, A. G. and L. D. PROKOP (1954). The newer anticholinergic agents. II. Effectiveness as antisialogogues. F. Amer. pharm. Ass., 43, 219$22 \mathrm{I}$. 


\section{SPONTANEOUS SECRETION OF SALIVA}

The digestive functions of saliva necessitate a regulatory mechanism which can adapt the secretory rate and the composition of the saliva during a meal to the amount of food and its chemical and physical properties. The reflex control of salivary secretion described in Chapter XII is responsible for this function. Attempts have been made to demonstrate the existence of a complementary hormonal control similar to that acting on the gastric or pancreatic gland cells. Sacks and Kim (I929), in apparent analogy with the classical experiments of Bayliss and Starling (1902) and Edkins ( 1906), injected extracts of oral mucosa of the dog intravenously. No secretion of saliva was obtained. The short period of time which the food spends in the mouth seems to make a nervous rather than a hormonal control mechanism suitable. The paralytic secretion described in Chapter VI offers an example of a salivary secretion brought about by hormones; but it is obtained only under exceptional laboratory conditions when large amounts of adrenaline and noradrenaline are released from the suprarenal medulla to act on salivary gland cells, sensitized by previous parasympathetic denervation.

Non-digestive functions of the saliva, particularly that of keeping the mucosa of the mouth and throat moist, seem to make a more or less continuous activity of at least some salivary glands necessary. This may also be attained reflexly, the dryness of the mucosa acting as a stimulus. There is, however, in addition the possibility that gland cells may be secreting permanently even in the absence of extraglandular stimuli. Apparently some glands of the alimentary canal possess this innate ability of secretion. For such a type of secretion Babkin (I950) used the term spontaneous secretion, "the result of the inherent ability of the secretory cells to elaborate and discharge a digestive juice; this process usually goes on continuously, and is not initiated by impulses carried to the gland cells along the nerves or by humoral regulators in the blood although it may be increased or diminished by such agencies". It seems appropriate to use the term in this sense and not 
simply as a synonym for continuous, permanent, basal or resting secretion, as is often done. These terms say nothing about the mechanism responsible for the secretory activity. Secretion described by these words may be spontaneous; but it may also be due to extraneous agents.

Some cases of spontaneous secretion. The French physiologist Colin seems to have been the first to report that in the ox the parotid differs from the submaxillary gland in secreting continuously, even between meals (see Milne Edwards, I860; Colin, I 871). The work of Ludwig and Claude Bernard had at that time established that salivary glands stop secreting immediately after denervation. Eckhard (1867), finding that the parotid gland of the sheep shows a continuous secretion like that of the ox, tried to denervate the gland by cutting all nerves in the vicinity of the gland. Eventually the gland was attached to the animal via the blood vessels only; nevertheless, saliva was discharged. He described the secretion as continuous and spontaneous. An additional observation was that the parotid gland of the sheep continues to secrete for more than 15 minutes after death, although at a decreasing rate (Brettel, i 869). The peculiar arrangement of the cranial innervation of the parotid gland in oxen and sheep was unknown in those days. Moussu (1888) discovered that the buccal nerve carries secretory fibres for the gland along the salivary duct; it was shown that there is some flow of saliva even after section of this nerve (Moussu, I890; Eckhard, 1893). This type of secretion seems to be characteristic of the parotid gland of ruminants; the gland of the horse, for instance, rests between meals (Colin, I871 ; Ellenberger and Hofmeister, I887).

The sublingual gland of the cat offers another example of continuous salivary secretion (Emmelin, I953). In the cat under chloralose anaesthesia there is no parotid or submaxillary secretion, whereas the sublingual gland incessantly discharges small amounts of saliva at a fairly regular rate. The flow is seen in decerebrate or spinal preparations as well. Section of the parasympathetic and sympathetic fibres of the gland does not affect the secretion although stimulation of these nerves accelerates the flow (see Fig. 3.5). The secretion goes on after injection of a dose of atropine which abolishes the secretory effect of chorda stimulation, or a dose of dihydroergotamine which annuls the effect of sympathetic stimulation. The flow continues at an unchanged rate in a gland 
removed from the body and perfused with blood from the carotid artery via a system of tubing and cannulae or with plasma from a motor-driven syringe.

In all these instances the permanent flow could be due to agents carried to the gland in the plasma. It might be suspected that such an agent could originate in some part of the alimentary canal. Experiments on eviscerated animals showed, however, that the sublingual gland continues to secrete for many hours at the same rate as before the operation. This possibility of a blood-borne secretory agent is ruled out in experiments in which a flow is obtained even when Tyrode solution is used as perfusion fluid. Furthermore, it is possible to dissect out the gland, with the duct cannulated, and keep this thin structure alive in a bath of heated and oxygenated Tyrode solution. Saliva of the characteristic viscous type continues to flow from the cannula for about two hours at about the same rate as in the natural surroundings and the secretion can be accelerated by the addition of pilocarpine to the bath (Fig. 5.I). The constancy of the rate of flow, and the similarity with the rate seen in viro, seems to rule out the possibility that the isolated gland does not secrete but merely expels saliva accumulated in the ducts before the gland was excised.

The experiments described indicate that the sublingual gland of the cat secretes spontaneously. This is not peculiar to the cat. In the dog the denervated sublingual gland is in continuous secretory activity (Emmelin, unpublished observation). Colin (I87 I) had, in fact, been able to cannulate separately the sublingual duct of the ox and observed a flow of saliva even between meals, a fact which he found surprising, considering Claude Bernard's view that the function of this gland is to facilitate swallowing by lubricating the food. Very likely this secretion in the ox during periods of digestive rest is at least partly a spontaneous process, although a reflex activity has not been excluded experimentally.

It is interesting that in the rabbit, which lacks the glandula sublingualis major, the submaxillary gland is in a state of low continuous secretory activity even after denervation or the injection of atropine or dihydroergotamine (Nordenfelt and Ohlin, I957).

Probably the small salivary glands of the oral mucosa behave like the sublingual gland. When saliva from the big glands is drained off from the mouth, small amounts of thick saliva drain into the 
bath of the mouth and can be seen on swallowing in the oesophagus of the horse, ox and sheep (Colin, I871; Ellenberger and Hofmeister, I 887; Scheunert and Krzywanek, 1930). It has been found that biopsy specimens of human palatine mucosa or pieces

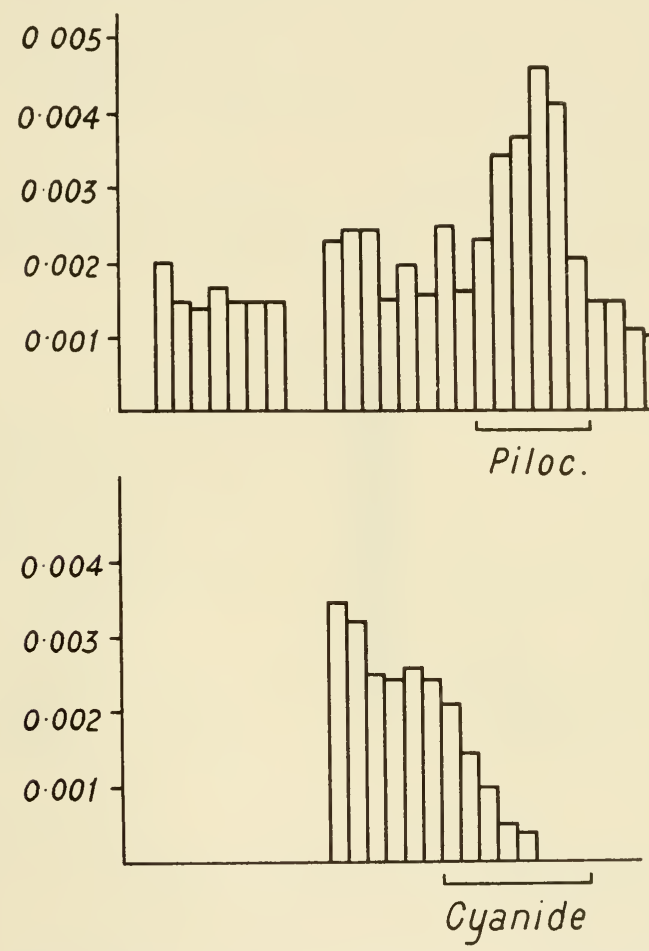

FIG. 5.I. Spontaneous secretion from the cat's sublingual glands, isolated in baths containing oxygenated Tyrode solution at $38^{\circ} \mathrm{C}$.

Upper diagram: right gland. Lower diagram: left gland. The upper diagram shows in addition the secretion during 35 minutes before the right gland was dissected out from the cat (chloralose anaesthesia). Pilocarpine hydrochloride $2.10^{-6}$ was added to the fluid bathing the right gland, sodium cyanide $2.10^{-1}$ to that bathing the left gland. Rate of secretion $=\mathrm{ml}$. $/ 5 \mathrm{~min}$ (Emmelin, 1953).

of the hard and soft palates of the rat kept for some hours in saline or Ringer's solution become covered by a film of thick saliva; the addition of atropine does not prevent the formation of this layer which is supposed to be due to spontaneous secretory activity in the palatine glands (Östlund, I953).

The continuous parotid secretion of ruminants has recently been further analysed (Coats, Denton, Goding and Wright, 1956). 
Section of Moussu's nerve in the sheep was found to diminish but not abolish the flow; a constant flow of about $0.3 \mathrm{ml}$. per minute was maintained. This was the case after section of the cervical sympathetic, facial and auriculo-temporal nerves, or after large doses of atropine given into the carotid artery. Likewise, there was a secretion after evisceration and from a perfused gland. Fig. 5.2 shows that the continuous flow can be increased reflexly or by stimulation of Moussu's nerve and is reduced to a low, constant level by denervation.

Whether there is a spontaneous secretion of saliva in human beings is difficult to state. A continuous flow between meals has

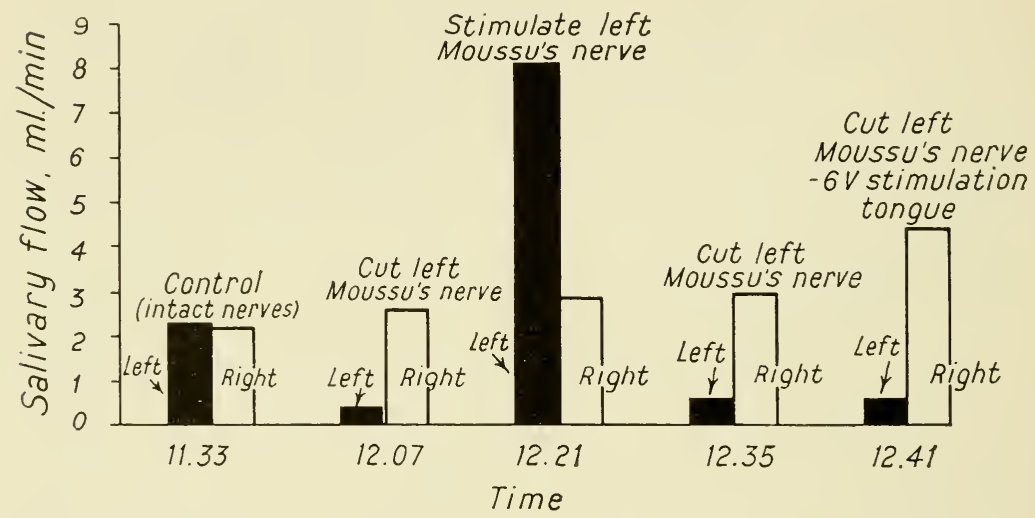

FIG. 5.2. The rate of saliva flow from the right and left parotid glands of a sheep under cyclopropane anaesthesia.

(Coats, Denton, Goding and Wright, 1956.)

often been reported. Lashley (1916), for instance, usually observed a secretion from the parotid gland, although in some subjects, when particularly quiet, the flow ceased for some minutes. The term "resting secretion" has been used to mean a secretion which occurs in the absence of any obvious external stimulus (Spealman, I943). It is clearly difficult to exclude the reflexly evoked secretion, caused by the devices used to collect the saliva. Observations on patients with an accidental fistula of the salivary duct are, therefore, of particular interest. In such persons Zebrowski (1905) found no secretion from the parotid gland between meals. He quotes an observation by Mitscherlich (1832) according to which a patient with a parotid fistula had a very scanty flow of saliva 
during sleep, $0.7 \mathrm{~g}$ during 9 hours, whereas during a meal $74.5 \mathrm{~g}$ were produced in some minutes. Later investigators have likewise tried to reduce or abolish the reflexly evoked activity by studying the glands during sleep (Schneyer, Pigman, Hanahan and Gilmore, 1956). Under such conditions no flow was found from the parotid gland. Sublingual and submaxillary secretion, investigated in one subject only, was very slow, much smaller than that obtained in a "resting" state. A reasonable way of eliminating the influence of the central nervous system would be to give parasympatholytic or ganglionic blocking agents. No such systematic investigations to see whether there is a spontaneous secretion in man seem to have been carried out. Nyman (1942), studying the efficiency of various parasympatholytic drugs, observed apparently no parotid secretion after the administration of such agents. Using a method in which a compound for making dentures was allowed to set slowly in contact with the palate, Östlund (1953) could record a flow of saliva from the palatine glands, seen as small pits in the material. A continuous flow of saliva was obtained, partly at least no doubt due to reflexes elicited mechanically. After administration of atropine, no impressions were obtained in the material. The setting of the compound took place, however, in a few minutes and a small remaining secretion would probably not be revealed. The observations by the same investigator on biopsy preparations of palatine mucosa, quoted above, suggest the existence of some spontaneous flow from the palatine glands.

The function of spontaneously secreted saliva. A spontaneous flow of saliva from some glands would provide a basal secretion to keep the mucous membranes of the mouth and throat moist, for instance, during sleep. With increased demands, for instance, during meals, during speech or in some animals for thermoregulatory purposes, reflex secretion can be superimposed upon the spontaneous flow. In ruminants, the continuous secretion of strongly alkaline parotid saliva apparently is of importance for the maintenance of the optimal reaction of the gastric contents.

The mechanism of spontaneous secretion. Experiments on tissue cultures of gastric or intestinal mucosa suggest that secretion of mucus may occur spontaneously (Florey, 1930, 1931; Florey, Wright and Jennings, I94I). Similarly, the mucous cells of the sublingual gland and of the small salivary glands may be endowed with the ability of secreting even in the absence of extraglandular 
stimuli. This is, however, apparently not a property common to all mucous cells. The mucous cells of the cat's submaxillary' gland which are very similar electrophysiologically (Lundberg, I957) and histologically to those of the sublingual gland, do not secrete spontaneously. Furthermore, some serous cells of salivary glands show a spontaneous secretion, for instance, those of the parotid glands of ruminants, whereas others do not. Examples of spontaneous secretion can in fact be found in different species in all types of salivary glands, as exemplified above.

When a preparation of the cat or dog submaxillary and sublingual glands is perfused with eserinized plasma, small amounts of acetylcholine can be detected in the venous effluent even when the parasympathetic nerve is not stimulated (Emmelin and Muren, I950). This is the case even when the gland has been acutely denervated and the perfusion fluid contains curarine (Fig. 3.2). It might be suggested that the "spontaneous" secretion is due to acetylcholine continuously released locally in the sublingual gland. Such a mechanism, similar to that responsible for the "paroxysmal secretion" described in Chapter VI, does not seem likely, however, since the spontaneous secretion is not abolished by atropine.

In order to support the view that the continuous sublingual flow of the cat is a true spontaneous secretion, it may be pointed out that this secretion differs in several respects from that caused by agents acting on the secretory cell via some receptor mechanism (Emmelin, I953). In the isolated sublingual gland it continues even when the gland has ceased to respond to secretory agents added to the bath. A further difference may be illustrated in the following way. If a continuous secretion is brought about in the submaxillary gland by injection of pilocarpine or ephedrine, the threshold dose of some other agent such as adrenaline is found to be very much lowered and the gland is extremely sensitive to this agent. The spontaneous sublingual secretion apparently lacks this effect, for the threshold dose of adrenaline, required to accelerate the flow, is high and of the same order of magnitude as that of a normal submaxillary gland. Further, more or less continuous activity in the submaxillary gland, caused by repeated injections of pilocarpine, prevents the development of a supersensitivity to chemical agents which normally follows denervation; the spontaneous sublingual secretion, on the other hand, has not this effect. These 
various observations indicate that there is a fundamental difference beween the continuous sublingual secretion and a secretion evoked by extrinsic agents.

Spontaneous secretion is certainly not due to a high permeability of the gland cells resulting merely in filtration of fluid. Several arguments can be adduced against such an assumption. The sublingual gland of the cat is able to secrete against a pressure of about $15 \mathrm{~cm}$ of water; this is true even if the gland is isolated in Tyrode solution. The flow occurs at a fairly constant rate against different counter-pressures in the salivary ducts. Similarly, great variations in arterial blood pressure affect the rate of flow very little and a perceptible flow has been found as late as 45 minutes after death. The very viscous saliva even from an isolated gland resembles very little a simple filtrate of plasma. The finding that cyanide stops the flow indicates that metabolic processes are necessary for the continuous secretion. This effect is obtained within a few minutes in a perfused gland. It can be demonstrated on the isolated gland, also, as shown in Fig. 5.I.

\section{REFERENCES}

BABKIN, B. P. (I950). Secretory mechanism of the digestive glands, and ed. Hoeber, New York.

BAYLISS, W. M. and E. H. STARLING (I902). The mechanism of pancreatic secretion. F. Physiol., 28, 325-353.

BRetTel, C. (1869). Die Parotidensecretion des Schafes im Vergleich zur Nierensecretion. Beitr. Anat. Physiol., 4, 89-107.

COATS, D. A., D. A. DENTON, J. R. GODING and R. D. WRIGHT (1956). Secretion by the parotid gland of the sheep. F. Physiol., I3I, I3-3I.

colin, G. (1871). Traité de physiologie comparée des animaux, and ed. Baillière, Paris.

ECKHARD, C. (I867). Beiträge zur Lehre von der Speichelsecretion. Z. rat. Med., 29, 74-87.

- (1893). Noch einmal die Parotis des Schafes. Centralblatt f. Physiol., 7, 365-368.

EDKins, J. S. (I906). The chemical mechanism of gastric secretion. $\mathcal{F}$. Physiol., 34, I33-144.

ELLENBERGER, W. and v. HOFMEISTER (I 887). Beitrag zur Lehre von der Speichelsecretion. Arch. Anat. Physiol., Physiol. Abt., Suppl.-Band I I, I38-I 47 .

emmelin, N. (1953). On spontaneous secretion of saliva. Acta physiol. scand., 30, Suppl. II I, 34-58.

EMmelin, N. and A. MUREN (I950). Acetylcholine release at parasympathetic synapses. Acta physiol. scand., 20, I3-32.

FLOREY, H. (1930). The secretion of mucus by the colon. Brit. F. exp. Path., I r, 348-36r. 
FLOREY, H. (I93I). The mechanism of goblet-cell secretion in the mammal; the effects of cyanide. Brit. $\mathcal{F}$. exp. Path., 12, $301-305$.

FLOREY, H. W., R. D. WRIGHT and M. A. JENNINGS (I94I). The secretions of the intestine. Physiol. Rev., 21, 36-69.

LASHLEY, K. S. (I9I6). Reflex secretion of the human parotid gland. $\mathcal{F}$. exp. Psychol., I, 46I-493.

LUNDBERG, A. (1957). Secretory potentials in the sublingual gland of the cat. Acta physiol. scand., 40, 2 I-34.

MILNE-EDWARDS, H. (1860). Leçons sur la physiologie et l'anatomie comparée de l'homme et des animaux, Vol. 6. Paris.

Mitscherlich, C. G. (I832). Ueber den Speichel des Menschen. Quoted from Babkin; Die äussere Sekretion der Verdaunngsdrüsen, 2 nd ed. 1928. Springer, Berlin.

Moussu, M. (i 888). Nerf moteur ou sécréteur de la glande parotide chez le bœuf. C.R. Soc. Biol., Paris, 40, 280-28ı.

- (1890). De l'innervation des glandes parotides chez les animaux domestiques. Arch. Physiol. norm. path., 5, 68-82.

NORDENFELT, I. and P. OHLIN (I 957). Supersensitivity of salivary glands of rabbits. Acta physiol. scand., 41, 12-17.

Nyman, E. (1942). Studien über die Atropingruppe. Acta physiol. scand., 3, Suppl. 10.

östlund, S. (1953). Palatine glands and mucin. Odontol. Tidskrift, 62, I-I 28.

SACKS, J. and M. S. KIM (I929). On the non-existence of a hormone for salivary secretion. Proc. Soc. exp. Biol., N.Y., 27, I $83-\mathbf{1} 84$.

SCHEUNERT, A. and F. W. KRZYWANEK (1930). Zum Studium der Speichelsekretion. VI. Ueber die an der Dauersekretion des Schafes beteiligten Drüsen und die Zusammensetzung des von ihnen gelieferten Sekretes. Arch. ges. Physiol., 223, 472-476.

SCHNEYER, L. H., W. PIGMAN, L. HANAHAN and R. W. GILMORE (1956). Rate of flow of human parotid, sublingual and submaxillary secretions during sleep. $\mathcal{F}$. dent. Res., 35, 109-1 I 4 .

SPEALMAN, C. R. (1943). The volume flow of resting salivary secretion. Amer. F. Physiol., 139, 222-229.

ZEBROWSKI, E. (I 905). Zur Frage der sekretorischen Funktion der Parotis beim Menschen. Arch. ges. Physiol., r 10, I05-173. 


\section{CHAPTER VI \\ EFFECTS OF DENERVATION}

Complete denervation affects the salivary glands seriously. Some glands, it is true, which are endowed with the ability of spontaneous activity, continue to secrete at a slow rate just as they did with the nerves intact; shortly after postganglionic parasympathetic denervation a transient secretion of peculiar, "paroxysmal" type may be observed and under exceptional conditions some of the denervated glands may show a "paralytic secretion". But with these exceptions the denervated glands do not discharge any saliva. In all glands the ability to adapt the activity to the functional requirements is lost, for there is no hormonal control mechanism left, as in the denervated pancreas, for instance; and there is no evidence to show that there are local reflexes, as in the lower part of the alimentary canal, through which the structures can be activated after section of the extrinsic nerves. Function is, in fact, usually as impaired in the salivary glands as in skeletal muscles after denervation. As in skeletal muscle an atrophy occurs with marked histological changes and a pronounced supersensitivity to chemical stimuli develops. The chemical composition of the glands is affected; particularly changes in the activity of certain enzymes have been investigated, in connection with studies of the mechanism of the supersensitivity.

The fact that the parasympathetic nerve supply of the salivary glands is much more important than the sympathetic supply is apparent from denervation experiments. Structural and functional changes are particularly serious after section of the parasympathetic fibres, as will be shown below.

\section{STRUCTURAL CHANGES}

Claude Bernard (1864) observed that the submaxillary gland diminishes in size after section of the chorda tympani, and this has been confirmed by numerous later investigators (Bidder, I 867 ; Heidenhain, I868; Langley, I885a; Bradford, I888; Maximow, I901; Chang and Gaddum, I933; MacIntosh, 1937; Emmelin, Jacobsohn and Muren, I95 I; Strömblad, I 955a). The gland seems 
gradually to lose about 30 per cent of its weight in the course of some weeks. It is interesting to find that a similar, or even more pronounced, atrophy occurs after hypophysectomy or adrenalectomy (Kahlson and Renvall, I956).

The atrophy following section of the chorda is reversible; after regeneration of the chorda fibres the gland regains its previous weight (Emmelin, Muren and Strömblad, 1957a). It has been observed that many changes in the gland due to section of the chorda can be prevented or abolished by prolonged administration of a secretory agent such as pilocarpine (Emmelin and Muren, I950a, I951 $a$, 1952; Emmelin, Jacobsohn and Muren, 1951). From figures given by Strömblad (1956a and $b$ ) it appears that this is true for the atrophy also. A continuous secretion due to spontaneous activity, however, does not prevent the atrophy following section of the chorda in the sublingual gland (Emmelin, I953a).

Many of the changes characteristic of a denervated gland can be reproduced in a normally innervated gland by long-continued treatment with a parasympatholytic agent like atropine. It is a puzzling fact, however, that no atrophy seems to follow such treatment (Emmelin, Jacobsohn and Muren, I95I; Strömblad, $1956 a$ and $b$ ). This may be connected with the fact that atropine does not entirely abolish the effects of the chorda, since a raised metabolism and vasodilatation can persist.

Section of the chorda on one side affects the contralateral gland also; it increases somewhat in size (Emmelin, Jacobsohn and Muren, I95I).

An atrophy has been observed in the parotid gland following destruction of the preganglionic, parasympathetic fibres (Bradford, I888). In the investigation of Strömblad (1955a) the atrophy of the parotid gland after pre- or postganglionic denervation seemed to be relatively small.

Sympathetic denervation is not followed by atrophy in the submaxillary and parotid glands (Bradford, I888; Strömblad, I956c). After extirpation of the superior cervical ganglion there may even be a slight increase in the weight of the glands. Whether this is due exclusively or at least to some extent to a greater content of blood following the loss of vasoconstrictor tone has not been investigated.

The microscopic picture of the submaxillary gland following section of the chorda shows a decrease in size of all structures of the gland except the connective tissue which seems to increase in 
amount. Changes in the demilune cells, the alveolar cells and the striated ducts give the gland a characteristic picture, which has been examined by many investigators, e.g. Heidenhain (1868), Langley (I 885b), Krause (1 897), Maximow (1901), Gerhardt (1 903), Rawlinson (1935 $a$ and $b$ ). Similar histological changes are found in a normally innervated gland of an animal treated for some time with atropine. When the treatment is discontinued the gland regains its normal histological appearance. The changes brought about by prolonged atropinization are thus reversible. This is true also for those obtained after section of the chorda, for aftcr treatment with pilocarpine for a few days the picture of a gland, whose chorda had been cut in advance, is fairly normal (Emmelin, Jacobsohn and Muren, 1951).

\section{CHEMICAL CHANGES}

Little is known of the changes in chemical composition which occur in a salivary gland after denervation. Systematic investigations have concerned mainly the activity of cholinesterase and amine oxidase (Strömblad, I955a, 1956c and $d$ ). Because of the pronounced atrophy resulting from parasympathetic denervation it is necessary to calculate the activity both per total gland and as a concentration. The results of Strömblad's work may be summarized briefly as follows.

The total activity of cholinesterase, mainly due to true cholinesterase, and of amine oxidase, decreases on preganglionic, parasympathetic denervation on about 30 or 40 per cent. This corresponds approximately to the loss in weight. Postganglionic, parasympathetic denervation (carried out in parotid glands) has a more striking effect on the cholinesterase; the total amount is reduced by about 55 per cent, the concentration about 50 per cent. The amine oxidase, on the other hand, is less affected by this operation.

Extirpation of the superior cervical ganglion does not reduce the amine oxidase activity. Indeed in the parotid gland there may be an increase.

It may be added that in the absence of nerve section treatment with a parasympatholytic agent reduces the amine oxidase activity but does not affect the cholinesterase activity. In a parasympathetically denervated gland treatment with pilocarpine tends to restore the activity of the two enzymes. 
The activity of the kallidin- (or bradykinin-) forming enzyme kallikrein diminishes in the submaxillary gland and in saliva secreted in response to adrenaline when the chorda has been cut (Emmelin and Henriksson, 1953). With the atrophy of the submaxillary gland caused by ligation of the duct a reduction in the content of protease and amylase, of indophenol oxidase, succinic dehydrogenase and acid phosphatase occurs (Junqueira, I95 I). It. seems particularly important to compare the activity of respiratory enzymes in normal and denervated glands in the light of the interesting finding that secretion of saliva in a denervated gland occurs with a smaller increase in oxygen consumption than in a normal gland; this has been shown both in vivo and in vitro, using chopped salivary glands (Strömblad, 1957a, 1959). Recently it has been demonstrated that parasympathetic denervation reduces the activity of succinic dehydrogenase, fumarase and cytochrome oxidase in salivary glands (Nordenfelt, Ohlin and Strömblad, 1960). This fact may account for the decrease in maximal secretory capacity which is seen after section of the chorda (Emmelin, Malm and Strömblad, 1960). Investigations on the composition of saliva secreted by denervated glands in response to chemical stimuli seem, also, highly desirable.

The finding of Chang and Gaddum (1933) that the acetylcholine content of the salivary glands decreases after parasympathetic denervation has been discussed in a previous context. Similarly, the content of adrenaline and noradrenaline has been found to diminish on sympathetic denervation (v. Euler and Purkhold, I95I).

\section{CHANGES IN SENSITIVITY TO CHEMICAL STIMULI}

Denervation of the salivary glands causes a supersensitivity to chemical agents, in agreement with Cannon's law of denervation. It was shown by Maevsky (1923) and Fleming and MacIntosh (1935) that when the chorda had been cut in advance, the submaxillary gland was more sensitive to adrenaline than normally. Removal of the superior cervical ganglion was found by Simeone and Maes (1939) to give rise to a supersensitivity in the gland. Later investigators have mainly studied the submaxillary gland of cats and dogs (Pierce and Gregersen, 1937; Wills, 1942; Emmelin and Muren, 1950b, 1951 $a$, 1952; Graham and Stavraky, 1951, 1954; Emmelin, 1952a; Emmelin and Strömblad, 1953; Dirn- 
huber and Evans, I954) but observations have also been made on the parotid gland (Strömblad, I955b; Nordenfelt and Ohlin, I 957) and the sublingual gland (Emmelin, r $953 a$ ).

These various investigations show that supersensitivity can be produced by parasympathetic and by sympathetic denervation, that the supersensitivity of one type resembles that of the other but is usually much more pronounced in the former, and that one supersensitivity can be superimposed upon the other.
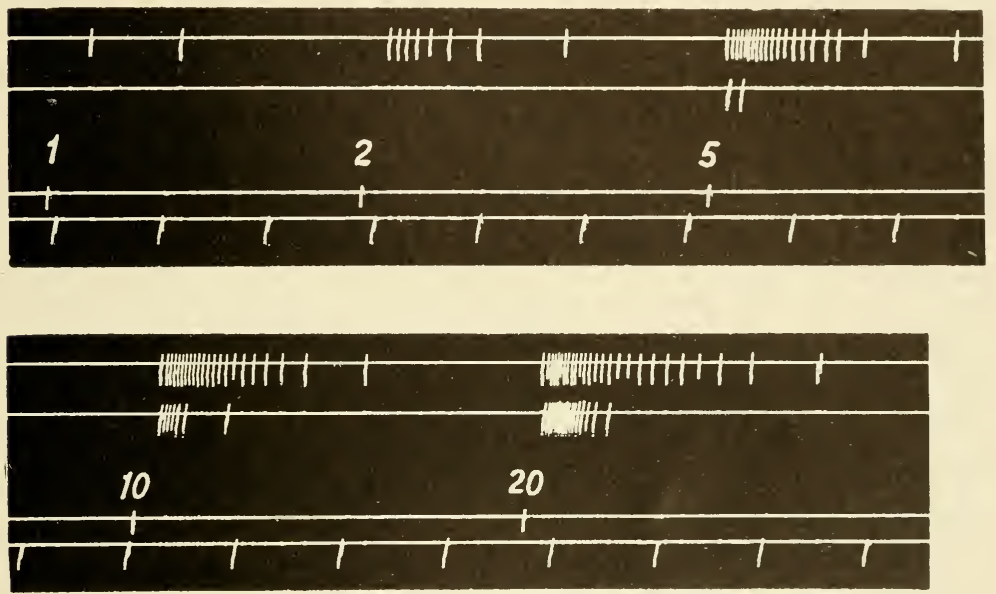

FIG. 6.I. Supersensitivity to adrenaline after section of the chorda tympani in a cat under chloralose anaesthesia.

From above: Drops of saliva from the right submaxillary gland. The right chorda cut two weeks previously. Drops from the left, innervated gland. Intravenous injection of adrenaline in doses of $1-20 \mu \mathrm{g} / \mathrm{kg}$. Times in minutes (Emmelin, unpublished).

Fig. 6. I shows the effect of different doses of adrenaline, injected intravenously, on the submaxillary gland two weeks after section of the chorda, and on the contralateral intact gland. Many of the characteristics of the hypersensitivity are shown in this figure. It can be seen that denervation lowers the threshold. A moderate dose of adrenaline causes a bigger response, because the rate of secretion is increased and the gland secretes for a longer period. When a big dose is given, causing secretion at a maximal rate, however, the flow is not quicker from the denervated than from the innervated gland; it may be somewhat slower, because of the atrophy of the decentralized gland.

Supersensitivity develops gradually; it can first be detected after two or three days, and reaches its maximum after two or 
three weeks. In order to study the development of supersensitivity, the level of sensitivity can be estimated repeatedly with intervals of some days using the following method: A cat is anaesthetized with a short-acting barbiturate, fine glass cannulae are introduced from the mouth into the salivary ducts and secretory agents such as adrenaline, acetylcholine or mecholyl are injected into the heart.

Supersensitivity following parasympathetic or sympathetic denervation is unspecific and can be shown for almost all agents which cause a secretion from the normal gland, e.g. adrenaline, noradrenaline and other sympathomimetic drugs, acetylcholine and other cholinesters, and pilocarpine. Statements to the contrary in the early literature seem mostly to be due to the fact that the doses of the drugs tested were too big; the maximal secretory rate of the denervated gland is not bigger than that of the normal gland but may, on the contrary, be smaller because of atrophy. Furthermore, it must be kept in mind that the denervated gland seems to be more readily exhaustible, and that secretion may be more easily inhibited in a denervated than in a normal gland by a big dose.

There are, however, undoubtedly some exceptions to the general rule. After postganglionic parasympathetic denervation anticholinesterases cause a very small secretion only, as shown in Fig. 3.8. A reasonable explanation is that these drugs act, wholly or mainly, by preserving acetylcholine released from the postganglionic fibres and therefore lose their secretory activity when these fibres have degenerated. Similarly, after postganglionic sympathetic denervation tyramine has no secretory effect, suggesting some indirect mode of action of this drug in the normal gland (Strömblad, 1956e). After preganglionic parasympathetic denervation, on the other hand, the glands are supersensitive both to anticholinesterases and tyramine.

According to the law of denervation preganglionic section ought to sensitize not only the gland cells, but the postganglionic neurone also; further, postganglionic section ought to sensitize the gland cells more than preganglionic section. On the whole, the salivary glands fulfil these requirements. After section of the chorda the dose of nicotine needed to evoke a perceptible secretion is smaller than in a normal gland, showing that the parasympathetic ganglion cells have been sensitized (Emmelin, 1953b). The gland cells are usually more sensitized after post- than after preganglionic dener- 
vation. This is found when the effect of acetylcholine is studied on the parotid gland (Strömblad, I955b). Complete parasympathetic postganglionic denervation of the submaxillary gland cannot be carried out, since many of the synapses are situated within the gland; but even after a partial denervation the gland is found to be more supersensitive to acetylcholine and adrenaline than after section of the preganglionic chorda fibres (Emmelin, I960a). Extirpation of the superior cervical ganglion is followed by a distinct supersensitivity in the submaxillary gland, whereas there is scarcely any sensitization at all after section of the preganglionic sympathetic fibres (Emmelin and Engström, I960). The exceptions to the law which anticholinesterases and tyramine form have already been discussed. A further exception is the fact that adrenaline has a bigger secretory effect on the parotid gland after pre- than after postganglionic parasympathetic denervation (Strömblad, I955 $b$ ). The explanation for this has recently been found (Ohlin and Strömblad, I958) in the fact that the vasoconstrictor effect of adrenaline is greater after post- than after preganglionic denervation, i.e. the vessels react according to Cannon's law, but since large doses of adrenaline are required to cause a secretion from the parotid gland, vasoconstriction will tend to reduce the secretion, and particularly after postganglionic denervation.

The hypothesis has been put forward that the sensitization is due to lack of secretory impulses (Emmelin and Muren, I950a and $b$; Emmelin, I $952 a$ and $b, 1960 b$ ). The following observations may be quoted in support of this view. Administration of a ganlionic blocking agent for some weeks sensitizes the submaxillary gland to a level similar to that produced by chorda section (Emmelin, I959). Parasympatholytic agents, likewise, cause a supersensitivity. If the flow of secretory impulses to the gland is reduced by section of some of the afferent fibres of the gustatory reflex arc, a supersensitivity ensues. Administration of secretory agents like pilocarpine, carbamylcholine or adrenaline for some days abolishes the supersensitivity created by denervation. When hypoglossal fibres after cross-suture have reinnervated the gland via the chorda, and secretion is elicited whenever tongue movements are intended, the supersensitivity caused by section of the chorda diminishes. Section of the preganglionic sympathetic fibres does not cause any supersensitivity in the submaxillary gland, as it does 
in the nictitating membrane, and an intact sympathetic trunk does not at all counteract the development of the chorda supersensitivity. The nictitating membrane is constantly activated via the sympathetic fibres; the salivary glands, on the other hand, are activated mainly via the parasympathetic fibres. If, however, the traffic of impulses for the gland via the sympathetic is greatly increased by reinnervating the gland from the hypoglossal nerye via the sympathetic fibres the chorda supersensitivity is found to decrease (Emmelin, Muren and Strömblad, r957b). All these observations seem to be compatible with the concept that supersensitivity is a consequence of lack of secretory impulses, from the central nervous system under ordinary conditions, or via the blood in the experiment when secretory agents are injected.

Such a hypothesis cannot, however, provide the whole explanation. It does not account for the fact that section of postganglionic parasympathetic neurones, or treatment with suitable parasympatholytic drugs, causes a higher supersensitivity than does section of the preganglionic parasympathetic fibres or treatment with a ganglionic blocking agent. Nor does it explain the fact that excision of the superior cervical ganglion, but not preganglionic sympathetic denervation, produces a supersensitivity - a supersensitivity that can be superimposed upon that produced by section of the preganglionic, or even postganglionic parasympathetic fibres. In order to account for these facts it seems necessary to assume that there is a continuous release of the transmitter from the postganglionic endings, as discussed on page 63; and that this leakage, although it causes no secretion, is able to counteract, to some extent, the development of supersensitivity (see Emmelin, 1960b).

Hence, preganglionic denervation, or treatment with a ganglionic blocking compound, should cause a supersensitivity because the gland is deprived of transmitter, released by the nerve impulse. Postganglionic denervation, or treatment with a parasympatholytic agent, should cause a greater supersensitivity because in addition no leaking transmitter acts on the gland cells. In the sympathetic system this latter factor may be the main one; removal of the superior cervical ganglion therefore causes a moderate supersensitivity only.

It seems reasonable to assume that the process of sensitization is related to some part of the receptor region rather than to the secretory mechanism. The continuous influence of the postgan- 
glionic neurone, revealed by a supersensitivity when the fibres are removed or prevented from acting by means of an antagonistic drug, does not manifest itself in secretion. A further argument may be that the activity of the secretory mechanism which appears as a spontaneous secretion, not elicited via the receptors, is not affected by denervation and whereas a more or less continuous activity evoked over a long period by injected agents such as pilocarpine prevents the development of the denervation supersensitivity, the spontaneous secretion lacks that effect (Emmelin I953a). It should be kept in mind, on the other hand, that the sensitization is non-specific. When the gland cell is deprived of the action of acetylcholine, for instance, it becomes supersensitive not only to acetylcholine but to adrenaline as well. The sensitization process, therefore, does not seem to take place in that part of the mechanism activating the secretory machinery which is responsible for the specificity of action of the stimulating agents and where the specific antagonists work.

The next problem concerns the nature of the changes in the receptor region which occur when the impingement of transmitters is reduced or abolished and no related agents, able to react with the receptors like the transmitters, are administered. These changes develop gradually to reach their maximum after two or three weeks. They are reversible; when pilocarpine is administered to a denervated gland, or a long-lasting treatment of a normal gland with a parasympathicolytic agent is discontinued, normal conditions are restored within a few days. No connection has so far been detected between the changes responsible for the supersensitivity and changes seen in the microscope after denervation. More attention has been paid to the chemical alterations which take place in the gland when nerves are cut; in particular, changes in the activity of enzymes which limit the action of secretory agents have been studied. The "enzyme hypothesis" applied to the salivary glands has been discussed by Strömblad (1956d, 1957b), who estimated the sensitivity to different drugs, and the activity of cholinesterase and amine oxidase, after denervation and after treatment with pilocarpine or an atropine-like drug; further, he made comparisons between the secretory responses after denervation and after acute administration of anticholinesterases. From this work it is apparent that there is as yet no general, clear-cut relation between sensitization and activity of the enzymes studied. There are some suggestive 
facts. For instance, preganglionic parasympathetic denervation of the parotid gland causes a diminished cholinesterase activity and an increased acetylcholine sensitivity; after postganglionic section the enzyme activity is further reduced and the sensitivity further raised. After excision of the superior cervical ganglion, however, there is a supersensitivity to acetylcholine but no detectable change in esterase activity. It is not easy to explain the sensitization to agents resistant to the action of enzymes, for instance pilocarpine or corbasil, on the basis of the enzyme hypothesis. The work is furthermore hampered by our defective knowledge of the physiological mode of elimination of the sympathetic transmitter. So far, no experiments have been carried out on the effect of denervation on the methylating enzyme recently assumed to be engaged in the breakdown of the transmitter molecule.

\section{SECRETION AFTER DENERVATION}

Although the salivary gland, disconnected from the central nervous system, does not usually show any secretory activity (if not secreting spontaneously) it may under certain conditions enter into activity. It still responds to injected secretory agents, and usually even more readily than the normal gland, as discussed above. Agents released into the circulation may under special circumstances attain a concentration high enough to excite the sensitized gland cells. It is known, for instance, that in asphyxia the hormones of the adrenal medulla may cause a secretion from a denervated gland. The phenomenon of paralytic secretion can probably be explained in a similar way. Secretion may occur for some days in a denervated gland while the cut postganglionic parasympathetic neurone is degenerating (the "paroxysmal salivary secretion").

Paralytic secretion. Some days after section of the chorda tympani in a dog Claude Bernard (1862, I864) discovered a flow of saliva from the decentralized submaxillary gland, a "paralytic secretion". In order to explain this puzzling phenomenon Bernard assumed that the chorda normally exerts an inhibitory action on the gland cells. A number of other explanations have been proposed by later investigators (for literature see Emmelin, 1952a). Fleming and MacIntosh (1935) suggested that the secretion is in some way connected with the supersensitivity to sympathetic impulses and adrenaline which follows section of the chorda.

Recent experiments indicate that the paralytic secretion is not 
constantly going on as generally assumed, but appears only under certain conditions which involve a sympathetic hyperactivity, and particularly an increased liberation of the hormones of the adrenal medulla (Emmelin and Muren, I $950 a$ and 195 I $b$; Emmelin, I $952 a$ and $b$ ). Hence, two conditions have to be fulfilled for the paralytic secretion to appear: there must be a pronounced supersensitivity of the gland cells, and a considerable release of adrenaline and noradrenaline. The paralytic secretion would thus have the same mechanism as "paradoxical pupillary dilation" and be related to "pseudomotor contractures". This theory is based on the following facts:

I. A pronounced supersensitivity is required. There is no paralytic secretion when removal of the superior cervical ganglion has created its fairly modest degree of supersensitivity. In animals in which section of the chorda causes a moderate sensitization only, the paralytic secretion is slow. No secretion is obtained until the sensitization is discernible, i.e. two or three days after cutting the chorda; the rate of flow then increases with the level of sensitivity, to reach its maximum after two or three weeks. If the chorda supersensitivity is further raised by removal of the superior cervical ganglion or acute injection of cocaine, the paralytic flow increases. In a normally innervated gland, treated for some time with a parasympathicolytic agent, a rapid paralytic secretion can be elicited; it can further be accelerated by the injection of cocaine. If the hypersensitivity of a gland, the chorda of which has been cut in advance, is abolished by treatment for some days with pilocarpine, no paralytic secretion can be evoked.

2. Adrenaline and noradrenaline from the suprarenals cause the paralytic secretion. No secretion is obtained unless the release of the hormones is greatly increased. Therefore, paralytic secretion is not seen in chloralose anaesthesia. It is found, however, in morphine anaesthesia, which is known to increase the output from the suprarenals. This explains why early investigators, such as Heidenhain, Bidder, and Langley, who used morphine, observed a paralytic secretion whereas later workers, studying the denervated submaxillary gland using modern anaesthetics, do not mention a paralytic flow. The denervated parotid gland, which is relatively insensitive to adrenaline, shows no paralytic secretion; the denervated submaxillary and sublingual glands, highly sensitive to adrenaline, do. Removal of the suprarenals abolishes the paralytic 
flow. So does the acute injection of sympathicolytic agents such as dihydroergotamine, whereas an acute injection of atropine does not affect the flow.

Some of the observations quoted above are illustrated in Fig. 6.2. In two cats the chorda was sectioned, and I 3 days later an acute experiment was carried out. One cat was anaesthetized with morphine; a slow paralytic secretion was found from the denervated

\section{Chloralose Morphine}
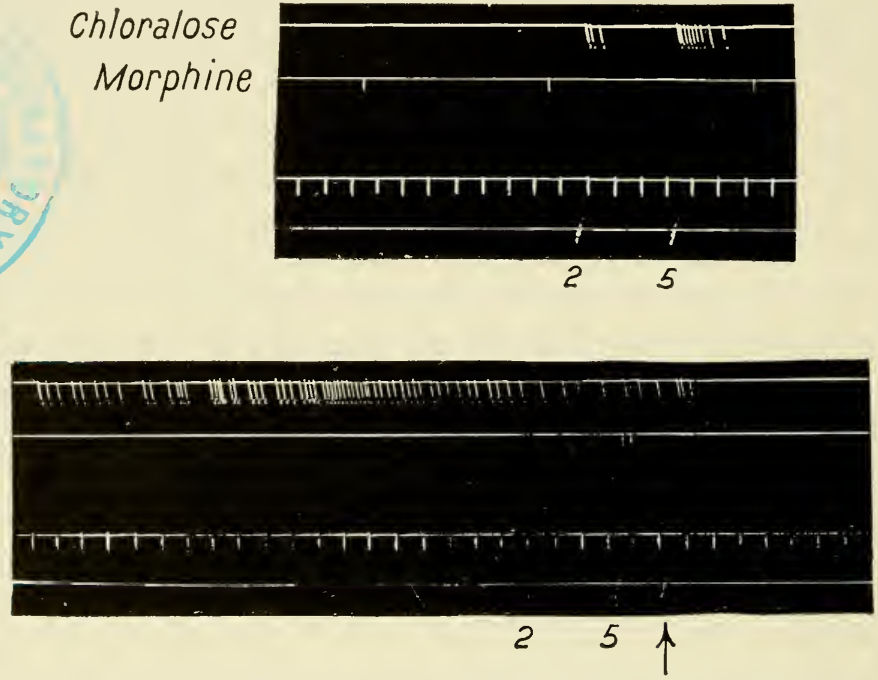

FIG. 6.2. Paralytic secretion.

Secretion from right submaxillary glands of two cats 13 days after chorda section, one under chloralose (uppermost line of records), the other under morphine anaesthesia (second line from above). Time: minutes. Lowest line: signal. In both cats all branches of the right common carotid tied except the artery of the gland. Venous blood from each gland drained off from cannula in the jugular vein after all venous branches except those of the gland had been ligated. Between the two sections of the tracing a crossed circulation was established, blood flowing from central part of right carotid of one cat into peripheral stump of right carotid of the other cat. 2 and 5 are doses of adrenaline, $\mu \mathrm{g} / \mathrm{kg}$, into the femoral vein of the chloralosecat. At the arrow the adrenals of the morphine cat were removed (Emmelin, 1952).

gland. The other animal was given chloralose; no secretion was found. A cross-circulation was then established so that arterial blood from the morphine cat perfused the denervated gland of the chloralose cat, and vice versa; after having passed the glands the blood was not allowed to enter the circulation of the recipient animals but was drained off through the cut submaxillary veins. The effect of this procedure was that the paralytic secretion of the morphine cat ceased, and instead a rapid flow started in the chloralose cat. Intravenous injection of adrenaline into the chloralose cat 
before the cross-circulation showed that the gland of this cat had been highly sensitized by the denervation. Similar injections into the same animal, during cross-circulation, disclosed that the gland of the morphine cat happened to be less sensitized by the denervation. When the suprarenals of the morphine cat were removed during cross-circulation, the paralytic secretion stopped in the gland of the chloralose cat. From such an experiment it can be inferred that no paralytic secretion is obtained in chloralose anaesthesia, even if the gland is highly sensitized; that secretion is obtained in morphine anaesthesia; that the paralytic flow is due to some blood-carried agent, derived from the suprarenals, and that the rate of flow depends on the level of sensitivity.

Antilytic secretion. During his investigations on paralytic secretion Heidenhain ( 1868 ) observed a flow of saliva from the normally innervated submaxillary gland, contralateral to the "paralytic" gland, a phenomenon which he considered "altogether inexplicable". It was slower than the paralytic secretion. Langley (I $88_{5} a$ and $b$ ) observed such a flow also and coined the term antiparalytic or antilytic secretion.

It may be tempting to try to find an explanation for this phenomenon similar to that given above for the paralytic secretion. Both Heidenhain and Langley used morphine anaesthesia in their experiments, and consequently the concentration in the blood of the hormones of the suprarenal medulla was high. The sensitivity of normal glands to adrenaline shows very great individual variations, as does that of a denervated gland; it might be that an exceptionally sensitive normal gland can be excited by the adrenaline of the blood in morphine anaesthesia. Apart from that, the following explanation may be suggested (Emmelin, I956). Unilateral section of the afferent fibres from the tongue causes a supersensitivity in both the submaxillary glands, probably by reducing the secretory impulses to the gland. Heidenhain denervated the gland by cutting the chorda-lingual nerve; important afferent fibres from the tongue were thus cut beside the secretory fibres, and a certain degree of supersensitivity can be supposed to have ensued in the contralateral gland. This could explain his antilytic secretion, smaller than the paralytic flow because the supersensitivity was not so pronounced as after section of the chorda.

Langley, however, did not cut the chorda-lingual nerve but the chorda. His "antilytic" glands were therefore not sensitized by 
partial afferent denervation, unless it be assumed that the chorda contains some afferent fibres from the gland, section of which causes some supersensitivity in the contralateral gland. Hence, a final explanation of the antilytic secretion is still lacking.

Paroxysmal secretion. This is a type of secretion which like the paralytic and antilytic secretion, can be seen after denervation (Emmelin and Strömblad, I957, 1958). It differs from these types of secretion in several respects. It is obtained from the parotid gland (of the cat) and is seen in chloralose anaesthesia. It
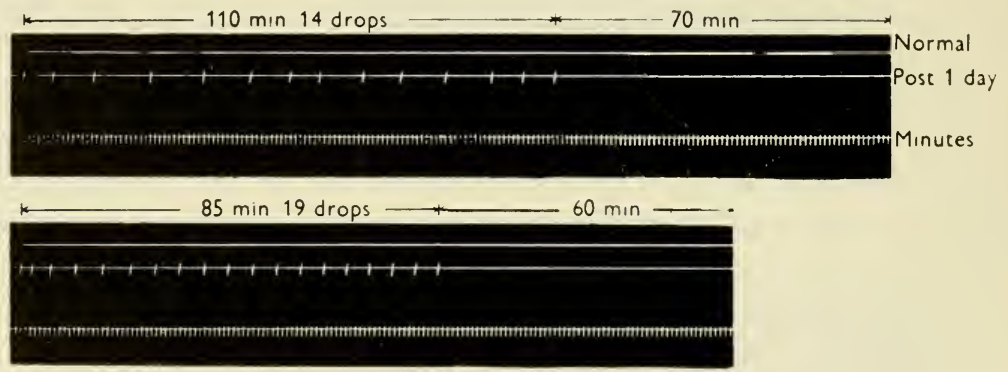

$80 \min 13$ drops

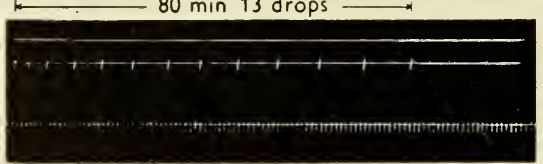

Fig. 6.3. Paroxysmal secretion.

Record of drops from the parotid glands of a cat under chloralose anaesthesia. Left auriculotemporal nerve cut 24 hours before. In each set of tracings, top line, secretion of right gland, no secretion; middle line, secretion of left, denervated gland; bottom line, time (minutes). The lower tracings are immediate continuations of the upper ones (Emmelin and Strömblad, 1958).

does not occur after preganglionic, but only after postganglionic denervation and then only during the initial stages of nerve degeneration. It seems to have nothing to do with hypersensitivity or adrenaline release.

When the auriculo-temporal fibres have been cut the paroxysmal secretion can be seen after one to three days. The salivary flow is not continuous. Periods of secretory activity, in some experiments lasting for several hours, sometimes for only ten minutes, alternate with periods of varying length in which there is no flow of saliva. This is illustrated in Fig. 6.3, which shows three consecutive periods of activity one day after postganglionic parasympathetic denervation of a parotid gland. From the contralateral, 
normal gland there was no flow of saliva. This is the ordinary finding in cats under chloralose anaesthesia.

During a period of activity the flow is not constant in rate but occurs in bursts, and this type of secretion has therefore been termed "paroxysmal". A drop forming slowly at the tip of the cannula in the parotid duct can be seen to increase suddenly in size and sometimes to fall quickly; after a short time the flow subsides and the drop forms slowly again until another sudden burst occurs. The start of a paroxysm is in most instances readily discernible, and it can then be seen that the bursts appear at remarkably regular intervals, usually of about one minute.

When the auriculo-temporal nerves are divided at the same time on both sides one to three days in advance it is found that the paroxysmal secretion of one gland occurs independently of that of the other. This suggests that the secretion results from local events rather than from general changes, such as in the composition of the blood. Cocaine injected into the duct towards the gland in a dose which does not affect the secretory response to intravenous acetylcholine abolishes the paroxysmal secretion. It can therefore be concluded that the secretion is of nervous origin. Since it is increased by eserine and abolished by atropine, the nerves concerned must be assumed to be cholinergic. It is reasonable to suppose that the secretion is caused by some activity in the degenerating postganglionic fibres. It might be supposed that bursts of impulses originating from the cut ends of the nerves elicit the paroxysms of secretion. This is, however, disproved by the findings that the secretion is not abolished when a piece of the degenerating nerve stump is cut off in an acute experiment nor when a local anaesthetic is applied to the stump. A possible explanation may be that a leakage of acetylcholine, normally occurring at a regular rate from the postganglionic parasympathetic terminals, during degeneration of the fibres occurs less regularly, in bursts, so that a concentration of acetylcholine is sometimes reached which is big enough to cause a secretion.

\section{REFERENCES}

BERNARD, C. (1862). Recherches expérimentales sur les ganglions du grand sympathique. C.R. Acad. Sci., 55, 34 I-350. 
BERNARD, C. (1864). Du rôle des action réflexes paralysantes dans le phénomène des sécrétions. F. Anat., Paris, I, 507-513.

BIDDER, F. (I 867). Weitere Untersuchungen über die Nerven der Glandula submaxillaris des Hundes. Arch.f. Anat., Physiol. u. wissensch. Med., I-30.

BRADFORD, J. R. (1888). Some points in the physiology of gland nerves. F. Physiol., 9, 287-316.

ChANG, H. C. and J. H. GADDUM (1933). Choline esters in tissue extracts. F. Physiol., 79, 255-285.

DIRNHUBER, P. and C. L. EVANS (1954). The effects of anticholinesteràses on humoral transmission in the submaxillary gland. Brit. F. Pharmacol., 9, $44 \mathrm{I}-458$.

Emmelin, N. (1952a). "Paralytic secretion" of saliva. An example of supersensitivity after denervation. Physiol. Rev., 32, 2 I-46.

- $(1952 b)$. On the mechanism of paralytic secretion. Acta physiol. scand., $26,232-242$.

- (1953a). On spontaneous secretion of saliva. Acta physiol. scand., 30, Suppl. I I I, 34-58.

- $(1953 b)$. Sensitization of parasympathetic ganglia by denervation. Acta physiol. scand., 30, Suppl. I I I, 59-64.

- (1956). Sensitization of salivary glands by denervation. XXth Int. Physiol. Cong. Brussels, Abstracts of Communications, 269270.

- (1959). Supersensitivity due to prolonged administration of ganglionblocking compounds. Brit. F. Pharmacol., I4, 229-233.

- (1 $960 a)$. Supersensitivity of the submaxillary gland following exclusion of the postganglionic parasympathetic neurone. Brit. F. Pharmacol., I5, 356-36o.

- $(1960 b)$. Is there a leakage of acetylcholine from postganglionic parasympathetic nerve endings? Nature, $\mathbf{1 8 5}, 297-298$.

EMMELIN, N. and J. ENGSTRÖM (I960). Effect of sympathetic denervation on the sensitivity of the submaxillary gland to stimulating agents. F. Physiol., 153, 9-16.

EMMELIN, N. and K. G. HENRIKSSON (1953). Depressor activity of saliva after section of the chorda tympani. Acta physiol. scand., 30, Suppl. I I I, 75-82.

EMMELIN, N., D. JACOBSOHN and A. MUREN (I95I). Effects of prolonged administration of atropine and pilocarpine on the submaxillary gland of the cat. Acta physiol. scand., 24, 128-143.

EMmelin, N., L. MALM and B. C. R. STRöMblad (I960). Effect of denervation on the maximal secretory capacity of salivary glands. Quart. $\mathcal{F}$. exp. Physiol., 45, 349-35I.

EMMELIN, N. and A. MUREN (I95०a). Supersensitivity of denervated organs to chemical stimuli. Nature, $\mathbf{1 6 6 , 6} 6$ io.

- - (1950b). "Paralytic" secretion of saliva. Acta physiol. scand., 21, $362-379$.

- - ( $195 \mathrm{I} a)$. Sensitization of the submaxillary gland to chemical stimuli. Acta physiol. scand., 24, 103-127.

- - ( $95 \mathrm{I} b)$. Paralytic secretion in cats after treatment with atropine. Acta physiol. scand., 22, 277-280.

- - (1952). The sensitivity of submaxillary glands to chemical agents studied in cats under various conditions over long periods. Acta physiol. scand., 26, 22 I-23I. 
EMMELIN, N., A. MUREN and R. STRÖMBLAD (I 957a). Effect of anastomosis between the hypoglossal and chorda-lingual nerves on the supersensitivity of the denervated submaxillary gland. Acta physiol. scand., 4I, I 8-34.

- - - (1957b). Effect of anastomosis between the hypoglossal and sympathetic nerves on the supersensitivity of the denervated submaxillary gland. Acta physiol. scand., 4I, 35-48.

EMMELIN, N. and R. STRÖMBLAD (I953). Salivary secretion after section of the chorda tympani in non-anaesthetized dogs. Acta physiol. scand., 30, Suppl. III, $65-74$.

- - (1957). A transient, periodic secretion from the parotid gland after postganglionic, parasympathetic denervation. F. Physiol., r40, $21-22 P$.

EMMELIN, N. and B. C. R. STRÖMBLAD (I958). A "paroxysmal" secretion of saliva following parasympathetic denervation of the parotid gland. J. Physiol., I43, 506-5 I4.

EULER, U. S. and A. PURKHOLD (I95I). Effect of sympathetic denervation on the noradrenaline and adrenaline content of the spleen, kidney and salivary glands in the sheep. Acta physiol. scand., 24, 212-217.

FLEMING, A. J. and F. C. MAcINTOSH (I935). The effect of sympathetic stimulation and of autonomic drugs on the paralytic submaxillary gland of the cat. Quart. F. exp. Physiol., 25, 207-2 I 2.

GERHARDT, U. (I 903). Ueber histologische Veränderungen in den Speicheldrüsen nach Durchschneidung der secretorischen Nerven. Arch. ges. Physiol., 97, 317-334.

GRAHAM, A. R. and G. W. STAVRAKY (I95I). Difference in response of normal and chronically denervated submaxillary gland of cat to acetylcholine. Fed. Proc., ro, 301.

- - (I954). The response of the chronically denervated submaxillary gland to acetylcholine and to adrenaline. Rev. canad. Biol., r3, I 20-I 43 .

HEIDENHAIN, R. (i 868). Die ohne nachweisbare Erregung der Nerven stattfindende Absonderung der Gld. submaxillaris. Leipzig. Stud. physiol. Inst. Breslau, 73-83.

JUNQUEIRA, L. C. U. (I95I). Cytological, cytochemical and biochemical observations on secreting and resting salivary glands. Exp. Cell Res., $2,327-338$.

KAHLSON, G. and S. RENVALl ( 1956). Atrophy of salivary gland following adrenalectomy or hypophysectomy and the effect of DOCA in cats. Acta physiol. scand., 37, I 50-I 58.

Krause, R. (1 897). Beiträge zur Histologie der Speicheldrüsen. Arch. mikr. Anat., 49, 707-769.

Langley, J. N. (I885a). The "paralytic" secretion of saliva. Proc. Roy'. Soc. B., 236, 212-215.

- $\left(\mathrm{r} 88_{5} b\right)$. On the physiology of the salivary secretion. Part III. The "paralytic" secretion of saliva. F. Physiol., 6, 7 I-92.

Macintosh, F. C. (I937). Choline-esterase content of normal and denervated submaxillary gland of the cat. Proc. Soc. exp. Biol., N.Y., 37 , 248-25I.

MAEvSKY, W. E. (I 923). See Babkin, B. P. Secretory mechanism of the digestive glands, 2nd ed. Hoeber, New York.

maximow, A. (I90I). Beiträge zur Histologie und Physiologie der Speicheldrüsen. Arch. mikr. Anat., 58, I-I34. 
NORDENFELT, I. and P. OHLIN (1957). Supersensitivity of salivary glands of rabbits. Acta physiol. scand., 41, 12-17.

NORDENFELT, I., P. OHLIN and B. C. R. STRÖMBLAD (1960). Effect of denervation on respiratory enzymes in salivary glands. $\mathcal{F}$. Physiol., r52, 99-107.

OHLIN, P. and B. C. R. STRÖMBLAD (I958). Supersensitivity of the vessels of the parotid gland after denervation. Brit. $\mathcal{F}$. Pharmacol., r3, 227-230.

PIERCE, F. R. and M. I. GREgersen (I937). Changes in the submaxillary secretory response to pilocarpine after section of the chorda tympani. Amer. F. Physiol., 120, 246-256.

RAWLINSON, H. E. (1935a). The changes in the cells of the striated ducts of the cat's submaxillary gland after autonomic stimulation and nerve section. Anat. Rec., 63, 295-3ro.

- $(1935 b)$. The changes in the alveolar and demilune cells of the simple and the stimulated paralytic submaxillary gland of the cat. $\mathcal{F}$. Anat., 70, $143-148$.

SIMEONE, F. A. and J. P. MAES (1939). Sensitization of submaxillary gland by sympathetic denervation. Amer. F. Physiol., r25, 674-679.

STRÖMBLAD, R. (I $955 a$ ). Acetylcholine inactivation and acetylcholine sensitivity in denervated salivary glands. Acta physiol. scand., 34, 38-58.

- $\left(1955^{b}\right)$. Sensitivity of the normal and denervated parotid gland to chemical agents. Acta physiol. scand., 33, 83-98.

STRÖMBLAD, B. C. R. (1956a). Acetylcholine splitting enzymes in salivary glands after prolonged treatment with pilocarpine and an atropinelike substance. Acta physiol. scand., 36, 47-65.

- (1956b). Amine oxidase in salivary glands after prolonged treatment with pilocarpine or an atropine-like substance. Acta physiol. scand., 36, г 58-1 70 .

- $(1956 c)$. Supersensitivity and amine oxidase activity in denervated salivary glands. Acta physiol. scand., 36, I37-1 53.

- (1 $956 d)$. Experiments on supersensitivity and the activity of cholinesterase and amine oxidase in denervated salivary glands. Berlingska, Lund.

- (r 956e). Tyramine as a secretory agent in the submaxillary gland of the cat. Acta physiol. scand., 36, I 54-1 57.

- (r957a). Oxygen consumption of the normal and denervated submaxillary gland in vitro. Acta physiol. scand., 40, I30-I 45.

- $(1957 b)$. Supersensitivity caused by denervation and by cholinesterase inhibitors. Acta physiol. scand., 41, I I 8-1 38 .

- (1959). Gaseous metabolism of the normal and denervated submaxillary gland of the cat. $\mathcal{F}$. Physiol., r45, 55 I-56r .

Wills, J. H. (1942). Sensitization of the submaxillary gland to acetylcholine by section of the chorda tympani. Amer. $\mathcal{F}$. Physiol., r35, $523-525$. 


\section{BLOOD FLOW AND SECRETION}

The intimate relationship between the supply of blood and the production of saliva will be the subject of the present chapter. The following examples may serve as illustrations of the problem. Stimulation of the chorda tympani in cats and dogs causes a lively secretion and a vasodilatation in the submaxillary gland. Stimulation of the sympathetic of dogs causes a scanty flow of saliva from this gland, richer in organic material than chorda saliva. 'The predominant vascular response is constriction. In cats, on the other hand, there is usually an abundant flow of saliva, more dilute than chorda saliva, and vasodilatation replaces or alternates with constriction. Is the secretory activity during chorda stimulation responsible for the intense vasodilatation, or is it the excitation of vasodilator fibres, simultaneously with the secretory fibres, which makes the rapid, steady flow of saliva possible? Are the vasomotor fibres of the dog's sympathetic exclusively constrictors, which by an intense action prevent the secretion of anything but a small amount of concentrated saliva, and is the lively secretion of dilute saliva in cats rendered possible by the existence of specific vasodilator fibres in the sympathetic; or is the secretory innervation more extensive in the cat's gland than in the dog's, and is therefore a vasodilatation, secondary to the secretion, more marked in the former species?

Generally it may be said that differences in composition and amount of parasympathetic and sympathetic saliva cannot be due solely to vascular factors. On the contrary, it seems highly probable that even the single salivary cell can deliver samples of saliva of different composition according to the nature of the transmitter acting upon it, and with the same supply of blood. There is, on the other hand, no doubt that variations in the flow of blood may affect the rate of secretion and the chemical composition of the saliva obtained. The amount of blood available is judged either from the arterial inflow into the gland or, more often, from the venous outflow. It would, of course, be more important to know the quantities of blood placed at the disposal of the different 
components of the secretory apparatus under various conditions. Unfortunately, little is known about this, much less than in the kidney. Arteriovenous anastomoses have been found in the salivary glands (Holzlöhner and Niessing, I936; Spanner, I937, 1942). It has been assumed that the striking increase in blood flow during chorda stimulation is mainly due to the opening up of these anastomoses, and that in the capillaries of the activated secretory alveoli the blood may even stagnate (Holzlöhner and Niessing, I936). The latter statement has, however, been disputed (v. Brücke and Zwiauer, I938). It may be that when the stimulation of the chorda starts, the flow of blood in these vessels momentarily slows down or even stops because fluid is lost to the saliva, and possibly also because the capacity of the vascular bed is suddenly increased through the activity of vasodilator nerves. Further work on the role of the arteriovenous anastomoses of the salivary glands is desirable. Some knowledge of the distribution of the blood within the parotid gland of the dog has recently been gained by Burgen and Seeman (1957). From studies on the iodide clearance of that gland these investigators concluded that the rate of blood flow through the capillaries enveloping the ducts is very high and that the blood perfusing the ducts also perfuses the acini through a portal system. For the present, however, it seems necessary to resort to estimations of the total flow of blood through the gland when investigating the effect of variations of the blood supply on the secretion.

In the following the various types of vasomotor fibres assumed to innervate the salivary glands will be discussed separately; in the different sections examples of the interaction between secretion and blood flow will be given.

\section{SYMPATHETIC VASOCONSTRICTORS}

The presence of sympathetic vasoconstrictor fibres for the salivary glands has been recognized since the time of Claude Bernard. In his classical experiments on the blood flow through the submaxillary gland of the dog ( 1858$)$ he demonstrated that the venous blood emerging from the gland turned brighter and flowed quicker when the sympathetic trunk was cut in the neck; a permanent vasoconstrictor tone in the gland was thus discovered. When the peripheral stump of the nerve was stimulated the blood became dark and the flow decreased or ceased completely. 
In many glands the effect of sympathetic stimulation can be seen directly on the exposed gland. When the nerve is excited the gland loses its rosy colour and becomes pale. In some glands, such as the submaxillary gland of the cat, the constriction is usually not maintained on continued stimulation. The same is true for the secretory response, as discussed in Chapter III. In Fig. 3.7 it was shown that the vanishing of the secretory effect to some extent was due to the vasoconstriction, since it could be postponed by blocking the constrictor action with priscol; but the main reason for the cessation of the secretion was probably shortage of mediator at the high rate of stimulation mostly used. Such a mechanism cannot explain the interruption of the constriction on continued sympathetic stimulation. It is closely related to the secretory response; when this has died away the constriction may reappear. In the dog submaxillary gland, in which the secretory effect of sympathetic stimulation is much smaller than in the cat, the constriction is much better retained. The secretory effect may be abolished in the cat by the administration of chlorpromazine in suitable dose (Emmelin, 1955a); the vasoconstriction is then more pronounced and can be maintained for a long time. The ordinary disappearance of the constriction in the cat submaxillary gland, therefore, seems to be the result of a strong vasodilator action accompanying the secretion. If the sympathetic trunk is stimulated at a low frequency, the secretory response is small and a wellmaintained constriction is obtained, similar to that kept up in the gland with an intact sympathetic supply.

The constriction elicited by sympathetic stimulation is counteracted by the vasodilatation produced by chorda stimulation, even in the presence of atropine. In some cases no constriction can then be seen; it may be possible, in those instances, to get a constriction by abolishing the vasodilator component of the sympathetic by injecting chlorpromazine. Usually, however, the sympathetic is able to exert some constrictor effect during chorda stimulation. The effect of constriction on the salivary flow induced by chorda stimulation when no atropine is present can then be studied. It is shown in Fig. 7.I which summarizes experiences made by numerous investigators. Stimulation of the chorda causes a quick flow of saliva and a marked vasodilatation. When sympathetic stimulation is added, the flow of blood diminishes, and the secretion as well. Some early investigators have taken such 

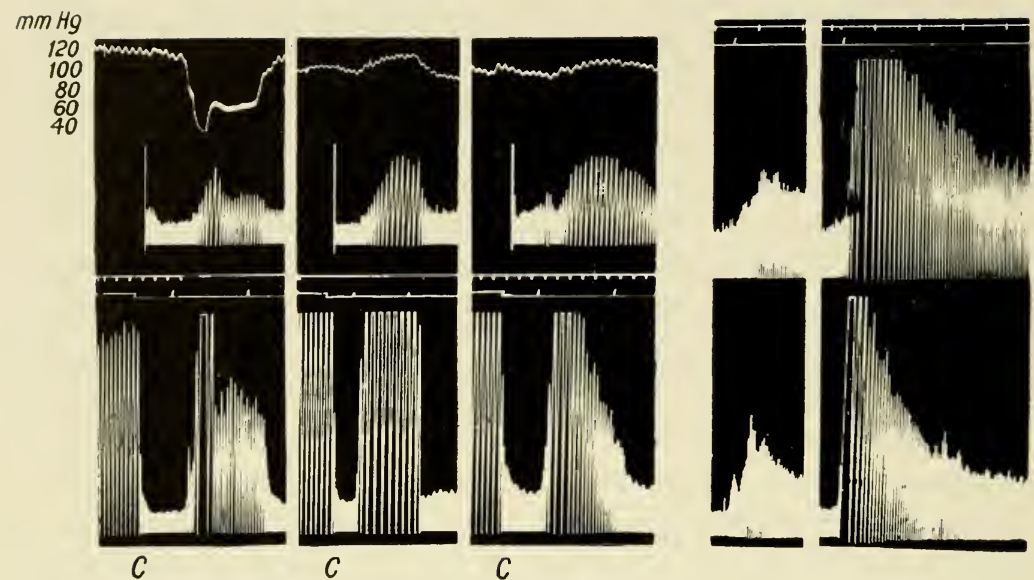

FIG. 7.1. The effect of diminished blood supply on submaxillary secretion evoked by chorda stimulation at maximal rate.

Two different experiments are shown, the first three sections of the tracing being from one cat, and the two last sections from another. Records of blood flow (lowermost) and secretion (above) using ordinate recorders. Time marks: minutes. $C$ marks the point where chorda stimulation starts to continue for the rest of the period shown in each section.

First section: Between the two marks of the signal the peripheral stump of the right vagus was stimulated.

Second section: The carotid artery was clamped.

Third section: Sympathetic stimulated.

In the second experiment the chorda was stimulated for the whole period shown. The first signal marks the injection of 0.2 I.U. of pitressin, and the second $0.3 \mathrm{I}$.U. given close arterially via the lingual artery (Emmelin, $1955 b$ ).

results as evidence for the existence of inhibitory secretory fibres in the sympathetic. That this is not so, but that the decreased secretion is secondary to the reduced supply of blood, is indicated by the fact, shown in the figure, that various other procedures which diminish the flow of blood through the gland have a similar effect on the rate of secretion. It might be suggested that the restricted flow in these instances favours the accumulation of acetylcholine to a concentration, sufficient to exert an inhibitory effect on the gland cells (Graham and Stavraky, I953) but it seems more reasonable to assume for instance lack of water for secretion or of oxygen as the decisive factor. The "inhibitory" action of sympathetic stimulation on the secretion is particularly easily obtained when the gland is secreting at a maximal rate.

In this connection an observation made by Denton (I957) is of particular interest. When a sheep supplied with a permanent parotid fistula was taken out of its cage and gently secured upon its side on the laboratory table the secretion from the parotid gland 
could be seen to stop completely for a considerable time. A contributing factor might be a central inhibition, reducing the flow of parasympathetic secretory impulses. 'This could, however, not cause a complete cessation of the flow of saliva, since the parotid gland of the sheep secretes spontaneously, even after denervation. The effect was largely abolished by extirpation of the superior cervical ganglion, and since the main effect of sympathetic stimulation on the sheep's parotid gland is a vasoconstriction (when the motor fibres have exerted their expelling action) the phenomenon must be interpreted as due chiefly to a sympathetic vasoconstriction. Vasoconstriction may thus affect salivary secretion even in a non-anaesthetized animal under fairly physiological conditions.

\section{PARASYMPATHETIC VASOCONSTRICTORS}

Although the ordinary vascular effect of chorda stimulation is a very striking vasodilatation, some investigators have made observations from which they have inferred that the nerve contains vasoconstrictor fibres. Fröhlich and Loewi (1906) found in decerebrate cats that stimulation of the chorda diminished the venous outflow from the submaxillary gland provided that sodium nitrite had been given intravenously or amyl nitrite into the trachea; this effect was abolished by atropine. Their conclusion was that the nitrites in some way put the dilator fibres of the chorda out of action and that thereby the presence of constrictors can be revealed. Dale (1930) repeated the experiment and saw the same effect of chorda stimulation after nitrites, contrary to Bayliss (I908a); he found it unlikely, however, that the nitrites would have a specific action on the vasodilators, since lowering of the vascular tone by other means, such as hyperventilation or injection of histamine affected the chorda response in the same direction as nitrites. The diminished venous outflow during chorda stimulation under these conditions could, according to Dale, be accounted for by loss of fluid from the blood to the saliva. The observation that the phenomenon was not found after atropine was, of course, compatible with this explanation also.

Carlson, Greer and Becht (I907), studying the effect of restricted blood supply on the composition of chorda saliva, had in fact observed that chorda stimulation was followed by a diminished venous outflow when the artery of the submaxillary gland was compressed. This effect was, however, not explained as an action 
of vasoconstrictor fibres but attributed to loss of water into the saliva and particularly to the action of vasodilator fibres; with a restricted arterial flow the first effect of the lowered arteriolar tone would be to diminish the venous outflow.

Experiments by Graham and Stavraky (1953) show, however, that under certain conditions a vasoconstriction can be obtained on chorda stimulation. Whether a dilatation or a constriction will be obtained when the chorda is excited depends, according to these investigators, on the concentration of acetylcholine acting on the vessels. A small dose of acetylcholine, injected intra-arterially towards the gland, causes a dilatation, a big dose constriction. When eserine has been given, even a small dose of acetylcholine could cause a constriction. Similarly, after eserine or a big dose of acetyl-
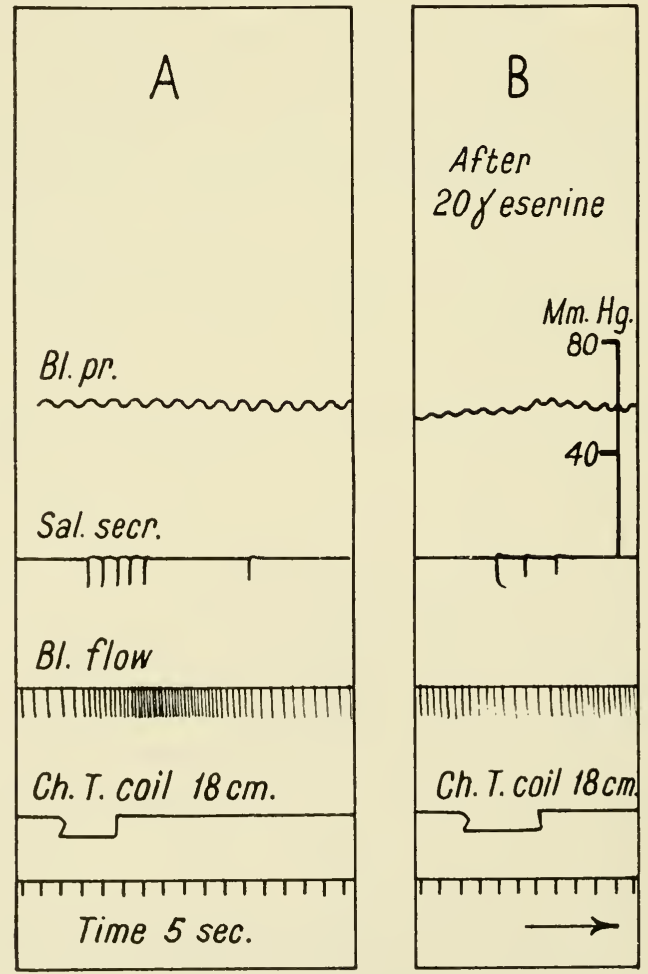

FIG. 7.2. Reversal of the response of the submaxillary gland of a cat to stimulation of the chorda tympani (Ch.T.) by the intra-arterial injection of eserine.

In $A$ stimulation resulted in vasodilatation and secretion, in $B, 2$ minutes after eserinization, stimulation led to vasoconstriction and a reduced secretory response (Graham and Stavraky, 1953). 
choline, chorda stimulation may diminish the venous outflow. Fig. 7.2 shows one of the experiments of Graham and Stavraky. Stimulation of the chorda increased the venous outflow before, but decreased it after the intra-arterial injection of eserine. 'The "reversal" was particularly marked when the blood pressure was low. Nevertheless, the diminished venous outflow could not be due to the factors discussed by Carlson et al. and by Dale, for control experiments showed that the arterial inflow was similarly diminished. The effect was therefore attributed to a vasoconstriction, and numerous instances of other organs in which acetylcholine causes dilatation in low, and constriction in high concentration, were quoted from the literature.

It may thus be said that it is possible to elicit a vasoconstriction by stimulating the chorda; but there is little evidence to show that the chorda contains nerve fibres, the normal function of which is to cause a vasoconstriction. The fibres causing the constriction in the experiments of Graham and Stavraky may have been the secretory fibres, or fibres which ordinarily cause vasodilatation, or both.

\section{PARASYMPATHETIC VASODILATORS}

When Claude Bernard (1858) instilled some vinegar into the mouth of a dog he observed that the dark blood emerging from the submaxillary gland quickly became brighter; this he assumed to be due to a gustatory reflex, the efferent pathway being the chorda tympani, since the response was not obtained when that nerve had been cut. Stimulation of the distal end of the cut nerve gave the same change in colour, and when the vein of the gland was cut open it could be seen that the blood flowed at a much higher speed and could even show pulsations. The effect of the chorda stimulation was obviously to dilate the vessels of the gland to such an extent that the blood passed into the veins "sans perdre l'impulsion cardiaque".

When the rate of blood flow was measured, chorda stimulation was found to cause a fourfold increase. Some later investigators have described a much bigger augmentation. 'The outcome probably depends, among other things, on whether the sympathetic constrictor tone has been abolished or not. Even when the sympathetic has been cut, chorda stimulation will cause a considerable increase in the blood flow. The chorda, on the other hand, seems 
to exert no permanent dilator action in the gland, at least in the anaesthetized animal, for section of that nerve does not diminish the flow of blood, even when the sympathetic constrictors are intact.

Ever since the experiment described, Claude Bernard has been regarded as the discoverer of a special type of nerve fibres, the vasodilators, and his experiment has belonged to the classroom demonstration repertoire, to show the action of such fibres. Nevertheless, the presence of dilator fibres in the chorda has repeatedly been questioned and is not considered as established by all investigators. The complicating factor is, of course, the secretion of saliva which is obtained concomitantly with the vasodilatation on stimulation of the chorda. It was early suggested that the vasodilatation might be secondary to the secretion, caused by metabolites possessing a vasodilator activity.

"The discovery that a vasodilatation can still be elicited when the secretion has been suppressed by atropine (Heidenhain, I 872) seemed to afford convincing proof of the existence of special vasodilator fibres until the investigations of Barcroft and his co-workers (Barcroft, I9I4) disclosed that stimulation of the chorda may increase the metabolism of the gland even under these conditions. Barcroft came to the conclusion that the dilatation in the submaxillary gland of the cat which appears during or after sympathetic stimulation is exclusively secondary to the secretion, a "functional dilatation". It was reasonable to assume a similar mechanism at work when the chorda is stimulated. Anrep and Cannan (I922) found chorda stimulation to raise the blood-sugar consumption of the submaxillary gland even after administration of a dose of atropine which abolished the secretory response.

Henderson and Loewi (1905) noticed that atropine diminishes the dilatation caused by chorda stimulation and suggested that the dilatation is in part due to some substance developed by the active salivary cells. Bayliss ( 1923 ) admitted that production of metabolites may aid in the dilatation observed during chorda stimulation but maintained that specific vasodilator fibres also contribute to the dilation. In support of this view he quoted Barcroft's figures in which he could find no correlation between the degree of dilatation and the increase in oxygen consumption. "Thus, a rog per cent increase in the latter coincides with a 488 per cent increase in the former in one case, while, in another case, a 50 per cent 
increase coincides with an increase in rate of blood flow in 812 per cent; that is, larger dilatation with a less consumption of oxygen." Recently Strömblad (1959) has, like Barcroft, found an increased oxygen consumption on stimulation of the chorda when the secretory response had been entirely prevented by atropine; there was no positive correlation between this increase and the increase in blood flow.

As a further argument suggesting that the chorda may supply the gland with vasodilator fibres, Bayliss pointed out that stimulation of the chorda causes a vasodilatation in the tongue even if the oxygen consumption is not increased (Anrep and Evans, 1920).

Dale and Gaddum (1930) accepted the view that the chorda contains vasodilators both for the tongue and the submaxillary gland and concluded that these fibres are cholinergic. Experiments by Bain (1933, 1936) and by Feldberg (1933) showed that acetylcholine is released in the tongue on stimulation of the chorda fibres. The fact that the dilatation in the gland, contrary to the secretion, was not abolished by atropine, whereas both actions elicited by injected acetylcholine were abolished, was supposed by Dale and Gaddum to be due to a release of the acetylcholine at the vasodilator endings in such great "intimacy with the receptive mechanism that atropine cannot prevent its access thereto".

In their investigations on the chemical transmission in the submaxillary gland Henderson and Roepke (1933) suggested another mode in which the vasodilatation could be secondary to activity in the secretory nerves. They found chorda stimulation to cause a release of acetylcholine even in the presence of atropine and pointed out that the vasodilatation obtained might be due to the transmitter diffusing from the terminals of the secretory fibres. In view of the fact that atropine abolishes the dilator effect of injected acetylcholine, this explanation seems rather unlikely.

On the other hand, Beznák (1934) who, likewise, demonstrated the release of acetylcholine in the submaxillary gland when the chorda was stimulated, postulated the existence of cholinergic vasodilator fibres and raised the question whether the secretion might be evoked by acetylcholine from the vasodilators. He came, however, to the conclusion that there are separate secretory and vasodilator fibres in the chorda. This view was based on the observation that secretion and dilatation could be elicited independently in the submaxillary gland of the dog. In the beginning P.S.G. - $\mathrm{K}$ 
of an experiment vasodilatation could be produced by weak stimulation of the chorda which did not cause any secretion. The experiments by Chauchard and Chauchard (1929) showing a different chronaxie for the secretory and the dilator response were quoted. Beznák made, in addition, some degeneration experiments and found that using stimuli of low intensity it was possible to get a secretion without dilatation when the chorda had been cut $3^{-9}$ days earlier.

The latter observation may seem surprising, for some kind of "functional dilatation" would be expected. As to the finding that vasodilatation could be elicited without secretion using a low intensity of stimulation this may be an analogy to the atropine experiment. It is conceivable that there are secretory fibres of different excitability, that activation of a small number of fibres by a weak stimulus may excite the gland cell (as shown in the electrical response, by Lundberg), without causing any secretion, and that a certain degree of summation, temporal or spatial, is required for the secretion to start. It would be interesting to repeat these experiments measuring the oxygen consumption of the gland at the same time. In order to accept the evidence for special vasodilator fibres it seems necessary to be able to elicit a pure vasodilator response, without any alterations in the secretory cells.

A possible approach might then be to try to elicit a reflex vasodilatation in the gland (when the cervical sympathetic trunk has been cut). Bayliss (I908b) found that a vasodilatation could be obtained in the submaxillary gland, after section of the sympathetic fibres, by stimulating the central end of the contralateral vagus. However, this cannot be used as an argument in the present discussion, since a secretion of saliva was sometimes obtained as well. Furthermore, Barcroft (I9I4) found that in those experiments in which he was able to obtain this reflex, there was at the same time an increase in the oxygen consumption of the gland. On the whole it seems improbable that it would be possible to elicit a reflex vasodilatation via the chorda without stimulating the gland cells even if vasodilator fibres do exist in it; for it is generally agreed that the function of parasympathetic vasodilators is to meet the local need for blood rather than to participate in general circulatory adjustments. 'The intimate connection between secretory and vasodilator fibres was illustrated in an investigation by Corbin, Harrison and Wigginton ( $194 \mathrm{I}$ ). These authors studied the "pseudo- 
motor contracture" in the tongue after previous section of the hypoglossal nerve. In order to elicit the contracture they stimulated the intramedullary portion of the seventh nerve and the reticular matter close to it, using a concentric bipolar electrode. Contractures were always accompanied by marked salivation; the glandular blood flow was not measured, but that of the tongue was recorded and found to increase at the same time. Judging from these experiments it seems unlikely that it would be possible to separate secretory and vascular effect by intramedullary stimulation.

A remarkable contribution to the discussion concerning the vasodilatation in the submaxillary gland was made by Ungar and Parrot (1936) in a paper, which apparently did not attract much attention at the time of its publication. These authors studied the vasodilator activity of saliva, then recently discovered and investigated by several research workers (Bellis and Scott, I933; Secker, I934; Feldberg and Guimarais, I935; Gibbs, I935; Larson, 1935). Ungar and Parrot found the activity to be due to kallikrein, described by Frey and Kraut (1928). Werle and Roden (I936) came to the same conclusion. The French investigators launched the hypothesis that kallikrein "jouait le rôle d'intermédiaire chimique dans la vasodilatation locale" during stimulation of the chorda.

Our knowledge of the vasodilatation in the submaxillary gland has been greatly widened by a series of investigations by Hilton and Lewis (1955 $a$ and $b, 195^{6}$ ). They found that the injection of botulinum toxin into the gland abolished simultaneously the secretory and vasodilator responses to chorda stimulation. Since this agent is assumed to paralyse preferentially cholinergic fibres they concluded that non-cholinergic fibres are not concerned in the vasodilatation. So far, their opinion is in agreement with that of Dale and Gaddum. Further experiments, however, led them to the conclusion that the agent causing the vasodilatation is not acetylcholine, set free from dilator fibres, but some more stable agent, produced or released in connection with the activity in the gland, even in the presence of atropine. Fig. $7 \cdot 3$ shows one of their experiments. It is apparent from this figure that the vasodilatation on stimulation of the chorda can be delayed by arterial occlusion; the same is true for the dilatation produced by injected acetylcholine. Venous occlusion, on the other hand, delays the dilator response only when the lymph drainage has been blocked. From 
these experiments it was concluded that the dilatation following chorda stimulation or injection of acetylcholine is caused by some fairly stable agent, which is normally eliminated by the lymph after having produced its effect. In agreement with this latter conclusion it was found that the agent could not be demonstrated in the venous blood. It was, however, shown to appear in the venous effluent during chorda stimulation in a gland perfused with Locke's solution. Such a perfusate was found to cause a vasodilatation when

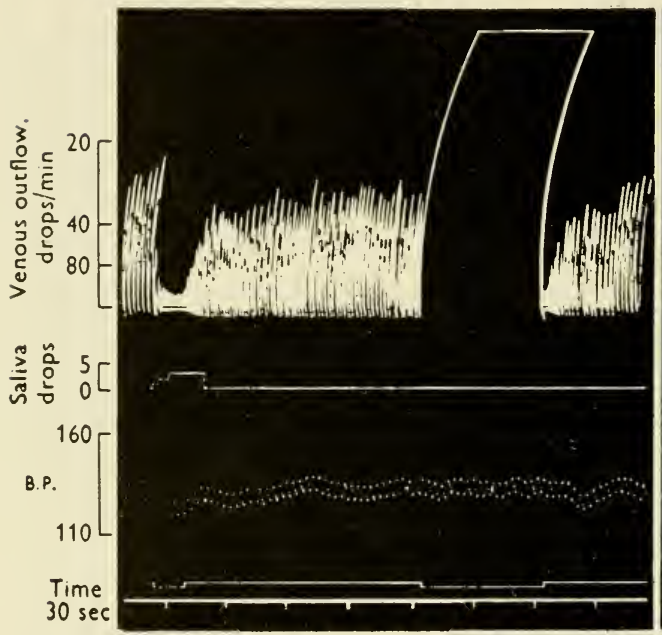

(a)

(b)

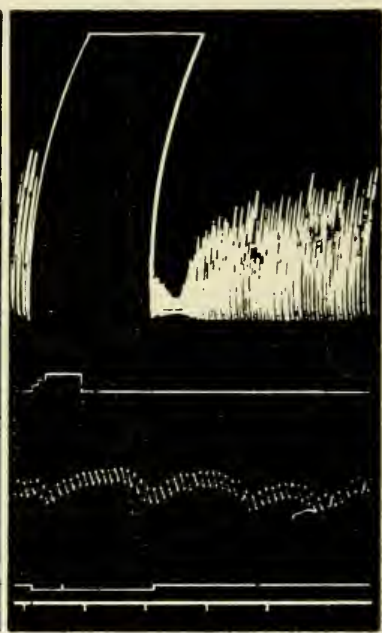

(c)

FIG. 7.3. Records of venous outflow from submaxillary gland of a cat, of secretion of saliva and arterial blood pressure.

Effect of stimulation of the chorda-lingual nerve for $\mathrm{I} 5$ seconds $(a)$, of arterial occlusion for I minute $(b)$, and of chorda stimulation for the first 15 seconds of I minute arterial occlusion (c) (Hilton and Lewis, I955a).

injected intra-arterially into a submaxillary gland with its normal blood supply; likewise, it caused a fall in blood pressure on intravenous injection. An important further step in the analysis depended on the observation that the venous perfusion sample, collected during chorda stimulation, had no effect on smooth muscle suspended in Tyrode solution but caused a contraction if previously incubated with plasma. This is illustrated in Fig. 7.4. Further experiments showed that the contraction obtained, and the vasodilatation as well, is due to the polypeptide bradykinin or kallidin of Rocha e Silva, Beraldo and Rosenfeld (1949) and Frey, Kraut and Werle (1950). 
From their experiments Hilton and Lewis concluded that the vasodilatation obtained on chorda stimulation, with or without atropine, or after injection of acetylcholine (with no atropine), is due to an intracellular enzyme, in itself without action on the blood vessels. Changes in the gland cells during activity lead to the escape of the enzyme into the interstitial fluid; there the enzyme acts upon protein to form the vasodilator polypeptide. This agent is then removed by the lymph. The enzyme can be detected in the saliva, and the vasodilator activity is, in fact, not

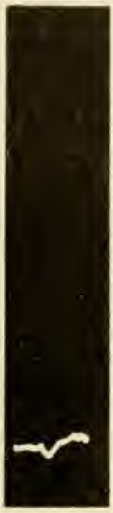

(a)

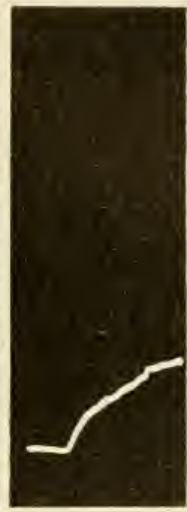

(b)

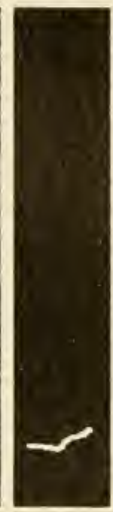

(c)

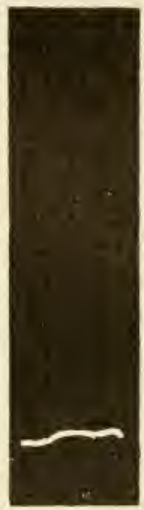

(d)

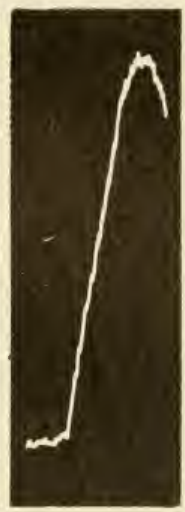

(e)

FIG. 7.4. Guinea-pig's ileum suspended in $15 \mathrm{ml}$. Tyrode solution.

Effects of $1 \mathrm{ml}$. perfusate from a submaxillary gland collected during 15 seconds chorda stimulation, alone $(a)$ and after I minute incubation with $0.2 \mathrm{ml}$. plasma $(b)$. Effect of $0.2 \mathrm{ml}$. plasma $(c)$ and of mixtures of $0.2 \mathrm{ml}$. plasma with a freeze-dried concentrate of perfusate (equivalent to $4 \mathrm{ml}$.) collected from a resting gland $(d)$ and from the gland during I minute chorda stimulation $(e)$ (Hilton and Lewis, 1955 b).

to be demonstrated unless the saliva has been in contact with protein to form bradykinin (kallidin).

Instead of a non-specified metabolite with a vasodilator action, the bradykinin-releasing enzyme, i.e. kallikrein, is considered to be the agent released from the activated gland cells. The "functional vasodilatation" of Barcroft seems thereby satisfactorily explained. We are still left with the problem how impulses in the chorda can, after administration of atropine, exert an action on the gland cells which injected acetylcholine cannot: increase the metabolism of the gland and release kallikrein, with a consequent vasodilatation. It may perhaps in addition be asked: is the evidence 
so far produced sufficient to disprove, beyond doubt, the existence of special vasodilator fibres in the chorda contributing to the vasodilatation, as assumed by Hilton and Lewis? 'The validity of the conclusions drawn from the botulinum toxin experiments depends on the specificity of this agent in paralysing cholinergic fibres. Further, the delayed vasodilatation after arterial occlusion indicates that a stable vasodilator agent appears when the gland cells are excited by chorda stimulation or injected acetylcholine; but they do not exclude the possibility that in addition injected acetylcholine, or acetylcholine released from dilator endings in such a way as not to be antagonized by atropine, has a vasodilator action of its own even if via kallikrein. There are some observations which suggest that the blood vessels of the submaxillary gland do have a supply of parasympathetic fibres. Histological investigations show that after degeneration of the sympathetic fibres there are still nerve fibres left in relation to the vessels of the submaxillary gland of the rat (Glimstedt and Hillarp, 1942) and of the cat, dog and monkey (Kuntz and Richins, I946). The words of Barcroft in his monograph The respiratory function of the blood (I9I4) may still be applicable to the problem: "The answer then to the question, 'Is it possible to demonstrate that the vaso-dilatation which follows upon stimulation of the chorda tympani involves a definite neuro-muscular vaso-dilator mechanism?' is 'It is not possible on the evidence at hand either to prove or disprove it'. The functional dilatation involved may be held to account for all known cases of dilatation in the submaxillary, but it is not proved to do so.-It is not impossible that under normal circumstances dilatation may be instituted by dilator fibres and maintained by metabolic products."

The latest contribution to the discussion comes from Terroux, Sekelj and Burgen (I959). They estimated simultaneously the rate of secretion, of blood flow and of oxygen consumption in submaxillary glands of dogs. The effects of varying the frequency of stimulation of the chorda and of atropinization were studied. During secretory activity there was an approximately linear relationship between the rate of saliva flow and the extra oxygen consumption, but a poor correlation between oxygen consumption and blood flow. Atropine depressed both the rate of saliva flow and the extra oxygen consumption associated with it, in doses which had no effect on the vasodilator response; compared with the response to iden- 
tical stimulation before atropine, oxygen consumption fell in parallel with the decrease in secretion rate, while the increased blood flow was as great as or greater than before. The enhanced effect of stimulation on the blood flow after atropine was explained by the lack of haemoconcentration when no secretion occurred. From this investigation the following conclusions were drawn: "the vasodilator responses of the gland are not secondary to the secretory metabolism. The metabolic and vasodilator responses can be dissociated with atropine, showing that atropine can preferentially enter those receptor sites in the structure of the gland associated with the secretory response. Dale and Gaddum came to the same conclusion."

\section{SYMPATHETIC VASODILATORS}

The usually pronounced vasodilatation seen in the submaxillary gland of the cat on stimulation of the sympathetic trunk in the neck induced Carlson (1907) to assume that vasodilator fibres are excited. Barcroft (I907, I9I4), on the other hand, produced evidence to show that the dilatation, obtained on sympathetic stimulation, is due to vasodilator metabolites. Ergotoxine had been shown by Dale (1906) to abolish the effect of stimulation of sympathetic vasoconstrictors but not of the dilators assumed to be present in the chorda tympani. Barcroft found the sympathetic vasodilatation to disappear, and the secretion as well, after the administration of ergotoxine. When adrenaline was injected, to imitate sympathetic stimulation, it was shown to increase the oxygen consumption of the gland; there was a parallelism between this increase and the vasodilatation (Barcroft and Piper, I9I2). Adrenaline could be deprived of its secretory effect by perfusing the gland a couple of hours after the death of the animal with saline; the vasodilator effect was, likewise, lost and the only response was a vasoconstriction.

It is, on the whole, striking that the sympathetic vasodilatation, contrary to the constriction, is closely linked to the secretion and cannot be separated from it (Emmelin, I955a). By injecting chlorpromazine it is possible to abolish both the secretion and the dilatation with the constriction retained. A small dose of the drug may only reduce the secretory response; this is true for the vasodilatation also. When the effect of a bigger dose is wearing off, the two effects return concomitantly. In an exceptional cat, in 
which sympathetic stimulation did not cause any secretion, vasoconstriction was the only vasomotor effect obtained. Priscol, on the other hand, reduces the sympathetic constriction, leaving the secretion; the vasodilatation is, likewise, retained. When this drug has been given vasoconstriction does not interfere with the dilatation, which is then obtained early in the stimulation period; the ordinary, characteristic vasodilatation when the sympathetic stimulation is discontinued, and which is sometimes as pronounced as during chorda stimulation, is not obtained after priscol.

All these observations are compatible with the view that the sympathetic dilatation is secondary to the secretion and due to some vasodilator agent appearing during glandular activity. The constrictor response obtained shortly after the start of a stimulation period favours the accumulation of the agent and the constriction diminishes; there may even temporarily be a period of marked dilatation. If so, the dilator agent is quickly removed and constriction again gets the upper hand. In this way, periods of constriction and dilatation may sometimes alternate. On cessation of stimulation the dilator agent, unopposed by constrictor impulses, causes a marked dilatation. After priscol, however, the constrictor fibres are without effect and the agent is able to guarantee an adequate blood supply during the stimulation period already, and there is no marked reactive hyperaemia afterwards.

Experiments by Hilton and Lewis (1956) suggest that the functional dilatation during sympathetic stimulation is due to the formation of a bradykinin-like agent.

In some cats there is evidence suggesting the presence of vasodilator fibres for the submaxillary gland in the sympathetic trunk (Emmelin, 1955a). The dilatation was in these instances obtained very early in the stimulation period and came to light when both secretion and constriction had been abolished by a sympathicolytic agent. This effect was not abolished by atropine.

\section{REFERENCES}

ANREP, G. V. and R. K. CANNAN (1922). The metabolism of the salivary glands. III. The blood sugar metabolism of the submaxillary gland. F. Physiol., 57, I-6.

ANREP, G. V. and C. L. EVANS ( 1920 ). The mode of action of vaso-dilator nerves. F. Physiol., 54, $\mathrm{x}-\mathrm{xi}$. 
BAIN, W. A. (1933). 'The mode of action of vasodilator and vasoconstrictor nerves. Quart. F. exp. Physiol., 23, 38I-389.

- (1936). The mode of action of vasodilator nerve. F. Physiol., 86, 33 $34 P$.

BARCROFT, J. (1907). The velocity and nature of the blood emerging from the submaxillary gland of the cat during stimulation of the cervical sympathetic nerve. F. Physiol., 35, 29-30P.

- (1914). The respiratory function of the blood. Cambridge University Press.

BARCROFT, J. and H. PIPER (I9I2). The gaseous metabolism of the submaxillary gland with reference especially to the effect of adrenalin and the time relation of the stimulus to the oxidation process. $\mathcal{F}$. Physiol., 44, 359-373.

BAYLISS, W. M. (1908a). Note on the supposed existence of vasoconstrictor fibres in the chorda tympani nerve. F. Physiol., 37, 256-263.

- $(1908 b)$. The excitation of the vaso-dilator nerve-fibres in depressor reflexes. F. Physiol., 37, 264-277.

- (1923). The vaso-motor system. London.

BELLIS, C. J. and F. H. SCOTT (i 933). Saliva and coagulation of blood. Proc. Soc. exp. Biol., N.Y., 30, 1373-1375.

BERNARD, C. ( 1858 ). De l'influence de deux ordres de nerfs qui déterminent les variations de couleur du sang veineux dans les organes glandulaires. C.R. Acad. Sci., 47, 245-253.

BEZNÁK, A. (1934). Zur Frage der Existenz gesonderter sekretorischer und vasodilatatorischer Fasern auf Grund der autakoiden Tätigkeit der Chorda tympani. Arch. ges. Physiol., 233, I 55-159.

BRÜCKE, E. T. and A. ZWIAUER (1938). Ueber den Blutstrom in den Capillaren der ruhenden und tätigen Speicheldrüse. Fiziol. Zhur., 24, 78-85. Quoted from Ber. ges. Physiol., 1938, 107, 582.

BURGEN, A. S. v. and P. SEEMAN (1957). The secretion of iodide in saliva. Can. F. Biochem. Physiol., 35, 481-489.

CARLSON, A. J. (1907). Vaso-dilator fibres to the submaxillary gland in the cervical sympathetic of the cat. Amer. F. Physiol., 19, 4084 I 6.

CARLSON, A. J., J. R. GREER and F. C. BECHT (I 907). The relation between the blood supply to the submaxillary gland and the character of the chorda and the sympathetic saliva in the dog and the cat. Amer. $\mathcal{F}$. Physiol., 20, 180-205.

CHAUCHARD, A. and B. CHAUCHARD (I929). Étude comparative de l'excitabilité des fibres sécrétoires et des fibres vaso-dilatatrices de la corde du tympan. C.R. Soc. Biol., Paris, roo, 825-826.

CORBIN, K. B., F. HARRISON and C. WIGGINTON (I94I). Elicitation of the "pseudomotor contracture" in the tongue by intramedullary stimulation. Arch. Neurol. Psychiat., 45, 271-281.

DALE, A. S. (1930). A reversed action of the chorda tympani on the venous outflow from the submaxillary gland. F. Physiol., 70, 449-454.

DALE, H. H. (1 906). On some physiological actions of ergot. F. Physiol., 34, I $63-206$.

DALE, H. H. and J. H. GADDUM (I930). Reactions of denervated voluntary muscle, and their bearing on the mode of action of parasympathetic and related nerves. F. Physiol., 70, 109-144.

DENTON, D. A. (I957). A gregarious factor in the natural conditioned salivary reflexes of sheep. Nature, I79, 34 I-344. 
EMmelin, N. (1955a). Sympathicolytic agents used to separate secretory and vascular effects of sympathetic stimulation in the submaxillary gland. Acta physiol. scand., 34, 29-37.

- $(1955 b)$. Blood flow and rate of secretion in the submaxillary gland. Acta physiol. scand., 34, 22-28.

FELDBERG, W. (1933). Der Nachweis eines acetylcholinähnlichen Stoffes im Zungenvenenblut des Hundes bei Reizung des Nervus lingualis. Arch. ges. Physiol., 232, 88-104.

FELDBERG, W. and J. A. GUIMARAIS (1935). Some observations on salivary secretion. F. Physiol., 85, i 5-36.

FREY, E. K. and H. KRAUT (I928). Ein neues Kreislaufhormon und seine Wirkung. Arch. exp. Path. Pharmak., 133, 1-56.

FREY, E. K., H. KRAUT and E. WERLE (1950). Kallikrein. Enke, Stuttgart. FRÖHLICH, A. and O. LOEWI (I906). Ueber vasokonstriktorische Fasern in der Chorda tympani. Zbl. Physiol., XX, 229-233.

GIBBS, O. S. (1935). On the alleged occurrence of acetylcholine in the saliva. F. Physiol., 84, 33-40.

GLIMSTEDT, G. and N.- $\AA$. HILLARP (1942). Ueber die Innervationsgebiete des Sympathikus und des Parasympathikus bei der Glandula submandibularis. Kungl. Fysiogr. Sällsk. Handl. N.F., 53, 3-38.

GRAHAM, A. R. and G. W. STAVRAKY (1953). Reversal of the effects of chorda tympani stimulation, and of acetylcholine and adrenaline, as seen in the submaxillary salivary gland of the cat. Rev. canad. Biol., Ir, 446-470.

heidenhain, R. (I 872). Ueber die Wirkung einiger Gifte auf die Nerven der glandula submaxillaris. Arch. ges. Physiol., 5, 309-3 I 8.

henderson, v. E. and O. LOEWI (1905). Ueber den Einfluss von Pilocarpin und Atropin auf die Durchblutung der Unterkieferspeicheldrüse. Arch. exp. Path. Pharmak., 53, 62-75.

HENDERSON, v. E. and M. H. ROEPKE (1933). Ueber den lokalen hormonalen Mechanismus der Parasympathikusreizung. Arch. exp. Path. Pharmak., 172, 314-324.

HILTON, S. M. and G. P. LEWIS (1955a). The cause of the vasodilatation accompanying activity in the submandibular salivary gland. $\mathcal{F}$. Physiol., 128, 235-248.

- - (1955b). The mechanism of the functional hyperaemia in the submandibular salivary gland. F. Physiol., 129, 253-271.

- - (1956). The relationship between glandular activity, bradykinin formation and functional vasodilatation in the submandibular salivary gland. F. Physiol., I34, 47 I-483.

HOLTZLÖHNER, E. and C. NIESSING (1936). Die Drüsentätigkeit bei Nervenreizung V. Lebendbeobachtungen an Zellen, Lymphspalten und Kapillaren der Unterkieferdrüse. Z. Biol., 97, 563-572.

KUNTZ, A. and C. A. RICHINS (1946). Components and distribution of the nerves of the parotid and submandibular glands. F. comp. Neurol., $85,21-32$.

LARSON, P. S. (I935). On the alleged occurrence of acetylcholine and adrenaline in cat's saliva. F. Pharmacol., 54, 34I-345.

ROCHA E SILVA, M., W. T. BERALDO and G. ROSENFELD (I 949). Bradykinin, a hypotensive and smooth muscle stimulating factor released from plasma globulin by snake venoms and by trypsin. Amer. F. Physiol., 156, 261-273.

SECKER, J. (I934). 'The humoral control of the secretion by the submaxil- 


\section{References}

lary gland of the cat following chorda stimulation. F. Physiol., 8x, $8 \mathrm{I}-92$.

SPANNER, R. (1937). Der Abkürzungskreislauf der Glandula submaxillaris. Z. Anat., 107, 124-153.

- (1942). Besonderheiten an der Gefässwand der grossen Mundspeicheldrüsen, sowie der Bauchspeicheldrüse. Morph. $\not b$., 87, I93-2 I 5 .

STRÖMBLAD, B. C. R. (I959). Gaseous metabolism of the normal and denervated submaxillary gland of the cat. Brit. F. Pharmacol., 145, 55 I$56 \mathrm{r}$.

TERROUX, K. G., P. SEKELJ and A. S. V. BURGEN (I 959). Oxygen consumption and blood flow in the submaxillary gland of the dog. Can. F. Biochem. Physiol., 37, 5-15.

UNGAR, G. and J.-L. PARROT (1936). Sur la présence de la callicréine dans la salive, et la possibilité de son intervention dans la transmission chimique de l'influx nerveux. C.R. Soc. Biol., Paris, 122, 1052-1055. WERLE, E. and P. RODEN (1936). Ueber das Vorkommen von Kallikrein in den Speicheldrüsen und im Mundspeichel. Biochem. Z., 286, 2 I3- $^{-}$ 219. 


\section{THE INORGANIC COMPONENTS OF SALIVA}

\section{SECRETION OF WATER}

While the secretion of water is considered in Chapter III in connection with the innervation of the salivary glands, it merits more detailed discussion here because it is the most abundant constituent of saliva. When parasympathetic nerve stimulation is commenced, the saliva flow appears with short latency-usually not more than a second - the secretion rate rapidly reaches a maximum and usually declines slightly to a plateau level and then falls off rather slowly during continued stimulation. (Fig. 8. I; Beznák and Farkas, I937; Maltesos and Weigmann, I939). The polyphasic curves obtained by Holtzlöhner (I93I) appear to be due to the use of unphysiologically high rates of nerve stimulation. In those few salivary glands with an active sympathetic secretomotor innervation, the secretion produced by sympathetic stimulation has usually a longer latent period and the rate of flow is less well maintained and rather high stimulation frequencies may be needed to produce any secretion at all. In the case of parasympathetic stimulation, the rate of secretion is nearly linearly related to rate of stimulation in both submaxillary and parotid glands (Fig. 8.2) up to a maximum rate which is reached at $10 \mathrm{c} / \mathrm{s}$ in the cat or dog submaxillary and at $20-25 \mathrm{c} / \mathrm{s}$ in the dog parotid gland. This maximum rate of secretion seems to be a specific property of the gland. In the presence of eserine or other anticholinesterase drugs the maximum rate is reached at considerably lower rate of stimulation but the maximum secretion rate is not itself increased (Beznák and Farkas, I937; Burgen, Keele and Slome, 1949). The maximum rates of water secretion are, for the dog parotid, $0.35^{-}$ $0.70 \mathrm{ml} . / \mathrm{g}$. min; the dog submaxillary $0.8-1.3 \mathrm{ml} . / \mathrm{g}$. min; the cat sublingual $0.05 \mathrm{ml} . / \mathrm{g}$. min (Burgen, unpublished; Lundberg, I957). The only procedure known to increase the maximum rate of secretion is an increase in plasma potassium (Langley, Gunthorpe and Beall, r 958; Burgen, unpublished). In dogs from birth onwards, the maximum rate of salivary secretion per unit weight 


\section{Series $B$}
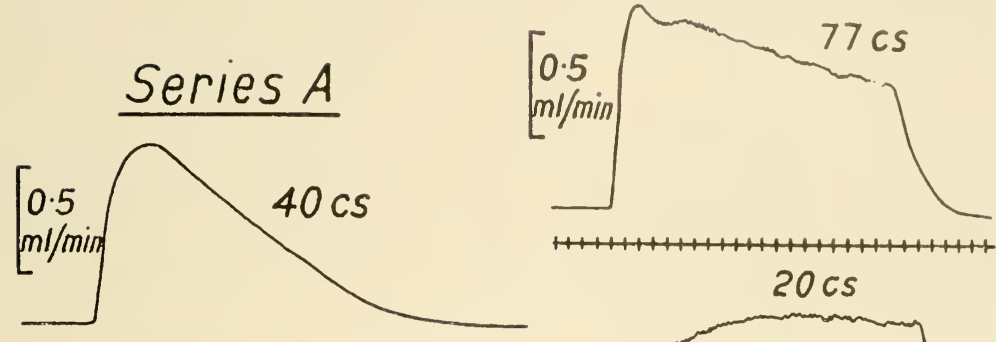

$H+H+H+H+H+H+H+H+H+H+H+H+H+H$
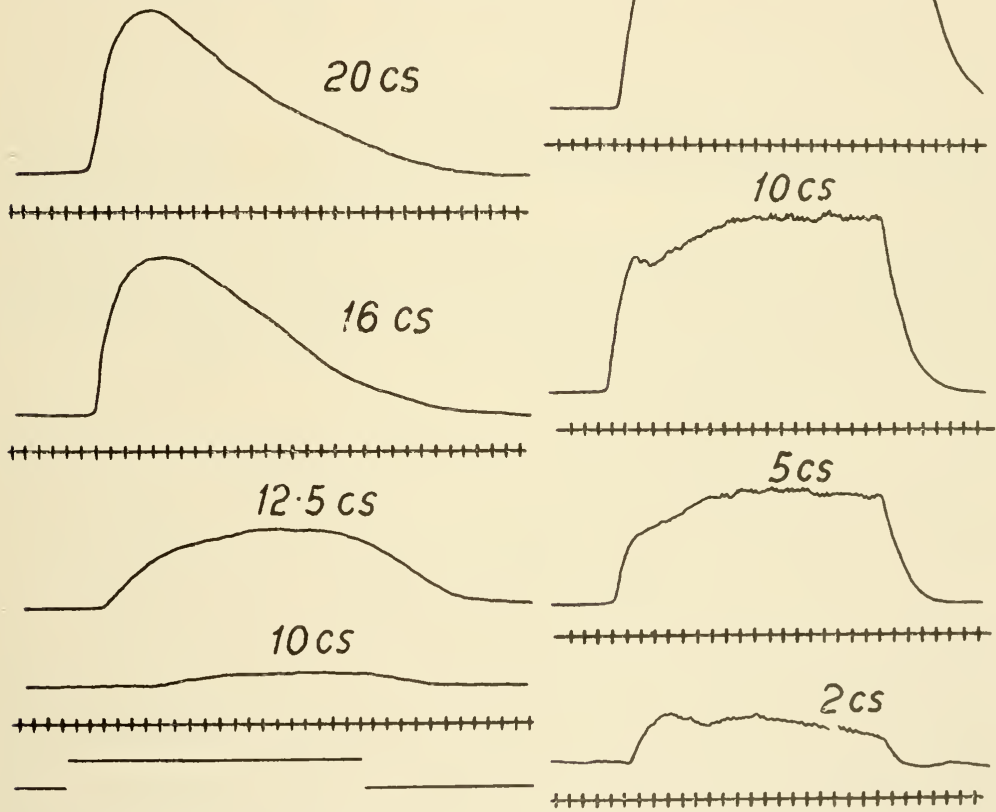

FIG. 8. I. The rate of secretion of the submaxillary gland of a cat recorded with a capacitance flow meter.

Ordinate rate of flow in $\mathrm{ml}$. per minute. Time marked seconds. In series $A$, the ipsilateral cervical sympathetic trunk was stimulated maximally at the frequencies indicated. In series $B$, the chorda tympani was stimulated (Burgen, unpublished).

produced by the submaxillary gland varies very little (Wechsler, unpublished). This is surprising since the neonatal gland has only a few poorly developed acini, although large dilated tubules are present. The rate of water secretion by this gland seems to proceed 


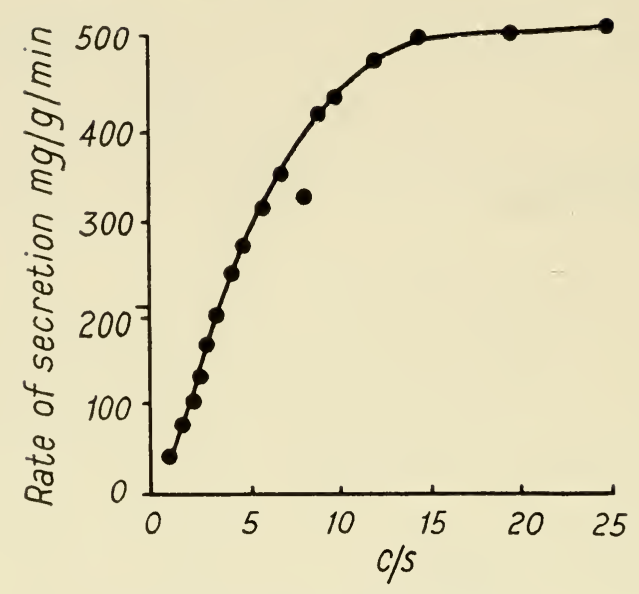

FIG. 8.2. Dog parotid gland.

Secretion was produced by maximal stimulation of the auriculo-temporal nerve at different frequencies. Ordinate: rate of secretion in $\mathrm{mg} / \mathrm{g} / \mathrm{min}$. Abscissa : frequency of stimulation (Burgen, unpublished).

unaltered in the face of major changes in structure occurring during maturation. Lourie (I 943) found that larger amounts of resting saliva were produced in young children than in adults.

\section{TOTAL OSMOLYTE CONCENTRATION}

At maximum secretory rates, the osmolyte concentration in the parotid saliva of the dog reaches a total of 200-260 milliosmols. The osmolyte concentration is proportional to flow and reaches a minimum of 50-1 00 milliosmols ( $5-30$ per cent of the plasma osmolarity) at about $5^{-10}$ per cent of the maximum secretory rate. At very low rates of secretion, the osmolyte concentration rises again and may come close to the plasma concentration (Burgen, I955; Brusilow and Cooke, I959; Burgen and Seeman, unpublished). Similar relationships are evidently present in the dog and cat submaxillary glands and the human parotid gland (Langstroth, McRae and Stavraky, I938a; Thaysen, Thorn and Schwartz, 1954). Cat sublingual saliva and rat parotid saliva are not hypotonic and their osmolarity at all rates of secretion is close to that of the plasma (Lundberg, I957; Schneyer and Schneyer, 1959). The secretion from all the salivary glands in man is hypotonic but the relationship of saliva osmolarity to the secretion rate has been established only in the case of the parotid (Köstlin and Rauch, 1957). Saliva 
secreted by the cat submaxillary gland in response to sympathetic stimulation, has a higher osmolarity than chorda saliva; after a large dose of adrenaline, the osmolarity of subsequently secreted chorda saliva is considerably increased (Langstroth, McRae and Stavraky, 1938b).

The production of hypotonicity is one of the most interesting and elusive phenomena in salivary secretion. The total amount of osmotic work that the gland can perform is not great (average for the dog parotid $\mathrm{I} 3.7 \mathrm{~m}$.cal/g. min) compared with the total energy

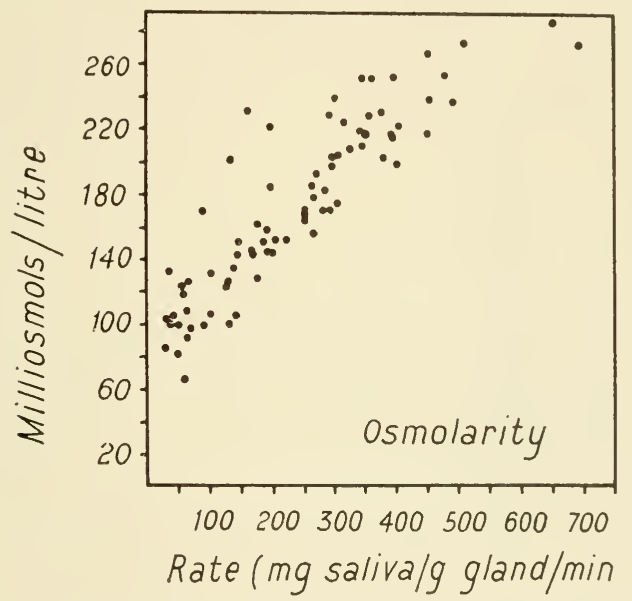

FIG. 8.3. Osmolarity of parotid saliva in the dog at different rates of saliva secretion.

(Brusilow and Cooke, 1959.)

production of the gland and it seems most improbable that the performance of osmotic work is a limiting factor in the secretory process (Burgen, I955). Japelli (I906) made the interesting observation that when the plasma osmolarity of the dog was raised by injection of ro per cent sodium chloride solution intravenously, there was an increase in saliva osmolarity although it was not necessarily proportionate. He also found that the freezing point depression of gland homogenates was identical to that of the plasma. Recently it has been found that in man, dehydration and subsequent repletion by water drinking leads to corresponding changes in the saliva osmolarity (Friedberg and Doyle, I959).

Burgen (1956b) has suggested that some water reabsorption 
occurs in the salivary ducts along the osmotic gradient that is present. This suggestion was based on the finding that a number of non-electrolytes are concentrated in the saliva above the plasma levels at low rates of saliva secretion. This can readily be understood if water reabsorption from the saliva occurred at a site in the ducts more distal to those across which non-electrolyte movement can occur. Direct evidence for this is available in the case of urea.

\section{pH AND BICARBONATE CONCENTRATION}

The hydrion concentration in saliva can only be determined if adequate means are taken to prevent loss of dissolved carbon dioxide and may then be determined either directly or from measurement of the bicarbonate concentration and the $\mathrm{pCO}_{2}$. Schmidt-Nielsen ( $1946 a$ ) has described a satisfactory method with a microquinhydrone electrode and analysed the sources of error in the method. He found the $\mathrm{pH}$ of the resting parotid saliva in 40 adults to average $5.8 \mathrm{I}$ (range $5 \cdot 45^{-6.06}$ ) and the submaxillary saliva a little higher at $6 \cdot 39$ (range $6 \cdot 02-7 \cdot 14$ ); on activation the $\mathrm{pH}$ of the parotid saliva increased by up to 2 units, the maximum pH recorded being 7.80 (Schmidt-Nielsen, I 946b). Rauch ( $195^{6}$ ) obtained similar values (i.e. $5 \cdot \mathrm{I}-6 \cdot 3$ for parotid and $5 \cdot 9-7 \cdot 3$ for submaxillary), as did Chauncey, Lisanti and Winer (1958). Chauncey and Weiss (1958) showed that acetazoleamide was without effect on the $\mathrm{pH}$. Sand ( 1949 ) measured the $\mathrm{pCO}_{2}$ of human submaxillary and sublingual saliva and found it to be $53^{-60} \mathrm{~mm} \mathrm{Hg}$ and practically independent of the rate of secretion. This means that the $\mathrm{pH}$ of the saliva can be predicted from the bicarbonate concentration. Sand found that the opalescence that often develops when saliva stands in the air was due to the formation of $\mathrm{Ca}_{3}\left(\mathrm{PO}_{4}\right)_{2}$ when the $\mathrm{pCO}_{2}$ was less than $20 \mathrm{~mm} \mathrm{Hg}$. Sand also found that the $\mathrm{pH}$ of saliva increased with increasing flow of the saliva. This has been confirmed in human parotid saliva (Hildes and Ferguson, I955; Anderson, I949). Yoshimura, Iwasaki, Nishikawa and Matsumoto (I959) have found that sublingual saliva in the dog has a fixed $\mathrm{pH}$ of about $7 \cdot 2$. Yoshimura, Takaoka and Mori (1954) have found that the $\mathrm{pCO}_{2}$ of saliva is increased when the $\mathrm{pCO}_{2}$ of the plasma is increased. As pointed out below, since the bicarbonate concentration of the saliva is also affected by changes in the arterial $\mathrm{pCO}_{2}$, the saliva $\mathrm{pH}$ is little affected by respiratory acidosis and alkalosis. 
It needs to be emphasized that saliva secreted at a reasonable rate and perhaps also resting saliva rapidly becomes alkaline in the mouth due to the loss of dissolved $\mathrm{CO}_{2}$.

Bicarbonate is present in the submaxillary and parotid saliva in a concentration higher than that in the serum when the rate of saliva secretion is above about 10-20 per cent of the maximum rate (Fig. 8.4). At lower rates of secretion, bicarbonate concentrations as low as $5^{-10} \mathrm{mEq} / \mathrm{l}$. may be found. With increased saliva flow rate the bicarbonate concentration rises and eventually stabilizes at a level which is not changed by further increase in saliva flow

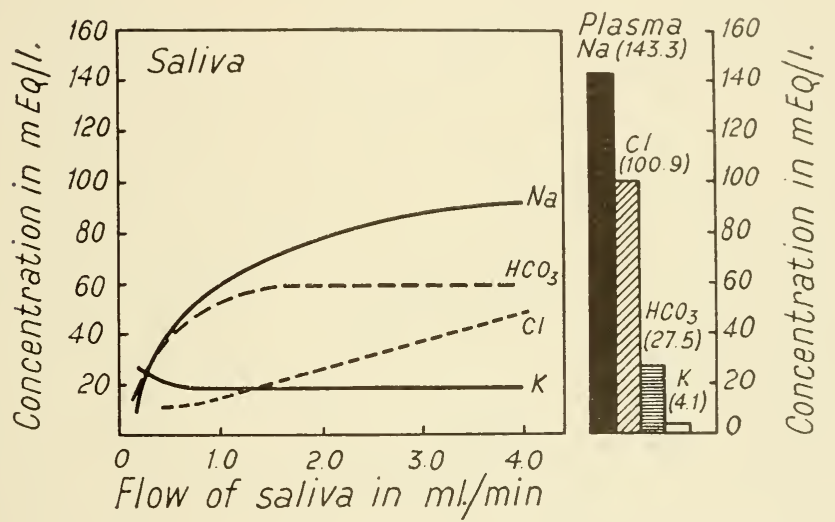

FIG. 8.4. Schematic diagram of concentrations of sodium, potassium, chloride and bicarbonate in human parotid saliva.

('Thaysen, Thorn and Schwartz, 1954.)

rate. In human parotid saliva the limiting level is normally about $60 \mathrm{mEq} / 1$. and in the $\operatorname{dog} 40-50 \mathrm{mEq} / 1$. (i.e. about twice the plasma bicarbonate) (Thaysen, Thorn and Schwartz, 1954; Hildes and Ferguson, 1955; Yoshimura, Takaoka and Mori, I954; Sand, 1949; Wechsler, 1959). The cat sublingual saliva on the other hand appears to be virtually free of bicarbonate. Lundberg (1957) found this saliva to contain ${ }_{5} 6 \mathrm{mEq} / 1$. sodium, $9 \mathrm{mEq} / \mathrm{l}$. potassium and I5 $1 \mathrm{mEq} / 1$. chloride. Since calcium and magnesium together amount to only $3-4 \mathrm{mEq} / 1$. and phosphate to not more than $3 \mathrm{mEq} / \mathrm{l}$., the bicarbonate must be less than $5 \mathrm{mEq} / 1$. Köstlin and Rauch's (1957) analysis of human sublingual saliva also suggests a low bicarbonate concentration. Werther (1886) reported an absence of "alkali" in sublingual saliva. Yoshimura et al. (1959) P.S.G.-L 
found the bicarbonate in the sublingual saliva of dogs to average only $5.2 \mathrm{mEq} / \mathrm{l}$. and not to be changed appreciably with flow rate.

The literature describing the relationship between the concentration of bicarbonate in plasma and saliva is rather confusing. For instance, de Beer and Wilson (1932) in the dog parotid gland stimulated by pilocarpine, found that on raising the plasma bicarbonate by an infusion of sodium carbonate, the saliva bicarbonate rose about proportionally, but continued to rise at a time when the plasma bicarbonate was falling.

McClanahan and Amberson (1935) found a linear relationship between plasma and saliva bicarbonate in the cat submaxillary gland but an unexplained feature of their experiments was that whereas the saliva bicarbonate was approximately equal to the plasma level in those experiments in which saliva secretion was caused by chorda stimulation, it was twice as great in those in which pilocarpine was used. In some of the experiments in this same paper in which perfused submaxillary glands were used, the proportionality between plasma and saliva concentration is much less clear. For instance, in one experiment when the plasma level was raised from $12.9 \mathrm{mEq} / 1$. to $20.9 \mathrm{mEq} / 1$. the saliva concentration remained unchanged! Sand (195I) found no satisfactory correlation between the saliva and plasma bicarbonate in man after ingestion of ammonium chloride. Wechsler (1959) also found the response to sodium bicarbonate administration to be unpredictable.

The elucidation of this confusing situation has come about through the study of the effects of change in $\mathrm{pCO}_{2}$ on the saliva bicarbonate (Burgen, I960). In dog parotid saliva the bicarbonate saliva/plasma ratio $(\mathrm{s} / \mathrm{p})$ is directly dependent on the arterial $\mathrm{pCO}_{2}$. In the experiment shown in Fig. 8.5 when the arterial $\mathrm{pCO}_{2}$ was reduced from $38 \mathrm{~mm} \mathrm{Hg}$ to I I. $5 \mathrm{~mm} \mathrm{Hg}$, by hyperventilation, the bicarbonate $\mathrm{s} / \mathrm{p}$ fell from $2 \cdot 78$ to $\mathrm{I} \cdot 25$ and, conversely, when the $\mathrm{pCO}_{2}$ was raised by inhalation of 10 per cent carbon dioxide in oxygen the saliva $\mathrm{s} / \mathrm{p}$ rose to $3 \cdot 8$. When the plasma bicarbonate level was increased by infusion of sodium bicarbonate the $s / p$ remained more or less unchanged when it was compared with the $\mathrm{s} / \mathrm{p}$ for the corresponding $\mathrm{pCO}_{2}$ before the infusion. The irregularities in the results reported in the literature are therefore probably due to the compensatory changes in $\mathrm{pCO}_{2}$ which are consequent 
on a metabolic alkalosis or acidosis. Sand (I 949) has shown that the $\mathrm{pCO}_{2}$ is independent of saliva secretion rate and closely follows the arterial $\mathrm{pCO}_{2}$ although it is usually 20-30 per cent higher. Because of this, the saliva $\mathrm{pH}$ changes little when the arterial $\mathrm{pCO}_{2}$ is changed because both the $\mathrm{pCO}_{2}$ and bicarbonate of the saliva are changed in the same direction nearly proportionately. In a careful study of human parotid saliva Chauncey and Weiss (I958) were unable to demonstrate any effect of quite large doses $(4 \cdot 8-22 \mathrm{mg} / \mathrm{kg})$ of the potent carbonic anhydrase inhibitor acetazoleamide (Dia$\operatorname{mox}$ ) on either salivary bicarbonate or $\mathrm{pH}$. Negative results were

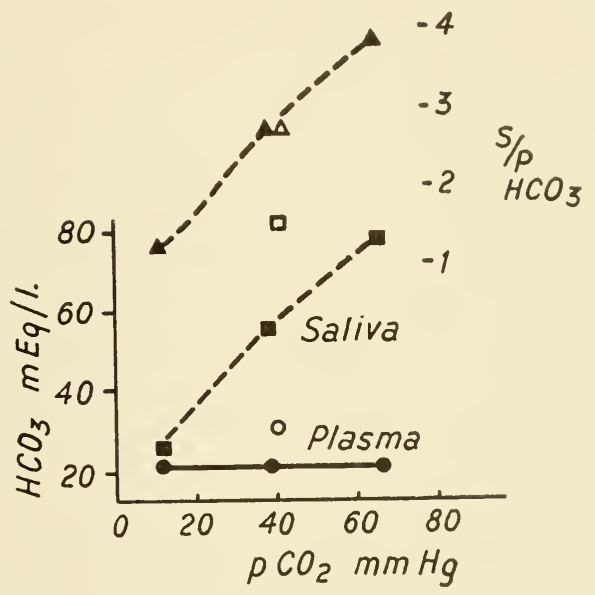

FIG. 8.5. The effect of change of $\mathrm{pCO}_{2}$ on the concentration of bicarbonate in the saliva.

The saliva plasma ratio is increased by a rise in arterial $\mathrm{pCO}_{2}$. The open symbols were values obtained after intravenous injection of $10 \mathrm{mEq} / \mathrm{kg}$ of $\mathrm{NaHCO}_{3}$. The plasma and saliva bicarbonate both increased but the saliva/plasma ratio did not change.

also obtained by Niedermeier, Stone, Dreizen and Spies (1955) and Burgen (1960).

Saliva produced in the cat submaxillary gland by sympathetic nerve stimulation has a much higher bicarbonate concentration than chorda saliva (Langstroth, McRae and Stavraky, I938b). This higher bicarbonate concentration is accompanied by a higher sodium and potassium concentration but by little change in the chloride. Similar changes are produced by adrenaline. On the other hand, large doses of adrenaline produce long-lasting aftereffects on the sodium and chloride concentrations in chorda saliva but only trivial changes in the bicarbonate. 
Wechsler (1960), in a study of the submaxillary secretion of young puppies, has found that up to the age of $\mathrm{I} 0$ days the saliva is virtually free of bicarbonate but, thereafter, the bicarbonate concentration rises to reach the adult level after 3-4 weeks.

The source of the salivary bicarbonate is of considerable interest because it might be derived in part by transfer from the plasma bicarbonate and in part from endogenous bicarbonate produced by the gland metabolism. A simple calculation shows that in a maximally secreting gland it would not be possible for all the secreted bicarbonate to be derived from metabolism. In an active dog submaxillary gland saliva is secreted at $0.3 \mathrm{ml} / \mathrm{g}$. min with a bicarbonate concentration of approximately $40 \mathrm{mEq} / \mathrm{l}$. - a total of approximately $12 \mu \mathrm{Eq} \mathrm{HCO}_{3} / \mathrm{g}$. min. The gland metabolism produces only $5 \mu \mathrm{Eq} \mathrm{HCO}_{3} / \mathrm{g}$. min so that even if all the metabolic bicarbonate of the gland were directed into the saliva this could account for less than half the total. The discrepancy would naturally become all the greater if the saliva bicarbonate level were raised by increase of the arterial $\mathrm{pCO}_{2}$ or bicarbonate. Sand ( $\left.195 \mathrm{I}\right)$ examined this question by injecting $\mathrm{C}^{14}$ labelled bicarbonate intravenously in a rabbit and measuring the specific activity of mixed saliva from the mouth and comparing this with that in the blood. The specific activity of the saliva bicarbonate was a little lower than in the blood. These experiments suffered from the defect that the blood bicarbonate concentration was falling rather rapidly during the experiment and the method of saliva collection led to a relatively large error in timing the sample. Wechsler (1959) has repeated this kind of experiment in the cat, taking care to maintain the serum level constant by continuous infusion of $\mathrm{C}^{14}$ bicarbonate and has found that the saliva specific activity was $10-20$ per cent lower than the arterial. These observations suggest that an appreciable proportion of the salivary bicarbonate is indeed derived from metabolism. Further support for this view was provided by Sand, who found that after injection of $\mathrm{C}^{14}$-lactate, the specific activity of the saliva bicarbonate was higher than in the arterial blood.

\section{POTASSIUM}

It has been known since the studies of Tiedemann and Gmelin (I826) that potassium is present in rather high concentrations in 
saliva. Clark and Shell (I927) found in a study of a large number of samples of human mixed saliva that the potassium concentration was invariably higher than in the plasma. This is true for all the individual glands in man (Köstlin and Rauch, I957) and is even the case for those salivary glands that secrete an isotonic saliva (Lundberg, 1957; Schneyer and Schneyer, 1959). Gregersen and Ingalls (I93 I) claimed that the concentration of potassium in dog parotid saliva was independent of the rate of the saliva secretion except at very low flows where a rise of concentration inversely proportionate to flow occurred. Similar relationships have been reported for cat submaxillary saliva and human parotid saliva

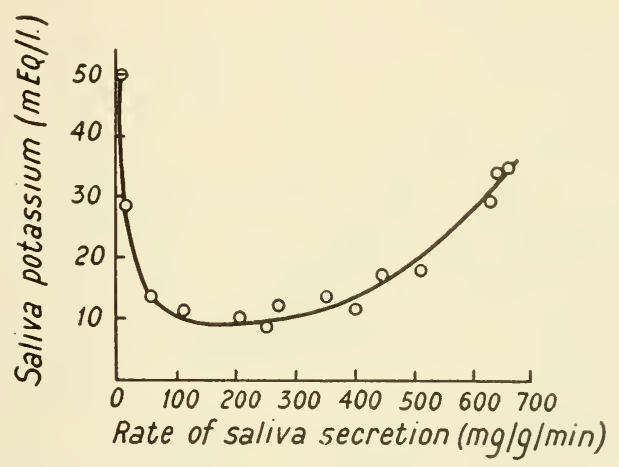

FIG. 8.6. The potassium concentration in dog parotid saliva when small samples were collected at different rates of secretion.

The relationship is U-shaped, rising at both low and high flow rates (Burgen, 1956a).

(Langstroth, McRae and Stavraky, I938a; Thaysen, Thorn and Schwartz, I954; Hildes, I955; Prader, Gautier, Gautier and Naef, I 955). The concentration in the saliva was $I^{\cdot} 5^{-4} 4$ times the plasma level; the higher values being found in man.

The constancy of the plasma concentration with flow was challenged by Burgen in 1956 , who found that in the dog and the cat, the saliva potassium was dependent on the size of the sample collected. At the beginning of the period of stimulation, the potassium concentration in the saliva is very high and then gradually falls off to reach a much lower steady level after a few minutes. When small samples of saliva are collected, the concentration of potassium shows a pronounced dependence on the flow rate, usually giving a $U$-shaped curve (Fig. 8.6). This dependence on flow rate 
is largely eliminated as the size of the sample is increased (Fig. 8.7). The initial difference in potassium concentration depends on the duration of the rest period since the previous stimulation; and previous authors had missed this inequality of concentrations either because of the large size of the saliva samples that they collected or because of dealing with a continuously secreting gland and discarding earlier "aberrant" samples or because they used very short intervals between collections of samples which did not

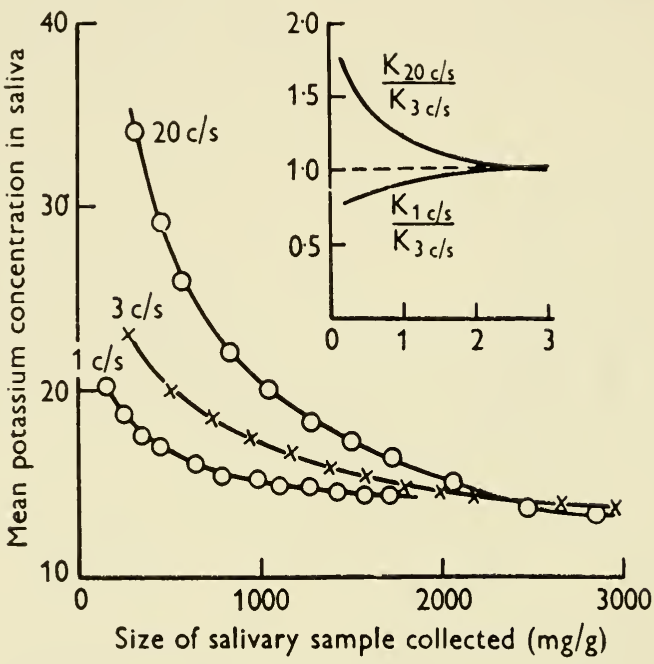

FIG. 8.7. Dependence of the concentration of potassium in submaxillary saliva of the dog on the size of the saliva sample collected.

(Burgen, 1956a.)

allow the early phase of secretion to appear. In the early phase, potassium concentrations up to 20 times the plasma level may be found. The rest period necessary for the return of the full initial transient concentration of potassium after a period of stimulation was investigated by Seeman (1956). He found that in the dog parotid gland, the transient was half restored by a rest of $2-5$ minutes whereas in the dog submaxillary gland this required $15-30$ minutes. Lundberg ( 1958 ) has found a similar potassium transient in the cat sublingual secretion. Brusilow and Cooke (1959) found virtually no potassium transient when the rest period was a minute or less. A fuller discussion of the potassium transient, its relationship to changes in gland electrolytes and implications for the secre- 
tory process, will be found on page 206. Schneyer and Schneyer ( 1959 ) have recently measured the potassium concentration in rat submaxillary-sublingual saliva and found values of $45^{-62.5} \mathrm{mEq} / 1$. These values are higher than usually reported for other glands but it is not clear how much of this is due to the presence of a possible potassium transient. The potassium concentration in both parotid and submaxillary saliva in the dog is dependent on the plasma level (Burgen, I 956a; Fig. 8.8) and this is presumably true in other

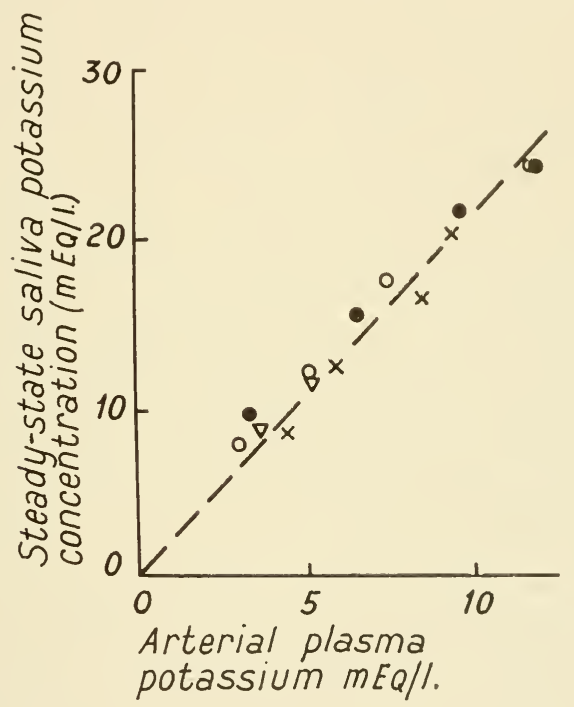

FIG. 8.8. The relationship between potassium concentrations in dog plasma and parotid saliva.

(Burgen, 1956a.)

species. Saliva potassium is only slightly elevated by adrenal corticoids (Grad, 1952; White, Entmacher, Rubin and Leiter, 1955; Martin, 1958 ; Burgen, unpublished) and is relatively unaffected by changes in $\mathrm{pCO}_{2}$. In the immature dog submaxillary gland, no significant changes in potassium occur as the gland matures, although striking changes are found in the sodium, chloride and bicarbonate concentrations (Wechsler, unpublished). Ferrari and Höber (1933) reported that iodacetate and cyanide in appropriate concentrations caused a large increase in the saliva potassium concentration. It is not clear whether this is just a transient dependent on release of part of the intracellular potassium into the saliva or 
represents a genuine change in the potassium secretory process. The concentration of potassium in saliva evoked by sympathetic stimulation or adrenaline injection is about twice that of chorda saliva; there are, however, no striking after-effects of the adrenaline on subsequent chorda stimulation (Langstroth, McRae and Stavraky, I93 $8 b$; Kesztyüs and Martin, I 937). No studies have been reported on the secretion of rubidium and caesium in the saliva.

\section{SODIUM AND LITHIUM}

In those glands producing a hypotonic saliva, the concentration of sodium is highly dependent on the rate of saliva flow (Fig. 8.4; Gregersen and Ingalls, I93 I Langstroth, McRae and Stavraky, I938a; Thaysen, Thorn and Schwartz, I954; Hildes, 1955; Prader, Gautier, Gautier and Naef, r955; Brusilow and Cooke, 1959). At low flow rates the concentration may be as little as $\mathrm{I}-5 \mathrm{mEq} / \mathrm{l}$. and rises to $100 \mathrm{mEq} / 1$. or more at the highest rates of secretion. In some glands, a rise of sodium concentration may occur also at very low flow rates. The flow dependence of saliva sodium concentrations makes it impossible to give any narrow normal range of concentrations but, despite this, values for sodium in resting saliva in man may be of use. In the small flow range involved, the variations of sodium concentration are relatively small. For instance, Prader and Gautier (1955) found that the resting saliva of normal children contained $2-15 \mathrm{mEq} / 1$. of sodium, whereas the saliva from children with cystic fibrosis of the pancreas contained 20-45 $\mathrm{mEq} / 1$. Similarly, changes in sodium concentration consequent on altered adrenocortical secretion may be quite consistent with resting flows although no consistent change may be found at high rates of secretion (Grad, 1952; White, Entmacher, Rubin and Leiter, I955; Martin, I958). In saliva produced by sympathetic stimulation, sodium concentrations are considerably higher than at the corresponding flow rates produced by chorda stimulation but they remain hypotonic (Langstroth, McRae and Stavraky, 1938b). In glands with an isotonic secretion such as the cat sublingual and rat parotid sodium is the predominant cation and is present at a concentration of $140-160 \mathrm{mEq} / 1$. (Lundberg, I958; Schneyer and Schneyer, 1959).

Brusilow and Cooke (I959) have reported that following brief interruption of regular stimulation, the secretion of sodium in the 
saliva is transiently depressed. This effect reaches its maximum with an interruption of flow for as little as one minute. Higher sodium concentrations are found in the saliva of human infants and puppies (Hungerland, Quenzlein and Weber, 1957; Prader, Gautier, Gautier and Naef, I955; Wechsler, I960).

Lithium concentrations in saliva are higher than in plasma. At low flow rates, they reach 2-3 times the plasma level and at high flow rates approximate to the plasma level. The saliva/plasma ratio for lithium is independent of the absolute plasma concentration. No other substance is known which has a concentration flow relationship of this kind (Burgen, I958).

\section{CHLORIDE AND BROMIDE}

The chloride concentration of the saliva shows considerable variation among different glands but the most common pattern is that found in the dog, cat and human submaxillary and parotid glands. In these glands there is a nearly linear relationship between flow rate and chloride concentration (Burgen and Seeman, I957; Hildes and Ferguson, I955; Thaysen, Thorn and Schwartz, I954; Ferguson, Hildes and Naimark, 1957) which, however, at all flows is well below the plasma concentration. A range between $5^{-70}$ $\mathrm{mEq} / 1$. has been commonly reported (de Beer and Wilson, I932; Kesztyüs and Martin, I937; Lipschitz, I929a; Köstlin and Rauch, I957; Freinkel and Ingbar, I953; Chauncey and Weiss, I958; Wills, I940; McCance, I938; Langstroth, McRae and Stavraky, I938a; Brusilow and Cooke, I959).

By contrast, the sublingual saliva of the cat has a higher chloride concentration than in the plasma. Lundberg (1957) found values of I 44-I $70 \mathrm{mEq} / \mathrm{l}$. which make chloride almost the exclusive anion in this isotonic saliva. Sublingual and palatine saliva in man have higher chloride concentrations than parotid or submaxillary but are not as high as cat sublingual (Köstlin and Rauch, I957). In young animals and in children under one year of age the chloride level is considerably higher than in more mature individuals (Kaiser, Kunstadter and Mendelsohn, I956; Wechsler, I960). Saliva obtained with pilocarpine as the secretogogue rather than parasympathetic nerve stimulation usually has a considerably higher chloride concentration (de Beer and Wilson, r 932; Wechsler, I 960 ).

Sympathetic saliva from the dog and cat submaxillary glands 
shows a similar chloride concentration to parasympathetic saliva but after large doses of adrenaline the chloride concentration is raised for many hours (Langstroth, McRae and Stavraky, I938). There is no clear evidence of the effects of changes in plasma chloride on the salivary secretion of chloride but when the plasma chloride was reduced from i $8 \mathrm{mEq} / 1$. to $80 \mathrm{mEq} /$. by administration of bromide there was no change in saliva/plasma ratio for chloride (Lipschitz, I 929a). On the other hand, when the serum chloride is reduced (and bicarbonate increased) by administration of bicarbonate or carbonate not only does the saliva bicarbonate sometimes rise but the chloride may rise considerably (de Beer and Wilson, I932). The chloride concentration in saliva may be influenced independently of the plasma chloride by changes of arterial $\mathrm{pCO}_{2}$ (see page 219). The chloride concentration of saliva is not affected by iodide, thiocyanate or perchlorate (Freinkel and Ingbar, I953; Ferguson, Naimark and Hildes, 1957). A fall in saliva chloride accompanies the decrease in sodium and rise in potassium of saliva after administration of desoxycorticosterone (White, Entmacher, Rubin and Leiter, 1955); no changes were produced by the diuretics mercuhydrin or acetazoleamide (Chauncey and Weiss, I958). McCance (I938) found no change in saliva chloride in patients that were salt depleted. Höber and Ferrari (I933) made the very interesting observation on perfused submaxillary glands that when suitable concentrations of cyanide or iodacetate were added to the perfusion fluid there was a sharp rise in the salivary chloride concentration. Finally, in cystic fibrosis of the pancreas, only moderate changes in chloride concentration in saliva have been found (Kaiser, Kunstadter and Mendelsohn, 1956) unlike the considerable changes in sodium (Prader and Gautier, I955). Bromide behaves very much like chloride but the saliva/plasma ratio tends to be slightly higher (Lipschitz, I929).

\section{FLUORIDE}

Surprisingly little data is available on salivary fluoride secretion in view of the great interest taken in this subject from the point of view of dental caries. McClure (I94I) found the saliva fluoride in children to be in the range of $0.006-0.015 \mathrm{mEq} / 1$. (i.e. $0 \cdot 10-0.24$ p.p.m.) and to bear a crude relationship to the level of fluoride in the drinking water. Martin and Hill (1950) found a slightly higher (0.008-0.019 mEq/1.) level in the Chicago area. In neither 
study was the saliva level related to the plasma level or the rate of secretion. Wills (I940, I943) injected carrier free F19 into cats and collected submaxillary saliva. The saliva/plasma fluoride ratio was in the range $0.064-0.13 \mathrm{I}$ whereas the ratio obtained in the same animals for chloride was 0.3 I $5-0.423$. No studies were done relating fluoride secretion in saliva either to the total plasma level or to the rate of saliva secretion. Fluoride is therefore secreted in saliva at a lower concentration than the other halides.

It has been suggested that the low concentration of fluoride in saliva is due to the indiffusibility of fluoride caused by the formation of insoluble calcium fluoride complexes in the blood. 'This is unlikely since the solubility of $\mathrm{CaF}_{2}$ in plasma is approximately $0.5 \mathrm{mEq} / 1$. (Stuber and Lang, I 929) while the blood concentration is only about $0.1 \mathrm{mEq} / \mathrm{l}$, and also because Wills ( 1940 ) found that after intravenous injection $\mathrm{F}^{19}$ distributed itself in 37 per cent of the body weight (as compared to 24 per cent for chloride), i.e. it distributed itself at least as readily as chloride in a predominantly extracellular location. Further studies on fluoride in saliva would be very welcome.

IODIDE, THIOCYANATE, PERCHLORATE AND NITRATE

The secretion of iodide in saliva was first noted by Bernard ( 856 ). Lipschitz ( $1929 a, b)$ showed that iodide was considerably concentrated in dog parotid saliva (and gastric juice) above the plasma level and that the saliva/plasma ratio was reduced when the plasma iodide concentration was raised sufficiently.

Whilst iodide is secreted in all salivas so far examined the ability to secrete at concentrations higher than the plasma level is not found in all glands. The results of an extensive study by Cohen and Myant (I959) of the secretions in which iodide is concentrated are shown in Table I. The human parotid gland seems to be the most active of any of those extensively studied. At low rates of secretion, the concentration of iodide is highest and at flow rates above $0.5 \mathrm{ml} . / \mathrm{min}$, the $\mathrm{s} / \mathrm{p}$ ratio becomes constant at about Io and does not change with further increase of saliva secretion rate (Ferguson, Naimark and Hildes, 1956); somewhat similar results have been obtained with the dog parotid (Burgen and Seeman, 1957) although the concentration ratio is lower than in man (Fig. 8.9).

The secretion of iodide can be expressed as a clearance. Owing 
Table I

Concentration of Iodide in Saliva of

Different Species

(Cohen and Myant, 1959)

Species Mixed Parotid Submandibular Sublingual Residual

Cat

Dog

Rabbit

Guinea pig

Cotton-rat

Rat

Mouse

++
++

0

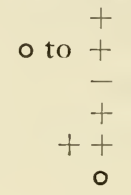

o to +

+
+
+

$+++$

Hamster

Mastomys

$+++$

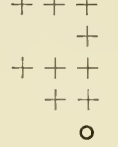

$++$

$+\quad++$

$+$

$+++$

$++$

Man $\mathrm{S}: \mathrm{P}: \mathrm{o}=\left\langle\mathrm{I},+=\mathrm{I}-5,++=5^{-10},+++=>\mathrm{IO}\right.$.

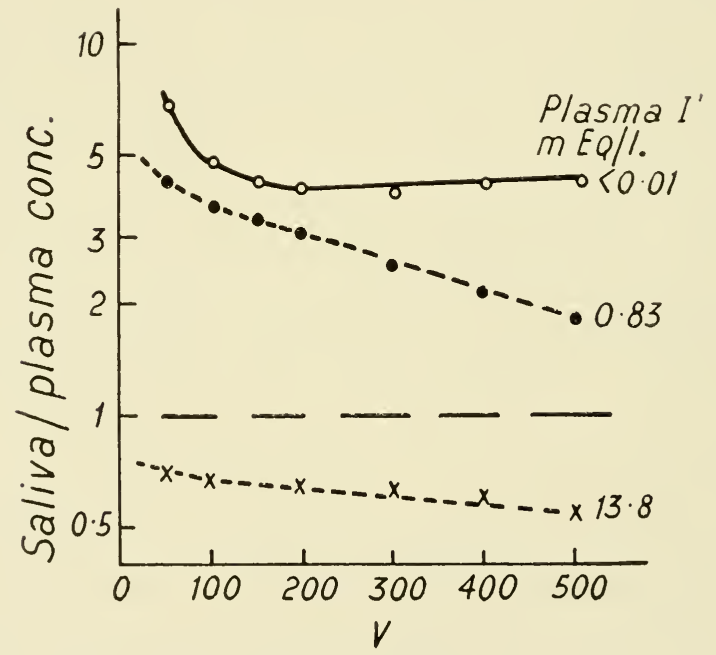

FIG. 8.9. Saliva/plasma ratios for iodide in dog parotid secretion.

Showing also the decrease in saliva concentration caused by a raised plasma iodide (Burgen and Seeman, 1957).

to the near independence of iodide concentration on flow rate, the clearance is almost linearly dependent on the flow rate. At the maximum rate of saliva secretion, it amounts to more than $2 \mathrm{ml}$. plasma $/ \mathrm{g}$. gland $/ \mathrm{min}$ in the dog parotid, and up to $10 \mathrm{ml} . / \mathrm{min}$ in the human parotid (at a flow rate of $\mathrm{I} \mathrm{ml} . / \mathrm{min}$ ). In the submaxillary gland of the dog this is the order of total blood flow through the gland during activity. Towbin and Perkins ( $195^{8}$ ) have 
attempted to measure arteriovenous differences in the dog parotid and have found that the extraction of iodide is not complete. Actually complete extraction from whole blood would not be expected in view of the relative slowness with which iodide exchanges between red cells and plasma (Tosteson, I959), but even allowing for this the values were usually such as to preclude complete plasma extraction. Nevertheless, the iodide clearance probably gives a good index of gland blood flow and to account for such high extractions we must conclude that a high proportion of the blood perfusing the gland comes into contact with the structures in the gland secreting iodide. At least in the dog parotid gland after a rest period the first secreted saliva contains a much higher concentration of iodide than does subsequently secreted saliva (Burgen and Seeman, 1957; Towbin and Perkins, 1958; Burgen, Terroux and Gonder, 1959). This "rest transient" is discussed in detail in Chapter X. Iodide is also concentrated in the salivary glands in some species, notably in human parotid and submaxillary glands and in mouse and hamster submaxillary glands (Cohen and Myant, I959), but many glands which produce a saliva rich in iodide do not themselves have a concentration of iodide higher than that in the plasma. This could be the case if either intracellular concentration of iodide did not occur or if iodide concentration were not a function of all the gland cells but rather of a specific group of cells. The distribution of iodide in the gland has been examined by radioautography of freeze-dried salivary glands in animals given $\mathrm{I}^{131}$. By this technique it has been shown that radioiodine is concentrated by the proximal ducts of the parotid gland in both mice and hamsters (Fig. 8.ro). Rats are unable to concentrate iodide in their saliva and in them no such selective accumulation can be seen (Cohen, Logothetopoulos and Myant, 1955; Logothetopoulos and Myant, 1956). Analysis of the time course of the rest transient mentioned above and of the time of appearance of iodide in the saliva after intra-arterial injection have provided evidence that the ducts are responsible for iodide transfer in the dog parotid as well (Burgen and Seeman, I957; Burgen, Terroux and Gonder, 1959). The rapidity with which saliva iodide concentration in man follows changes in blood iodide content suggests that the same is true in this species (Freinkel and Ingbar, 1953). In the radioautographic studies iodide appears to be concentrated about equally over the duct epithelium and lumen, and where the tissue section 
included duct epithelium without the duct lumen iodide concentration was still apparent. In Chapter $\mathrm{X}$ evidence is given based on kinetic studies for assuming that concentration of iodide in the

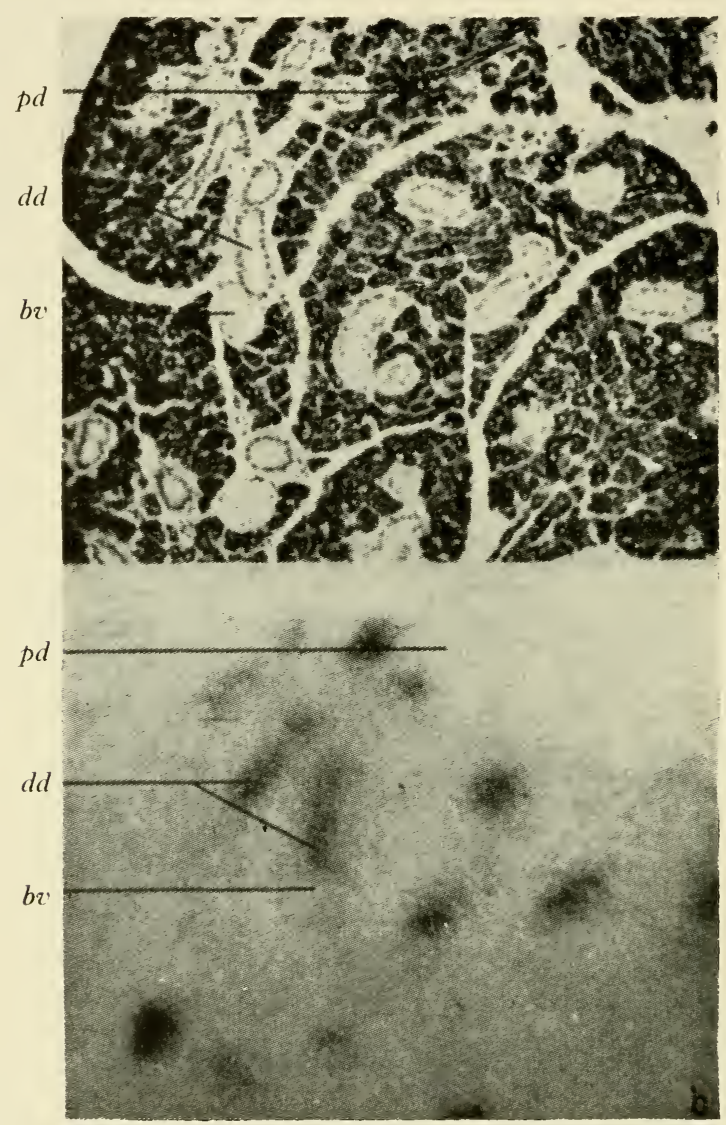

FIg. 8. Io. Radioautographic localization of $\mathrm{I}^{131}$ in the parotid gland of the hamster.

Upper photograph: gland stained by periodic acid-Schiff. Lower photograph: radioautograph. Activity is present over the distal ducts. $p d$, proximal duct; $d d$, distal duct; $b v$, blood vessel (Cohen, Logothetopoulos and Myant, 1955).

duct cells occurs in the dog parotid gland and also for concluding that little or no iodide can enter the saliva via the acini.

It seems probable that in all the species in which iodide can be concentrated in the saliva, this is accomplished by some part of the duct epithelium. Cohen and Myant observe that they can find no 
particular kind of cell common to the glands where iodide secretion is most active. If there is a cytological feature characteristic of iodide-secreting cells this has not yet been identified.

In the dog submaxillary gland saliva iodide concentrations are normally lower than in the plasma and the relationship of concentration of iodide to the rate of saliva flow is unlike that in the parotid. In this secretion the concentration decreases at low flow rates (Fig. 8.II) (Burgen and Seeman, I957). Nothing is known of the mechanism of iodide secretion in this gland.

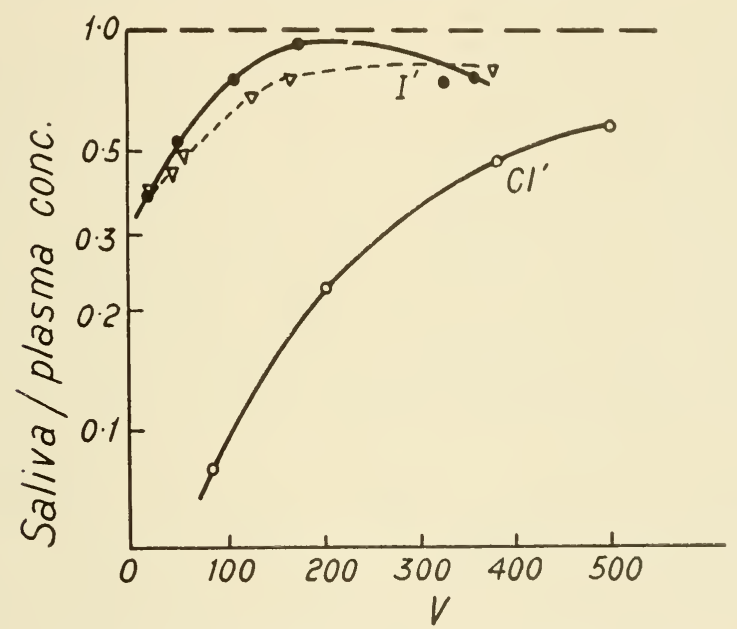

FIG. 8.11. Saliva/plasma ratio for iodide and chloride.

$\nabla \ldots \nabla$ submaxillary iodide; $0-\bigcirc$ parotid chloride; -0 parotid iodide when the plasma iodide was $2.3 \mathrm{mEq} / 1$ and perchlorate was administered to give a blood concentration of about $2 \mathrm{mEq} / 1$. (Burgen and Seeman, 1957).

The saliva/plasma ratio of iodide can be self-depressed by rather high concentrations of iodide (greater than $0.5 \mathrm{mEq} / \mathrm{l}$. in the dog) and also by perchlorate, thiocyanate and less effectively by nitrate (Rowlands, Edwards and Honour, I953; Edwards, Fletcher and Rowlands, i954; Ferguson, Naimark and Hildes, I957; Burgen and Seeman, I957). A thorough study of the relationship between these ions has been carried out in vitro with slices of mouse salivary glands (Fletcher, Honour and Rowlands, I957). With this preparation half depression of iodide concentration was found with $2.5 \mu \mathrm{M}$ of $\mathrm{ClO}_{4}^{-}, 35 \mu \mathrm{M}$ of $\mathrm{I}^{-}$or $\mathrm{CNS}$, and $250 \mu \mathrm{M}$ of $\mathrm{NO}_{3}{ }^{-}$. Bromide was completely ineffective. These authors make the interesting observation that the concentration of 
iodide is greater in the older mice. When a high enough dose of one of these anions is used either in vitro or in rivo the $\mathrm{I}^{131}$ concentration ratio asymptotes to a value less than I (usually $0.3-0.7$ ) and cannot be further depressed by increase in anion concentration.

Evidence is available that this residual secretion of iodide occurs via the duct cells (Burgen, Weiss and Weiss, i 960). The relationship between concentration of iodide and flow found in the dog parotid saliva when the iodide transport process has been depressed by a high $\mathrm{I}^{-}$and $\mathrm{ClO}_{4}{ }^{--}$concentration is very similar to that found in the normal submaxillary gland (Fig. 8.I I).

It has been known for over a century that thiocyanate is concentrated in the saliva and is found in the saliva of many species. The thiocyanate appears to be mostly produced endogenously from cyanide; its concentration is considerably increased in smokers. Thiocyanate is less well concentrated by the salivary glands than iodide (Ferguson, Naimark and Hildes, 1957) but otherwise its behaviour is quite similar. Radioautographic studies have shown that thiocyanate is concentrated in the same duct segments as iodide (Logothetopoulos and Myant, I956). Perchlorate is also concentrated at least tenfold in human parotid saliva (Edwards, Fletcher and Rowlands, 1954), but the difficulty of measuring the concentration of this ion has inhibited further study. Nothing is known of nitrate concentrations in saliva.

It is probable that iodide, perchlorate, thiocyanate and nitrate can all be transported by the same anion transport system in the salivary duct cells and that the ions can compete for transport by this carrier. A similar transport system exists in the thyroid (Wyngaarden, Wright and Ways, I952; Wyngaarden, Stanbury and Rapp, 1953), in the gastric mucosa (Lipschitz, I929a; Honour, Myant and Rowlands, 1952; Fletcher, Honour and Rowlands, 1956; Howell and Middlesworth, 1956) and in the mammary gland (Brown-Grant, 1957). A study of the effect of X-irradiation of the parotid gland has shown no depression of iodide secretion after doses as great as 3,500 r (Awwad, 1959). Large doses of inorganic iodine have been known for a very long time to lead not infrequently to swelling and pain in the salivary glands. In man and in the mouse virtually all the iodine secreted in the saliva is in the form of inorganic iodide, but in the dog a considerable proportion is incorporated into proteins. 


\section{CALCIUM AND MAGNESIUM}

In human parotid saliva there is a positive correlation between flow rate and calcium concentration (Chauncey, Lisanti and Viner, I 958) which ranges from $\mathrm{I} \cdot 0 \mathrm{mEq} / \mathrm{l}$. at low flows up to $3-4 \mathrm{mEq} / \mathrm{l}$. at high flows. Values of $\mathrm{I}-3 \mathrm{mEq} / 1$. for resting parotid saliva and $3^{-6} \mathrm{mEq} / \mathrm{l}$. for resting submandibular saliva have been reported (Rauch, I956; Henriques and Chauncey, I958). de Beer and Wilson (1932) also found in the dog parotid excited by pilocarpine that there was a positive correlation with secretion rate and, further, that the saliva calcium was increased by raising the plasma level. Andreyev and Pugsley (1933) also found the saliva calcium to follow the plasma calcium. Kesztyüs and Martin (1937) found that the submaxillary saliva of the dog contained 4-6 mEq/l. calcium after chorda stimulation, showed no appreciable rest transient and was practically independent of rate of flow in the range tested.

The concentration in sympathetic saliva is much higher (I I-32 $\mathrm{mEq} / \mathrm{l}$.) and considerably above the normal plasma level of $4^{-6}$ $\mathrm{mEq} / \mathrm{l}$. Baxter (I933) found approximately i I $\mathrm{mEq} / \mathrm{l}$. in $\mathrm{dog}$ parotid saliva and $5 \mathrm{mEq} / 1$. in mixed saliva produced by reflex stimulation.

Levels of $0 \cdot 6-\mathrm{I} \cdot 4 \mathrm{mEq} / \mathrm{l}$. of magnesium have been found in parasympathetic saliva (Rauch, 1956; Kesztyüs and Martin, 1937) compared with $\mathrm{I} \cdot 5^{-2} \cdot 5 \mathrm{mEq} / \mathrm{l}$. in plasma. Sympathetic submaxillary saliva, however, may have concentrations as high as $3.2 \mathrm{mEq} / \mathrm{l}$.

\section{PHOSPHATE}

The total phosphate of saliva is usually about twice the plasma level and, of this, at least 80 per cent is present as inorganic phosphate (Chauncey and Weiss, I958; Clark and Shell, I927; White and Bunting, 1946; Becks and Wainwright, I946; Hildes, I955; Köstlin and Rauch, I957; Eggers-Lura, I947; Krasnow, I945). Stevens (1953) found a similar relation in mixed saliva after injection of inorganic phosphate as $\mathrm{P}^{32}$ but Wills (1943) found in the cat a saliva/plasma ratio of only $0.28-0.40$ with chorda stimulation and lower figures with pilocarpine.

The concentration is relatively flow independent but shows some upswing at low secretion rates (Hildes, 1955). The organic phosphate of saliva is acid-soluble and partially split by phosphatases (Eggers-Lura, 1947). Rose and Kerr (1958) have presented 
evidence that phosphoethanolamine accounts for part of the organic phosphorus in saliva. There are also traces of phospholipid present.

\section{PAROTID SECRETION OF THE SHEEP}

The parotid secretion of the sheep has recently been studied in detail and provides some interesting comparisons with the saliva of non-ruminant mammals. The saliva is hypertonic to plasma, the osmolarity averaging about 335 milliosmols/1. as compared with 285 for plasma. It is also quite alkaline due to a high bicarbonate concentration ( $100-140 \mathrm{mEq} / \mathrm{l}$.). The chloride concentra-

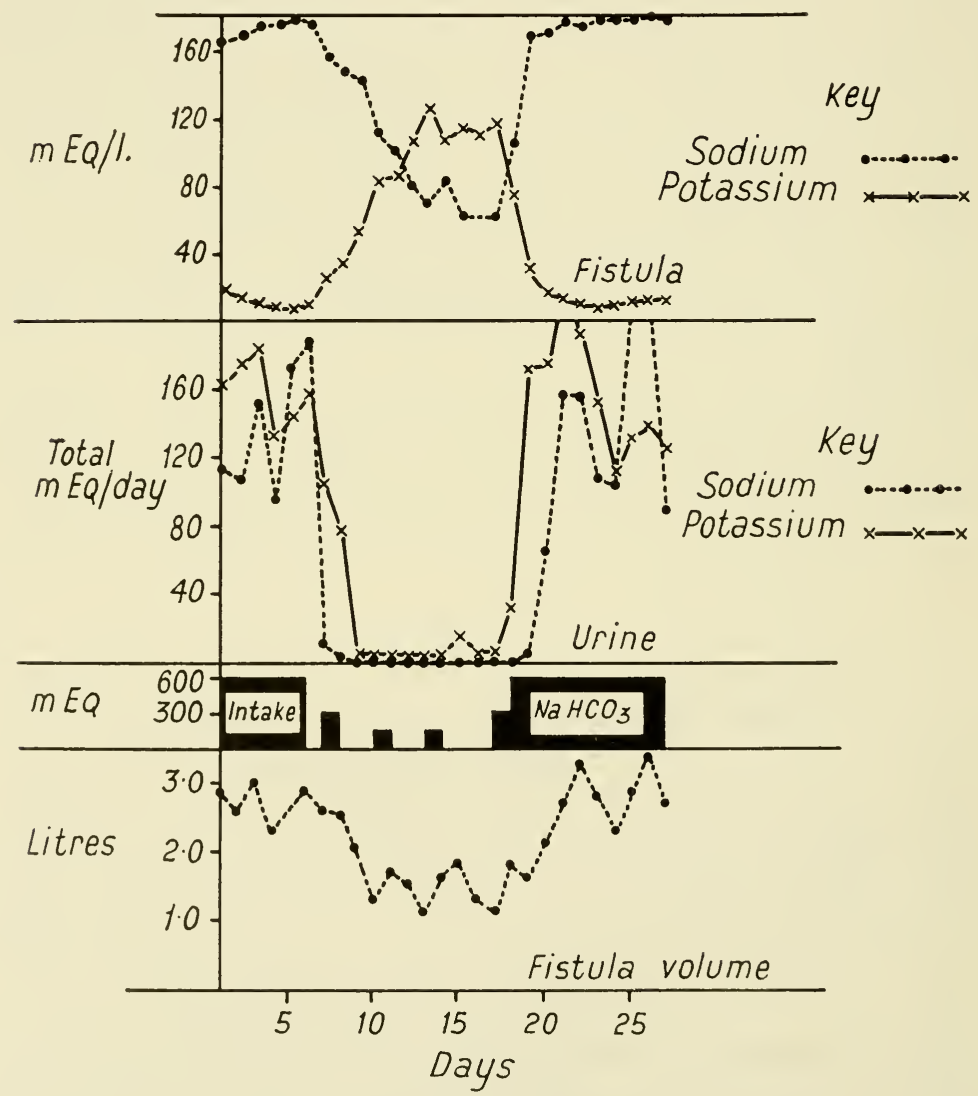

FIG. 8. I2. Saliva from a sheep with a parotid fistula.

When the daily intake of $595 \mathrm{mEq} \mathrm{NaHCO}{ }_{3}$ was withheld, the saliva sodium fell and the potassium rose. When the intake of sodium was restored, restitution of the cation concentrations in the saliva occurred (Denton, 1956). 
tion is correspondingly low. In overall composition, it resembles much more closely the pancreatic secretion of other mammals rather than saliva. Despite these differences, it resembles other salivas in having a potassium concentration that is higher than the serum level and a positive dependence of sodium and bicarbonate on flow rate. Potassium, chloride and phosphate, however, are negatively dependent on flow rate. Very well marked transient concentrations of all the ions are seen when the flow of saliva is increased above the basal level by nerve stimulation or the intraarterial injection of acetylcholine.

The most interesting feature of the gland is the very striking change in saliva composition produced by variations in adrenocortical function. If a sheep with a parotid fistula is placed on a low sodium intake, it rapidly becomes sodium-depleted due to the losses in the saliva. The endogenous secretion of mineralocorticoids is thereby stimulated and these lead to a change in the composition of the saliva such that sodium is almost entirely replaced by potassium. In the repleted state, the saliva may contain $10 \mathrm{mEq} / \mathrm{l}$. of potassium and $190 \mathrm{mEq} / 1$. sodium, but after $4^{-5}$ days of sodium depletion, the saliva potassium commonly rises to $140 \mathrm{mEq} / 1$. and the sodium falls to less than $60 \mathrm{mEq} / \mathrm{l}$. (Fig. 8.12). This change does not occur in adrenalectomized sheep maintained on deoxycortone. The effects of sodium depletion can be rapidly reversed by an intravenous infusion of sodium chloride; correction of the salivary electrolytes composition begins after a latent period of about an hour. These cation changes occur in the absence of any significant alterations in the anion composition. The parotid gland of the sheep appears to be a very sensitive assay preparation for mineralocorticoids (Denton, 1956, 1957a, b; Coats and Wright, I957; Denton and McDonald, I956; Goding and Denton, I956).

\section{REFERENCES}

ANDERSON, D. J. (I 949). The hydrogen ion concentration of saliva. F. dent. Res., 28, 583-588.

ANDREYEV, L. and L. I. PUGSLEY (1933). The effects of parathyroid hormone and of irradiated ergosterol upon the calcium content of the parotid saliva of the dog. F. Physiol., 86, 98.

AWWAD, H. K. (I959). The influence of x-irradiation on the iodide-trapping mechanism of the human parotid gland. Brit. F. Radiol., 32, $259^{-262 .}$ 
BAXTER, H. (1933). Variations in the inorganic constituents of mixed and parotid gland saliva activated by reflex stimulation in the dog. $\mathcal{F}$. biol. Chem., 102, 203-217.

BECKS, H. and W. W. WAINWRIGHT (i946). Relationship of calcium and inorganic phosphorus to rate of flow of resting saliva. $\mathcal{F}$. dent. Res., $25,275-283$.

DE BEER, E. and D. W. WILSON (I932). The inorganic composition of the parotid saliva of the dog and its relation to the composition of the serum. F. biol. Chem., 95, 671-685.

BERNARD, C. (1856). Leçons de physiologie expérimentale appliquée, Vol. 2. Baillière, Paris.

BEZNÁK, M. and E. FARKAS (1937). The interpretation of some phenomena of salivary secretion caused by direct electrical stimulation of the effector nerve in terms of the present knowledge of the nervous impulse and its chemical transmission. Quart. $\mathcal{F}$. exp. Physiol., 26, $265-283$.

BROWN-GRANT, K. (I957). The iodide concentrating mechanisms of the mammary gland. $\mathcal{F}$. Physiol., 135, 644-654.

BRUSILOW, S. W. and R. E. COOKE (1959). Role of parotid ducts in secretion of hypotonic saliva. Amer. $\mathcal{F}$. Physiol., r 96, 83 I-834.

BURGEN, A. S. V. (1955). The osmotic work of salivary secretion in the dog. f. cell. comp. Physiol., 45, 465-478.

- (1956a). The secretion of potassium in saliva. F. Physiol., r32, 2039.

- ( $1956 b)$. The secretion of non-electrolytes in the parotid saliva. $\mathcal{F}$. cell. comp. Physiol, 48, I I 3 - 138 .

- (1958). The secretion of lithium in the saliva of the dog. Can. $\mathcal{F}$. Biochem. Physiol., 36, 409-4I I.

- (1960). To be published.

BURGEN, A. S. V. and P. SEEMAN (I957). The secretion of iodine in saliva. Can. F. Biochem. Physiol., 35, 481-489.

BURGEN, A. S. V., D. SLOME and C. A. KEELE (r 949). Pharmacological actions of tetraethyl pyrophosphate and hexaethyl tetraphosphate. $\mathcal{F}$. Pharmacol., 96, 396-409.

BURGEN, A. S. V., K. G. TERROUX and E. GONDER (I959). The sites of transfer of sodium, potassium and iodide in the parotid duct system of the dog. Can. F. Biochem. Physiol., 37, 359-370.

BURGEN, A. S. V., M. WEISS and G. WEISS (I960). In preparation.

CHAUNCEY, H. H., V. F. LISANTI and R. A. WINER (I958). Human parotid saliva: flow rate and interrelationships of $\mathrm{pH}$ and inorganic components. Proc. Soc. exp. Biol., N.Y., 97, 539-542.

CHAUNCEY, H. H. and P. A. WEISS (1958). Composition of human saliva. Parotid gland secretion: flow rate, $\mathrm{pH}$ and inorganic composition after oral administration of a carbonic anhydrase inhibitor. Arch. int. Pharmacodyn, I1 3, 377-383.

CLARK, C. W. and J. J. SHELL (i 927). Influence of diet upon the inorganic constituents of human saliva. Dental cosmos., 69, 605-6r 7.

COATS, D. A. and R. D. WRIGHT (I957). Secretion by the parotid gland of the sheep: The relationship between salivary flow and composition. $\mathcal{F}$. Physiol., r35, 6 I I-622.

COHEN, B., J. H. LOGOTHETOPOUlos and N. B. MYANT (I955). Autoradiographic localisation of Iodine-I 3 in the salivary glands of the hamster. Nature, I76, 1 268-1 269. 
COHEN, B. and N. B. MYANT (r 959), Concentration of salivary iodide; a comparative study. F. Physiol., I45, 595-6 го.

DENTON, D. A. (1956). The effect of $\mathrm{Na}$ depletion on the $\mathrm{Na}: \mathrm{K}$ ratio of the parotid saliva of the sheep. F. Physiol., r31, 516-525.

- (1957a). The effect of variation of secretion rate and blood flow on the parotid saliva composition of $\mathrm{Na}$ depleted sheep. F. Physiol., I35, $227-244$.

- (r957b). The study of sheep with permanent unilateral parotid fistulae. Quart. F. exp. Physiol., 42, 72-95.

DENTON, D. A. and I. R. MCDONALD (1956). The effect of a rapid change of $\mathrm{Na}$ balance on the $\mathrm{Na}, \mathrm{K}$ ratio of the parotid saliva of $\mathrm{Na}$ depleted sheep. F. Physiol., I33, 37-38P.

EDWARDS, D. A., K. FLETCHER and E. N. ROWLANDS (1954). Antagonism between perchlorate, iodide, thiocyanate and nitrate for secretion in human saliva. Lancet, 266, 498-499.

EGGERS-LURA, H. (1947). Investigations on the salivary phosphates and phosphatases. F. dent. Res., 26, 203-224.

FERGUSON, M. H., A. NAIMARK and J. A. HILDES (1956). Parotid secretion of iodide. Can. F. Biochem. Physiol., 34, 683-688.

- - (1957). The interrelationship between the parotid secretion of thiocyanate, iodide and chloride. Can. F. Biochem. Physiol., 35, $333-337$.

FERRARI, R. and R. HÖBER (1 933). Untersuchungen über den der Sekretionsarbeit zugrunde liegenden Stoffwechsel von Leber, Niere und Speicheldrüse. Arch. ges. Physiol., 232, 299-321.

FLETCHER, K., A. J. HONOUR and E. N. ROWLANDS (1 956). Studies on the concentration of radioiodide and thiocyanate by slices of the salivary gland. Biochem. F., 63, 194-199.

FREINKEL, N. and S. H. INGBAR (I953). Concentration gradients for inorganic $\mathrm{I}^{\mathbf{1 3 1}}$ and chloride in mixed human saliva. $\mathcal{F}$. clin. Invest., 32, 1077-1084.

FRIEDBERG, S. J. and E. M. DOYLE (I 959). Clinical Research, 7, I 50.

GODING, J. R. and D. A. DENTON (I956). The adrenal cortex and the parotid secretion of sodium depleted sheep. Science, I23, 986-987.

GRAD, B. (I952). The influence of ACTH on the sodium and potassium concentration of human mixed saliva. F. Clin. Endocr., 12, 708-718.

GREGERSEN, M. I. and E. M. INGALLS (I93I). The influence of rate of secretion on the concentration of potassium and sodium in the dog submaxillary saliva. Amer. F. Physiol., 98, 44 I-446.

HENRIQUES, B. L. and H. H. CHAUNCEY (1958). Comparative electrolyte concentrations of submaxillary and parotid salivas. F. dent. Res., 37, 28-29.

HildES, J. A. (1955). Glandular secretion of electrolytes. Can. F. Biochem. Physiol., 33, 48I-490.

HILDES, J. A. and M. H. FERGUSON (I 955). The concentration of electrolytes in normal human saliva. Can. F. Biochem. Physiol., 33, 21 7-225.

HOLTZlöHnER, E. (r93I). Die Drüsentätigkeit bei Nervenreizung. I. Sekretionstachogramme der Glandula submaxillaris bei Reizung der Chorda tympani. Z. Biol., 9I, 53 I-55r.

HONOUR, A. J., N. B. MYANT and E. N. ROWLANDS (1952). Secretion of radioiodine in digestive juices and milk in man. Clin. Sci., I I, 447-462. HOWELL, G. L. and L. MIDDLESWORTH (I956). Gastric iodide and chloride clearances in dogs. Proc. Soc. exp. Biol., N.Y., 93, 602-605. 
HUNGERLAND, H., J. QUENZLEIN and H. WEBER (1957). Über den Natriumund Kalium-gehalt des Speichels gesunder Säuglinge, Kinder und Erwachsener. Z. Kinderheilk., 80, i 78-189.

JAPELli, G. (I 906). Über die physiko-chemischen Bedingungen der Speichelabsonderung. Z. Biol., 48, 398-43 I.

KAISER, E., R. H. KUNSTADTER and R. S. MENDELSOHN (I956). Electrolyte concentrations in sweat and saliva. Amer. F. Dis. Child, 92, 369373 .

KESZTYÜs, L. and J. MARTIN (i 937). Über den Einfluss von Chorda- und Sympathicus-reizung auf die Zusammensetzung des Submaxillarspeichels. Arch. ges. Physiol., 239, 408-4I8.

KÖSTLIN, A. and S. RAUCH ( I 957). Zur Chemie des Ruhespeichels einzelner Speicheldrüsen. Helv. Med. Acta, 24, 600-62 I.

KRASNOW, F. (I945). Physiological significance of phospholipid in human saliva. 7 . dent. Res., 24, 2 I9-326.

LANGley, L. C., C. H. GUNTHORPE and W. A. BEALl (1958). Parotid clearance of sodium and potassium. Amer. F. Physiol., I95, 693-696.

LANGSTROTH, G. O., D. R. MCRAE and G. W. STAVRAKY (I938a). The secretion of protein material in the parasympathetic submaxillary saliva. Proc. Roy. Soc. B., 125, 335-347.

- - - (1938b). A study of cat's submaxillary saliva obtained under nerve stimulation or adrenaline administration. Arch. int. Pharmacodyn., 58, $6 \mathrm{I}-77$.

Lipschitz, W. (I929a). Der Durchtritt der Halogene durch die Membranen des tierischen Organismus. Arch. exp. Path. Pharmak., I47, $142-167$.

- (1929b). Die Bedeutung des “inneren Kreislaufes” für Krystalloide, speziell das Jodion. Klin. Wschr., 8, I I6- I 17.

Logothetopoulos, J. H. and N. B. MYANT (1956). Concentration of radioiodide and $\mathrm{S}_{35}$ thiocyanate by the salivary glands. $\mathcal{F}$. Physiol., I34, I 89-I 94 .

LOURIE, R. S. (I943). Rate of secretion of parotid glands in normal children. Amer. F. Dis. Child., 65, 455-479.

LUNDBERG, A. (1957). The mechanism of establishment of secretary potentials in sublingual gland cells. Acta physiol. scand., 40, 35-38.

- (1958). Electrophysiology of the salivary glands. Physiol. Rev., 38, $2 \mathrm{I}-40$.

MCCANCE, R. A. (I938). The effect of salt deficiency in man on the volume of the extracellular fluids and on the composition of sweat, gastric juice and cerebrospinal fluid. F. Physiol., 92, 208-2 I 8.

MCCLANAHAN, H. H. and W. R. AMBERSON (I935). Bicarbonate elimination through the salivary glands under nervous and chemical stimulation.

7. Pharmacol., 53, 189-197.

M Clure, F. J. (I94 I). Fluorine in human saliva. Amer. F. Dis. Child., 62, 5 I $2-5$ I 5 .

MALTESOS, C. and R. WEIGMANN (1939). Über den Sekretionsablauf der Unterkieferdrüse bei Chordareizung. Arch. ges. Physiol., 241, 64I.

MARTIN, D. J. and I. N. HILL (1950). The fluorine content of saliva and its relaticnship to lactobacillus counts and the prevalence of dental caries. $\mathcal{J}$. dent. Res., 29, 29 I-297.

MARTIN, J. A. (I958). Intérêt des dosages de sodium et potassium salivaires pour l'exploration cortico-surrenalienne. Ann. Biol. clin. (Paris), r6, 546-55 I. 
NIEDERMEYER, W., R. E. STONE, S. DREIZEN and T. D. SPIES (1955). 'The effect of 2-acetylamino-r,3,4-thiadiazole-5 sulphonamide (Diamox) on sodium, potassium, bicarbonate and buffer content of saliva. Proc. Soc. exp. Biol., N.Y., 88, 273-275.

PRADER, A. and E. GAUTIER (1955). Die Na- und K-Konzentration im gemischten Speichel. II. Erhöhte Werte bei der Pancreasfibrose. Helv. Paed. Acta, 10, 56-62.

PRADER, A., E. GAUTIER, R. GAUTIER and D. NAEF (I955). Die Na- und KKonzentration im gemischen Speichel. I. Der Einfluss von Sekretionsgeschwindigkeit, Stimulations und Sammelmethode, Geschlecht, Alter, Tageszeit und Salzgehalt der Nahrung. Helv. Paed. Acta, ro, 29-55.

RAUCH, S. (1956). Zur Physiologie und Pathologie der Speicheldrüsen. Schweiz. med. Woch., 86, 77 I-775.

ROSE, G. A. and A. C. KERR (I958). The amino acids and phosphoethanolamine in salivary gland secretions of normal men and of patients with abnormal calcium, phosphorus and amino acid metabolism.

Quart. F. exp. Physiol., 43, I60-168.

ROWLANDS, E. N., D. A. W. EDWARDS and A. J. HONOUR (I 953). Study of effect of perchlorate and thiocyanate on salivary iodide. Clin. Sci., I2, 399-406.

SAND, H. F. (I949). The carbonic acid content of saliva and its role in the formation of dental calculus. Thesis, University of Oslo.

SAND, H. (I95I). Source of the bicarbonate of saliva. F. appl. Physiol., 4, $66-76$.

SCHMidt-Nielsen, B. (I946a). Micro determination of $\mathrm{pH}$ in saliva. Acta physiol. scand., Ir, 97-I03.

- (1946b). The $\mathrm{pH}$ in parotid and mandibular saliva. Acta physiol. scand., II, IO4-I IO.

SCHNEYER, C. A. and L. H. SCHNEYER (I959). Electrolyte levels of rat salivary secretions. Proc. Soc. exp. Biol., N.Y., ror, 568-569.

SEEMAN, P. (1956). The exchange of sodium and potassium in salivary glands. M.Sc. Thesis, McGill University.

STEVENS, J. (1953). The secretion of radioactive phosphorus in saliva and gastric juice in man. Clin. Sci., I2, 375-383.

STUBER, B. and K. LANG (1929). Blutgerinnung u. Fluorgehalt des Blutes. Biochem. Z., 212, 96-IOI.

THAYSEN, J. H., N. A. THORN and I. L. SCHWARTZ (1954). Excretion of sodium, potassium, chloride and carbon dioxide in human parotid saliva. Amer. F. Physiol., I78, I 55-1 59.

TIEDEMANN, F. and L. GMELIN (I826). Recherches experimentale physiologiques et cliniques sur la digestion. Baillière, Paris.

Tosteson, D. C. (I959). Halide transport in red blood cells. Acta physiol. scand., 46, I9-4I.

TOWBIN, E. J. and W. H. PERKINS (I 958). Salivary secretion of $I^{131}$. Physiologist, $\mathbf{1}, 82$.

WECHSLER, A. (I 959). The secretion of bicarbonate in saliva. M.Sc. Thesis, McGill University.

- (1960). To be published.

WERTHER, M. (1886). Einige Beobachtungen über die Absonderung der Salze im Speichel. Arch. ges. Physiol., 38, 293-3 I I.

ivhite, A. G., P. S. ENTMACHeR, G. RUBiN and L. LeITER (1955). Physiological and pharmacological regulations of human salivary electrolyte 
concentrations: with a discussion of electrolyte concentrations of some other exocrine secretions. F. clin. Invest., 34, 246-255.

White, J. and R. W. BUNTING (1936). Chemical composition of saliva. Amer. F. Physiol., II7, 529-532.

WILLS, J. H. (1940). The secretion of intravenously injected fluorine in the submaxillary saliva of cats. F. dent. Res., 19, 585-590.

- (1943). Secretion of intravenously injected electrolytes in the submaxillary saliva of cats. $\mathcal{F}$. dent. Res., 22, 27-31.

WYNGaARDEN, J. B., J. B. STANBURY and в. RAPP (1953). The effects of iodide, perchlorate, thiocyanate and nitrate administration upon the iodide concentrating mechanism of the rat thyroid. Endocrinology, 52, 568-574.

WYNGAARDEN, J. B., B. M. WRIGHT and P. WAYS (1952). The effect of certain anions upon the accumulation and retention of iodide by the thyroid gland. Endocrinology, 50, 537-549.

YOSHIMURA, H., H. IWASAKI, T. NISHIKAWA and S. MATSUMOTO (1959). Role of carbonic anhydrase in the bicarbonate excretion from salivary glands and mechanism of ionic excretion. Fap. F. Physiol., 9, 106-123. YOSHIMURA, H., W. TAKAOKA and T. MORI (I 954). Essential factors governing the acid-base balance of saliva. Fap. F. Physiol., 4, I54-158. 


\section{CHAPTER IX \\ THE PROTEINS AND ORGANIC \\ CONSTITUENTS OF SALIVA}

\section{PROTEINS}

The proteins of the saliva are complex in origin and nature and are not adequately described by the old classification of mucins and albumins. Further, the electrophoretic classification that has proved useful as a simple description of the plasma proteins helps rather little in the case of saliva. The beginnings of a system of mucoprotein classification based on sugar composition is being worked out by Blix and others but at present is handicapped by the impurity of the materials to which it has been applied. Indeed, it seems that progress in understanding salivary proteins will come only with the development of good methods of separation of the individual proteins that give adequate recognition to the lability of the native proteins. In this chapter we will deal with physical and chemical properties of the bulked or partly purified salivary proteins as well as with the specific protein components detected by enzymatic or other reactions.

\section{GENERAL PROPERTIES OF SALIVA PROTEINS}

The physical characteristics of saliva are determined by their protein constituents, for example, dog parotid saliva is usually limpid with a viscosity only slightly greater than that of water, whereas submaxillary saliva from the same animal is viscous, sticky and can readily be drawn out into long threads. These salivas contain comparable total quantities of protein bound carbohydrate; indeed the concentration in parotid saliva is frequently greater than in submaxillary saliva. Upon standing at room temperature for an hour or two the viscosity of submaxillary saliva usually decreases considerably so that already under these mild conditions changes in the saliva proteins have occurred. The gelatinous secretion of the palatine and sublingual glands represents an extreme of the viscous type of secretion. Ever since the discovery by Tiedemann and Gmelin (1826) that most of the viscous material of saliva 
could be precipitated by dilute acetic acid, this criterion has been used as a test for the presence of "mucin". Hammarsten (i 888) made a detailed study of methods of extraction of mucin from the salivary glands and found that the most satisfactory method was to extract with cold $0.1-0.2$ per cent hydrochloric acid and then dilute the extract with water when precipitation of the mucin occurred. By this method $0 . \mathrm{I}-0.2$ per cent of mucin is found in submaxillary saliva and $0.5^{-1}$ per cent in extracts of submaxillary glands; none is found in either parotid saliva or gland. McCrea (1953) has found neutral extraction of dried submaxillary glands to give less degradation of the polysaccharides. Komarov and Stavraky (1940) did not find that acetic acid or trichloracetic acid produced consistent or complete precipitation of the proteins in dog or cat submaxillary saliva although it produced apparently complete precipitation of the proteins of parotid saliva. They found that reliable precipitation was obtained by the addition of two volumes of acetone acidified with acetic acid. Araki (I95I) confirmed this finding and found that tungstic, metaphosphoric and sulphosalicylic acids were also unreliable precipitating agents. He found that saturation with ammonium sulphate was as satisfactory as acid alcohol or acetone. These findings provide a glimpse into the complex species differences between saliva proteins that make precipitation methods of doubtful reliability. The safest way to prepare saliva protein solutions from saliva is by ultrafiltration or equilibrium dialysis followed by lyophilization. Anomalous precipitation reactions are commonly found with a variety of mucoproteins and are presumably due to interference with reactions satisfactory for ordinary proteins by the hydrophilic properties of the carbohydrate residues in the molecule.

Viscosity in hyaluronate solutions and in synovial fluid has been studied carefully by Ogston (Ogston and Stanier, I95I; Blumberg and Ogston, 1958). The hyaluronate particles in solution are very dilute spheroids in which one gram of solid occupies a solute volume of $200-500 \mathrm{ml}$. The viscosity of the solution is due to the size of the particles and does not become excessive until overlap between the polymer domains occurs, i.e. when the concentration is greater than about $\mathrm{I} \mathrm{g} / 500 \mathrm{ml}$. In other words, as the molecular domains overlap, the polysaccharide chains interpenetrate, form larger aggregates and ultimately a rigid structure within which virtually all the solvent is trapped. Ogston has come to the conclu- 
sion that molecules having these properties have a voluminous random coil structure within which large volumes of solvent are trapped, this is in contrast to the more compact hydrogen bonded structure characteristic for ordinary proteins in solution. Presumably submaxillary and other viscous salivas contain mucoproteins with molecular configurations similar to those found in hyaluronate, whereas in the mucoproteins of non-viscous saliva the intramolecular structure is determined more by the peptide framework than by long freely coiling polysaccharide chains.

The property of forming a "mucin clot" with dilute acid appears to be restricted to acidic mucoproteins, i.e. those with free carboxyl groups of uronic acids or sulphato groups of sulphohexosamine. While the free polysaccharide may show this reaction in dilute solution it usually needs the presence of proteins such as serum albumin for an insoluble complex to form. The nature of the precipitate is quite dependent on the character of this adsorbed protein. For instance, hyaluronate forms a stringy clot in the presence of native albumin, but a flocculent precipitate in the presence of partly proteolysed albumin. Komarov and Stavraky (1940) noted that the saliva produced by sympathetic stimulation of the cat submaxillary gland gave a flocculent precipitate with acid acetone, whereas chorda saliva from the same gland precipitated as compact viscous masses. While part of this difference is probably due to intrinsic differences in the protein secreted coprecipitation effects may also be involved.

The multicomponent nature of saliva proteins has been demonstrated by electrophoresis, ultracentrifugation and immunological methods (Blix, I940; Patton, I956; Patton and Pigman, 1957, I959; Köstlin and Rauch, I957; Ferguson, Krahn and Hildes, I 958; Ellison and Mashimo, I958; Motta and Motta, I958; Gabl and Egger, 1959). In the best of the electrophoretic studies 5-9 distinct components were found which differ in submaxillary and parotid saliva (Figs. 9. I and 9.2). In human parotid saliva the major peak has been identified as amylase (which is not present in all parotid salivas; $v$. infra). In submaxillary saliva the major component is a mucroprotein of low mobility, presumably a neutral mucoprotein, but carbohydrate-rich fractions of high mobility (acidic mucoproteins) are also present. In the ultracentrifuge, parotid saliva shows 4 components ( $1 \cdot 1,2 \cdot 0,4.2$ and 10.7-Svedberg units) and submaxillary saliva 3 components (I.3, 4.I and II.O 
- Svedberg units). Apart from amylase none of these components has been definitely characterized. By the gel diffusion technique 8 components have been recognized in tests between human mixed saliva and antisera prepared against it. Of these 4 components appear also to be present in plasma but the other 4 are not. In

Serum

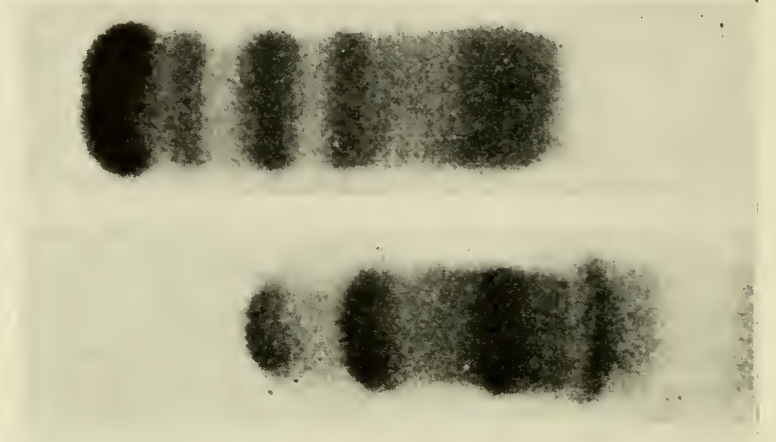

Parotid saliva

Submaxillary saliva

saliva

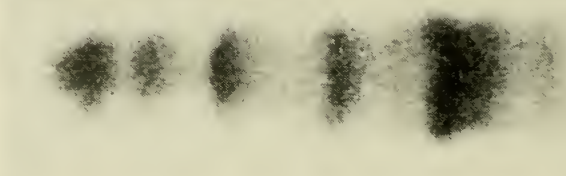

Serum

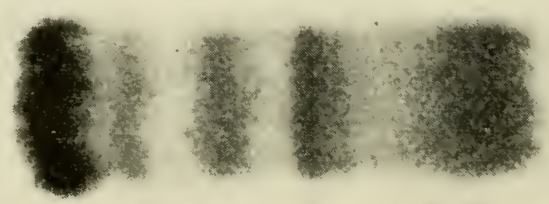

FIG. 9. I. Paper electrophoresis of human parotid and submaxillary saliva compared with blood serum. Michaelis buffer $\mathrm{pH} 8.5$.

(Köstlin and Rauch, 1957.)

multiple myeloma the characteristic abnormal serum proteins have also been found in the saliva (Gabl and Egger, I959).

Logically studies of the composition of salivary proteins should be preceded by their isolation in the pure state, but so far this has been accomplished only in the case of amylase and lysozyme, neither of which are mucoproteins. All studies on "mucin" have been carried out on impure fractions often prepared by methods that we know produce partial degradation. Indeed glycoside bonds 
are quite readily hydrolysed under the acid conditions commonly used for isolation of mucins.

On the basis of chemical studies, mucoproteins from various sources have been divided up into three broad classes.

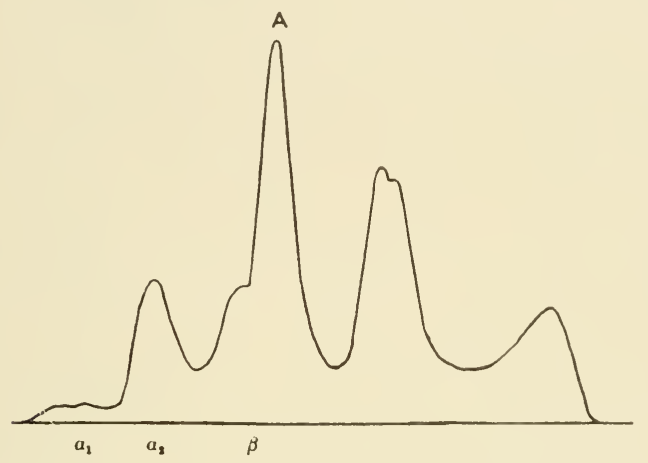

(a)

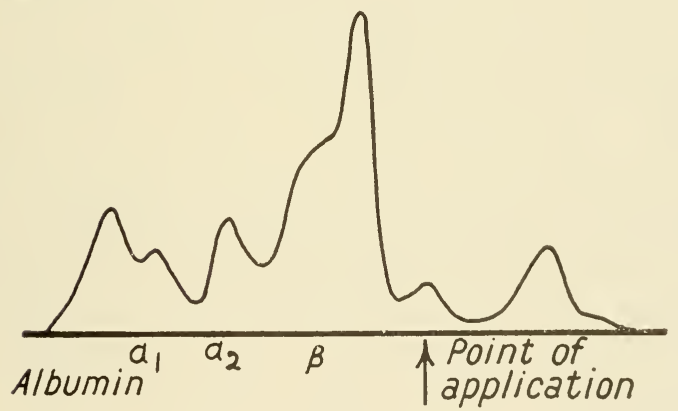

(b)

FIG. 9.2. Densitometry of paper electrophoretograms of $(a)$ human parotid saliva: the peak marked $A$ contains the amylase activity, $(b)$ human submaxillary saliva.

The arrow marks point of application, note that some fractions move towards the cathode. The notations $A l b, \alpha_{1}, \alpha_{2}, \beta$ indicate the portions of these fractions in plasma (Köstlin and Rauch, I 957 ).

I. Fucomucins-composed of about equal amounts of fucose (6-deoxygalactose), glucosamine, galactosamine and galactose.

2. Sialomucins - probably composed exclusively of sialic acid and $\mathrm{N}$-acetylgalactosamine.

3. Mucoitin sulphuric acid-composed of equal amounts of Nacetyl-glucosamine, glucuronic acid, and sulphuric acid. 
These classes do not account for the consistent presence of mannose and glucose and occasionally ribose in hydrolysates of mucin. Presumably there is at least one more chemical class of mucin (Blix, I940; Blix, Svennerholm and Werner, I952; Werner, 1953; Kent and Whitehouse, I955; Odin, 1958).

There is no evidence that mucoitin sulphuric acid is a normal constituent of saliva as neither isolated salivary mucin nor, saliva contain appreciable amounts of ester sulphate (Blix, I936; Meyer, I945; Knox and Still, I953). The high sulphur content reported in samples of "isolated mucin" (for instance by Komarov and Stavraky, 1940) is due to the presence of sulphur containing aminoacids. It is interesting that both the other mucoprotein classes are characterized by a high proportion of sugars with the galactose configuration (i.e. galactose, 6-deoxygalactose, galactosamine and galacturonic acid). The sialomucins are quite labile and readily lose sialic acid in mild acid solutions. They are probably a major constituent of submaxillary saliva proteins but their presence in parotid saliva in man or animals does not seem to have been looked for. Bovine submaxillary mucin prepared by McCrea's method contained $27 \cdot 5$ per cent sialic acid, I 2 per cent galactosamine, 4 per cent glucosamine and 3.5 per cent galactose and fucose (Odin, I 958). The glucosamine and fucose content is probably due to admixture of some fucomucins with the predominant sialomucins. On the other hand a typical fucomucin from a pseudomucinous ovarian cyst contained 19 per cent hexosamine, Io per cent galactose, 9 per cent fucose and I. 6 per cent sialic acid. An important fucomucin present in submaxillary saliva has blood group properties.

Sialic acid. Sialic acid was or iginally crystallized from a material released from a mild acid hydrolysis of submaxillary mucin. In its reactions it resembles $\mathrm{N}$-acetyl-hexosamine but gives an Ehrlich reaction without alkali pretreatment and a purple colour with orcinol. This acid has been identified in many muco- and glycoproteins, including submaxillary mucin, nasal, tracheo-bronchial, gastric and intestinal mucus, brain ganglioside, urinary mucoprotein, erythrocytes and amyloid substances (Klenk, I94I, I958; Werner, I953; Zilliken, I956; Zilliken and Whitehouse, r958; Gottschalk, i 960 ).

The structure of sialic acid seems now to be well established as a substituted 9 carbon amino-ketoseuronic acid of a quite novel 
type. Cornforth, Daines and Gottschalk (1957) have obtained this substance in low yield on heating $\mathrm{N}$-acetyl-glucosamine and oxalacetic acid; further, on treatment of sialic acid with Vibrio cholerae extracts, it is enzymatically split into $\mathrm{N}$-acetyl-D-glucosamine and pyruvate (Heimer and Meyer, I956), so that sialic acid can be regarded as an aldol condensate of these two substances. The name agreed upon by most of the workers in the field is neuraminic acid for the unsubstituted acid $\left(R_{1}=R_{2}=H\right)$; the substituents

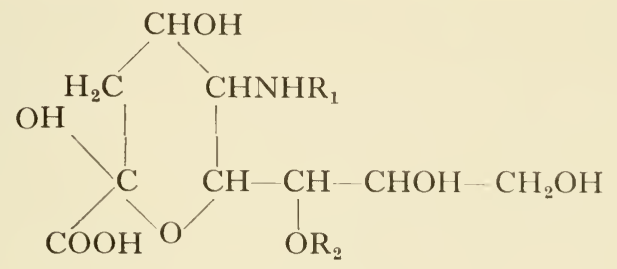

Neuraminic acid

in $R_{1}$ and $R_{2}$ vary. Human and sheep sialic acids have an $N$-acetyl substituent, pig an $\mathrm{N}$-glycolyl and cow and horse $\mathrm{O}, \mathrm{N}$-diacetyl substituents; the latter are not identical but differ in melting point, optical activity and X-ray spectra, presumably they are stereoisomers (Blix, Lindberg, Odin and Werner, 1956; Svennerholm, 1956).

Since the neuraminic acids are strongly reducing and the mucins are not, glycoside formation between neuraminic acid and other sugar residues must occur through the 2-keto group. On mild hydrolysis of mucin in hot water or enzymatic hydrolysis with $V$. cholorae extracts ("Receptor destroying enzyme" or RDE) or influenza virus (Gottschalk, 1957) the only soluble material released may be neuraminic acid in amounts up to 50 per cent of the total present in the unhydrolysed mucin or roughly io per cent by weight of submaxillary mucin. It seems likely therefore that much of the neuraminic acid in mucin is terminal. With more vigorous hydrolysis some of the neuraminic acid is recovered as the glycoside neuraminyl-N-acetyl-galactosamine (Gottschalk, I958). It is possible that the major part of the carbohydrate of mucin consists of these short disaccharide units covalently bound to peptide side chains. The nature of the bond between glycosides and amino-acids is at present quite obscure. The presence of neuraminic acid in a mucoprotein gives it strong acidic properties since the $\mathrm{pK}^{\prime}$ of neuraminic acid is about 2.7 . The major component 
of the high mobility mucoproteins found on electrophoresis of saliva is a sialomucin. The inhibitory action of mucin and other neuraminic acid containing substances on the haemaglutination produced by some viruses (e.g. influenza) is due to the presence in these organisms of an enzyme (neuraminidase) with an affinity for neuraminyl terminal groups and the power to hydrolyse the glucoside linkage joining neuraminic acid to the next carbohydrate residue. Mucin prevents haemagglutination by providing neuramidyl groups which compete with those on the red cells for the virus neuraminidase (Gottschalk, I954, I958).

\section{BLOOD GROUP SUBSTANCES}

Soluble blood group specific substance is present in human submaxillary saliva (Landsteiner and Harte, I94I). This substance has the same characteristics as the agglutinogen on the erythrocyte and may be demonstrated by direct precipitin reaction with type specific sera or by inhibition of red cell agglutination. It is not precipitated by trichloracetic, picric or sulphosalicylic acids but is quantitatively precipitated by alcohol (see comprehensive review by Kabat, 1956 ).

Blood group substances are present in the submaxillary saliva from all individuals but if the red cells have the Le ${ }^{a}$ antigent the saliva contains Le $\mathrm{L}^{\mathrm{a}}$ substance rather than $\mathrm{A}, \mathrm{B}$ or $\mathrm{O}(\mathrm{H})$. Purified blood group substances from saliva seem to be typical fucomucins and there is rather little difference in gross chemical composition between $\mathrm{A}, \mathrm{B}, \mathrm{AB}, \mathrm{H}$ and Le $\mathrm{e}^{\mathrm{a}}$ substances (Morgan and Watkins, I959). The purified materials contain I4-I9 per cent of fucose and 24-32 per cent of hexosamine. By controlled hydrolysis, some disaccharides are produced and may be isolated. For instance, the following disaccharides were isolated from Group A substance:

I. $\alpha$-galactosyl I $\rightarrow 3 \mathrm{~N}$-acetyl galactosamine.

2. $\beta$-galactosyl $\mathrm{I} \rightarrow 3 \mathrm{~N}$-acetyl galactosamine.

3. $\beta$-galactosyl $\mathrm{I} \rightarrow 4 \mathrm{~N}$-acetyl galactosamine.

4. $\alpha-\mathrm{N}$-acetylgalactosaminyl $\mathrm{I} \rightarrow 3$ galactose.

5. $\beta$-N-acetylgalactosaminyl $\mathrm{I} \rightarrow 3$ galactose.

6. $\alpha$-fucosyl $\mathrm{I} \rightarrow 6 \mathrm{~N}$-acetylglucosamine.

This type of work may lead to the establishment of sugar sequences in the blood group substances comparable to that already successfully achieved for the amino-acid sequences in a number of pro- 
teins. The establishment of the end group character of sialic acid in submaxillary mucin has been mentioned above. Similar work on the blood group substances with enzymes from Trichomonas foetus and $\mathrm{Cl}$. welchii lead to release of fucose from $\mathrm{H}$ substance, $\alpha$-galactose from $\mathrm{B}$ substance and both fucose and $\beta$-galactose from Le $e^{a}$ substance.

The concentration of blood group substance in saliva is com-

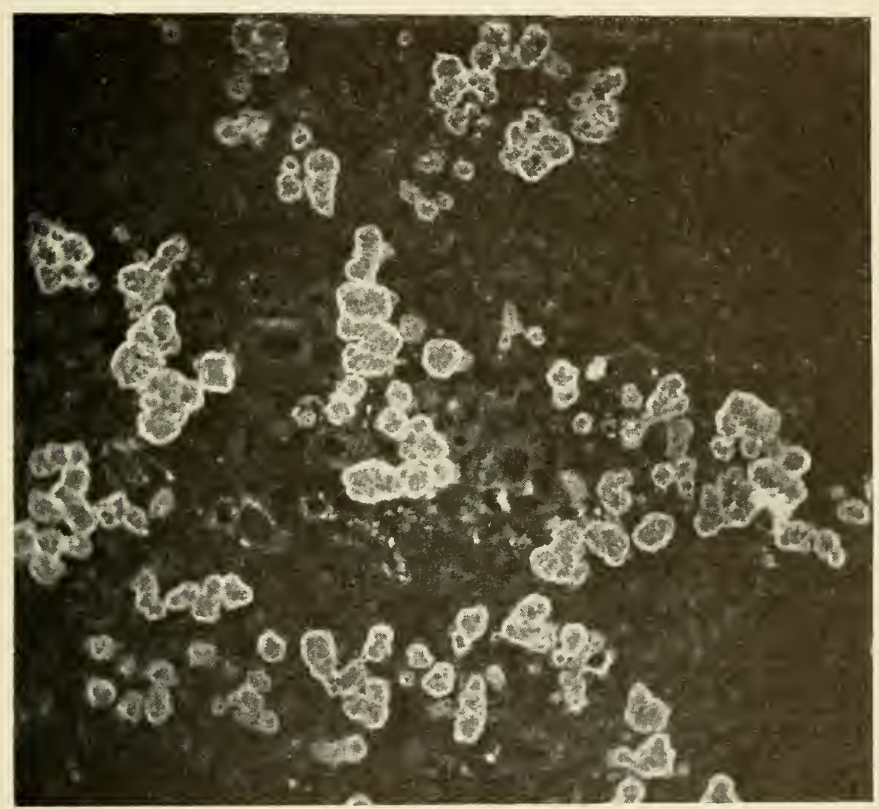

FIG. 9.3. Human submaxillary gland from a subject of erythrocyte Group A.

Stained with anti A-fluorescein conjugate by Coon's technique. Note the high concentration of A substance in the mucous cells and absence from serous cells or ducts. (Glynn and Holboron, 1959.)

monly of the order of $10-20 \mathrm{mg} / \mathrm{l}$. It is therefore only a relatively minor constituent of the total protein in saliva. In man very little activity is found in extracts of parotid gland (Hartmann, I94 I) as compared to submaxillary and the A substance cannot be detected in parotid saliva (Burgen, unpublished). Glynn and Holborow ( 1959 ) have studied the distribution of blood group substance in the human saliva glands using Coon's fluorescent antibody technique and found strong staining specifically in the mucous cells of the submaxillary gland with no staining in the duct cells (Fig. 9.3). 
In the parotid gland no specific staining for blood group substances was found. It appears therefore that in man the blood group substances are specifically secreted by the mucous cells of the submaxillary gland. Blood group substances have also been reported in the saliva of the horse, pig, cow, rabbit, sheep, goat, dog, elephant, guinea pig and monkey. In man secretion appears to be limited to the A, B, O and Le ${ }^{\mathrm{a}}$ substances.

\section{AMYLASE}

The discovery of amylase in saliva is usually attributed to Leuchs (I83I) but was actually described earlier by Tiedemann and Gmelin (1826). Amylase is present in the saliva of many species including man, apes, guinea pig, mouse, rat and rabbit but is absent or present only in very low concentrations in the parotid and submaxillary saliva of the dog, cat, cow, horse, sheep and goat. The absence of the enzyme in the saliva of some herbivores suggests that salivary digestion of starches is not of great importance. In the parotid saliva of man amylase is the major single protein component (Ferguson, Krahn and Hildes, I958; Köstlin and Rauch, I957; Patton and Pigman, I957). Amylase is present in human saliva at birth but its concentration is very low and only reaches near adult levels towards the first year of life (Nicory, I922; Mayer, I929). In human parotid saliva, the concentration of amylase is virtually independent of the rate of saliva secretion (Ferguson, Krahn and Hildes, 1958) but a transient reduction in salivary amylase occurs in man after internal radiation to the gland with $I^{131}$ (Schneyer, I953). In the mouse the amylase content of the salivary glands is only slightly dependent on sex or maturity, suggesting that it is not secreted by the granular tubule (see page $3 \mathrm{I}$ ) (Junqueira, Fajer, Rabinovitch and Frankenthal, I949; Reynaud and Rebeyrotte, 1949).

Amylase is readily crystallized from saliva following successive acetone and ammonium sulphate precipitations (Meyer, Fischer, Staub and Bernfeld, I948) and is a carbohydrate-free protein (Muus, I954) with a $\mathrm{pH}$ optimum of 6.9 and a requirement for chloride ions in order to reach full activity. Bromide, nitrate and iodide will replace chloride but yield a lower activity (Bernfeld, Staub and Fischer, I948). There is only one amylase in saliva, belonging as do all other animal amylases to the class of $\alpha$-amylases which specifically split I : 4-glycoside linkages. In linear starch and 
glycogen molecules amylase attacks the molecule at multiple points leading to the formation of dextrins (6-8 glucose units) which are unable to give a blue colour with aqueous iodine, these are split finally to about 87 per cent of maltose and i 3 per cent glucose. In the more common branched amylases, the branching occurs through $\mathrm{I}: 6$ linkages which are not susceptible to amylase action so that the hydrolytic products also contain iso-maltose (6-glucosido glucose) (Myrbäck and Neumüller, I950). Amylase release from salivary gland has been studied in vitro (Hokin and Hokin, I954; Hokin and Sherwin, 1957) and in vivo by Schneyer and Schneyer (1956). Variation in the amylase content of the salivary glands in different genetic mouse strains has been reported (Schneyer, I 958).

\section{LYSOZYME}

Fleming (1922; Fleming and Allison, I922) found that the saliva, tears, nasal mucus and serum as well as extracts of many tissues were capable of lysing certain bacteria. The substance responsible had enzymatic properties and was named lysozyme. A similar substance is present in egg white and certain plant materials. This substance has been isolated in crystalline form from egg white and spleen (Alderton, Ward and Fevold, I945; Jolles and Fromageot, I954) as a small protein of molecular weight I4,000 to I 5,000 with an alkaline isoelectric point. The two lysozymes differ in aminoacid composition. Cat and human saliva lysozymes which have not so far been obtained pure can be distinguished immunologically (Roberts, Macgraith and Florey, 1938). The term lysozyme, therefore, applies to a family of substances. Lysozyme is bacteriolytic for organisms belonging to the genera Bacillus, Micrococcus, Staphylococcus, Streptococcus, Proteus and Brucella. Lysis occurs due to hydrolysis of a constituent of the bacterial wall which appears to be a mucoprotein from which the enzyme is able to split off $\mathrm{N}$-acetyl-hexosamine and oligosaccharides containing $\mathrm{N}$-acetyl-hexosamine and a keto hexose (Meyer, Palmer, Thompson and Khorazo, 1936; Epstein and Chain, I940; Salton, 1957). Measurement of the lysozyme concentration in saliva is difficult because of the strong tendency of lysozyme to form inactive complexes with acidic polymers such as the sialomucins as well as due to interference by soluble substrates in the saliva. The enzyme is present in both parotid and submaxillary saliva in man and in animals 
(Hoerman, Englander and Shklair, 1956) and can be separated electrophoretically because it behaves as a cation at the usual $\mathrm{pH}$ employed for electrophoresis (Kinersley and Högberg, I955). The contribution of lysozyme to the antibacterial properties of saliva is still under debate (Thompson, 1940; Salton, 1957).

\section{KALLIKREIN AND FACTORS CONCERNED IN BLOOD}

\section{COAGULATION}

Injection of saliva intravenously produces a short-lived fall of blood pressure (Secker, I934; Feldberg and Guimarais, 1935). This effect was analysed in detail by Werle (Frey, Kraut and Werle, 1950; Werle, 1955) who showed that an enzyme in saliva and other body fluids and tissues acted on a plasma protein setting free a vasodilator polypeptide. The enzyme is called kallikrein and the polypeptide kallidin. Kallidin appears to be identical with bradykinin and the common name of plasma kinin has been adopted for this peptide. Kallikrein is found in both submaxillary and parotid secretion in man, cat, dog and cow, but not in the horse. The enzyme has also been detected in the perfusate from Ringer perfused salivary glands (Werle and Roden, I939). Hilton and Lewis (1957) have proposed that kallikrein release is responsible for the functional vasodilatation in the salivary gland during activity (see page I3I) and have also shown the presence of a kinin-destroying enzyme in saliva. Presumably both kinin production and destruction are due to the presence of proteolytic enzymes in saliva, but these must be quite specific in their action since they are unable to hydrolyse serum albumin, casein, or benzoyl arginamide. The mechanism of vasodilatation in horse salivary glands should be studied in view of the apparent lack of kallikrein in these glands.

Albrechtsen and Thaysen (1955) have examined human saliva for components of the fibrinolytic system and have found large amounts of proactivator, traces of activator, but no plasminogen. Resting saliva contained more proactivator than did stimulated saliva. Nour-Eldin and Wilkinson (1957) examined saliva for blood-clotting factors and found activity comparable to that classified in plasma as Christmas factor, antihaemophilic globulin and platelet factor, but no trace of factors V or VII. Saliva can replace platelets in the thrombin generation test but not in thromboplastin generation. Glazko and Greenberg (1939) had found a thrombo- 
plastin-like activity in saliva, presumably this can be equated with the platelet factor of the later workers.

\section{IODOPROTEINS}

In the dog, radioactive iodine is incorporated into some of the proteins secreted by the parotid gland (Burgen, Weiss and Weiss, 1959). Frequently over 50 per cent of the total iodine secreted is so bound and cannot be extracted by butanol or other organic solvents. After tryptic digestion of the proteins and chromato-

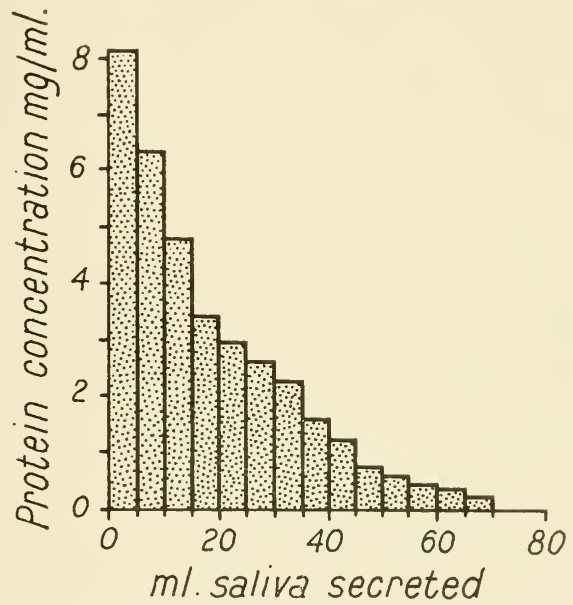

FIG. 9.4. Protein concentration in successive 5-ml. portions of saliva secreted by the dog submaxillary gland.

Data of Anrep (1921).

graphy most of the iodine is found as monoiodotyrosine and small amounts as di-iodotyrosine but no detectable amounts of thyronines. Presumably the iodotyrosines are present in the peptide structure of the proteins. The organic incorporation of iodine is inhibited by thiouracil and other drugs which can block incorporation of iodine in the thyroid gland. This iodine-containing protein represents only a small proportion of the total salivary protein as judged by paper electrophoresis since the peak of radioactivity is found to lie between the three main peaks of protein concentration present in dog parotid saliva.

No organic iodine is present in human saliva (Ferguson, Krahn and Hildes, 1958) but organic iodine compounds perhaps similar 
to those produced by the dog, are formed by slices of the rat submaxillary gland in vitro ('Taurog, Potter, Tong and Chaikoff, I956). An iodine protein apparently similar to that present in the saliva has been found in milk from several species (Brown-Grant and Galton, 1958).

\section{TOTAL PROTEIN SECRETION}

It has been known for a long time that the concentration of protein in the saliva is in general dependent on the rate of saliva secretion, and also that the concentration in the saliva is progressively lowered during prolonged stimulation of the salivary gland (Heidenhain, 1883; Langley, 1898). Anrep (1921) found that the protein concentration in the saliva from the submaxillary gland of the dog fell exponentially with the duration of stimulation (Fig. 9.4), a circumstance that is to be expected if the rate of protein synthesis by the gland is very low compared with the rate of protein secretion, so that secretion represents (for a given rate of nerve stimulation) removal of a fixed fraction of the available proteins stored in the gland per unit time. Anrep's experiments showed that about 20 per cent of the protein nitrogen of the resting gland was available for secretion; similar results have been obtained in the dog parotid (Burgen, Weiss and Seeman, 1959). Anrep and Khan (1923) found that restitution of the protein content of the saliva was very slow, needing some 48 to 72 hours for completion. Langstroth, McRae and Stavraky (1938a) provided an empirical mathematical basis for following the concentration of protein in the saliva at different phases of secretion. Stavraky (1940) pointed out that after prolonged stimulation the concentration of protein in saliva does not fall to zero but reaches a steady state presumably determined by a balance between the rate of synthesis and secretion of protein.

In Fig. 9.5 is seen a typical relationship between protein output and the flow of saliva. The concentration in the saliva rises more or less linearly with flow so that the total output of protein per unit time rises steeply with flow rate. The output of protein is not necessarily related to the flow of saliva but is rather a direct function of the stimulation of the gland. The following fact illustrates this: in a dog parotid gland the maximum rate of saliva flow is usually produced when the rate of stimulation of the auriculotemporal nerve reaches 20 to $30 \mathrm{c} / \mathrm{s}$, but further increase in fre- 
quency up to $50 \mathrm{c} / \mathrm{s}$ increases the concentration and output of protein without further increase in the flow of saliva (Burgen, Weiss and Seeman, I959). In human parotid secretion protein concentration seems less closely affected by rate of secretion (Ferguson, Krahn and Hildes, 1958). More detailed analysis of the output of protein from the dog parotid gland shows at the beginning of stimulation a short transient of high protein concentration

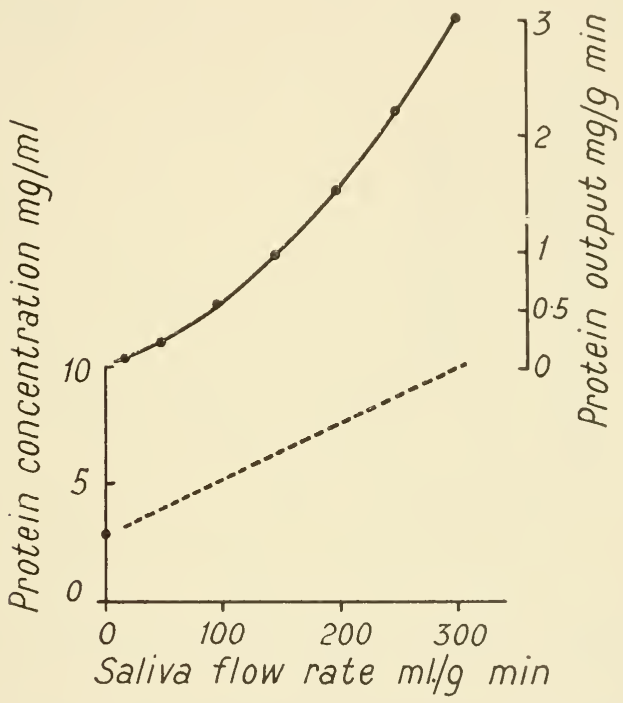

FIG. 9.5. Dog parotid secretion. Auriculo-temporal stimulation.

. - concentration of protein in saliva when saliva flow rate was altered by changing rate of nerve stimulation. - minute output of protein in the saliva.

followed by a minimum and the rather slow subsequent development of a steady protein concentration over the following 30 to 100 seconds (Fig. 9.6). The earlier protein peak $\left(P_{1}\right)$ is relatively independent of stimulation conditions and cannot be exhausted by repeated periods of stimulation, but on the other hand is highly dependent on the rest period following the previous period of stimulation. From its time of appearance and these characteristics it appears to result from a continuous secretion of protein from duct cells. In contrast the late phase of protein secretion can readily be exhausted by repeated stimulation and is dependent on stimulation frequency; it appears to be the result of acinar secretion of protein. The relatively long latency during which it develops 
reinforces the conclusion drawn above that the control of protein secretion is not directly dependent on water secretion.

In the submaxillary gland in both the cat and the dog stimulation of the sympathetic nerves produces a saliva rich in protein in which both the character and the concentration of the protein are relatively independent of the secretion produced by parasympathetic stimulation in the same gland (Langstroth, McRae and Stavraky, I938b; Kesztyüs and Martin, I937; Komarov and Stavraky, r940; Stavraky, 1940). For instance, when repetition of

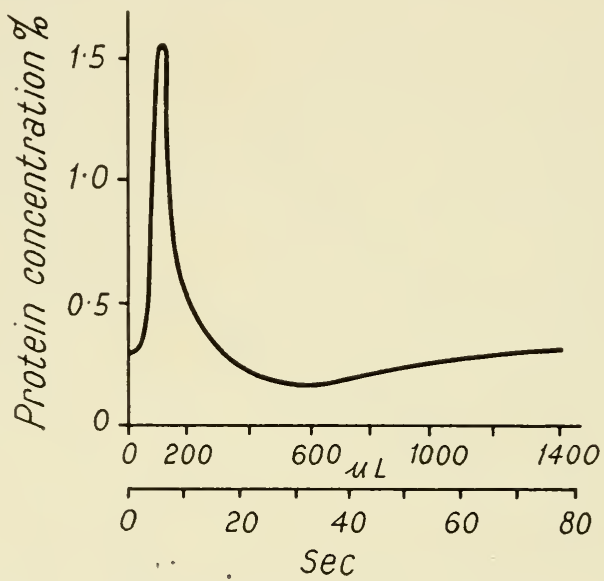

Fig. 9.6. Dog parotid. Auriculo-temporal stimulation at ro $\mathrm{c} / \mathrm{s}$. Single drops of saliva analysed.

A rest period of 40 minutes had been allowed since the last period of stimulation. Note that very soon after the start of stimulation a high peak of protein $(1 \cdot 5 \%)$ concentration $\left(P_{1}\right)$ is reached followed by a minimum $(0.15 \%)$ and then the gradual establishment of a steady protein concentration. The concentration of protein in $\mathrm{P}_{1}$ is dependent on the duration of the rest period.

chorda stimulation has reduced the protein concentration of the saliva to a low level sympathetic stimulation can still lead to a saliva relatively rich in protein. In addition, the protein produced by sympathetic stimulation appears to differ in physical and possibly chemical properties from that produced by chorda stimulation, although it is not possible to say whether this is due to the addition of a specific component or merely to a change in the proportions of proteins present. In any case since there is evidence (Ch. III) that the sympathetic and parasympathetic nerve fibres innervate the same cells within the gland this difference must be explained as the result of specific effects by the autonomic transmitters on extrusion of particular intracellular materials. 


\section{AMINO-ACIDS}

The concentrations of free amino-acids in human saliva have been measured by microbiological assay and by paper and column chromatography (Kirch, Kesel, O’Donnell and Wach, I947, I953; Berry, I95I; Moor and Gilligan, I95I; Berry and Cain, I95I; Capozzi, I954; Woldring, I955; Rose and Kerr, 1958). Free amino-acids are present in saliva although in concentrations lower than in plasma. For the most part the concentrations are of the order of IO-20 per cent of the plasma level, but higher percentages have been reported for glycine, histidine, isoleucine and tyrosine. In addition, quite large amounts of $\gamma$-amino glutamate, taurine and $\mathrm{O}$-phosphoethanolamine are found in both parotid and submaxillary salivas and indeed represent the most intense ninhydrinpositive spots on the paper chromatogram. In submaxillary saliva part of the O-phosphoethanolamine appears as the hydrolytic product ethanolamine due to the action of the weak alkaline phosphatase present in the saliva. When the level of free amino-acids in the blood is raised, the concentrations in the saliva follow the plasma levels passively. Rose and Kerr found no appreciable change in the saliva amino-acid pattern in patients with cystinuria and hypophosphatasia. They also found that the concentration of amino-acids was lower when the salivary flow rate was high than when it was low. Martin ( 1959) has found that with the exception of proline and hydroxyproline which are present in saliva at about half the plasma concentration, all the other amino-acids in dog parotid saliva are present at less than io per cent of the plasma level. Phosphoethanolamine, taurine and $\gamma$-amino glutamate are not present in appreciable amounts in dog saliva. Rather higher concentrations of all the amino-acids were found in dog submaxillary saliva. Intra-arterial injection of $\mathrm{C}^{14}$-valine, tyrosine, methionine or isoleucine into the arterial supply to the parotid gland did not lead to the appearance of detectable amounts of either free or protein-bound labelled amino-acids in the saliva within two minutes of injection. This means either that a relatively large aminoacid pool exists in the salivary gland to supply immediate needs for protein synthesis or that the amino-acid is effectively trapped by a peptide synthesis within the gland with delayed release of the protein. Amberson and Höber (1932) found the perfused cat submaxillary gland to be impermeable to glycine and alanine. 
In summary it appears that the salivary $\alpha$-amino-acids are derived from plasma amino-acids because they reflect the plasma concentrations quite accurately, but in addition in human saliva three non- $\alpha$-amino-acids are present in high concentration and are probably the product of gland metabolism.

\section{GLUCOSE}

The absence of appreciable amounts of glucose in normal saliva has generally been reported (Pearce, I9I6; Johns, I933; Morris and Way, 1924; Hebb and Stavraky, 1936; Langley, Gunthorpe and Beall, 1958; Pigman and Hawkins, 1958). Pigman and Hawkins, using chromatographic analysis, found no trace of free

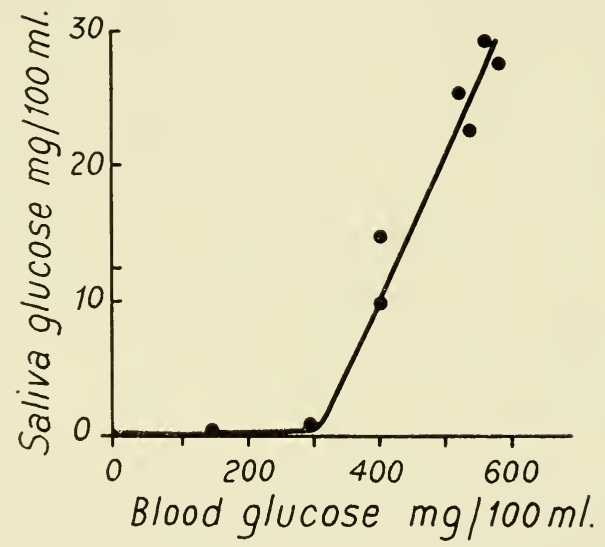

FIG. 9.7. Concentration of glucose in cat submaxillary saliva as the blood glucose concentration was raised.

No significant concentration was found when the blood level was less than about $300 \mathrm{mg} / 100 \mathrm{ml}$. (data of Hebb and Stavraky, 1936).

glucose, glucosamine, $\mathrm{N}$-acetyl-glucosamine or other reducing monosaccharides in saliva, the small amount of dialysable reducing substance present appeared to be a mixture of oligosaccharides. Amberson and Höber (1932) found that small amounts of glucose passed into the saliva in their perfused submaxillary preparations. Hebb and Stavraky (Fig. 9.7) found that when the blood-sugar level exceeded $300 \mathrm{mg} / \mathrm{r} 00 \mathrm{ml}$. small amounts of glucose appeared in the saliva, and were proportionate to further increase in the blood concentration. The amounts found were relatively small, for instance at a plasma glucose level of $500 \mathrm{mg} / \mathrm{r} 00 \mathrm{ml}$. the saliva glucose was only $25 \mathrm{mg} / \mathrm{I} 00 \mathrm{ml}$. Langley, Gunthorpe and Beall 
similarly found that in the dog parotid stimulated by pilocarpine the glucose threshold averaged $500 \mathrm{mg} / \mathrm{I} 00 \mathrm{ml}$. Hebb and Stavraky also made the interesting observation that administration of enough adrenaline to cause a flow of saliva resulted in the appearance of large amounts of glucose in the saliva, and that this increased glucose permeability persisted for many hours after the initial adrenaline injection. Sympathetic stimulation was not effective in producing this response, but the adrenaline effect was not purely pharmacological as was shown in experiments in which cats were exposed to cold and were found to have glucose in their saliva due to endogenous adrenaline release. Noradrenaline is less effective (Martin, 1959) in producing this response and perhaps the ineffectiveness of sympathetic stimulation may be due to release only of noradrenaline by the nerve terminals. This effect of adrenaline is not peculiar to the submaxillary gland of the cat but is also found in the dog submaxillary and blood glands and affects the concentrations of amino-acids, creatinine, sucrose, electrolytes and probably other constituents of saliva as well as glucose (Martin, 1959; Langstroth, McRae and Stavraky, 1938b). It has recently been found (Langley, Gunthorpe and Beall, I958) that the salivary glucose threshold is considerably lowered in dogs made diabetic with alloxan and is raised by insulin administration. Pearce (1916) claimed that phloridzin caused glucose to appear in saliva in a proportion of dogs to which it had been given in doses large enough to produce glycosuria.

The relationship of saliva glucose to carbohydrate metabolism both within the gland and in the body as a whole is a problem of considerable interest. Johns (1933) has reviewed the fascinating but conflicting clinical evidence showing a relationship between pathological changes in the parotid gland and alterations in systemic glucose metabolism.

\section{ASCORBIC ACID}

Ascorbic acid appears to be present in saliva although concentrations are smaller than in the plasma (Stuteville, I935; Freeman and Hafkesbring, 1951).

\section{ORGANIC NON-ELECTROLYTES}

Systematic studies of the permeability of the salivary glands to organic non-electrolytes have been carried out by Amberson and 
Höber (1932) and Burgen (1956). They found that small molecules of high lipoid solubility penetrated into the saliva with ease but that when the molecular radius exceeded $3 \cdot 2 \AA$, or the oil/water distribution ratio was less than 0.001 , only small amounts appeared in the saliva. For example, the minimum saliva to plasma ratio for mannitol was 0.02 , for creatinine 0.05 , glycerol 0.10 , and

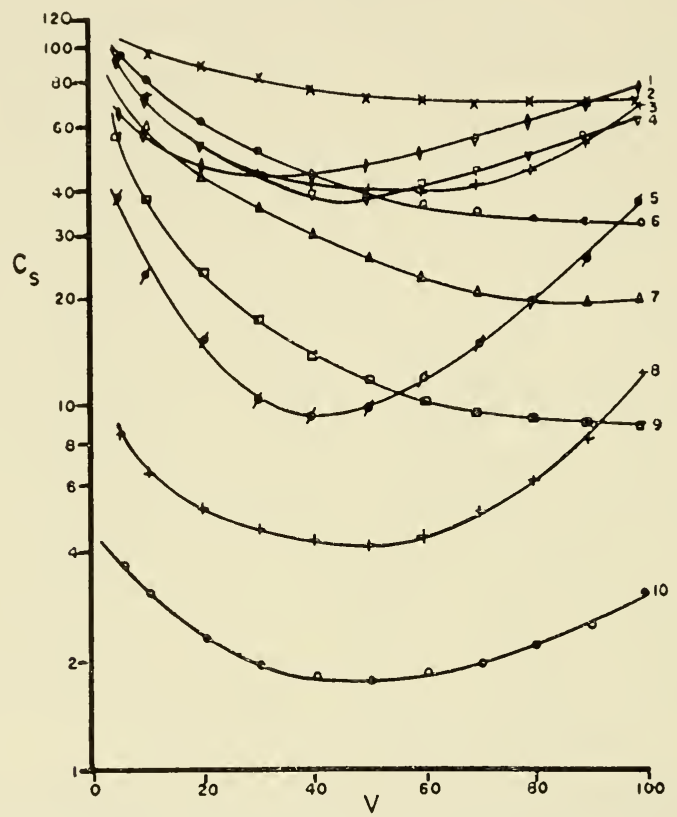

FIG. 9.8. Results showing relation between saliva-plasma ratios $\times$ I 00 for ten non-electrolytes in dog parotid saliva secreted at different rates.

Ordinates: Saliva-plasma ratio $\times$ roo.

Abscissae: Saliva flow as \% of the maximum rate.

Flow rate varied by changing the frequency of auriculo-temporal stimulation. Maximum rate averaged $0.55 \mathrm{ml} . / \mathrm{g} . / \mathrm{min}$.

1, thiourea ; 2 , ethylurea ; 3 , N-methylurea ; 4 , urea ; 5 , glycerol; 6 , chloramphenicol; 7,4 -acetamidoantipyrine, 8 , creatinine; 9 , methenamine; Io, mannitol (Burgen, $1956 b$ ).

urea 0.4 ; sucrose was not detectable at all in the saliva. On the other hand, the lipoid soluble molecules acetamide, propionamide, butyramide and malonamide passed into the saliva quite easily. Killman and Thaysen (I955) found that in a series of sulphonamides the ease of penetration into the saliva could be related to the percentage of non-ionized form of the molecules present. They also found that traces of $\mathrm{p}$-aminohippurate appeared in saliva but that inulin did not. Burgen analysed in detail the behaviour of ten 
non-electrolytes (Fig. 9.8) as a function of salivary flow rate and found that the results could best be interpreted on the assumption of two routes of transfer, one, a fixed permeability through which movement of the substance depended mainly on its lipoid solubility, and a second whose permeability increased with flow rate and through which the movement of molecules depended mainly on their radius. Subsequent analysis by Burgen and Seeman (I 958) suggests that this second path is in the duct system. There are in the literature numerous reports of the presence in saliva of antibiotics, vitamins, and miscellaneous organic molecules but few of these have been studied in any detail (for a comprehensive bibliography see Pigman and Reid, I952). The concentrations of most of these substances in the saliva can be predicted from the rules given above.

\section{REFERENCES}

ALBRECHTSEN, O. K. and J. H. THAYSEN (1955). Fibrinolytic activity in human saliva. Acta physiol. scand., 35, I38-145.

ALDERTON, G., W. H. WARD and H. L. FEVOLD (I945). Isolation of lysozyme from egg white. F. biol. Chem., I57, 43-58.

AMBERSON, W. R. and R. HÖBER (I932). The permeability of mammalian salivary glands for organic non-electrolytes. F. cell. comp. Physiol., 2, $201-221$.

ANREP, G. V. (192I). The relation of the chorda tympani to the nitrogen metabolism of the submaxillary gland. F. Physiol., 54, 319-331.

ANREP, G. V. and H. N. KHAN (1923). The metabolism of the salivary glands. $\mathrm{V}$. The process of reconstruction of the submaxillary gland. $\mathcal{F}$. Physiol., 58, 302-309.

ARAKI, Y. (I95I). Nitrogenous substances in saliva. I. Protein and nonprotein nitrogens. Fap. F. Physiol., 2, 69-78.

BERNFELD, P., A. STAUB and E. H. FISCHER (I948). Sur les enzymes amylolytiques XI. Proprietes de l' $\alpha$-amylase de salive humaine cristallisée. Helv. chim. acta, 31, 2165-2 I72.

BERRY, H. K. (I95I). Further studies on individual urinary and salivary amino acid patterns. Univ. Texas Pubs. Biol. Med., 5109, I57-164. BERRY, H. K. and L. CAIN (I95 I). Quantitative study of urinary and salivary amino acids using paper chromatography. Univ. Texas Pubs. Biol. Med., 5ro9, $71-76$.

BLIx, G. (1936). Über die Kohlenhydratengruppen des Submaxillarismucins. Z. phys. Chem., 240, 32-54.

- (1940). Studies in glycoproteins. Acta physiol. scand., I, 29-42.

BLIX, G., E. LINDBERG, L. ODIN and I. WERNER (1956). Studies on sialic acids. Acta Soc. med. Upsal., 61, I-25.

BLIX, G., L. SVENNERHOLM and I. WERNER (1952). The isolation of chondrosamine from gangliosides and from submaxillary mucin. Acta chem. scand., 6, 358-362. 
BLumberG, B. S. and A. G. Ogston (1958). Physiochemical studies on hyaluronic acid. In Chemistry and biology of mucopolysaccharides, ed. Wolstenholme and O'Connor. Churchill, London.

BROWN-GRANT, K. and v. A. GALTON (1958). Iodinated compounds in milk after radioiodide administration. Biochim. biophys. acta, 27, 422423.

BURGEN, A. S. V. (1956). The secretion of non-electrolytes in the parotid saliva. 7 . cell. comp. Physiol., 48, I I $3^{-1} 3^{8}$.

BURGEN, A. S. V. and P. SEEMAN (1958). The role of the salivary duct system in the formation of saliva. Can. F. Biochem. Physiol., 36, I 19-143. BURGEN, A. S. V., M. WEISS and P. SEEMAN (1959). The dynamics of protein secretion by the parotid gland of the dog. In preparation.

BURGEN, A. S. V., M. WEISS and G. WEISS (I959). The secretion of protein bound iodine in parotid saliva. In preparation.

CAPOZZI, L. (1954). Cromatografia bidimensionale su carta da filtro degli amino-acidi liberi della saliva. Ann. Stomatologia, 3, 21-29.

CORNFORTH, W. J., M. E. DAINES and A. GOTTSCHALK (1957). Synthesis of N-acetyl-neuraminic acid. F. chem. Soc., p. 25.

ELlisON, S. A., and P. A. MASHimo (1958). Immunochemical studies of saliva. F. dent. Res., 37, 28.

EPSTEIN, L. A. and E. B. CHAIN (1940). Some observations on the preparation and properties of the substrate of lysozyme. Brit. F. exp. Path., 2I, 339-355.

FELDBERG, W. and J. A. GUimarais (I 935). Some observations on salivary secretion. 7. Physiol., 85, I 5-36.

FERGUSON, M. H., H. P. KRAHN and J. A. HILDES (I958). Parotid secretion of protein in man. Can. F. Biochem. Physiol., 36, 100 I-1 008.

FLEMING, A. (1922). On a remarkable bacteriolytic element found in tissues and secretions. Proc. Roy. Soc. B., 93, 306-317.

FLEMING, A. and V. D. ALLISON (I 922). Observations on a bacteriolytic substance ("Lysozyme") found in secretions and tissues. Brit. F. exp. Path., 3, 252-260.

FREEMAN, J. T. and R. HAFKESBRING (I95 I). Comparative study of ascorbic acid levels in gastric secretion, blood, urine, and saliva. Gastroenterology, I8, 224-229.

FREY, E. K., H. KRAUT and E. WERLE (1950). Kallikrein. Enke, Stuttgart. GABL, F. and E. EGGER (I959). Charakterisierung von Speichelproteinen. Clin. Chim. Acta, 4, 62-67.

GLAZKO, A. J. and D. M. GREENBERG (I 939). The mechanism of the action of saliva in blood coagulation. Amer. F. Physiol., r25, 108-1 12.

GLYNN, L. E. and E. J. HOLBOROW (1959). Distribution of blood group substances in human tissues. Brit. med. Bull., I5, I 50-1 53.

GotTschalk, A. (1954). The influenza virus enzyme and its mucoprotein substrate. Yale $\mathcal{F}$. biol. med., 26, 352-364.

- (1957). Neuraminidase; the specific enzyme of influenza virus and vibrio cholerae. Biochim. biophys. acta, 23, 645-646.

- (1958). The prosthetic group of some mucoproteins and its relationship to influenza virus. In Chemistry and biology of mucopolysaccharides, ed. Wolstenholme and O'Connor. Churchill, London.

- (I960). The chemistry and biology of sialic acids and related substances. Cambridge.

HAMMARSTEN, O. (I888). Ueber das Mucin der Submaxillardrüse. $Z$. phys. Chem., 12, I63-195. 
HARTMANN, G. (I94I). Group antigens in human organs. Munksgaard, Copenhagen.

HEBB, C. O. and G. W. STAVRAKY (1936). 'The presence of glucose in the salivary secretion after the administration of adrenaline. Quart. $\mathcal{F}$. exp. Physiol., 26, I41-1 53 .

HeIDENHAIN, R. (I883). Physiologie der Absonderungsvorgänge. Handbuch der Physiologie, ed. Hermann. Vogel, Leipzig.

HEIMER, R. and K. MEYER (I956). Studies on sialic acid of submaxillary mucoid. Proc. U.S. Nat. Acad. Sci., 42, 728-734.

HILTON, S. M. and G. P. LEWIS (1957). Functional vasodilatation in the submandibular salivary gland. Brit. med. Bull., r3, 189-196.

HOERMAN, K. C., H. R. ENGLANDER and I. L. SHKLAIR (I 956). Lysozyme; Its characteristics in human parotid and submaxillolingual saliva. Proc. Soc. exp. Biol., N.Y., 92, 875-878.

HOKIN, L. E. and M. R. HOKIN (I954). The ribonucleic acid content of pancreas and parotid glands during enzyme synthesis and secretion in vitro. Biochim. biophys. acta, 13, 236-240.

HOKIN, L. E. and A. L. SHERWIN (1957). Protein secretion and phosphate turnover in the phospholipids in salivary glands in vitro. $\mathscr{f}$. Physiol., 135, I 8-29.

john, H. J. (I933). Mikulicz's disease and diabetes. F. Amer. med. Ass., I Or, I 84-I 87.

JOLLES, G. and C. FROMAGEOT (I954). La proteine lysant II de la rate du lapin. Biochim. biophys. acta, r4, 219-227.

JUNQUEIRA, L. C., A. FAJER, M. RABINOVITCH and L. FRANKENTHAL (I949). Biochemical and histochemical observations on the sexual dimorphism of mouse submaxillary gland. F. cell. comp. Physiol., 34, I 29-1 48.

KABAT, E. A. (1956). Blood group substances. Their chemistry and immunochemistry. Academic Press, New York.

KENT, P. W. and M. W. WHITEHOUSE (1955). Biochemistry of the amino sugars. Butterworth, London.

KESZTYÜS, L. and J. MARTIN (I937). Über den Einfluss von Chorda und Sympathicus-reizung auf die Zusammensetzung des Submaxillarspeichels. Arch. ges. Physiol., 239, 408-4 I 8.

KILLMAN, S. A. and J. H. THAYSEN (I955). The permeability of the human parotid gland to a series of sulphonamide compounds, para-aminohippurate and inulin. Scand. F. clin. lab. invest., 7, 86-9I.

KINERSLEY, T. and O. HÖGBERG (1955). An antibacterial effect of saliva demonstrated with use of paper electrophoresis. Yale F. biol. med., 28, I45-I 47 .

KIRCH, E. R., R. G. KESEL, J. F. O'DONNELL and E. C. WACH (I947). Amino acids in human saliva. $\mathcal{F}$. dent. Res., 26, 297-301.

- - - (I953). Influence of ingestion of single amino acids on human saliva. F. dent. Res., 32, 57-60.

KLENK, E. (I94 I). Neuraminsäure, das Spaltprodukt eines neuen Gehirnlipoids. Z. phys. Chem., 268, 50-58.

- (1958). Neuraminic acid. In Chemistry and biology of mucopolysaccharides, ed. Wolstenholme and O'Connor. Churchill, London.

KNOX, K. W. and J. L. STILL (1953). Observations on the salivary mucoids. F. dent Res., 32, 379-385.

KOMAROV, S. A. and G. W. STAVRAKY (I940). The nitrogenous constituents of cat's submaxillary saliva evoked by parasympathetic and sympathetic stimulation. Can. F. res., D.18, $233^{-247}$ 
KÖSTLIN, A. and S. RAUCH (I 957). Zur Chemie des Ruhespeichels einzelner Speicheldrüsen. Helv. Med. Acta, 24, 600-62 1.

LANDSTEINER, K. and R. A. HARTE (194I). Group specific substances in human saliva. $\mathcal{F}$. biol. Chem., I40, 673-674.

LANGley, I. L., C. H. GUNTHORPE and W. A. BEALL (1958). Salivary glucose threshold. Amer. F. Physiol., 192, 482-484.

LANGLeY, J. (I898). The salivary glands. In Textbook of physiology, ed. Schaefer. Young, J. Pentland, Edinburgh.

LANGSTROTH, G. O., D. R. MCRAE and G. W. STAVRAKy (I938a). The secretion of protein material in the parasympathetic submaxillary saliva. Proc. Roy. Soc. B., 125, 335-347.

- - - (1938b). A study of cat's submaxillary saliva obtained under nerve stimulation or adrenaline administration. Arch. int. Pharmacodyn., 58, $61-77$.

Leuchs, E. F. (1831). Wirkung des Speichel auf Stärke. Ann. Phys. Chem., 22, 623 .

McCREA, J. F. (I953). Studies on influenza virus receptor-substance and receptor-substance analogues. I. Preparations and properties of a homogeneous mucoid from the salivary gland of the sheep. Biochem. f., 55, $132-138$.

MARTIN, K. (I 959). Unpublished observations.

MAYER, W. B. (1929). A comparison of the amylase concentration in the saliva of infants and adults. Fohns Hopkins Hosp. Bull., 44, 246-247.

meyer, K. (1945). Mucoids and glycoproteins. Advanc. Protein Chem., 2, 249-268.

MEYER, K., J. W. PALMER, R. THOMPSON and D. KHORAZO (I936). On the mechanism of lysozyme action. F. biol. Chem., II3, 479-486.

MEYER, K. H., E. H. FISCHER, A. STAUB and P. BERNFELD (1948). Sur les enzymes amylolytiques $\mathrm{X}$. Isolement et cristallisation de l' $a$ amylase de salive humaine. Helv. chim. acta, 31, 21 58-2 164.

MOOR, J. R. and D. R. GILLIGAN (I 95I). Paper partition chromatography of free amino acids and peptides of normal human saliva. F. Nat. Cancer Inst., 12, 691-697.

MORGAN, W. T. J. and W. M. WATKIns (1959). Some aspects of the biochemistry of the human blood group substances. Brit. Med. Bull., I5, I09-I I 3 .

MORRIS, J. L. and C. T. WAY (I 924). Further observations on chemical constituents of saliva. F. biol. Chem., 59, xxvi-xxvii.

моттA, G. and L. мотта (1958). Ricerche elettroforetiche sulle proteine della saliva parotidea umana. Otorinolar. Ital., 26, 68-84.

MUUS, J. (1954). The amino acid composition of human salivary amylase. f. Amer. chem. Soc., 76, 5163-5165.

MYRBÄCK, K. and G. NEUMC̈LLER (I 950). Amylases and the hydrolysis of starch and glycogen. In The enzymes, ed. Sumner and Myrbäck. Academic Press, New York.

NiCORY, c. (1 922). Salivary secretion in infants. Biochem. F., 6, 387-389. NOUR-ELDIN, F. and J. F. WILKINSON (1957). The blood clotting factors in human saliva. F. Physiol., 136, 324-332.

ODIN, L. (I958). Mucopolysaccharides of epithelial mucus. In Chemistry and biology of mucopolysaccharides, ed. Wolstenholme and O'Connor. Churchill, London.

ogston, A. G. and J. E. STANiER (I95I). The dimensions of the particle of hyaluronic acid complex in synovial fluid. Biochem. F., 49, 585-590. 
PATTON, J. R. (I956). The carbohydrates and proteins of human saliva. Ph.D. Thesis, University of Alabama.

PATTON, J. R. and W. PIGMAN (I 957). Amylase in electrophoretic and ultracentrifugal patterns of human parotid saliva. Science, I25, I 292-1293.

- (1959). Electrophoretic and ultracentrifugal components of human salivary secretions. F. Amer. chem. Soc., 8r, 3035-3039.

PEARCE, R. G. (19I6). The appearance of sugar in the secretion of the digestive tract following the administration of phlorhizin. Amer. $\mathcal{F}$. Physiol., 40, 4I8-425.

PIGMAN, W. and W. L. HAWKins (1958). The reducing power of human saliva and its component secretions. F. dent. Res., 37, 688-696.

PIGMAN, W. and A. J. REID (I 952). The organic compounds and enzymes of human saliva. F. Amer. Dent. Ass., 45, 325-338.

REYNAUD, J. and P. REBEYROTTE (I949). Différence d'activité amylasique de la glande sous maxillaire des souris males et des souris femelles: conditionnement de cette activité par les hormones androgènes. C.R. Acad. Sci., 229, 84-86.

RoberTs, E. A., B. G. MacGRaith and H. W. FLOREy (1938). Comparison of lysozyme preparations from egg white, cat and human saliva. Quart. f. exp. Physiol., 27, 381-391.

ROSE, G. A. and A. C. KERR (1958). The amino acids and phosphoethanolamine in salivary gland secretion of normal men and of patients with abnormal calcium, phosphorus, and amino acid metabolism. Quart. F. exp. Physiol., 43, 160-168.

SALTON, M. R. J. (I957). The properties of lysozyme and its action on micro organisms. Bact. Rev., 21, 82-99.

SCHNEYER, C. A. (I958). Genetic control of amylase levels of mouse submaxillary glands. Proc. Soc. exp. Biol., N.Y., 98, 160-162.

SCHNEYER, L. H. (I 953). Effect of administration of radioactive iodine on human salivary gland function. F. dent. Res., 32, 146.

SCHNEYER, L. H. and C. A. SCHNEYER (1956). Apparent synthesis of submaxillary gland amylase during pilocarpine administration. Amer. F. Physiol., 187, 403-406.

SECKER, J. (1934). The humoral control of the secretion by the submaxillary gland of the cat following chorda stimulation. F. Physiol., 8I, $8 \mathrm{I}-92$.

STAVRAKY, G. W. (I940). The partition of nitrogen in the submaxillary saliva evoked by chorda tympani stimulation in the cat. Amer. F. Physiol., 129, 539-545.

stuteville, o. H. (I 935). Presence of vitamin C in saliva. Proc. Soc. exp. Biol., N.Y., 32, I454-1455.

SVENNERHOLM, L. (I956). On sialic acids and their quantitative estimation. Biochem. F., 64, I I-12P.

TAUROG, A., G. D. PO'TTER, W. TONG and I. L. ChaikofF (1956). The formation of $\mathrm{I}^{131}$-monoiodotyrosine from $\mathrm{I}^{131}$-iodide by isolated particulate fractions of non-thyroid tissues. Endocrinology, 58, I $32-134$.

THOMPSON, R. (I940). Lysozyme and its relation to antibacterial properties of various tissues and secretions. Arch. Path., 30, I096-I I34.

TIEDEMANN, F. and L. GMELIN (1826). Recherches expérimentales physiologiques et chimiques sur la digestion. Baillière, Paris.

WERLE, E. (I955). The chemistry and pharmacology of Kallikrein and Kallidin. In Polypeptides which stimulate smooth muscle, ed. Gaddum. Livingstone, Edinburgh. 
WERLE, E. and P. V. RODEN (I939). Über das Vorkommen von Kallikrein in den Speicheldrüsen und im Mundspeichel und über eine blutdrucksteigernde Substanz in der Submaxillarisdrüse des Hundes. Biochem. Z., 301, 328-337.

WERNER, I. (1953). Studies on glycoproteins from mucous epithelium and epithelial secretion. Acta Soc. med. Upsal., 58, 1-55.

WOLDRING, M. G. (1955). Free amino acids of human saliva; a chromatographic investigation. $\mathcal{F}$. dent. Res., 34, 248-256.

ZillikeN, F. (1956). Sialic acid and related compounds. Fosiah Macy, $\mathfrak{F r}_{\mathrm{r}}$ Foundation. 2nd Conference on Polysaccharides in Biology.

Zilliken, F. and M. W. Whitehouse (i 958). The Nonulosaminic acids. Advanc. Carbohyd. Chem., 13, 237-263. 


\section{CHAPTER $\mathrm{X}$ \\ THEORIES OF SECRE'TION}

\section{GENERAL CONSIDERATIONS}

In the enumeration of the more abundant saliva constituents (in Chapters VIII and IX) it was repeatedly brought to the attention of the reader that the amounts of these substances in the saliva were dependent on the nerve stimulated (whether sympathetic or parasympathetic), the frequency of stimulation, the previous secretory history of the gland, the plasma composition, as well as other variables. In addition, the secretory products of the submaxillary, parotid and other glands differ amongst themselves. Saliva is not a simple fluid, the salivary glands are morphologically complex, and we must expect that the secretory process will not be simple either. None of the present theories of salivary secretion are adequate to account for all the phenomena encountered, and the object of this chapter will be to examine critically their merits and defects.

The most deeply entrenched prejudice about salivary secretion is that the acini are the main or sole begetters of the secretion. Later in this chapter abundant evidence will be presented that the salivary duct system is not a passive tube but plays a complex role in salivary secretion. We may, for the moment, however, assume the role of the devil's advocate and ask what evidence there is that the acini have any important part to play in secretion. In both rats and dogs at birth, the acini are primitive or altogether absent (Leeson and Jacoby, 1959; Wechsler, 1960), while the ducts, although differing from the adult in some particulars, show a considerable degree of elaboration. Secretion of saliva in the new-born animal is as abundant as it is in the mature one. It seems, therefore, very probable that most of the water of the saliva is secreted by the ducts in the immature animal. What of the mature animal? Does this capacity to secrete water disappear with the onset of maturity or is it a persistent process in the adult gland? There are other features of the gland which suggest a less important role for the acini than the ducts; the ducts have a very rich blood supply, probably richer than that of the acini (see page ${ }_{15}$ ) and the duct 
cells are much richer in mitochondria and succinic dehydrogenase than the acinar cells. These latter features are both good indications that the respiratory activity of the duct cells is higher than that of the acinar cell and suggest that duct cells may have an important role to play in material transfer. It is interesting at this point to compare the salivary gland with the aglomerular kidney found in some fish which is a simple tubule capable of secreting a complex mixture of water, electrolytes and organic substances; indeed, the histological resemblance between the tubules of these kidneys and the striated tubule of the salivary gland is very striking. Against these arguments there is no reasonable doubt that degranulation of acinar cells occurs during stimulation and that the liberated granules can be seen to enter the acinar saliva (see for instance Holtzlöhner and Niessing, 1936, and numerous other authors); secondly, soluble blood group substances that are secreted in the saliva apparently take origin only from the mucous cells of the submaxillary gland and are not present at all in the duct cells (Glynn and Holborow, 1959). At the very least, enough water must be secreted by the acini to carry these products into the saliva. This fundamental question of the proportion of the salivary water secreted through different routes remains uncertain and a quantitative evaluation must await the development of new techniques.

Theories of secretion based on the comparison of the histological structure of various glands with the chemistry of their secretion have been widely adopted but the evidence on which they have been based is of the flimsiest. The suppositions made are that a specific cell type carries out a single function and further that a cell whose appearance differs from this cannot carry out this function. Against this it may be noted firstly that even the basic facts on which these theories are based are shaky. For instance, it has been suggested that the cat sublingual gland produces an isotonic saliva because it lacks an organized striated duct epithelium whose function is supposedly to reabsorb sodium and chloride (Lundberg, I958); yet the human sublingual gland which apparently is just as poor in striated duct cells can produce a saliva as hypotonic as the parotid gland (Köstlin and Rauch, 1957). Cohen and Myant ( I959), in a study of the comparative physiology of iodide secretion in the salivary glands, point out that they could find no correlation between the histology of the glands in different species and their ability to concentrate iodide. Unfortunately, cytological theories 
will continue to be widely adopted because of their apparent simplicity and because of the long tradition going back to Heidenhain and Merkel which has hallowed them.

We have not attempted in the rest of this chapter to undertake a comparison of salivary secretion with that of other glands because, although there are obvious similarities in the ground plan of most secreting glands, so little is known of secretion in these other structures.

\section{ELECTROPHYSIOLOGY OF THE SALIVARY GLANDS}

It was originally found by Bayliss and Bradford (1885) that a potential difference appeared between an electrode placed on the convexity of the submaxillary gland and one placed on the hilus when secretion was produced by stimulation of the chorda tympani. It was quickly established that this potential was not due to a change in blood flow because amongst other experiments, the administration of atropine in a dose sufficient to abolish secretion
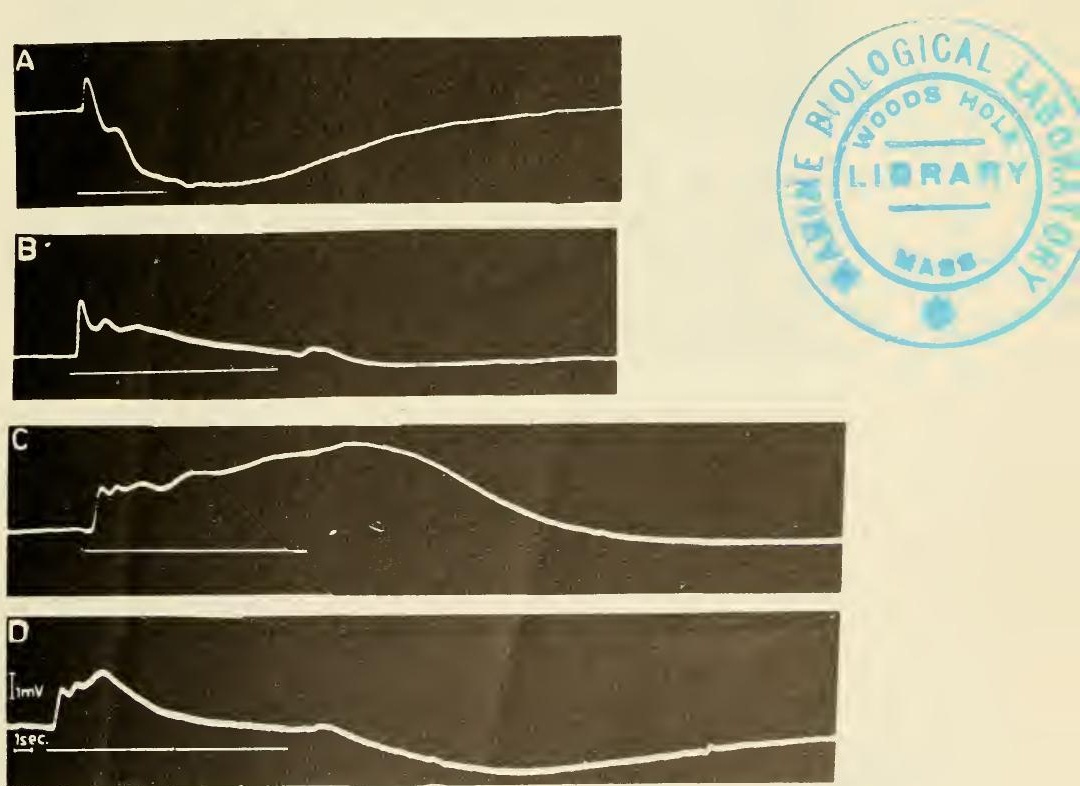

FIG. IO. I. Cat submaxillary electrogram in response to chorda stimulation. One electrode was placed on the gland convexity and the other close to the hilus.

Hilus positivity corresponds to an upward deflection on the record. The records are successive ones from the same gland, showing the great variation in response (Lundberg, 1955). 
also prevented the potential from appearing while the vasodilator action was not markedly affected. The potential was also not due primarily to flow of secretion since essentially the same changes were found when the duct was clamped and saliva not permitted to flow. There seems little doubt that the gland electrogram is a concomitant of secretory activity in the gland cell (Bayliss and Bradford, i 886; Bradford, I887, i 888; Harreveld, I930).

The electrogram has subsequently been studied by other workers and the results obtained comprehensively reviewed by Langenskiöld (I94I) and Lundberg (I958). Both parasympathetic and sympathetic stimulation yields complicated potential patterns during and following stimulation (Figs. IO.I and I0.2). Apart from the initial sign of the potential which is consistent, the rest of the complex is extremely variable between individual glands and is
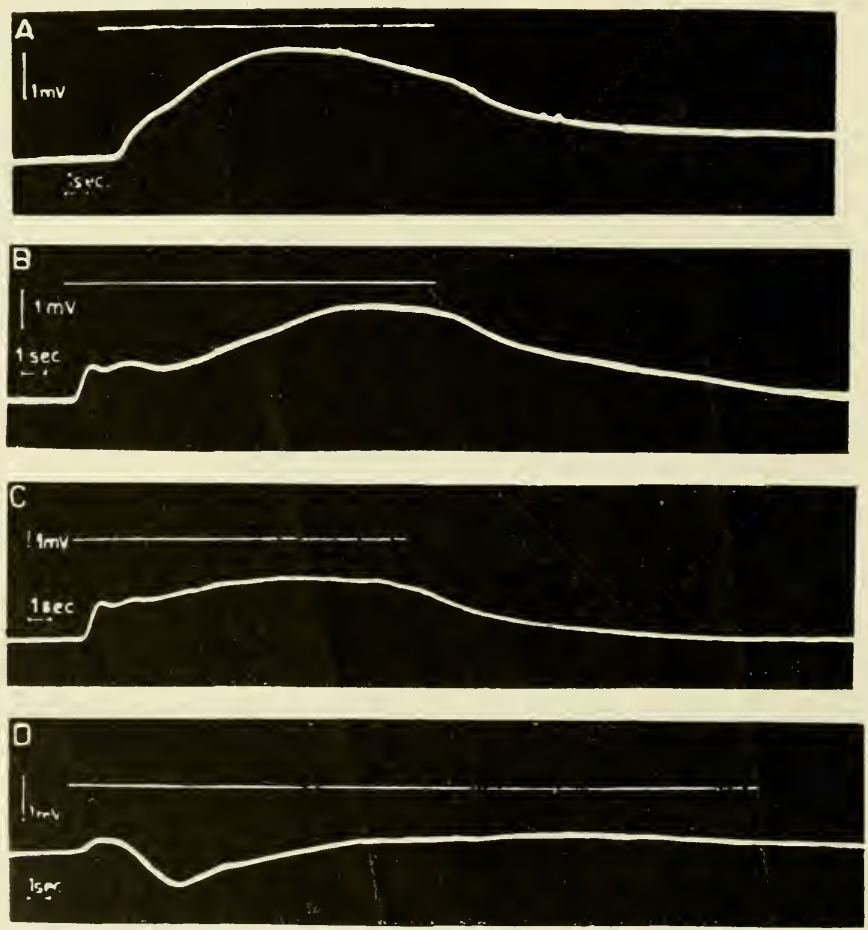

FIG. 10.2. The same gland as Fig. ro. I but responses to stimulation of the cervical sympathetic nerve. 
also changed during repeated periods of stimulation. In the cat submaxillary gland with chorda stimulation, the complex commences with a hilus positive potential after a latency of $0.2-0.6$ seconds; with sympathetic stimulation the latency is a little longer but the initial deflection is also hilus positive. On the other hand, in the sublingual gland, the initial potential is hilus negative with both sympathetic and parasympathetic stimulation and the form of the complex is simpler than in the submaxillary gland. Despite valiant attempts, analysis of the external salivary electrogram has not yielded results useful in explaining secretory activity but the presence of such electrical activity has encouraged the development of more sensitive methods of study. Lundberg (1955) explored the cat submaxillary gland with intracellular microelectrodes and was able to distinguish with them three types of potentials generated within cells.

'The first and commonest type (Type I) was obtained from cells near the surface of the gland, some of which could be seen under direct vision to be acinar cells. The resting potential across the

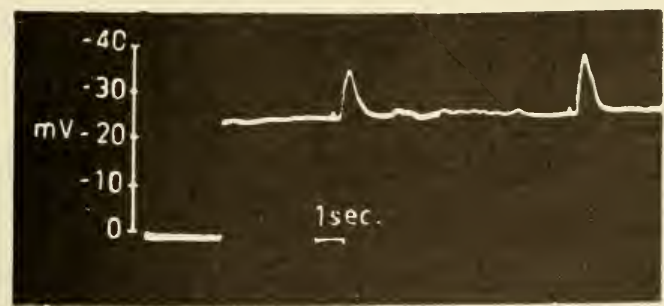

(a)

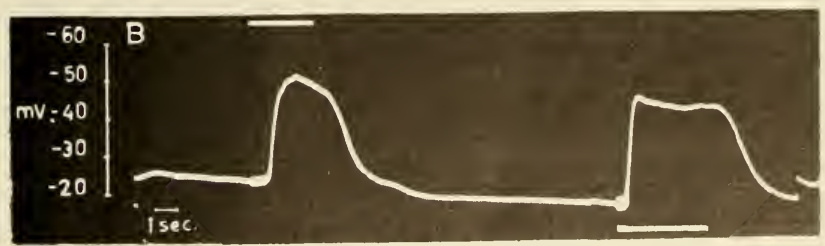

(b)

FIG. 10.3. Intracellular potentials in the cat submaxillary gland obtained from acinar cells (Type I potentials). (a) Potential jump on inserting electrode in the cell and the response to single shocks applied to the chorda. (b) The same type of cell as in $(a)$.

During the period marked by a white line at the upper margin of the figure, the cervical sympathetic was stimulated at $25 \mathrm{c} / \mathrm{s}$ : during the period marked by a white line at the lower margin the chorda was stimulated at $25 \mathrm{c} / \mathrm{s}$ (Lundberg, 1955). 
outer face of these cells averaged $-22 \mathrm{mV}$ (range $-\mathrm{I}_{5} \mathrm{mV}$ to $-35 \mathrm{mV}$ ). On stimulation of the chorda with single shocks the internal negativity increased by 5 to $20 \mathrm{mV}$ after a latency of 0.2 to 0.4 second and then returned to the initial potential level in about a second. With repetitive stimulation, the membrane was hyperpolarized by as much as $40 \mathrm{mV}$ although 25 to $35 \mathrm{mV}$ was more usual. With continued stimulation, the potential was maintained and on cessation of stimulation, the potential returned to the initial value in 2 to 5 seconds (Fig. I0.3). Single shocks to the cervical sympathetic produced no electrical changes but with repetitive stimulation, a hyperpolarization similar to that produced by chorda stimulation was seen; usually the latency was longer and the magnitude of the potential change smaller than that of the chorda. Similar changes in potential were produced by adrenaline, acetylcholine or pilocarpine.

In cells near the surface of the gland, a second type of potential (Type II) was also found but the structure in which it is developed has not yet been identified. The resting potential was of the same order as in Type I cells and on stimulating the chorda a hyperpolarization of $\mathrm{I} 5 \mathrm{mV}$ to $20 \mathrm{mV}$ occurred (Fig. I0.4a). The latency was brief but the potential rose slowly (only $15 \mathrm{mV} / \mathrm{sec}$ as com-

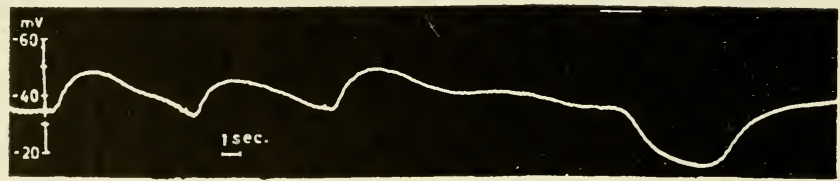

(a)

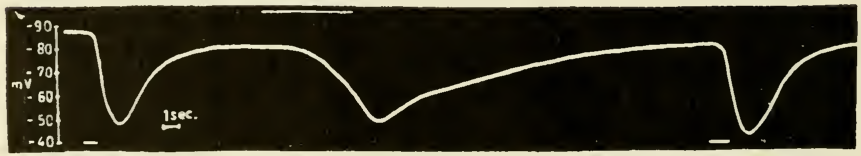

(b)

FIG. I o.4. Cat submaxillary gland. Chorda stimulation indicated by white at lower margin; sympathetic stimulation by line at upper margin. (a) Electrode in unidentified structure producing Type II potentials.

The first three responses were produced by single shocks to the chorda and the last response by sympathetic stimulation at $25 \mathrm{c} / \mathrm{s}$. Notice the opposite polarities of the responses and compare the time course with the time seen in Fig. 10.3.

(b) Electrode inserted deep into the gland substance and inside a cell (? duct cell) producing a Type III response.

Note the high resting potential of this cell and the striking depolarization produced by both chorda and sympathetic stimulation (Lundberg, 1955). 
pared with $150 \mathrm{mV} / \mathrm{sec}$ for Type I cells) and disappeared slowly over 7-10 seconds. However, the most striking difference from Type I is that stimulation of the sympathetic in these cells leads to a depolarization rather than a hyperpolarization; this also develops and declines slowly. No further exploration of this potential has been carried out.

When a microelectrode is inserted deep into the gland, a third type of potential may be found (Type III). In these cells the resting potential was $-80 \mathrm{mV}$ and chorda stimulation reduced this over a period of a few seconds to only $-20 \mathrm{mV}$ to $-30 \mathrm{mV}$ (Fig. 10.4b). At the end of stimulation, the potential returned only very slowly to the initial level. Sympathetic stimulation caused a similar depolarization but with a more drawn-out time course. Lundberg suggests that this potential is derived from the cells of the intralobular ducts, because it is found only in the depths of the gland where the probability of encountering a duct is considerable, and because the time course of the potential is rather similar to that recorded between a polyethylene catheter inserted backwards into the gland through the main duct and an electrode on the hilus. This potential has not been found in the sublingual gland where striated duct cells are rather scarce. This evidence can hardly be regarded as proving that Type III potential is produced by striated duct cells, although it is rather suggestive.

In view of these multiple sources of potential within the gland with their individually varying time courses, polarities and spatial dispositions, it is not really surprising that the external electrogram should be so complex. Further analysis of the potentials in the submaxillary gland was not pursued because of the difficulties in visualizing the structures and inserting an electrode into the lumen of the acini. Lundberg therefore turned to the sublingual gland in which the tubular arrangement of the acini and their relatively large lumens made further study feasible.

The acinar cells of the cat sublingual gave a potential identical with the Type I potential of the submaxillary gland-indeed, this is the only type of potential so far detected in this gland. If an electrode was inserted into the acinar lumen this also became more negative to the gland surface during activity; in the first few seconds the transmembrane potential across the outer face of the cell of a typical cell rose from 31 to $5^{6} \mathrm{mV}$ but that across the inner face (whose resting potential was also about $-30 \mathrm{mV}$ ) 
changed by no more than I $\mathrm{mV}$ (Lundberg, I957a). However, with continued stimulation, the potential over the inner cell membrane also gradually rose by some $10 \mathrm{mV}$ but never attained the same degree of hyperpolarization as that of the outer cell mem-

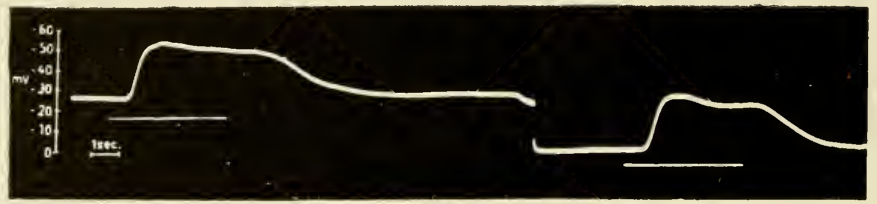

FIG. 10.5. At the left of the figure the microelectrode is within a sublingual cell and the hyperpolarization on chorda stimulation is seen.

The sudden potential jump back to zero is due to the electrode being inserted into the acinar lumen. A very similar hyperpolarization is still recorded (Lundberg, 1957a).

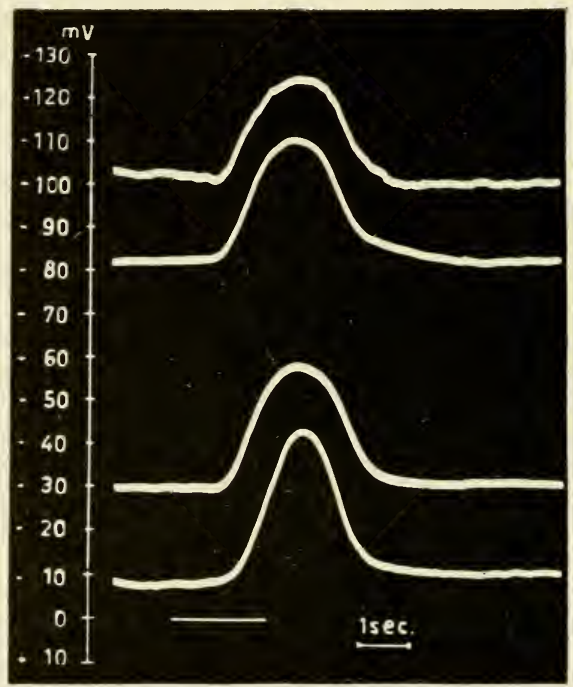

FIG. 10.6. Intracellular recording from a sublingual gland cell with a double-barrelled microelectrode.

Current was passed through the second barrel to shift the cell resting potential from $-8 \mathrm{mV}$ at one extreme to $-102 \mathrm{mV}$ at the other. Chorda stimulated at $25 \mathrm{c} / \mathrm{s}$ during period indicated by white line (Lundberg, 1957b).

brane (Fig. 10.5). Lundberg $(1957 b, c)$ has further shown that hyperpolarization of the outer membrane (Fig. 10.6) is practically independent of the resting potential when this is shifted from $8 \mathrm{mV}$ to $102 \mathrm{mV}$ by the passage of current through a second intracellular electrode. This finding is of great importance and immediately 
distinguishes the hyperpolarization in salivary gland cells from that found in the heart, spinal motor neurons and crustacean stretch receptor cells (see Eccles, I957). In all these cells the degree and the sign of the potential change produced by nerve stimulation is dependent on the resting potential of the cell. If the resting potential is depressed below normal by the passage of current, hyperpolarization is accentuated; when the resting potential is increased by some $10 \mathrm{mV}$ to $20 \mathrm{mV}$, the hyperpolarization disappears and is replaced by depolarization. Analysis has shown that in all these cases the potential is due solely to an increase in conductivity for one or more of the several ions crossing the membrane so as to permit the cell potential to approximate more closely to a diffusion potential (or combination of diffusion potentials). The cell thus tends to approach the equilibrium potentials for the ions concerned. If the resting potential is lower than the equilibrium potential, hyperpolarization results; if it is higher than the equilibrium potential, depolarization results. Clearly, the hyperpolarization in Type I cells cannot be explained in this way but must be due rather to the active movement of an ion relatively unhindered by the electrochemical gradient. The existence of active ion movements of this kind have been established for sodium in the frog skin (Ussing and Zerahn, I95I) and for chloride in the gastric mucosa (Hogben, 1955). Accompanying the hyperpolarization the conductivity of the outer cell membrane increases from $74 \mathrm{mmho} /$ $\mathrm{cm}^{2}$ to $\mathrm{I} 4 \mathrm{I} \mathrm{mmho} / \mathrm{cm}^{2}$. The increased ion movement causing the hyperpolarization could be due to increased cation extrusion from the cell or, alternatively, to active anion entry. Lundberg favours the latter explanation because it involves active movement of an ion in the same direction as that in which secretion is presumed to be going on. However, potassium loss from these cells does occur (see page 208), but whether this involves active ion transport is quite unknown. Because secretion proceeds normally when the gland is perfused with a salt solution, in which the sole anion is chloride, Lundberg favours chloride as the likely ion. He has attempted to test this hypothesis by replacing chloride in the perfusing fluid by another anion and measuring the effects on cell potential change and secretion produced by injecting I $\mu$ g acetylcholine (Lundberg, 1956, I957c). Replacement of chloride by bromide produced no change, but replacement by nitrate reduced both the secretion rate and the hyperpolarization to about $x_{5}$ per 
cent of that found in the controls (Fig. 10.7). Similar results were obtained when chloride was replaced by thiocyanate or iodide. These changes were readily reversed by restoration of chloride to the perfusion fluid. However, it was not shown that the changes were not due to a reduced sensitivity to acetylcholine rather than to a reduced intrinsic ability of the membrane to respond; further, a similar reduction to response was seen when potassium was omitted from the medium. Some of these experiments should be

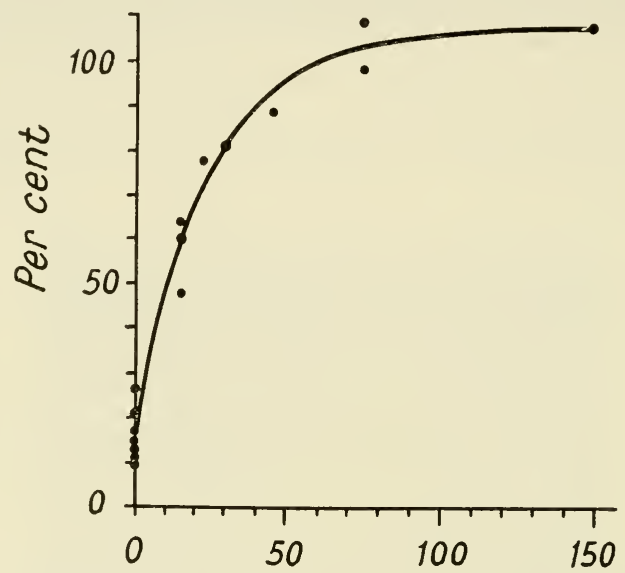

FIG. 10.7. Secretory response of the perfused cat sublingual gland to I $\mu \mathrm{g}$ acetylcholine and its dependence on the anion composition of the perfusing fluid.

The control perfusion fluid contained $150 \mathrm{mEq} / 1$. chloride, otherwise the chloride was replaced partly or completely by nitrate. Abscissa: concentration of chloride in perfusion fluid (Lundberg. $1957 c)$.

repeated, using a range of acetylcholine doses to make sure that the maximum response is really reduced. The reduced secretion when all the chloride is replaced by nitrate is also difficult to explain. It seems somewhat improbable that the active transport process for chloride could carry nitrate, iodide and thiocyanate, albeit at reduced efficiency. It would be most interesting to know what happens when chloride is replaced by a bulky ion such as sulphate.

There is no question that this work is of the greatest importance for the understanding of salivary secretion, but there are a number of puzzling and interesting aspects of these findings which need further exploration. For instance, the resting potential across the outer surface of the sublingual cells averages $-33 \mathrm{mV}$; that across 
the Type I submaxillary cells $-22 \mathrm{mV}$. The higher potential in the sublingual cells is presumably because these are not truly resting as this gland is a continuous secretor. It is probably better then to assume that $-22 \mathrm{mV}$ represents a resting potential. Accepting the analyses of Wills and Fenn (1938) the intracellular ion concentrations in the submaxillary gland are about I I $5 \mathrm{mEq} / \mathrm{kg} \mathrm{H}_{2} \mathrm{O}$ for potassium, $47 \mathrm{mEq} / \mathrm{kg} \mathrm{H}_{2} \mathrm{O}$ for sodium, and $72 \mathrm{mEq} / \mathrm{kg} \mathrm{H}_{2} \mathrm{O}$ for chloride; other analyses for the sublingual (Lundberg, 1958) and parotid (Burgen, unpublished) give rather similar figures. The equilibrium potentials for the three ions are thus: $\mathrm{E}_{\mathrm{K}}=-90 \mathrm{mV}$; $\mathrm{E}_{\mathrm{xa}}=+32 \mathrm{mV} ; \mathrm{E}_{\mathrm{CI}}=-\mathrm{I}_{5} \mathrm{mV}$. The resting potential, therefore, is quite close to the equilibrium potential for chloride but not to that for either potassium or sodium. Hodgkin and Horowicz (1959) have recently shown that in normal skeletal muscle the resting potential appears to be dominated by the potassium concentrations because the intracellular chloride concentration is so low that it can rapidly adjust to changes in the resting potential. If, however, the interior of the muscle is loaded with chloride by soaking the muscle in isotonic potassium chloride for an hour or so, the resting potential then appears to be chloride dominated due to the higher permeability of the membrane for chloride than for potassium. In this state, the resting potential is changed far more by changes in extracellular chloride concentration than by changes in potassium. Because of the high intracellular chloride concentration in the salivary gland, it might be expected that these cells were normally chloride dominated. Burgen and Seeman (1958) have pointed out that since their measurements of sodium and potassium fluxes in the submaxillary gland show an apparent increase of at least tenfold during activity while the total membrane conductivity changes at most twofold, the anion contribution must account for at least 90 per cent of the total membrane conductivity. However, if the chloride flux were passive, we should expect that the resting potential of salivary gland cells would be strongly affected by the external chloride concentration. Lundberg (1957c) shows two illustrations of sublingual cells in $160 \mathrm{mEq} / 1$. chloride and then in zero chloride ( $160 \mathrm{mEq} / 1$. nitrate). The effect of this removal of chloride was to increase the resting potential by only $3 \mathrm{mV}$ to $8 \mathrm{mV}$. If the membrane were passively chloride dominated, the potential should decrease and indeed become reversed by at least $50 \mathrm{mV}$. Therefore, if chloride ions are mainly responsible 
for the resting potential of these cells, their entry into the cell must be almost exclusively by an active process and very nearly independent of the external concentration. Since the sodium and potassium concentrations in these cells are not very different from those found in muscle or nerve, these are presumably maintained by cation "pumps" acting more or less independently of any anion uptake. The dependence of the resting potential on the external ion concentrations should be studied directly in view of the unusual features present.

It is particularly difficult to understand what connection there is between hyperpolarization of the outer face of the acinar cells and the secretory process. Neither the electrochemical potential of the ions within the cell with respect to the fluid in the acinar lumen nor the conductivity of the inner membrane change much. Of course, the nature of the potential across the inner cell membrane will remain puzzling as long as the composition of the acinar lumenal fluid is unknown, on the other hand, this method has provided unequivocal proof of the convergence of parasympathetic and sympathetic nerves on to the same cell; this must not lead us to assume, however, that because similar hyperpolarizations are produced by the two nerves, their effects on the secretion of either electrolytes or non-electrolytes is identical. The possible relationship of the Type III potential to permeability changes in the ducts during stimulation is discussed below. It is obviously of great importance that the membrane conductivity changes occurring during these potentials, as well as the time course of the potential over a longer period of stimulation, should be examined further.

\section{SALIVARY REST TRANSIENTS}

Potassium. It was first noted by Kesztyüs and Martin (I937) that the concentration of potassium in the saliva secreted at the beginning of a period of stimulation was greater than the concentration found after secretion had continued for a minute or two. This phenomenon has subsequently been investigated in some detail (Burgen, I956a; Burgen and Seeman, I958; Burgen, Terroux and Gonder, I959; Seeman, I956). After a rest period of half an hour or more has been allowed since the last period of stimulation, the first saliva secreted on stimulation contains up to $60 \mathrm{mEq} / \mathrm{l}$. of potassium. With continued stimulation, this concentration gradually falls over a period of $2-3$ minutes 
until the steady level of only $8-20 \mathrm{mEq} / 1$. is reached. On closer examination of this transient, it can be seen that it has two phases (Fig. I0.8). It rises to a peak with a very short latency and then falls quite rapidly in about 20 seconds. The rate of fall then becomes very much slower and a steady state is reached only after I-2 ml. saliva/g. gland has been secreted. Lundberg (I958) has

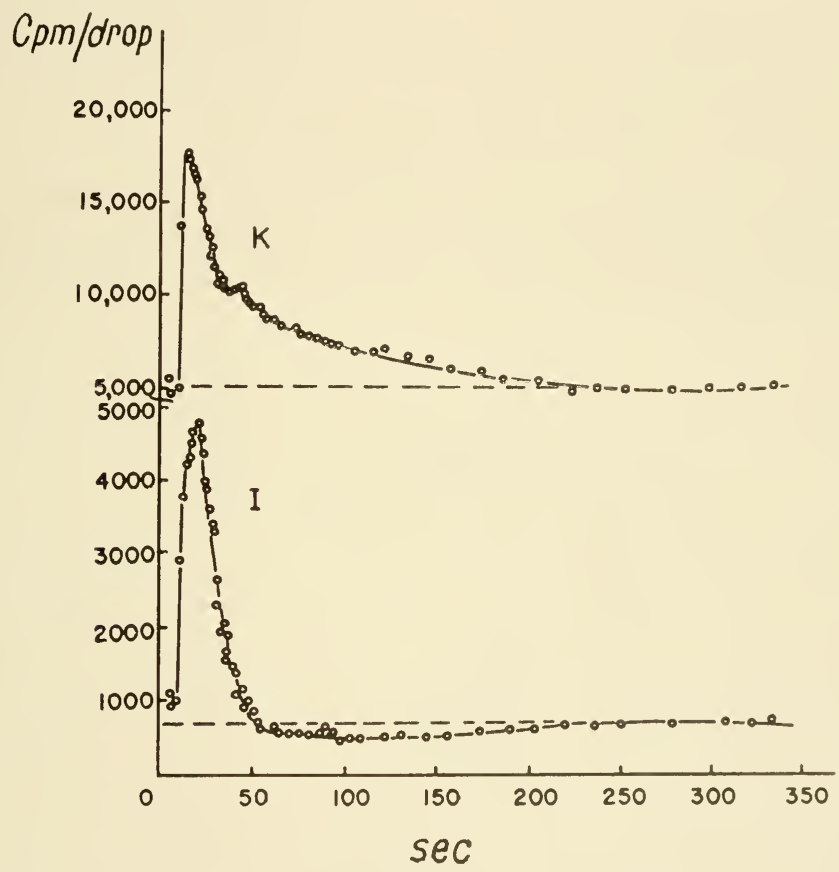

FIG. 10.8. Rest transients of iodide and potassium in the parotid saliva of the dog.

Notice the notch in the falling limb of the potassium record separating the early phase from the later prolonged phase, which lasts for about 220 seconds. The rest period was 31 minutes. The abscissa gives the time from the start of stimulation (Burgen, Terroux and Gonder, 1959).

reported finding similar transients in the sublingual gland. Both phases of this transient are dependent on the period of rest the gland has had since the previous period of stimulation; in the case of the dog parotid, half recovery of the first phase occurs after a rest period of 2-5 minutes; in the dog submaxillary, recovery is much slower (half time r5-30 minutes) (Seeman, r956). Brusilow and Cooke (I959) did not find appreciable potassium transients when using very brief periods (less than I minute) in the dog parotid 
but Seeman was able to show transients at this time. The decline in potassium output in the saliva is reflected in the depletion in the total potassium in the gland which may amount to 40 per cent of the initial content after only 3 minutes' stimulation (dog submaxillary); a nearly equivalent amount of sodium is gained by the gland. However, there is only a relatively small change in the intracellular content of potassium because the intracellular space of the gland shrinks considerably during stimulation (Burgen, unpublished). Most, but not all, of the increase in gland sodium is due to the corresponding increase in gland extracellular space. A similar but rather smaller loss of potassium has been found in the cat sublingual gland (Lundberg, I958). The loss of potassium from the gland during stimulation has also been followed continuously by the balance method (Fig. 10.9) in which the venous effluent

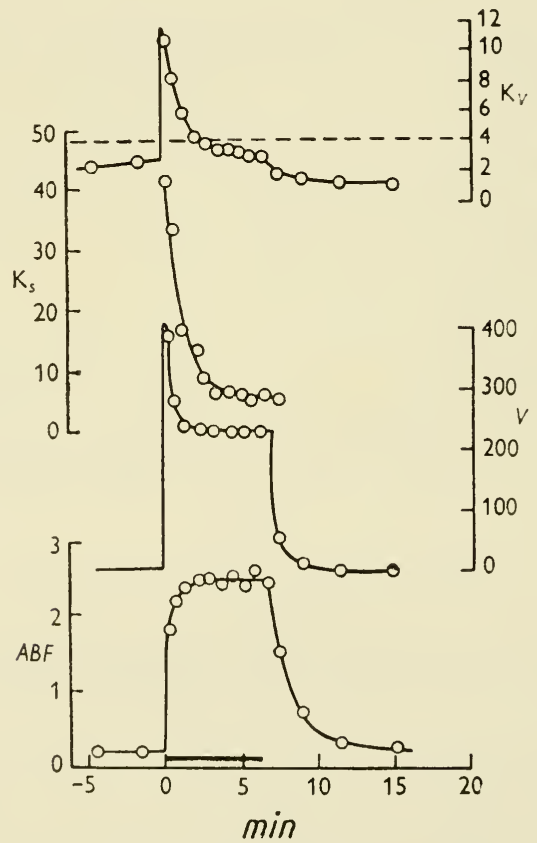

FIG. 10.9. The submaxillary gland circulation in a dog was isolated so that the venous blood draining from the gland could be collected. Following a rest period, the chorda tympani was stimulated at $20 \mathrm{c} / \mathrm{s}$.

$K v=$ venous plasma potassium in $\mathrm{mEq} / 1 . ; K_{s}=$ saliva potassium in $\mathrm{mEq} / 1 .: V=$ saliva flow rate in $\mathrm{mg} / \mathrm{g} \mathrm{min} ; A B F$ arterial blood flow through the gland in $\mathrm{ml} / \mathrm{g} \mathrm{min}$. Note that at the beginning of stimulation the potassium concentration in the saliva was over $40 \mathrm{mFq} / \mathrm{l}$., whereas in the steady state it was only $6 \mathrm{mEq} / \mathrm{l}$. At the beginning of stimulation the concentration of potassium in the venous plasma reached over i I mEq/1. and later settled down to $2.6 \mathrm{mEq} / \mathrm{l}$. 
draining from the gland is measured so that the arteriovenous difference of potassium as well as the salivary output is known. By this method it is found that the potassium loss from the gland proceeds at a very rapid rate during the first minute of stimulation, but soon thereafter, a steady state of potassium content is reached and on cessation of stimulation the gland slowly regains its potassium content. The concentration of potassium in the venous blood from the gland rises sharply above the arterial level at the beginning of stimulation and during this period potassium is being lost both into the blood and into the saliva, but gradually the venous potassium concentration falls and stabilizes at $40-70$ per cent of the arterial level. In this steady state as much potassium is being picked up from the blood going through the gland as is being secreted in the saliva. The time course of the venous transient is very similar to the early phase of the potassium transient in saliva and indeed the initial rates of potassium loss by the two routes are proportionate whatever the flow rate. In the dog submaxillary gland, about one-fifth of the initial potassium loss is into the blood and about four-fifths into the saliva (Burgen, 1956a). In the cat sublingual, the losses are about evenly divided between blood and saliva (Lundberg, 1958). It should be noted that both the amplitude of the saliva transient and the rate of potassium loss in it are dependent on the rate of nerve stimulation, the transient being much bigger at higher rates of stimulation. A related phenomenon is illustrated in Fig. Io. Io. Here stimulation was started at $2 \mathrm{c} / \mathrm{s}$ and when a steady state had been reached, the rate of stimulation was increased to $20 \mathrm{c} / \mathrm{s}$. A second transient ensued in both saliva and venous blood. The steady state gland content of potassium fell by a further i I $\mathrm{mEq} / \mathrm{kg}$ when the rate of secretion was increased. Seeman (1956) has also shown the presence of a negative potassium transient when the reverse experiment is carried out, i.e. initial stimulation at a high rate followed by sudden reduction to a low rate. Evidently, the steady state potassium content reached after stimulation is not a fixed one but is dynamically dependent on the rate of stimulation (and saliva secretion). The behaviour of potassium in the gland in response to abrupt changes in gland activity offers important evidence as to the function of the gland but the published explanations cannot be regarded as adequate. Burgen, Terroux and Gonder (1959) pointed out that since the early phase of the potassium transient had such a brief latency, it P.S.G.-P 


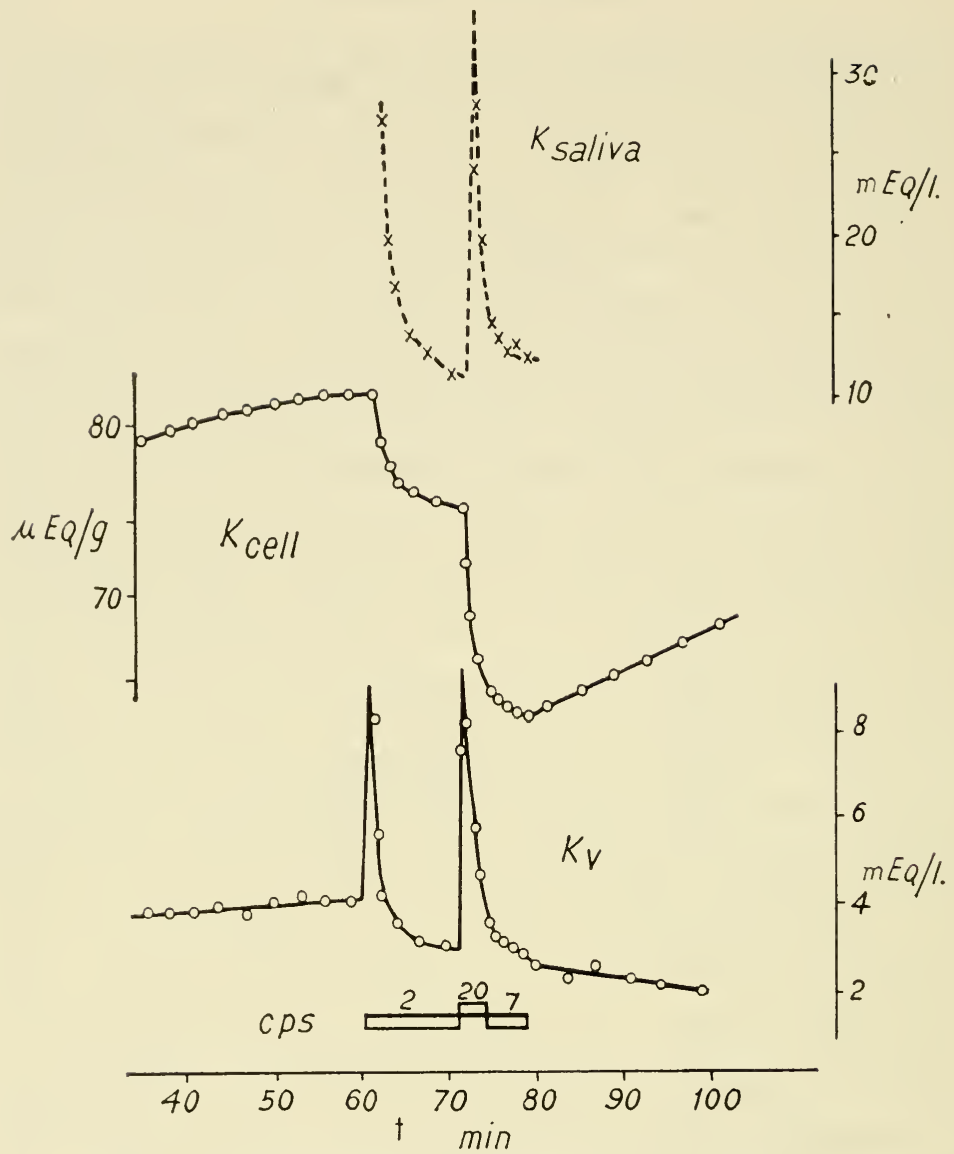

FIG. I0.10. A similar experiment to that shown in Fig. 10.9.

$K_{\text {eell }}$ refers to the total gland potassium in $\mathrm{mEq} / \mathrm{g}$ calculated from the potassium balance and direct gland analysis at 100 minutes. $K v$ and $K$ saliva are the concentration of potassium in the venous blood and saliva respectively. The arterial plasma potassium was $4.2 \mathrm{mEq} / 1$. Stimulation was started at $2 \mathrm{c} / \mathrm{s}$, saliva and venous transients ensued and the gland potassium content declined from $82 \mathrm{mEq} / \mathrm{g}$ to $75 \mathrm{mEq} / \mathrm{g}$. The stimulation frequency was then increased to $20 \mathrm{c} / \mathrm{s}$ without interruption of stimulation. A further saliva and venous transient ensued and the gland content abruptly fell by a further $10 \mathrm{mEq} / \mathrm{g}$. Reduction of stimulation frequency to $7 \mathrm{c} / \mathrm{s}$ did not produce any striking change. On cessation of stimulation the gland began to recover its potassium concentration (Seeman, 1956).

could not be due to acinar secretion although the later phase could very well be acinar in origin. They then made the assumption that since this saliva was of duct origin, potassium must accumulate in the duct lumen during the rest period. This theory, however, is totally unable to explain the appearance of a potassium transient on changing the rate of nerve stimulation nor the dependence of the magnitude of the transient on the rate of stimulation following 
the rest period. If the potassium were indeed stored in the lumen we would expect that the transient would be independent of the rate of nerve stimulation and would not be present when the rate of stimulation was changed. All these phenomena, however, can be accounted for quite satisfactorily if the source of the potassium in the first phase of the rest transient is the intracellular potassium of the duct cells which is discharged partly into the saliva and partly into the periductal blood. The loss across both faces of the cell would then be dependent on the rate of stimulation. The blood and saliva transients would be proportional to each other and the effect of raising the rate of stimulation without a rest period would also be adequately accounted for. Persumably, just as the whole gland potassium content reaches a different steady state depending on the intensity of stimulation, so the duct cell potassium might be similarly affected. The duration of the initial phase of the rest transient would therefore be dictated by the time taken for the duct cell potassium to reach a new steady state with its surroundings. The time taken for the rest transient to be restored after a period of stimulation would correspond to the time taken for the duct cells to recover their intracellular potassium concentration. The relative rapidity with which this occurs is another argument in favour of believing that there is a high rate of blood perfusion through the periductal capillaries.

Can we conclude that the late phase of the potassium transient is also of duct origin? This seems improbable for the following reasons: (a) potassium loss from the gland during stimulation is larger than can be accounted for by loss of all the duct potassium; (b) following intra-arterial injection of $\mathrm{K}^{42}$ (see page 2I6) the outflow curve shows a prolonged course without a correspondingly slow rise in activity; $(c)$ in unloading type experiments with $\mathrm{K}^{42}$ after the initial transient, the specific activity of the saliva potassium follows that of the whole gland potassium although it is always somewhat lower.

These deductions about the behaviour of the duct cells during stimulation may be correlated with the changes in the Type III potential described by Lundberg. The resting potential in these cells is high (about $-80 \mathrm{mV}$ ), therefore they probably have a high intracellular potassium. On stimulation, a striking depolarization to about $-20 \mathrm{mV}$ occurs over a few seconds. On cessation of stimulation, the potential is restored quite slowly. Such a potential 
change could occur if nerve stimulation facilitated sodium entry into the cell and also potassium loss from the cell, with the latter lagging behind the sodium entry. This can be regarded as a variant of the events that occur during activity in nerve and muscle. After a brief period of stimulation, depolarization will be mainly due to restoration of cell permeabilities to normal, but after longer stimulation reaccumulation of potassium and extrusion of sodium from the cells will be the rate limiting step. Judging from the amount of potassium released in the initial phase of the rest transient, a considerable proportion of the whole duct epithelium must be involved in both the submaxillary and parotid glands of the dog. If the changes suggested above do happen in the duct cells, it is at least plausible that the greater rate of loss of potassium from the inner face of the cells (as compared with the outer face) implies also a greater tendency to absorb sodium from the inner face. This assumption would be supported if a greater depolarization occurred at the inner cell face. Lundberg's measurements of the potential across the duct support this. This differential permeability to sodium might lead to transport from the saliva across the cells and into the blood; a similar process might also occur for anions.

Sodium. Burgen, Terroux and Gonder (1959) did not find any striking rest transient for sodium; on the other hand, Brusilow and Cooke (1959) found consistent negative sodium and chloride transients that developed after very brief rest period (10-60 seconds). With such short rests they did not find any appreciable potassium transient in the same samples; an unusual feature of these experiments was the high concentrations of sodium (up to $135 \mathrm{mEq} / \mathrm{l}$.) and potassium $(25 \mathrm{mEq} / \mathrm{l}$.), which are greater than those usually found in this secretion. At present no satisfactory correlation can be made between these results and those of Seeman (1956) and Burgen, Terroux and Gonder (1959). Over the longer rest periods when a larger potassium transient is developed, there must be concurrent changes in other ions. These have not been investigated fully as yet, but it appears that the potassium transient is accompanied by a corresponding increase in chloride concentration and some decrease in bicarbonate concentration. Much further work is needed, however, to establish the interrelationships of these four ions during different periods of rest.

Iodine. The presence of a striking iodide rest transient in dog parotid saliva has been mentioned on page 157 . Iodide accumula- 
tion during rest starts out at a high rate but as the duration of the rest period proceeds, the increments of iodide accumulated decrease until eventually a steady state is reached which is presumably dictated by a balance between the rate of active secretion of iodide into the cells and passive back-diffusion across the cells. Towbin and Perkins (1958) have reported that at the beginning of stimulation, the iodide concentration in the venous blood leaving the dog parotid may rise transiently above the arterial level. 'I'his phenomenon seems rather similar to that discussed above for potassium and can perhaps be accounted for in a similar manner. Due to this loss into the blood, the amount of iodide that appears in the saliva transient underestimates the total amount actually accumulated during the rest period.

\section{OUTFLOW PATTERNS AFTER CLOSE ARTERIAL INJECTION}

\section{OF ISOTOPES}

If a small amount of an isotope is injected rapidly into the arterial supply of a salivary gland which is secreting at a constant rate (and is otherwise in a steady state), the outflow pattern of the substance in the saliva can give useful information about the process of secretion in the gland. In this procedure, the gland is exposed only briefly to the labelled material since after passing through the gland the isotope is rapidly diluted in the animal's blood and body fluids. Before saliva which has acquired isotope from the blood can reach the exterior it must displace out the secretion that is already more distal to it. Thus, the more distal is the site at which the isotope can cross the blood into the saliva, the earlier will it appear in the saliva collected (Fig. IO. I I). In an actual experiment some of the delay in appearance of the isotope in the saliva is also due to the time taken for the injected material to travel to the gland in the blood as well as the time taken to traverse the dead space of the main salivary duct and cannula. In the average experiment these delays amount to about 2-3 seconds or approximately $\mathrm{IO}-\mathrm{I} 5 \mu \mathrm{l} / \mathrm{g}$. From histological sections, the lumen of the ducts has been estimated to occupy a volume of some 50-100 $\mu \mathrm{l} . / \mathrm{g}$ (Burgen, I956). The time resolution possible with the method as developed by Burgen, Terroux and Gonder ( 1959 ) is usually better than 0.5 second $(=2 \mu \mathrm{l} . / \mathrm{g})$. The method is therefore capable of resolving entry sites whose spatial separation is not more than 5 per cent of the total duct volume. Optimal 


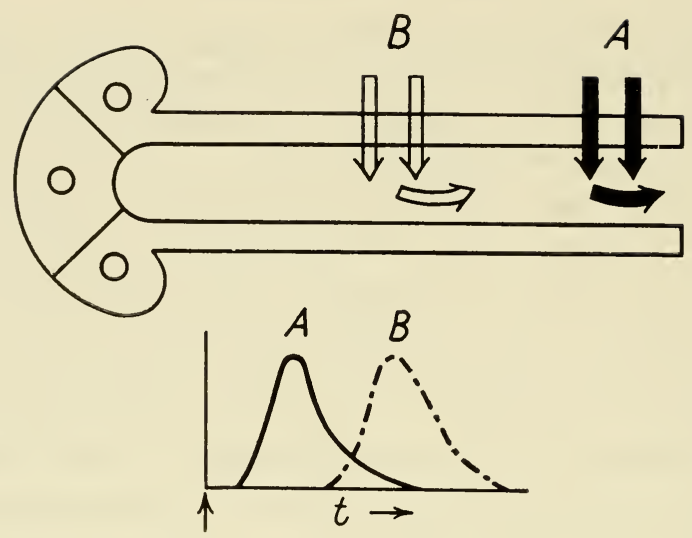

FIG. IO.II. Schema of the close arterial injection type of experiment.

Two substances $A$ and $B$ are injected into the blood supply of a salivary gland secreting at a constant rate. Since substance $A$ can penetrate the ducts at a more distal site than can substance $B$, it appears in the saliva earlier than substance $B$ as shown in the lower part of the figure.

sensitivity is reached when a pair of isotopes are injected together so that direct comparison of the outflow patterns is made on the same samples of saliva.

These methods have so far been applied only to the dog parotid

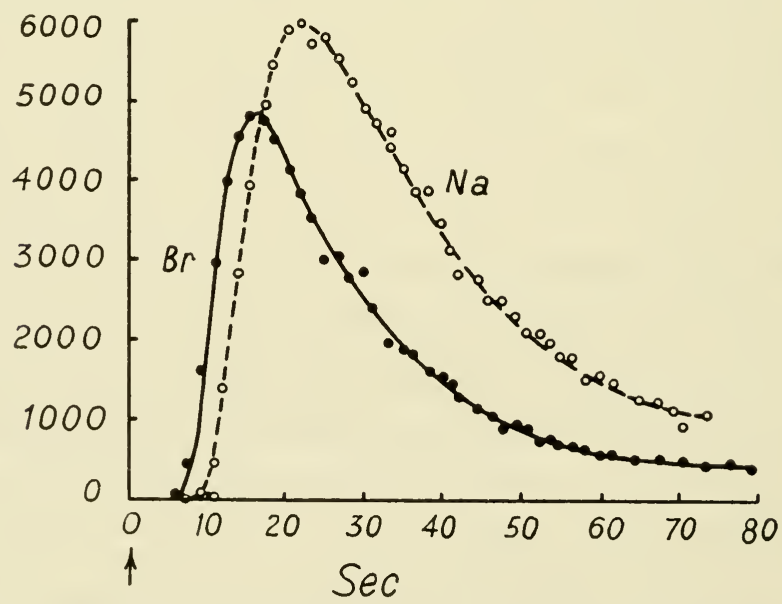

FIG. I0. I2. The parotid gland of this dog was secreting at a rate of $4 \mu \mathrm{l} . / \mathrm{g} / \mathrm{sec}$. At zero time tracer amounts of $\mathrm{Na}^{22}$ and $\mathrm{Br}^{82}$ were injected into the ipsilateral carotid artery. Single drops of saliva were collected and analysed for the two isotopes.

Ordinate: counts per minute per drop of saliva. Note that $\mathrm{Br}$ appears in the saliva about $2 \mathrm{sec}$ (i.e. $8 \mu \mathrm{l} . / \mathrm{g}$ ) ahead of the sodium (Burgen, Terroux and Martin, 1960). 
gland using the following substances: water $\left(\mathrm{T}_{2} \mathrm{O}\right)$, chloride, bromide, iodide, sulphate, bicarbonate, sodium, potassium, urea and four amino-acids (valine, methionine, isoleucine and tyrosine).

Neither sulphate nor any of the amino-acids appeared in detectable amounts in the saliva but all the other isotopes appeared after more or less brief latencies and reached peak concentrations of the same order. A typical experiment is illustrated in Fig. IO. I2. In this case, $\mathrm{Br}^{82-}$ and $\mathrm{Na}^{22+}$ were injected together-it can be seen that the curves are very much alike but that $\mathrm{Br}$ entered the saliva some ro $\mu \mathrm{l} . / \mathrm{g}$ earlier than $\mathrm{Na}$ and also reached a peak and declined more rapidly. The behaviour of all the substances studied is summarized in Fig. IO.I3. The earliest substance is tritiated water with a latency of $5^{-10} \mu \mathrm{l} . / \mathrm{g}$. Its concentration rises rapidly to a peak and then falls off with a half time of $5^{-10}$ seconds. Bicarbonate enters the saliva at the same point and has a very similar time course; chloride and bromide are delayed by $3 \mu 1 . / \mathrm{g}$ but

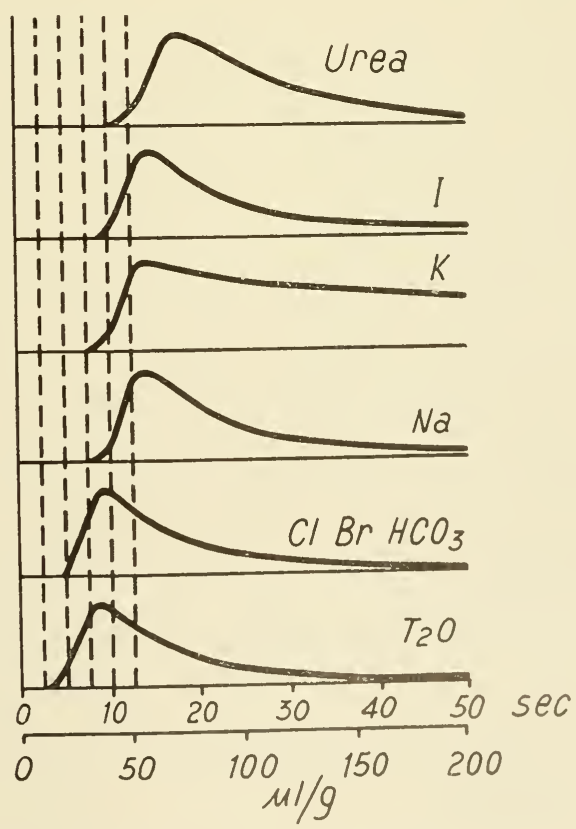

FIG. IO. I3. The form of saliva outflow curves after intra-arterial injection of various substances.

Note the progressively longer latency from $\mathrm{T}_{2} \mathrm{O}$ up to urea (Burgen, Terroux and Martin, 
otherwise are identical in shape as in sodium which is delayed by a further $7 \mu \mathrm{l}$. g. Potassium appears at the same time as sodium and reaches a similar peak height but then declines very slowly over a period of 2-3 minutes. Sometimes an inflection can be seen on this curve shortly after the peak has been passed. Iodide is slightly delayed with respect to sodium and potassium by about $2 \mu \mathrm{l}$. $\mathrm{g}$, it falls off more slowly than sodium but not nearly as slowly as potassium and its height is about ten times as great as the others. Finally, urea is delayed by a further $3 \mu \mathrm{l} / \mathrm{g}$ (see also Fig. I0.16) and falls off rather slowly.

How can we interpret these results? The volume of saliva secreted before the appearance of an injected substance indicates the most distal region at which the substance can penetrate into the saliva and we can conclude that all these substances are entering through the duct epithelium for the following reasons. Firstly, the small volume involved which is less than the total duct volume (the latest appearing substances, urea, is delayed by about 20 $\mu \mathrm{l} / \mathrm{g})$. Secondly, in the case of the two latest appearing constituents, iodide and urea, there is independent evidence that tubular transport occurs (see pages $I_{57}$ and 222). This type of experiment then reveals a minimum of five permeability areas in the salivary ducts and suggests that there is considerably more specialization in the physiological behaviour of these structures than had previously been supposed. It might be argued that these delays in appearance do not represent different sites but rather selective retardation in the duct cells. This does not seem a likely hypothesis because it would imply that the take-off points for all these substances are really identical and that only the rates of rise are affected. Similarly, it would be expected that the more delayed the rate of rise, the lower would be the peak height, and the slower the rate of recovery. Careful examination of the results does not give support to any of these features. For instance, in Fig. I0.12 at a time when a considerable amount of $\mathrm{Br}^{82}$ was present in the saliva, there was no trace of $\mathrm{Na}^{22}$ present. Furthermore, the parallelism of the rising phase of these two curves is very striking; there appears to be evidence here of delay but not of other significant differences in behaviour.

Before proceeding further, we must make it quite clear that experiments of this kind do not directly demonstrate sites for bulk transfer of ions, all they show is sites at which interchange between 
the ion in the blood and that in the saliva may proceed. Of course, such regions may coincide with ones at which bulk transfer is occurring, but independent supporting evidence must be found for this in the case of each ion under consideration.

As yet, we have only considered the interpretation of the leading edge of the outflow curve as giving evidence of the most distal locus at which permeation is possible. Can we obtain any evidence as to how far proximal this zone extends and also are we safe in assuming that a rapid uninflected fall away of the curve means that no acinar process is involved? For example, there are a number of reasons for believing that water is taken up by the acinar cells during activity and is also excreted into the acinar saliva, but the smooth, rapid decline of the labelled water concentration in the saliva gives no indication that this is the case. The reason for this becomes clear when we consider the experiments of Burgen and Seeman (1958) with radioactive sodium. The submaxillary gland was loaded with radioactive sodium unil it was in a steady state and then was autoperfused with non-radioactive blood. During stimulation, the specific activity of sodium in the saliva was never more than a few per cent of that in the gland due to a very extensive radioactive exchange occurring in the salivary ducts. This, together with the countercurrent nature of the duct circulation (page 19), leads to almost complete dilution of the radioactive sodium in the proximal saliva by non-radioactive sodium from the blood. We may generalize fiom this experiment as follows: we can only expect to see evidence of a more proximal process in the outflow pattern if $(a)$ there is no distal process or $(b)$ the proximal process is quantitatively large and the outward (saliva to blood) permeability of the ducts to this constituent is not great. 'This brings us to a consideration of the late phase of the potassium curve. There is clear evidence here of a proximal process since the potassium secretion in the saliva continues for at least $\mathrm{I}-3 \mathrm{~m} ! \mathrm{l} / \mathrm{g}$. This duration is so long that it must involve acinar secretion. We have direct evidence in this case also that outward permeability of the ducts to potassium is not very great because in unloading experiments (Burgen and Seeman, $195^{8}$ ), the saliva specific activity averaged $70-80$ per cent of that in the gland. Indeed, the rate of decline of radioactivity in the saliva in the close arterial experiments resembles very closely the rate of loss of gland radioactivity in the unloading type of experiment. The analysis of rest transients also had led to the 
conclusion that the outward permeability of the ducts to potassium is lower than the inward permeability.

A feature of considerable interest that this technique has revealed is that there is a distal region in the ducts where anions are able to enter the saliva but where cations cannot. Since anions can enter, they must also be able to leave the saliva at this point, because in the absence of cation entry anion movement can only occur by anionic exchange. It is pointed out below that a reciprocity between bicarbonate and chloride concentrations in the saliva can be demonstrated that is under the control of the arterial $\mathrm{pCO}_{2}$. It is tempting to believe that this distal site is the place where a chloride-bicarbonate exchange occurs.

Finally, it must be remarked that the permeability of the ducts for water is very great. This is especially interesting in view of the fact that the saliva is quite hypotonic and that, therefore, a considerable osmotic gradient exists across the duct. However, there is evidence in the case of the frog skin and of amphibian eggs that diffusional permeability for water may bear no close relationship to the osmotic hydrostatic permeability of the same cells (Prescott and Zeuthen, I953; Koefoed-Johnsen and Ussing, I953).

In summary, this technique has demonstrated that the salivary ducts of the dog parotid gland contain a minimum of five functional regions across which selective isotope movement can occur. These do not correspond to any known histological characteristic of the duct cells.

\section{EVIDENCE FROM ASSOCIATION AND DISASSOCIATION}

\section{IN CHANGES IN COMPOSITION}

Whilst the changes in composition in saliva at different rates of secretion do not, of themselves, provide useful information relating to the mechanism of secretion, when taken together with other observations they can be of value.

The Immature Dog. In the submaxillary gland of the neonatal puppy, saliva secretion is quite as active as in the adult. This is so despite a surprising degree of histological immaturity. Acini of adult type are almost totally absent and the ducts are large, frequently multilayered and quite unlike those of the mature animal (Wechsler, unpublished). The saliva produced is hypotonic although less so than the adult but bicarbonate is absent and chloride practically the sole anion. By three weeks of age, the gland appears 
much more mature histologically but the bicarbonate concentration remains very low. These observations suggest that in the immature animal, water and electrolyte secretion might largely originate in the salivary duct system and that the secretion could become hypotonic under these circumstances. Bicarbonate secretion appears to be a process maturing later and is associated with a reciprocal depression of the chloride concentration rather than any change in the cations. Potassium secretion stays remarkably constant at all stages of development; a high concentration of potassium in saliva seems to be one of its most universal and stable features.

The effect of alterations in arterial $\mathrm{pCO}_{2}$ on saliva bicarbonate and other ions. When the arterial $\mathrm{pCO}_{2}$ is reduced by hyperventilation, the saliva bicarbonate falls; however, the total anion concentration in the saliva does not usually change markedly. The reduction in bicarbonate is accompanied by an equivalent increase in the chloride concentration. Conversely, when the $\mathrm{pCO}_{2}$ is increased, the bicarbonate in the saliva rises and the chloride falls, although frequently, if the saliva carbonate has reached a very high level, some increase in sodium concentration also occurs. 'This evidence also suggests that the concentrations of bicarbonate and chloride in saliva are intimately related and that probably bicarbonate enters the saliva in exchange for chloride reabsorbed and that this exchange process is controlled by the arterial $\mathrm{pCO}_{2}$. In some animals, however, changes in bicarbonate are accompanied mainly by changes in sodium concentration. It is not known what favours one process rather than the other.

Effects of adrenaline. It was found by Langstroth, McRae and Stavraky (I938) that following a relatively large does of adrenaline, the inorganic composition of cat submaxillary saliva evoked by subsequent chorda stimulation was changed. The major alteration is a considerable increase in total osmolyte concentration, accounted for almost wholly by an increase in sodium and chloride. Neither potassium nor bicarbonate are greatly affected. Martin ( 1960 ) has shown that at least part of this effect is exerted on the salivary duct system and involves an increase in permeability for a number of substances including amino-acids, sucrose, creatinine and urea. The lack of effect on bicarbonate suggests that in this case sodium and chloride are behaving as an ion pair and that the effect of adrenaline is either to inhibit their reabsorption from the 
saliva or to facilitate their entering. The importance of this observation is that in this case chloride is being affected independently of bicarbonate and in association with a cation; this process cannot, for instance, be proceeding at an anion exchange area in the distal part of the salivary duct.

Effects of adrenal corticoids. The effect of adrenal corticoids is to raise the potassium and lower the sodium concentration in saliva.

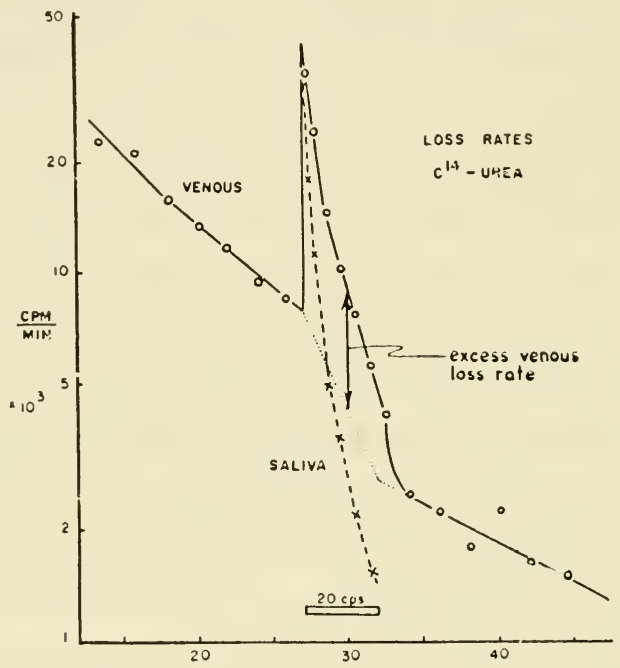

FIG. IO.I4. Unloading experiment with $\mathrm{C}^{14}$ urea in the dog submaxillary gland.

During stimulation the rate of loss of labelled urea in the venous blood increased. This excess venous loss rate corresponded to the amount of urea crossing the duct epithelium into the periductal blood (Burgen and Seeman, 1958).

This is most strikingly seen in the sheep parotid (Fig. 8.12), but the same process has been noted in all the other glands although to a lesser degree. No analysis of this effect has been carried out but this appears to be a case where the primary change is on the two major cations, without important changes in the anions. It is possible that the corticoids control an exchange of sodium and potassium in the duct system.

\section{REABSORPTION OF FLUID IN THE DISTAL DUCTS}

Several pieces of evidence point to the occurrence of fluid reabsorption in the most distal region of the salivary ducts. At low 
rates of secretion, the concentration of passively distributed nonelectrolytes such as urea, thiourea and methenamine rises above the plasma level (Burgen, I956). Similar increases occur with the electrolytes. Following a brief rest interval, a moderate increase in concentration of protein and iodine occurs in the first few drops of saliva secreted. This increase reaches a maximum after only 2 or 3 minutes. A similar increase of total osmolytes occurs in the same few drops (Seeman, unpublished). It has also been noted by many observers that following a period of parasympathetic stimulation, if a small drop remains on the end of the cannula, this can be seen to recede slowly during a brief rest period. All these observations suggest that water reabsorption, possibly under an osmotic gradient, proceeds in the duct system. The fact that this leads to concentration of only the first few drops of saliva secreted after a rest period and also the fact that it changes the concentration of urea which is known to cross the epithelium of the proximal part of the duct system, leads us to believe that this process occurs in the extreme distal region of the salivary ducts.

The sum of the observations in the present section is that one needs to postulate a minimum of five mechanisms that are concerned with the concentrations of the four major ions in the saliva. These are: $(a)$ a bi-ionic movement of sodium and chloride, $(b)$ an anion exchange of chloride with bicarbonate, $(c)$ an exchange of sodium with potassium under the control of adrenal corticoids, (d) a potassium secretion depending on the potassium plasma level, and $(e)$ a water reabsorptive process.

\section{THE SECRETION OF NON-ELECTROLYTES}

In the study of the steady state secretion of ten non-electrolytes, Burgen (1956) found that these could be classified according to the relationship between the saliva concentration and the rate of saliva secretion which they exhibited. For some components (N-ethylurea, chloramphenicol, 4 -acetamidoantipyrine and methenamine) the concentration was inversely related to flow rate. This relationship can be accounted for satisfactorily on the hypothesis that the permeability of the gland for these substances did not change significantly with alteration in the rate of nerve stimulation. With the other group of substances (urea, thiourea, N-methylurea, mannitol, creatinine and glycerol) the relation of saliva concentration to flow rate was U-shaped (see Fig. 9.8). 'The permeability of the 
gland to these substances increases progressively with increasing rate of nerve stimulation. The behaviour of all these ten substances could be explained quite satisfactorily on the assumption that there were two pathways by which non-electrolytes could enter the saliva. One of these was a lipoid membrane whose properties were not altered by nerve stimulation. The other was a porous structure the size of whose pores was severely restrictive on the passage of molecules with a diameter greater than about $6 \cdot 4 \AA$. These pores appeared to increase in number or diameter with increasing rate of nerve stimulation, thus leading to an increased permeability. It is of particular interest that the concentration of these substances in the gland substance was not different from that present in the plasma; difficulty of penetration into the gland cells was not therefore the cause of the lower concentration of these substances in the saliva as compared with that in the plasma. Further analysis of the mechanism of transfer of the non-electrolytes has been undertaken with urea (Burgen and Seeman, I958). The submaxillary gland of the dog was isolated from the rest of the animal so that it could be autoperfused with blood; the venous effluent from the gland was not returned to the animal. The gland was then equilibrated with $\mathrm{C}^{14}$-urea by intra-arterial injection and subsequently perfused with non-radioactive blood. In Fig. IO.I4 such an experiment is shown. Initially, radioactivity was being lost with a half time of 8 minutes. On stimulating the nerve, the output of radioactive urea in the venous blood increased and radioactive urea also appeared in the saliva. However, the specific activity of urea in the saliva was always considerably lower than that in the gland. This could be due to equilibration of radioactive urea secreted by the acinar with non-radioactive urea from the blood during the passage of saliva along the ducts, or to the addition of non-radioactive urea from the blood during the passage of saliva along the ducts. Mathematical analysis of this system can be carried out very satisfactorily and showed that both these processes occurred. On the average, only about one-third of the urea in the saliva was derived from urea secreted by the acini and two-thirds was contributed by diffusion from the blood into the saliva occurring across the ducts. It would, of course, be expected that if non-radioactive urea enters the saliva through the ducts, then also radioactive urea will be lost from the saliva into the blood through the same route. The amount lost was calculated by Burgen and Seeman and compared with the 
extra radioactivity lost into the venous blood during stimulation (Fig. IO.I4). It appears that transductal loss of radioactive urea from the saliva could account entirely for the excess amount appearing in the venous blood. This suggests that the permeability of the outer face of the acinar cells for urea is not significantly affected by stimulation. On the other hand, it is possible to calculate directly the permeability of both the ducts and the inner face of the acinar cells at different rates of saliva flow (Fig. IO. I 5 ). 'I'his

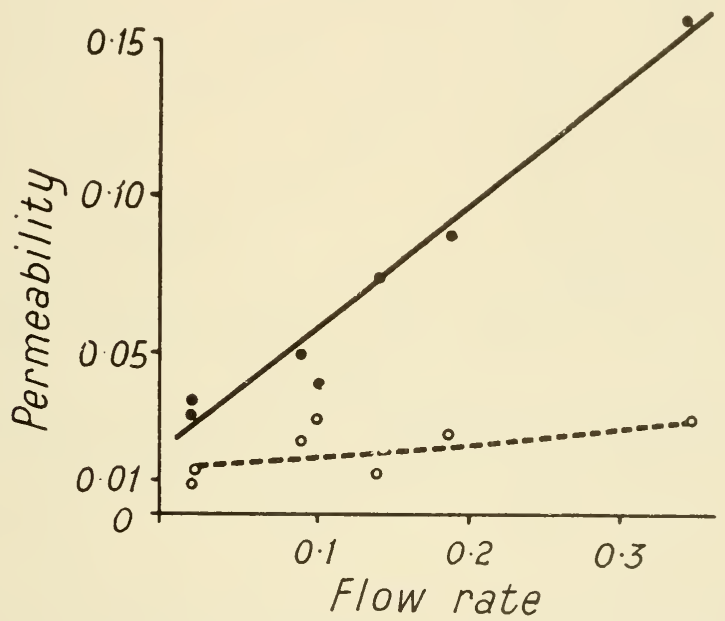

Fic. I0.15. Changes in the permeability of the acinar cells $\bigcirc \ldots$ and duct cells $\mathrm{O}-\mathrm{O}$ to urea with change in saliva flow rate.

Note the large increase in duct permeability and relatively small change in acinar permeability as the flow rate increases. $\mathrm{Abscissa}$ : saliva flow rate in $\mathrm{ml} . / \mathrm{g}$. $\mathrm{min}$. Ordinate: arbitrary permeability units (calculated from data given by Burgen and Seeman, 1958).

calculation shows that the permeability of the inner face of the acinar does not change very much with the rate of stimulation but that there is a considerable increase in the permeability of the ducts proportional to the rate of secretion. It seems quite possible, therefore, that the lipoid membrane of fixed permeability postulated by Burgen (1956) is the inner cell membrane of the acinar cells and that the membrane of variable permeability is in the ducts. It is highly desirable that these findings should be confirmed by a similar analysis carried out with a non-electrolyte of different physiochemical properties. Since the evidence obtained by the techniques just described indicates very convincingly that equilibration of urea occurs across the ducts, it is of special interest to see how urea 
behaves when tested by the close intra-arterial injection technique (Burgen, Terroux and Gonder, I959). In Fig. I0.16 it is seen that urea crosses the ducts at a point proximal to sodium. Indeed, it enters at the most proximal permeability site yet encountered. The rate of decline of the curve is also slower than encountered with

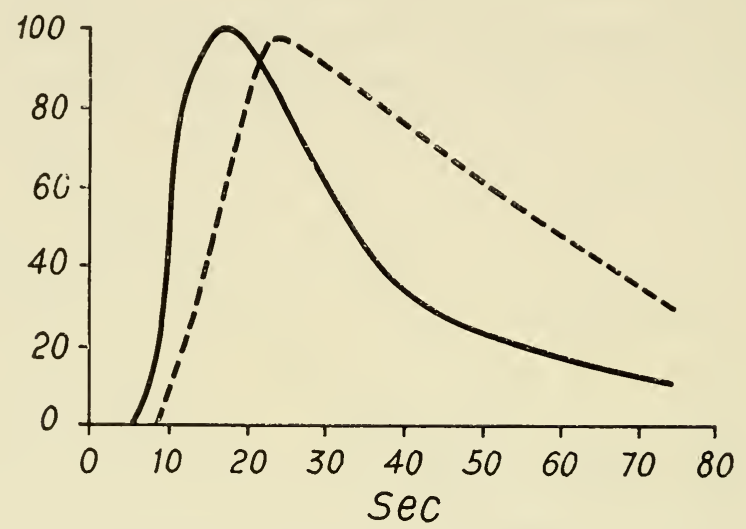

Fig. I0.I6. Simultaneous injection of $\mathrm{Na}^{22}$ and $\mathrm{C}^{14}$ urea close arterially into the parotid gland of the dog.

Urea (- - ) trails the $\mathrm{Na}(-)$ by $2 \cdot 5$ seconds at the take off and also declines more slowly (Burgen, Terroux and Martin, 1960).

sodium and this is presumably due to the presence of an acinar component. This was to be expected in view of the relatively low duct permeability for urea found in the experiments of Burgen and Seeman. It is perhaps unwise to assume without experimental proof that other non-electrolytes will behave in a way predicted from these relationships, because our experience has been that each new substance studied reveals some detail of the secretory process that had not been known previously.

EVIDENCE CONCERNING THE BLOOD SUPPLY

OF THE GLAND

It has been mentioned elsewhere (page i9) that the high clearance rate for iodide in the parotid gland of the dog and man, together with the evidence showing that iodide secretion occurs exclusively in the duct system of the salivary gland, must be interpreted to mean that the blood flow to that part of the ducts secreting iodide is very high and probably accounts for a large proportion of the total gland blood flow. In some experiments, 
Towbin and Perkins (1958) found that as much as 88 per cent of the iodide was extracted from blood flowing through the gland. In this instance, very little of the blood cannot have perfused the ducts. Where does the blood required by the acini come from? Is this a separate supply or is it shared with the duct supply through a portal system analogous to the glomerulo-tubular system of the mammalian kidney? Information relevant to this may be obtained from a consideration of the specific activity of potassium in the venous blood from the submaxillary gland at rest after previous intra-arterial loading (Burgen and Seeman, 1958). The specific activity of the venous blood was usually about $60-80$ per cent of that in the gland. It is known that a large proportion of the gland potassium must be contained in acinar cells because after intravenous infusion of $\mathrm{K}^{42}$ the whole gland potassium reaches the same specific activity as the plasma, and further that the kinetics with which this occurs do not indicate the presence of more than one major compartment. We must conclude, therefore, that at least $60-80$ per cent of the blood perfusing the gland comes in contact with the acini. These results were of course obtained in different glands but, nevertheless, ones that in other ways behave in very similar fashion. This evidence then suggests that a considerable degree of serial perfusion to the acinar and ducts occurs in the resting gland. What of the stimulated gland? The iodide clearance of the parotid gland rises about proportionately to the rate of salivary secretion (Burgen and Seeman, 1957). In the submaxillary gland the blood flow also bears a more or less constant relationship to the rate of secretion (see Terroux, Sekelj and Burgen, 1959). It therefore seems likely that the proportion of the total gland blood flow that perfuses the ducts is not greatly changed during activity. These facts, then, make it probable that at least half the total blood flow through the gland passes through the portal system both at rest and during activity. Which way does the blood flow in such a system? Does it flow in the same direction as the saliva (concurrent) or in the opposite direction (countercurrent)? Burgen and Seeman (1958) pointed out that if the direction of flow were concurrent, the minimum saliva specific activity for a substance that exchanged freely across the duct epithelium would be that of the venous blood. On the other hand, if the flow is countercurrent, the limiting specific activity of the saliva is that of the arterial blood which in an unloading type of experiment is 
zero. They found not infrequently that the specific activity of sodium and urea in the saliva was lower than that in the venous blood. This finding argues in favour of a countercurrent flow but because of the anatomical irregularity of the gland vasculature, this argument cannot be regarded as completely proven. For instance, if the terminal part of the duct were to receive an independent arterial supply which might be a small fraction of the total gland blood flow, this could serve to lower the specific activity of the saliva below that in the venous blood. How do these ideas conform with the anatomy of the gland vasculature as demonstrated by injection procedures? A full account will be found in Chapter II. It suffices here to say that injection procedures fully confirm the presence of a rich vascularization of the ducts. It also confirms that, in general, the flow of blood in the periductal capillaries is indeed largely countercurrent. Anatomical evidence for a portal system is very meagre. It should also be noted that a considerable proportion of the blood water (Io-20 per cent) is extracted by the gland and if the bulk of the saliva water were secreted by the acini and if, as some of the anatomical evidence suggests, the acinar receives only a meagre blood supply, the haemoconcentration in the acinar capillaries might be very considerable. As discussed elsewhere there is also considerable doubt as to the proportion of the saliva water that is contributed by the acinar and the proportion contributed by the ducts.

\section{SUMMARY}

A number of new methods have been developed to attempt to uncover the nature of secretory processes in the salivary glands. The presently available evidence shows that the secretory process is highly complex. This is particularly true of the salivary duct system which seems to play a more important role in the formation of this secretion than had previously been realized. By various techniques, segregated sites and distinct processes in the ducts have been distinguished. At least three types of cells can be distinguished on electrophysiological grounds and some progress has been made in correlating electrical events in salivary gland cells with the ionic movements taking place in secretion. 


\section{REFERENCES}

ALEXANDER, N. M. (1959). Iodide peroxidase in rat thyroid and salivary glands and its inhibition by antithyroid compounds. F. biol. Chem., 234, I $530-1533$.

BAYLISS, W. M. and J. R. BRADFORD (1885). On the electrical changes accompanying secretion. F. Physiol., 6, xii-xvi.

- - (I886). The electrical phenomena accompanying the process of secretion in the salivary glands of the dog and cat. Proc. R. Soc. Lond., 40, 203-206.

BRADFORD, J. R. (I887). The electrical phenomena accompanying the excitation of so-called secretory and the optic nerve fibres in the salivary glands of the dog and cat. F. Physiol., 8, 86-98.

- (1888). Some points in the physiology of gland nerves. F. Physiol., 9, 287-3 16.

BRUSILOW, S. W. and R. E. COOKE (1959). Role of parotid ducts in the secretion of hypotonic saliva. Amer. F. Physiol., r96, 831-834.

BURGEN, A. S. v. $(1956 a)$. The secretion of potassium in the saliva. $\mathcal{F}$. Physiol., 132, 20-39.

- (1956b). The secretion of non-electrolytes in the parotid saliva. F. cell. comp. Physiol., 48, I1 $3^{-1} 3^{8}$.

Burgen, A. S. V. and P. SEEMAN (1957). The secretion of iodide in saliva. Can. F. Biochem. Physiol., 35, 48I-489.

- - (1958). The role of the salivary duct system in the formation of the saliva. Can. F. Biochem. Physiol., 36, I I9-143.

BURGEN, A. S. V., K. G. TERROUX and E. GONDER (I 959). The sites of transfer of sodium, potassium and iodide in the parotid system of the dog. Can. F. Biochem. Physiol., 37, 359-370.

BURGEN, A. S. V., K. G. TERROUX and K. MARTIN (ig60). Unpublished.

BURGEN, A. S. V., M. WEISS and G. WEISS (1960). Unpublished.

COHEN, B. and N. B. MYANT (1959). Concentration of salivary iodide; a comparative study. F. Physiol., 145, 595-6ro.

ECCLES, J. C. (1957). The physiology of nerve cells. Johns Hopkins Press, Baltimore.

GLYNN, L. E. and E. J. HOLBOROW (I959). Blood group substances in human tissues. Brit. med. Bull., 15, I50-153.

HARREVELD, A. (I930). Das Elektrogramm und die Widerstandveränderungen der Unterkieferspeicheldrüse. Arch. néerl. Physiol., r5, 23.

HODGKIN, A. L. and P. HOROWICZ (1959). The influence of potassium and chloride ions on the membrane potential of single muscle fibres. $\mathcal{F}$. Physiol., 148, 127-160.

HOGBEN, C. A. M. (I955). Active transport of chloride by isolated frog gastric epithelium. Amer. F. Physiol., r8o, 641-649.

HOLTZLÖHNER, E. and C. NiEssing (1936). Die Drüsentätigkeit bei Nervenreizung $\mathrm{V}$. Lebendbeobachtungen an Zellen, Lymphspalten und Kapillaren der Unterkieferdrüse. Z. Biol., 97, 563-572.

KESZTYǗS, L. and J. MARTIN (1937). Ueber den Einfluss von Chorda- und Sympathicus-reizung auf die Zusammensetzung des Submaxillarspeichels. Arch. ges. Physiol., 239, 408-418.

KOEFOED-JOHNSEN, v. and H. H. USSING (I953). The contributions of diffusion and flow to the passage of $\mathrm{D}_{2} \mathrm{O}$ through living membranes. Acta physiol. scand., 28, 60-76. 
KöSTlin, A. and S. RAUCH (1957). Zur Chemie des Ruhespeichels einzelner Speicheldrüsen. Helv. Med. Acta, 24, 600-62 I.

LANGENSKIÖLD, A. (I94I). Component potentials of the submaxillary gland electrogram. Acta physiol. scand., 2, Suppl. 6, I-109.

LANGSTRoth, G. O., D. R. MCRAE and G. W. STAVRAKY (1938). A study of cat's submaxillary saliva obtained under nerve stimulation or adrenaline administration. Arch. int. Pharmacodyn., 58, 6I-77.

LEESON, C. R. and F. JACOBY (I 959). The post-natal development of the rat submaxillary gland. F. Anat., Lond., 93, 287-295.

LUNDBERG, A. (I 955). The electrophysiology of the submaxillary gland of the cat. Acta physiol. scand., 35, I-25.

- (1956). Secretory potentials and secretion in the sublingual gland of the cat. Nature, 177, ro8o-1081.

- (1957b). Secretory potentials in the sublingual gland of the cat. Acta physiol. scand., 40, $2 \mathrm{I}-34$.

- (I957é). The mechanism of establishment of secretory potentials in sublingual gland cells. Acta physiol. scand., 40, 35-58.

- (1957c). Anionic dependence of secretion and secretory potentials in the perfused sublingual gland. Acta physiol. scand., 40, I0 I-I I 2.

- (1958). Electrophysiology of salivary glands. Physiol. Rev., 38, 2 I-40. MARTIN, K. (I960). Changes in the composition of the saliva produced by adrenaline and insulin. Fed. Proc. In the Press.

PRESCOTT, D. M. and E. ZEUTHEN (I953). Comparison of water diffusion and water filtration across cell surfaces. Acta physiol. scand., 28, 77-94.

SEEMAN, P. (1956). The exchange of sodium and potassium in salivary glands. M.Sc. Thesis, McGill University.

TERROUX, K. G., P. SEKELJ and A. S. V. BURGEN (I 959). Oxygen consumption and blood flow in the submaxillary gland of the dog. Can. F. Biochem. Physiol., 37, 5-15.

TOWBin, E. J. and W. H. PERkins (I958). Salivary secretion of $\mathrm{I}^{131}$. Physiologist, $\mathbf{1}, 82$.

USSING, H. H. and K. ZERAHN (I95I). Active transport of sodium as the source of electric current in the short-circuited isolated frog skin. Acta physiol. scand., 23, I10-127.

WECHSLER, A. (I 960 ). Unpublished.

WeIss, M. (1957). The secretion of protein in the saliva. M.Sc. Thesis, McGill University.

Wills, J. H. and W. O. FENN (1938). Potassium changes in the submaxillary glands during stimulation. Amer. F. Physiol., 124, 72-76. 


\section{CHAPTER XI \\ ME'TABOLISM}

The respiration of the salivary glands has been measured both in viro and in vitro by a number of workers. The resting oxygen consumption in dog submaxillary glands is $22-27 \mu \mathrm{l} / \mathrm{g}$. min (Barcroft, I9 I4; Barcroft and Kato, I916; Terroux, Sekelj and Burgen, I959) and in the cat $29 \mu \mathrm{l} . / \mathrm{g}$. min (Strömblad, I959). With isolated gland slices or minces somewhat higher values are usually found (Deutsch and Raper, I936; Brock, Druckrey and Herken, 1938; Strömblad, 1957). The respiration rates are quite similar in the various glands from different mammalian species. The R.Q. at rest has been reported between 0.9I-I.02 (Barcroft, I90I; Deutsch and Raper, I938; Strömblad, r959). With parasympathetic stimulation or injection of acetylcholine or pilocarpine the oxygen consumption rises rapidly to a maximum of $\mathrm{I} 30$ to $\mathrm{I} 75 \mu \mathrm{l} / \mathrm{g}$. min. In both the cat and the dog the increase in respiration is linearly related to the saliva flow rate, but the dog requires only $300 \mu 1 . \mathrm{O}_{2} / \mathrm{ml}$. saliva secreted compared with 630 for the cat. Barcroft and Kato (19I6) found that if the dog submaxillary gland was stimulated over a long period ( 3 hours) by pilocarpine infusion there was a progressive rise in both the blood flow and oxygen consumption required for saliva secretion. After 3 hours $\mathrm{I} \cdot 3 \mathrm{ml}$. of oxygen was required for each $\mathrm{ml}$. of saliva produced. Over a shorter period of time the same phenomenon had been encountered. Following a period of stimulation a moderate oxygen debt develops which is mostly dissipated in a few minutes. The R.Q. of the active glands was found to be increased up to I $\cdot 8-3 \cdot 7$ by Strömblad (I959), but on the other hand no consistent change was seen by Barcroft (19I4). Barcroft and Müller (I9I2) found no correlation between changes in blood flow per se and oxygen consumption in experiments in which yohimbine was injected. This drug produced a striking increase in blood flow through the gland without either salivary secretion or the slightest change in oxygen consumption. Strömblad (1959), however, suggests that the carbon dioxide output may be dependent on blood flow.

When adequate doses of atropine are given no saliva secretion 
occurs when the chorda is stimulated, but the blood flow through the gland increases to about the same degree as in the absence of atropine and the oxygen consumption increases Io-100 per cent (compared with 200-400 per cent in the absence of atropine). It appears that the secretory response is the most sensitive and the vascular response the least sensitive to the effects of atropine (Barcroft, I9I4; Terroux, Sekelj and Burgen, 1959; Strömblad, I959).
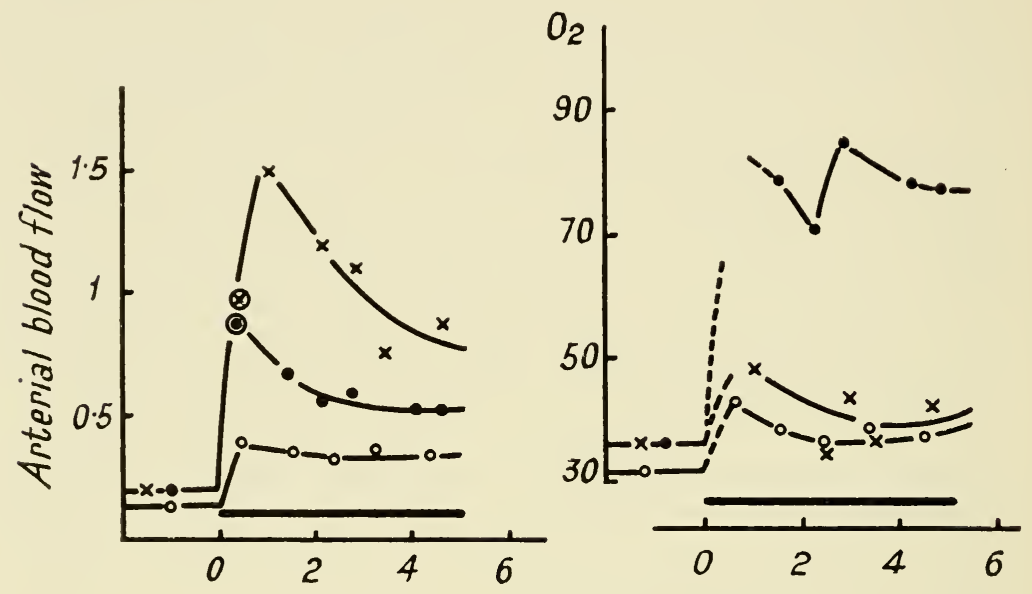

\section{Min}

FIG. İ.r. Arterial blood flow $(A B F \mathrm{ml} / \mathrm{g} / \mathrm{min})$ and oxygen consumption $\left(\mathrm{O}_{2} \mu \mathrm{l} . / \mathrm{g} / \mathrm{min}\right)$ of dog submaxillary gland.

During the period marked by the bar the chorda tympani was stimulated at 5 c.p.s. before administration of atropine $x-X$ I5 minutes after I $\mathrm{mg} / \mathrm{kg}$. of atropine. No secretion occurred. $\bigcirc-\bigcirc 35$ minutes after the atropine (Terroux, Sekelj and Burgen, 1959).

In vitro techniques have shown a complete block by atropine of the metabolic effects of acetylcholine (Deutsch and Raper, I936; Brock, Druckrey and Herken, I938). This is presumably due to the larger doses of atropine used in these experiments although it is well known that atropine antagonizes the effects of injected acetylcholine more readily than the effects of parasympathetic stimulation (see Hilton and Lewis, r957). Similar increases of oxygen consumption have been obtained in the cat submaxillary gland stimulated by adrenaline or the sympathetic (Barcroft and Piper, I912; Barcroft, I914; Deutsch and Raper, I936; Strömblad, 1957 and I959). The amount of oxygen required in the secretion of sympathetic saliva is less than that for chorda saliva (Strömblad, 
I959). Deutsch and Raper (1936) reported that no change in oxygen consumption was produced by adrenaline in the cat parotid or the dog and rabbit parotid and submaxillary; however, Hokin and Sherwin (1957) obtained a considerable increase in respiration with adrenaline in the rabbit parotid and submaxillary glands using somewhat higher doses. Four weeks following chorda section the resting oxygen consumption of the submaxillary gland of the cat was reduced by one-third and the extra oxygen consumption per $\mathrm{ml}$. of saliva was reduced proportionately as was the maximal rate of oxygen usage of the gland (Strömblad, I959).

Not much is known of the substrates utilized by the salivary gland in situ. Anrep and Cannan (1922, I923) measured the utilization of glucose by the dog submaxillary gland and found at rest an uptake of about $60 \mu \mathrm{g} / \mathrm{g}$. $\min (0.33 \mu \mathrm{M} / \mathrm{g}$. min) or roughly 0.33 $\mu \mathrm{M}$ glucose per $\mu \mathrm{M}$ of oxygen. During activity glucose utilization increased up to eightfold, running roughly in parallel with the oxygen usage. It is of course not certain that all of this glucose is used in respiration; some may be used as a carbon source in synthesis of the secretory product. Small amounts of lactate are formed by the resting gland and during activity an increased output occurs, particularly during the first minute, a period when the increase in respiration lags behind the rate of secretion (Bergonzi and Bolcato, I930; Bergonzi, I93 I; Ferrari and Höber, I933; Wills, I94I). Ferrari and Höber (r933) found with perfused glands an increase in lactate output when cyanide $\left(0.5^{-2} \mathrm{mM}\right)$ was added to the perfusion fluid and a reduction with iodacetate (0.0 - $-0.05 \mathrm{mM})$. Only modest changes in the gland lactate content have been reported after stimulation, but in part this may be due to inadequate experimental technique. Moderate reduction in glycogen and creatine phosphate have been reported after stimulation (Bergonzi and Bolcato, I930; Himwich and Adams, I930b; Northup, I935). Anaerobic incubation of minced submaxillary glands leads to quantitative conversion of glycogen to lactate (Himwich and Adams, I930a).

In vitro the metabolic behaviour of salivary slices or minces has interesting features. Under anaerobiosis, with cyanide, iodacetate or fluoride the metabolic effect of acetylcholine is no longer present. Resting metabolism is changed little by the addition of extraneous substrates (glucose, fructose, succinate, lactate or pyruvate), and indeed in the absence of added substrate a steady $\mathrm{QO}_{2}$ 
is maintained for many hours. 'The acetylcholine effect, however, is readily attenuated when there is no added substrate and is considerably augmented by the addition of large amounts (100-200 $\mathrm{mg} / \mathrm{I} 00 \mathrm{ml}$.) of lactate. This effect of lactate is prevented by the simultaneous addition of small amounts of glucose. The $\mathrm{Qo}_{2}$ in the presence of iodacetate is also increased by lactate. Anaerobic glycolysis is not very active except in the presence of glucose and is not satisfactorily maintained by fructose (Deutsch and Raper, 1938; Brock, Druckrey and Loch, I942). Dinitrophenol increases the $\mathrm{Qo}_{2}$ of the resting gland to the maximum found after addition of acetylcholine (Strömblad, I957).

When gland atrophy was produced in the rat by a duct ligation, the $\mathrm{Qo}_{2}$ was reduced to 40 per cent of normal and similar reductions occurred in pyruvate oxidation, succinic dehydrogenase and the content of high energy phosphates. No change was found in glycolysis (Junqueira, I955; Junqueira and Hirsch, 1956). It has been pointed out elsewhere (page 225) that a high concentration of mitochondria, succinic dehydrogenase, and the rich vascularization of the salivary ducts suggests that a considerable fraction of the total gland respiration is due to these elements.

\section{PHOSPHORUS TURNOVER}

Extensive studies on phospholipid turnover in the salivary glands, pancreas, brain and other tissues have been carried out by the Hokins (Hokin and Hokin, 1953, 1954, 1958, 1959 $a$ and $b$ ). They found that $\mathrm{P}^{32}$ incorporation into the phospholipids of rabbit parotid and submaxillary and guinea pig parotid slices was increased several fold by the addition of acetylcholine and adrenaline. These effects could be prevented by atropine and ergotamine, dibenamine or chlorpromazine, respectively. Noradrenaline was less effective than adrenaline. Submaximal doses of adrenaline and acetylcholine were additive, but maximal effects were not additive. In the rabbit but not in the guinea pig parotid, increased incorporation of $\mathrm{P}^{32}$ into the acid-soluble phosphate esters also occurred.

Under anaerobic conditions the stimulating effect of carbamylcholine on phospholipide synthesis in the pancreas is no longer present (Hokin and Hokin, 1953). Further analyses of these effects have been carried out in the pancreas and the brain and since it seems likely that these do not differ in any important degree from the effect in the salivary glands they are relevant to our account. 
The increased $\mathrm{P}^{32}$ incorporation occurs into two monophosphoinositides as well as into phosphatidylcholine, phosphatidylethanolamine, and phosphatidylserine. Glycerol- $\mathrm{C}^{14}$ incorporation into the phosphatidic acid was not stimulated but incorporation into the phosphoinositide of high Rf was increased. A modest increase in inositol- $\mathrm{H}^{3}$ incorporation was also found. Hokin points out that the known pathways of phosphatidic acid synthesis are from $\alpha$ glycerophosphate or from ATP. P ${ }^{32}$ experiments showed that only the formation of phosphatidic acid derived from ATP was stimulated by acetylcholine. The enzymes responsible for this acetylcholine response are present in the microsome fraction and can be brought into solution by desoxycholate. This behaviour is that expected from an enzyme system located in the lipid membranes either of the cell surface or the endoplasmic reticulum, and has led to the proposal that this effect is concerned with protein secretion and perhaps with the transfer of lipid-insoluble substances across the cell membrane by the formation of lipid-soluble phosphatidic complexes.

\section{PROTEIN SYNTHESIS}

While no direct study on protein synthesis in vitro has been carried out on the salivary glands, it is quite likely that great similarities exist in the synthesis in the pancreas which has been studied in detail by Hokin ( $195 \mathrm{I} a$ and $b$ ) and others. He found that protein synthesis was dependent on normal cell respiration and was abolished by anaerobiosis and metabolic poisons such as cyanide, iodacetate and dinitrophenol. The synthesis was not affected by stimulants of secretion such as feeding or carbamylcholine. Optimum synthesis of amylase depended on the presence of ten aminoacids amongst which tryptophane, tyrosine, valine and leucine could be replaced by their corresponding keto-acids. Anrep and Khan (I923) found that restoration of the protein output of the submaxillary gland after physiological exhaustion was very slow so that on the average three days was necessary for complete restitution. Stavraky (I940) arrived at a similar estimate on the basis of the steady state of protein secretion after prolonged stimulation of the cat's submaxillary gland. Burgen, Weiss and Seeman (I959) found that the proteins of the dog parotid saliva could be divided into two fractions, one apparently derived from the ducts and the other from the acinar. The acinar protein behaved in a 
similar way to that found by Anrep, Khan, Stavraky and others (Langstroth, McRae and Stavraky, I938) in being readily exhaustible and in being regenerated at a very slow rate of about 0.5 per cent/hour. On the other hand, proteins of duct origin were not exhausted by stimulation and were synthesized at a higher rate more comparable to that found in the pancreas. It appears that protein of duct origin is not an important fraction of the, submaxillary gland secretion. Fritz (1955) found that $\mathrm{N}^{15}$ labelled glycine appeared in salivary gland proteins to about the same extent as in liver proteins, but as the shortest period of study was 18 hours and no distinction was made between structural proteins and secretory products this study is not very helpful. Martin (unpublished) has found that $\mathrm{C}^{\mathbf{1 4}}$ valine is incorporated into salivary proteins, but the rate of appearance is quite slow. Similar results have been obtained in the pancreas (Junqueira, Hirsch and Rothschild, 1955; Siekevitz and Palade, 1958). Nothing is known of the rate of incorporation of carbohydrates in the mucoproteins of saliva. There is no change whatsoever in the content of RNA or DNA in the cell following starvation or physiological exhaustion of the salivary gland or pancreas (Hokin and Hokin, $1954 b$; Daly and Mirsky, i952).

\section{REFERENCES}

ANREP, G. V. and R. K. CANNAN (I 922). The blood sugar metabolism of the submaxillary gland. F. Physiol., 56, 248-258.

- ( 1923 ). The blood sugar metabolism of the submaxillary gland. $\mathcal{F}$. Physiol., 57, I-6.

ANREP, G. V. and H. N. KHAN (1923). The metabolism of the salivary glands. V. The process of reconstruction of the submaxillary gland. F. Physiol., 58, 302-309.

BARCROFT, J. (I9OI). The gaseous metabolism of the submaxillary gland. Part III. The effect of chorda activity on the respiration of the gland. F. Physiol., 27, 3I-47.

- (I9I4). The respiratory function of the blood. University Press, Cambridge.

BARCROFT, J. and T. KATO (I9I6). Effects of functional activity in striated muscle and the submaxillary gland. Philos. Trans. B., 207, 149-182. BARCROFT, J. and F. MÜLLER (I 912 ). The relation of blood flow to metabolism in the submaxillary gland. $\mathcal{F}$. Physiol., 44, 259-264.

BARCROFT, J. and H. PIPER (1912). The gaseous metabolism of the submaxillary gland with reference especially to the effect of adrenaline and the time relation of the stimulus to the oxidation process. $\mathcal{F}$. Physiol., 44, 359-373. 
BERGONZI, M. (I931). Ulteriore contributo allo studio del comportamento degli acidi fosforico e lattico nella attivita funzionale de 1 ghiandola sottomascellare. Arch. scienze biol. (Ital.), r6, 235-244.

BERGONZI, M. and V. BOLCATO (I930). Contributo allo studio del comportamento degli acidi fosforico e lattico e del glicogeno nella attivita funzionale della ghiandola sottomascellare. Arch. scienze biol. (Ital.), I4, 573-598.

BROCK, N., H. DRUCKREY and H. HERKEN (1938). Der Gewebsstoffwechsel nach Schädigung und physiologischer Erregung. Arch. exp. Path. Pharmak., r9r, 687-695.

BROCK, N., H. DRUCKREY and W. LOCH (1942). Die Bedeutung verschiedener Substrate für den Stoffwechsel der Gewebe. Biochem. Z., 313, 3003 I6.

BURGEN, A. S. V., M. WEISS and P. SEEMAN (I959). The secretion of proteins in parotid saliva. In preparation.

DALY, M. M. and A. E. MIRSKY (1952). Formation of protein in the pancreas. F. gen. Physiol., 36, 243-254.

DEUTSCH, W. and H. S. RAPER (1936). Respiration and functional activity. F. Physiol., 87, 275-286.

- (1938). The respiration and metabolism of submaxillary gland tissue of the cat. $\mathcal{F}$. Physiol., 92, 439-458.

FERRARI, R. and R. HÖBER (I 933). Untersuchungen über den der Sekretionsarbeit zugrunde liegenden Stoffwechsel von Leber, Niere und Speicheldrüse. Arch. ges. Physiol., 232, 299-321.

FRITZ, I. (1955). Studies on the incorporation and release of $\mathrm{N}^{15}$ by tissue proteins of rats fed $\mathrm{N}^{15}$ glycine. F. dent. Res., 34, 435-45 I.

HILTON, S. M. and G. P. LEWIS (1957). Functional vasodilatation in the submandibular salivary gland. Brit. med. Bull., 13, 189-196.

IIMWICH, H. E. and M. A. ADAMS (1930a). Studies in glandular metabolism. I. The source of the lactic acid produced on incubation of the testicle and the submaxillary gland. Amer. F. Physiol., 91, I72-177.

- - (1930b). Studies in glandular metabolism. II. The carbohydrates of resting and secreting submaxillary glands. Amer. F. Physiol., 93, $568-573$.

IIOKIN, L. E. (I95 I $a$ ). The synthesis and secretion of amylase by pigeon pancreas in vitro. Biochem. F., 48, 320-326.

- $(195 \mathrm{I} b)$. Amino acid requirements of amylase synthesis by pigeon pancreas slices. Biochem. F., 50, 2 I6-220.

HOKIN, L. E. and M. R. HOKIN (I958). Phosphoinositides and protein synthesis in pancreas slices. F. biol. Chem., 233, 805-810.

- - (1959a). The mechanism of phosphate exchange in phosphatidic acid in response to acetylcholine. $\mathcal{F}$. biol. Chem., 234, 1387-1 390.

- (1959b). Studies of pancreatic tissue in vitro. Gastroenterology, 36, 368-376.

HOKIN, L. E. and A. L. SHERWIN (1957). Protein secretion and phosphate turnover in the phospholipids in salivary glands in vitro. $\mathcal{F}$. Physiol., I35, I 8-29.

HOKIN, M. R. and L. E. HOKIN (1953). Enzyme secretion and the incorporation of $\mathrm{P}^{32}$ into phospholipides of pancreas slices. F. biol. Chem., 203, $967-977$.

- - (1 $954 a)$. Effects of acetylcholine on phospholipides in the pancreas. f. biol. Chem., 209, 549-558.

- $(1954 b)$. The ribonucleic acid content of pancreas and parotid 
glands during enzyme synthesis and secretion in vivo. Biochim. biophys. acta, 13, 236-240.

JUNQUEIRA, L. C. U. (I955). Aspects of the biochemistry of cell secretion. Symposium on cell secretion. Belo Horizonte.

JUNQueIRA, L. C. U., G. C. HIRSCH and H. A. ROTHSCHILD (I955). Glycine uptake into the proteins of the rat pancreatic juice. Biochem. F., 6r, $275^{-278 .}$

JunQueira, L. C. U. and G. C. HiRsch (1956). Cell Secretion; A study of the pancreas and salivary glands. Int. rev. cytol., 5, 323-364.

LANGSTROTH, G. O., D. R. MCRAE and G. W. STAVRAKY (I938). The secretion of protein material in the parasympathetic submaxillary saliva. Proc. Roy. Soc. B., 125, 335-347.

NORTHUP, D. (I935). The secretory metabolism of the salivary glands. Amer. F. Physiol., 114, 46-52.

Siekevitz, P. and G. E. PALADE (1958). A cytochemical study on the pancreas of the guinea pig. III. In vivo incorporation of leucine- $\mathrm{I}-\mathrm{C}^{14}$ into the proteins of cell fractions. F. Biophys. Biochem. Cytol., 4, $557-566$.

STAVRAKY, G. W. (1940). The partition of nitrogen in the submaxillary saliva evoked by chorda tympani stimulation in the cat. Amer. $\mathscr{F}$. Physiol., 129, 539-545.

STRÖMBLAD, B. C. R. (1957). Oxygen consumption of the normal and denervated submaxillary gland in vitro. Acta physiol. scand., 40, I30-I 45 .

- (1959). Gaseous metabolism of the normal and denervated submaxillary gland of the cat. F. Physiol., I45, 55 I-56r .

TERROUX, K. G., P. SEKELJ and A. S. v. BURGEN (1959). Oxygen consumption and blood flow in the submaxillary gland of the dog. Can. F. Biochem. Physiol., 37, 5-15.

wills, J. H. (I941). Electrolyte changes in submaxillary glands during stimulation. Amer. F. Physiol., 135, 164-174. 


\section{THE CONTROL OF SALIVARY SECRETION}

Our knowledge of the control of salivary secretion originates from different sources. The first indication of the existence of a "salivary centre" was obtained by chance in experiments in which irritative damage was done to various parts of the brain stem. 'Transverse sections through the central nervous system later on served to locate the region from which a salivary reflex can be evoked. After degenerative section of the preganglionic secretory nerves the position of their cell bodies in the central nervous system could be found by microscopic examination. Some knowledge of the control of salivary secretion has been gained by clinical observations and in experiments in which drugs have been applied to different parts of the central nervous system. The most precise information has been obtained by electrical stimulation of restricted areas, followed by histological control.

The double supply of secretory fibres to the glands from the two divisions of the autonomic nervous system makes it necessary to decide, in stimulation experiments, whether parasympathetic or sympathetic fibres were activated. This can be done by cutting the fibres or by using specific inhibitors, such as atropine and ergotamine. In several of the investigations reported in the literature such precautions were omitted and we do not know which type of fibres were excited. When pronounced and well-maintained secretory responses were obtained it can usually be concluded that the parasympathetic mechanism was at work. It should further be kept in mind that stimulation of various parts of the central nervous system may increase the discharge of adrenaline from the suprarenal medulla, thereby causing a flow of saliva; in experiments on glands relatively sensitive to adrenaline such as the submaxillary or sublingual gland of the cat, or the parotid gland of the rabbit, it seems advisable to remove or denervate the adrenals. For example stimulation of the central end of the sciatic nerve causes a flow of saliva which, at least in part, is due to adrenaline, released reflexly from the adrenal medulla. 


\section{PRIMARY CENTRES OF SALIVARY SECRETION}

The only source of information about the location of the cell bodies of the preganglionic, sympathetic secretory fibres seems to be an investigation by Langley (1892), and it applies exclusively to the submaxillary gland of cats and dogs. Langley stimulated the cervical and thoracic nerves and obtained a secretory response particularly from the second thoracic nerve. This effect was smaller than that evoked by stimulation of the cervical sympathetic trunk; some flow of saliva usually occurred when the first, third, fourth and fifth thoracic nerves were excited. Vasoconstriction was elicited via the same nerves. No attempts have been made to cause secretion by stimulating the lateral column of the spinal cord in the corresponding segments. It is not known whether secretion can be evoked reflexly at this level, nor have any supraspinal pathways been explored. The only suggestion of supraspinal fibres acting on the spinal secretory cells can be found in a paper by Grützner ( 1873 ), who stimulated the medulla oblongata electrically and obtained a secretion which ceased when the cervical sympathetic trunk had been cut.

For the parasympathetic system the nerve cells of the preganglionic neurone are situated in the lower brain stem. When studying the diabetes produced by puncture of the floor of the fourth ventricle in dogs, Claude Bernard $(1856)$ sometimes observed a flow of saliva; the wound could elicit a secretion both from the parotid and submaxillary glands, but lesions could be made which activated the latter gland only. Similar observations were later made by Eckhard (1869) and Loeb (1870). Loeb associated the secretory effects with damage to the fibres and nuclei of the facial and glossopharyngeal nerves and quoted a case of hypersalivation described by Meynert in 1863 ; at autopsy an abscess was found in the pons which had perforated into the fourth ventricle and injured the medulla. In his experiments, referred to above, Grützner (1 873) inserted two needles into the medulla and often found this to cause some secretion from the submaxillary gland. When the needles were used as electrodes for electrical stimulation there was an abundant flow of saliva; after section of the chorda tympani this effect was small, and no secretion at all was obtained when the sympathetic fibres had been cut as well.

Beck (r898) made a series of transverse sections through the 
central nervous system in curarized dogs and studied the effect on the submaxillary secretion evoked reflexly by afferent stimulation. The reflex was retained as long as the section was made rostrally to the region containing the nucleus of the facial nerve.

Histological methods were applied by Kohnstamm (1902, 1907), Solomowicz (1908), and Yagita and Hayama (1909, I910). After degenerative section of the preganglionic parasympathetic fibres in dogs, the chromatolysis in the brain stem was studied. As a result of this work it was established that a "nucleus salivatorius" consisting of a neurone pool in the reticular formation extends from the nucleus of the facial nerve to the anterior part of the nucleus ambiguus. The rostral portion, the nucleus salivatorius superior, is connected with the submaxillary and presumably the sublingual gland, the nucleus salivatorius inferior with the parotid gland. Clinical observations suggest that a similar arrangement exists in man (Feiling, r9r3).

Stimulation experiments, combined with histological examination, have confirmed these findings. Miller (I9r3) stimulated electrically the dorsal surface of the medulla oblongata in decerebrate cats using a unipolar electrode. When currents of minimal intensity were used it was possible to localize one point yielding only parotid, and a second point yielding only submaxillary secretion; responses were obtained solely from the ipsilateral glands. The "parotid point" was situated about $6 \mathrm{~mm}$ in front of the tip of the calamus scriptorius, the "submaxillary point" about $2 \mathrm{~mm}$ in front of the "parotid point". More recently the salivary centres have been explored systematically (Fig. I2.I) using small, bipolar electrodes in cats (Chatfield, I94I; Wang, 1943) and monkeys (Magoun and Beaton, I942). From this work it is obvious that there is no sharp division between the two salivary nuclei; in the intermediate zone, stimulation yields both submaxillary and parotid secretion. It may be of interest to point out in this connection that the human parotid gland is supposed to be supplied not only by glossopharyngeal, but also by facial fibres (Reichert and Poth, 1933). In the stimulation experiments of the more recent investigators a parasympathetic mechanism was activated, for the secretory responses were abolished by atropine or parasympathetic denervation. In an investigation on "pseudomotor contracture" in the tongue, Corbin, Harrison and Wigginton (194I) found that stimulation of the intramedullary portion of the seventh nerve and the reticular matter 

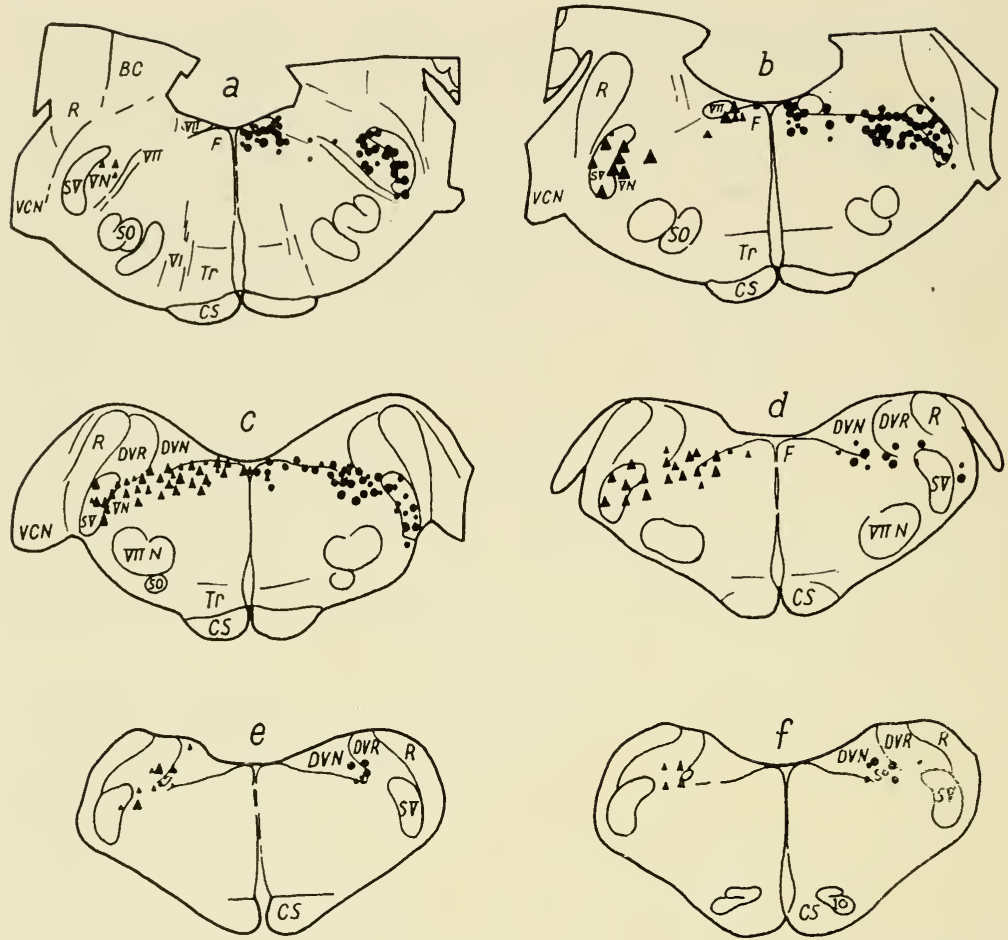

FIG. I2.I. Diagrammatic representation of results obtained upon stimulation of the medulla of 35 cats.

The sections are about $\mathrm{I} \mathrm{mm}$ apart. Each large solid circle or triangle represents a response of salivary flow at a rate of more than 0.25 c.c. per min, and each small solid circle or triangle, at a rate of 0.1 c.c. to 0.25 c.c. per min. Secretion of less than 0.1 c.c. per min is not represented. Circles indicate responses from the right submaxillary gland, and triangles, responses from the right parotid gland but transposed to the opposite side. Abbreviations are: $B C-$ brachium conjunctivum; $C S$-cortico-spinal tract; $D V N$-dorsal or medial vestibular nucleus: $D V R$-descending vestibular root: $F$-medial longitudinal fasciculus; $I O$-inferior olive; $R$-restiform body; $S$-solitary fasciculus; $S O$-superior olive; $S V$-spinal tract of the trigeminal nerve; $T r$-trapezoid body; $V C N$-ventral cochlear nucleus; $V N$-spinal nucleus of the trigeminal nerve; $V I$-abducens nerve; $V I I$-facial nerve: $I I I N$-facial nucleus (Wang, 1943 ).

close to it caused a contracture, and vasodilatation in the tongue as well as salivary secretion. Vascular responses in the submaxillary gland were not studied, but the observations seem to suggest that the secretory and vasodilator mechanisms of the glands are closely connected and difficult to separate, at least at the medullary level.

On stimulation of the salivary nuclei, predominantly ipsilateral responses were obtained, and these were ascribed to the activation of salivary motor nuclei and their efferent root fibres. The centres seem to innervate mainly the glands of the same side. Sometimes, however, bilateral effects were elicited; they were supposed to be 
the result of excitation of afferent fibres, particularly taste fibres, acting upon the salivary centres of both sides. The bilateral secretory responses usually observed when afferent fibres of one side were stimulated would therefore be due to a partial decussation of the afferent limb of the reflex arc. Claude Bernard (1858) had found that stimulation of the central end of one of the lingual nerves (medial to the submaxillary duct) caused a flow of saliva from both submaxillary glands. Also unilateral section of the lingual nerve causes a supersensitivity to chemical agents in both submaxillary glands (Emmelin, 1956). In his experiments on the human parotid gland Lashley (1916) noticed that a small amount of hydrochloric acid applied to one side of the tongue gave a secretion from both glands but it was particularly marked on the side stimulated. In decerebrate cats Miller (I9I3) observed that stimulation of the central end of the lingual nerve brought about an abundant secretion from the ipsilateral submaxillary gland, less secretion from the ipsilateral parotid gland and a slight secretion from the contralateral submaxillary and parotid glands. When the central end of the glossopharyngeal nerve was stimulated he found a good flow from the ipsilateral parotid gland, less from the ipsilateral submaxillary gland and small responses from the contralateral glands. Krasnogorski's (I93I) observations on children seem to agree with these findings. When the anterior part of the tongue was stimulated the submaxillary gland was especially affected, whereas stimulation of the lateral and posterior part of the tongue activated predominantly the parotid gland. These experiments suggest that the afferent fibres from the mouth act on all the four salivary nuclei of the medulla and particularly the ipsilateral ones, and that the lingual fibres affect more the superior than the inferior nucleus salivatorius, whereas the opposite is true for the glossopharyngeal fibres.

\section{EFFECTS OF SUPRABULBAR STRUCTURES}

Secretion of saliva can be evoked reflexly in decorticated dogs and cats (Rothmann, 1910, 1923; Dusser de Barenne, 1920). It can even be elicited in decerebrate animals, for instance by placing some acid on the tongue. The medullary salivary nuclei, therefore, must be able to act as centres for the gustatory reflex. It is obvious, on the other hand, that suprabulbar structures exert excitatory and inhibitory actions on the centres in the brain stem. This is evident from the classical experiments by Pavlov on conditioned salivary 
secretion, extensively dealt with in his monograph Conditioned reflexes (I940) and from all the observations which resulted from Pavlov's pioneer work (see for instance Lashley, i9i6; Krasnogorski, I93 I Wolff, I 937). Numerous other examples of physiological or clinical observations indicative of an influence on the medullary secretory centres from higher levels could be quoted. Experiments in which salivary secretion could be elicited by electrical stimuli or certain drugs applied locally to various suprabulbar structures will be described later on. Inhibition of salivary secretion can, in most instances, be explained only as due to an inhibitory influence of higher regions on the medullary centres; there is no reason to believe in the existence of peripheral inhibitory fibres to the glands, and a diminished secretion caused by hyperactivity in the sympathetic vasoconstrictor fibres, as described in Chapter VII, is certainly in most cases only of secondary importance. Inhibition of secretion is seen in sleep (see for instance Schneyer, Pigman, Hanahan and Gilmore, 1956). Similarly, the reflex response to lemon juice was found to be reduced by hypnosis (Jenness and Hackman, 1938). The dryness of the mouth in fear is well known. Knowledge of this emotional effect was made use of long ago in the Indian rice test; a suspect unable to swallow his rice because of lack of saliva was assumed to be afraid of detection, i.e. to be guilty. According to Lourie (I 943) the flow of parotid saliva is extremely abundant in infancy and declines rapidly to the age of 5 years, then falling off more gradually until early puberty. Lourie assumes that during these first years higher centres mature and gradually gain an inhibitory control over the medullary salivary centres. It may be pointed out that Krasnogorski (I93I) obtained greater secretory response in older than in younger children. This discrepancy might be due to the fact that the latter investigator studied secretion elicited reflexly by citric acid, whereas Lourie collected saliva without application of any stimuli except those always present in such experiments.

Clinical experience provides many further samples of disturbance in the secretion of saliva in diseases of the central nervous system, for instance the hypersalivation in parkinsonism. In many cases of epilepsy, hypersalivation has been mentioned as a symptom (see Penfield and Jasper, 1954, and for animal experiments Hunter and Jasper, I949). In the first case of "diencephalic autonomic epilepsy", described by Penfield (I929), a cholesteatoma in 
the upper and anterior part of the wall of the third ventricle was found to provoke peculiar seizures, characterized by sudden sweating, flushing, salivation, lachrymation and respiratory disturbances. Strongin and Hinsie (1938) studied the secretory rate in schizophrenia and found it to increase as the deterioration proceeded; it was assumed that as the patient regressed to more infantile levels his salivary secretion likewise returned to the infantile level characterized by a high rate of flow (Lourie, Barrera and Strongin, 1942). In depressions of the manic-depressive type the flow, on the other hand, is said to be diminished (Lourie, Barrera and Strongin, r942; Ekblad, I944).

In many of the examples enumerated above there is a more or less clear indication as to the region of the central nervous system engaged in the control of the secretion of saliva. Diencephalic and cortical areas seem to be of particular interest. There is direct experimental evidence to show that electrical stimulation of certain diencephalic and telencephalic regions may affect salivary secretion.

Stimulation in the diencephalon. In their classical experiments on "Gehirn und Sympathicus" Karplus and Kreidl (I909) mainly studied effects on the pupil of electrical stimulation of the base of the brain in the hypothalamic area; they observed also, however, secretion of saliva, tears and sweat. The secretion they observed could have been of sympathetic origin and even brought about by adrenaline from the suprarenals, since the experiments were on cats. Stavraky (1936) stimulated the posterior hypothalamus from the opened third ventricle in cats under dial anaesthesia and recorded various effects which were ascribed to excitation of the sympathetic nervous system, among them salivation.

From such experiments on anaesthetized animals it can be concluded that the salivary glands belong to those structures, innervated by autonomic nerves, that can be activated from the hypothalamus. Experiments on unanaesthetized animals have, however, been necessary to throw light on the functional significance of the salivary secretion which can be initiated from this region. In different patterns of physiological reactions which can, in freelymoving cats, be imitated by electrical stimulation of various parts of the hypothalamus from an implanted electrode, secretion of saliva often is one of the symptoms. In "sham rage" (Bard, I928) of cats, for instance, spitting is described as a characteristic feature. Ranson, Kabat and Magoun (I 935) implanted a bipolar needle electrode 
in the hypothalamus of cats; on electrical stimulation a picture of intense emotional excitement was obtained and after stimulation for one minute or more saliva was observed to run from the mouth. Similar observations were reported by Masserman (1937, I938, I939a, I94I). Other symptoms were found in these experiments, which do not seem to belong to the pseudo-affective reaction, such as licking movements of the tongue and jaws.

The investigations by Hess and his associates throw further light on such findings and give a very interesting picture of salivation as participating in various physiological mechanisms for which there is evidence to show that the diencephalon serves as an integrative area (Hess and Magnus, I943; Baum, I945; Hess, I948, 1949). Stimulation of certain regions in the waking cat resulted in secretion of saliva, combined with movements of the lips and tongue, and chewing and swallowing; the picture was that of an eating cat. Responses from other areas were those of a cat trying to rid itself of an objectionable substance: a special type of licking, salivation, retching and vomiting. Another group of symptoms bring the thermoregulatory function of the hypothalamus to mind. In cats and dogs where sweat glands occur only over a very small area of skin, removal of heat by evaporation of water depends mainly on a free flow of saliva over the tongue, and a rapid passage of air over these surfaces through panting. In the experiments referred to, stimulation produced a widely opened mouth with the tongue protruded, rapid and shallow respiration, and saliva dripping from the mouth. Finally, defence reactions, similar to those described by Bard, Ranson et al. and Masserman, were initiated from certain regions. For a closer anatomical localization of the different groups of symptoms studied, the papers and monographs by Hess and his co-workers, including the topographical atlas by Hess (1956), should be consulted.

Chemical agents, injected into the hypothalamus, may produce the same symptoms as electrical stimulation. Masserman (1938, 1939b, I94I) injected strychnine, metrazol and picrotoxin into the hypothalamus through a needle that was also used for electrical stimulation, and obtained the symptoms of the sham rage reaction although they were more prolonged than when electrical current was used for excitation; among the symptoms mentioned is salivation. As described in Chapter IV, numerous drugs may induce a secretion of saliva when introduced into the ventricular system of 
the brain. Of particular interest for the present discussion are the observations made by Feldberg and Sherwood (1954) on nonanaesthetized cats. Various agents, injected into a lateral ventricle, were found to cause secretion of saliva combined with symptoms such as panting, retching, vomiting, licking and swallowing.

Very little is known as to the type of peripheral, secretory fibres that can be activated from the diencephalon. In alimentary reflexes parasympathetic fibres are very likely involved. In emotional reactions the sympathetic system is generally assumed to discharge, as described by Cannon for the "emergency reaction". When trying to attribute some function to the sympathetic secretory fibres of the salivary glands, which apparently take no part in digestive reflexes, it is tempting to assume that these fibres are excited in the emergency reaction. On the other hand, the reduction of salivary secretion as an expression of less aggressive emotions must imply a central inhibition, possibly from the hypothalamus, exerted on the parasympathetic nuclei in the lower brain stem.

Stimulation in the telencephalon. During the nineteenth century numerous investigators observed a flow of parotid and submaxillary saliva when an area above and in front of the Sylvian fissure was excited in dogs (Bochefontaine, 1876 ; Bechterew and Mislawski, I888, I889; Eckhard, I889; Ziehen, I 899). The secretion resembled that evoked by stimulation of the parasympathetic secretory nerves and could be abolished by section of these fibres. These observations have been confirmed and extended by more recent investigators using stimulation methods which allow a more detailed localization of the response. In general the secretory responses obtained seem to be part of feeding reactions, elicited from areas representing taste, tactile perception in the oral region, smell, and from areas where responses of the muscles of the face, the mouth and the throat can be produced. Walker and Green (1938) frequently observed a profuse salivation when stimulating the motor face area in primates. Crouch and Thompson (1939) studied various autonomic effects of stimulation of the cerebral cortex. Such effects, among them a flow of saliva, could be obtained in cats and dogs at the junction of the frontal and anterior sigmoid gyri, and in monkeys from the superior frontal gyrus and the portions of the precentral gyrus adjoining it. Several other investigators have, likewise, observed salivation when stimulating this part, or the orbital gyri, of the frontal lobe in cats, dogs and 
monkeys (Sachs, Brendler and Fulton, I949; Hess and Akert, 195I). In their operations on patients under local anaesthesia Penfield and Rasmussen (1950) noticed a flow of saliva when the region surrounding the lower part of the fissure of Rolando was stimulated electrically; the secretion was associated with tongue movements, mastication and swallowing. In anaesthetized dogs Babkin and van Buren (195I) could elicit the same effects by stimulating the corresponding gyri (Fig. I2.2).

Salivation has also been produced by electrical stimulation in the rhinencephalon. In cats with the neopallium previously removed Schaltenbrand and Cobb (1930) found that excitation of the an-
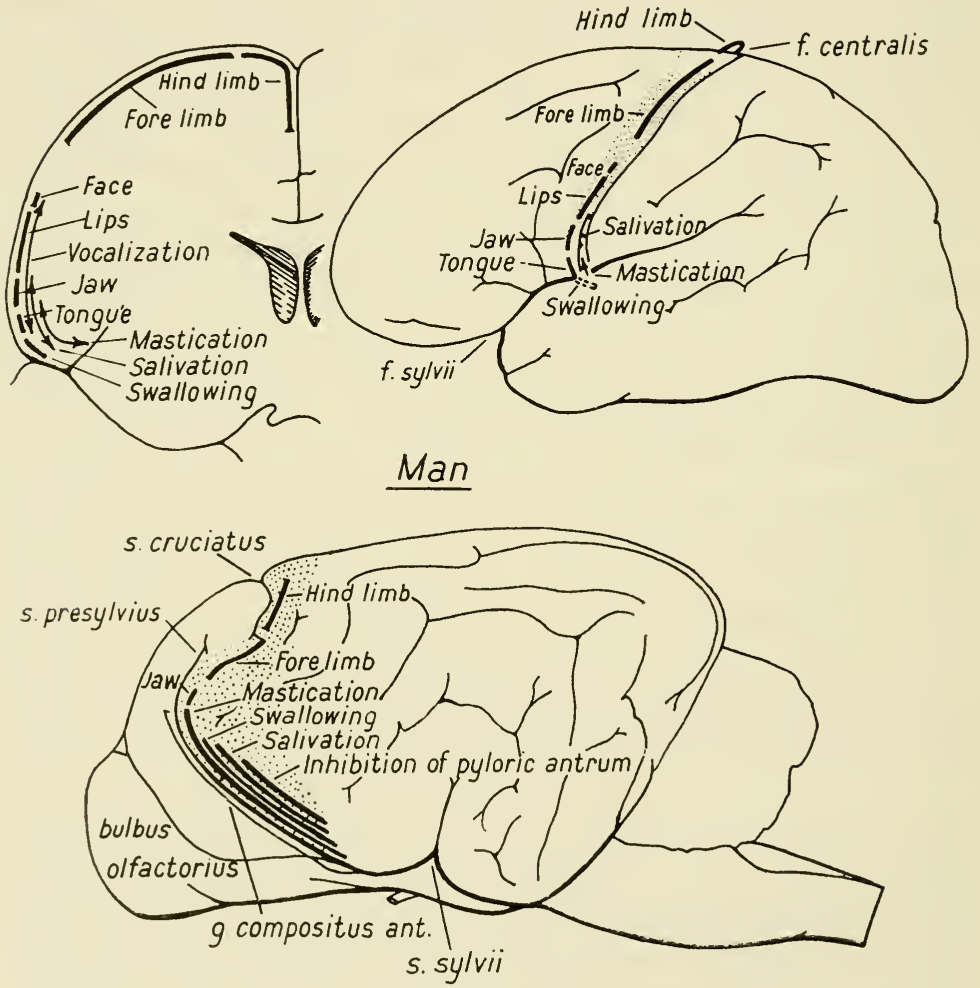

Dog.

FIG. I2.2. Diagram illustrating the distribution of the motor representation in man and dog. 
terior commissure caused flow of saliva and licking, chewing and swallowing movements. Rioch and Brenner ( 1938 ) obtained similar effects in cats and opossums, after ablation of the neocortex, when they stimulated the basal olfactory areas; they concluded that the central representation of the feeding reactions which are associated with smell is in the basal olfactory brain, and possibly chiefly in the pyriform lobe. Stimulation of the amygdaloid nuclear complex may cause a profuse secretion of saliva, often associated with licking, sniffing, chewing and swallowing movements, as described by numerous investigators (Kaada, I95I; Gastaut, Vigouroux, Corriol and Badier, 195I; MacLean and Delgado, I953; Baldwin, Frost and Wood, I954; Kaada, Andersen and Jansen, I954; Magnus and Lammers, I956; Kaada and Ursin, I957; Shealy and Peele, I957; Molina and Hunsperger, I959).

\section{REFERENCES}

BABKIN, B. P. and J. M. VAN BUREN (I95I). Mechanism and cortical representation of the feeding pattern. Arch. Neurol. Psychiat., 66, I-1 9.

BALDWIN, M., L. L. FROST and C. D. WOOD (1954). Investigation of the primate amygdala. Neurology, 4, 586-598.

BARD, P. (1928). A diencephalic mechanism for the expression of rage with special reference to the sympathetic nervous system. Amer. $\mathcal{F}$. Physiol., 84, 490-51 5.

BAUM, W. (1945). Speichelfluss als Symptom elektrischer Reizung im Zwischenhirn und den angrenzenden Gebieten. Helv. physiol. acta, 3, $21-40$.

BECHTEREw, w. and N. Mislawski (1888). Ueber den Einfluss der Hirnrinde auf die Speichelsecretion. Neurol. Centralblatt, 7, 553-556.

- - (1889). Zur Frage über die die Speichelsecretion anregenden Rindenfelder. Neurol. Centralblatt, 8, 190-193.

веCк, A. (1898). Zur Innervation der Speicheldrüsen. Centralblatt $f$. Physiol., 12, 33-37.

BERNARD, C. (1856). Leçons de physiologie expérimentale, Vol. 2. Baillière, Paris.

- (1858). Leçons sur la physiologie et la pathologie du système nerveux, Vol. 2. Baillière, Paris.

Bochefontaine (1876). Étude expérimentale de l'influence exercée par la faradisation de l'écorce grise du cerveau sur quelques fonctions de la vie organique. Arch. Physiol. norm. path., 140-172.

CHATFIELD, P. O. (I94I). Salivation in response to localized stimulation of the medulla. Amer. F. Physiol., 133, 637-64I.

CORBIN, K. B., F. HARRISON and C. WIGGINTON (I94I). Elicitation of the "pseudo-motor contracture" in the tongue by intramedullary stimulation. Arch. Neurol. Psychiat., 45, 27 I-281.

CROUCH, R. L. and J. K. THOMPSON (1939). Autonomic functions of the cerebral cortex. F. Nerv. Ment. Dis., 89, 328-334. 
DUSSER DE BARENNE, J. G. (I920). Recherches expérimentales sur les fonctions du système nerveux central, faites en particulier sur deux chats dont le néopallium avait été enlevé. Arch. néerl. Physiol., 4, $3 \mathrm{I}-\mathrm{I} 23$.

ECkhard, C. (1 869). Untersuchungen über Hydrurie. Beitr. Anat. Physiol., 4, I 53-I 93 .

- (I 889). Die Speichelsecretion bei Reizung der Grosshirnrinde. Neurol. Centralblatt, 8, 65-67.

EKBlaD, M. (I944). Förändringar i salivsekretionen vid depressiva tillstånd. Svenska Läkartidn., nr 27.

EMMELIN, N. (I956). Sensitization of salivary glands by denervation. XXth Int. Physiol. Cong. Brussels, 269-270.

FEILING, A. (19I3). On the bulbar nuclei, with special reference to the existence of a salivary centre in man. Brain, 36, 255-265.

FELDBERG, W. and S. L. SHERwOOD (1954). Injections of drugs into the lateral ventricle of the cat. $\mathcal{F}$. Physiol., 123, I48-167.

GASTAUT, H., R. VIgOUROUX, J. CORRIOL and M. BADIER (I95 I). Effects de la stimulation électrique (par électrodes à demeure) du complexe amygdalien chez la chat non narcosé. F. Physiol., Paris, 43, 740-746. GRÜTZNER, P. (I873). Beiträge zur Physiologie der Speichelsecretion. Arch. ges. Physiol., 7, 522-529.

HESS, W. R. (I 948). Die funktionelle Organisation des vegetativen Nerven systems. Schwabe, Basel.

- (1 949). Das Zwischenhirn. Schwabe, Basel.

- (1956). Hypothalamus und Thalamus. Thieme, Stuttgart.

HESS, W. R. and K. AKERT (I95 I). Die corticale Repräsentation von Gesicht, Oral- und Pharyngealsphäre bei der Katze. Helv. physiol. acta, 9, 269-289.

HESS, W. R. and W. O. C. MAGNus (I 943). Leck- und Kau-Automatismen bei elektrischer Reizung im Zwischenhirn. Helv. physiol. acta, I, $533-547$.

HUNTER, J. and H. H. JASPER (I949). Effects of thalamic stimulation in unanaesthetized animals. Electroenceph. clin. Neurophysiol., r, 305324.

JENNESS, A. and R. C. HACKMAN (I938). Salivary secretion during hypnosis. F. exp. Psychol., 22, 58-66.

KAADA, B. R. (I95I). Somato-motor, autonomic and electrocorticographic responses to electrical stimulation of "rhinencephalic" and other structures in primates, cat and dog. Acta physiol. scand., 24, Suppl. 83.

KAADA, B. R., P. ANDERSEN and J. JANSEN (1954). Stimulation of the amygdaloid nuclear complex in unanaesthetized cats. Neurology, 4, 48-64.

KAADA, B. R. and H. URSIN (I957). Further localization of behavioral responses elicited from the amygdala in unanaesthetized cats. Acta physiol. scand., 42, Suppl. I 45, 80-8 I.

KARPLUS, J. P. and A. KREIDL (I 909). Gehirn und Sympathicus. I. Mitteilung. Zwischenhirnbasis und Halssympathicus. Arch. ges. Physiol., I 29, I $38-$ I 44 .

kOHNSTAMm, O. (I902). Der Nucleus salivatorius chordae tympani (nervi intermedii). Neurol. Centralblatt, 21, 848.

KOHNSTAMM, O. and J. WOLFSTEIN (I907). Versuch einer physiologischen Anatomie der Vagusursprünge und des Kopfsympathicus. F. Psychol. Neurol., 8, I 77-203. 
KRASNOGORSKI, N. I. (I93I). Bedingte und unbedingte Reflexe im Kindesalter und ihre Bedeutung für die Klinik. Ergebn. inn. Med. Kinderheilk., 39, 613-730.

LANGLEY, J. N. (I 892). On the origin from the spinal cord of the cervical and upper thoracic sympathetic fibres, with some observations on white and grey rami communicantes. Philos. Trans., 183, 85-124.

LASHLEY, K. S. (I9I6). Reflex secretion of the human parotid gland. F. exp. Psychol., r, 46I-493.

LOEB, L. (I870). Ueber die Secretionsnerven der Parotis und über Salivation nach Verletzung des Bodens des vierten Ventrikels. Beitr. Anat. Physiol., 5, I-26.

I.OURIE, R. S. (1943). Rate of secretion of parotid glands in normal children. Amer. F. Dis. Child., 65, 455-479.

LOURIE, R. S., S. E. BARRERA and E. I. STRONGIN (I942). Autonomic nervous system function in children with behavior problems as measured by the parotid secretory rate. Amer. F. Psychiat., 99, 419-425.

MacLEAN, P. D. and J. M. R. DELGADo (I953). Electrical and chemical stimulation of frontotemporal portion of limbic system in the waking animal. Electroenceph. clin. Neurophysiol., 5, 91-100.

Magnus, o. and H. J. Lammers ( 1956). The Amygdaloid-Nuclear Complex. Folia Psychiat. Neurol. Neurochir. Néerl., 59, 555-582.

MAGOUN, H. W. and L. E. BEATON (1942). The salivatory motor nuclei in the monkey. Amer. F. Physiol., 136, 720-725.

MASSERMAN, J. H. (1937). Effects of sodium amytal and other drugs on the reactivity of the hypothalamus of the cat. Arch. Neurol. Psychiat., $37,617-628$.

- (1938). The effect of strychnine sulphate on the emotional mimetic functions of the hypothalamus of the cat. F. Pharmacol., 64, 335-354.

- (1939a). Effects of morphine sulphate on hypothalamus of the cat. Proc. Soc. exp. Biol., N.Y., 42, 315-317.

- (1939b). Action of metrazol (pentamethylenetetrazol) on the hypothalamus of the cat. Arch. Neurol. Psychiat., 4I, 504-510.

- (194I). Is the hypothalamus a center of emotion? Psychosom. med., $3,3^{-25}$.

MiLler, F. R. (19I3). On the reactions of the salivary centres. Quart. $\mathcal{F}$. exp. Physiol., 6, 57-72.

MOLINA, A. F. DE and R. W. HUNSPERGER (1959). Central representation of affective reactions in forebrain and brain stem; electrical stimulation of amygdala, stria terminalis, and adjacent structures. F. Physiol., $\mathrm{r} 45,25 \mathrm{I}-265$.

Pavlov, J. P. (I940). Conditioned reflexes. Oxford University Press.

PENFiEld, w. (1929). Diencephalic autonomic epilepsy. Arch. Neurol. Psychiat., 22, 358-374.

PENFIELD, w. and H. JASPER (1954). Epilepsy and the functional anatomy of the human brain. Little, Brown, Boston.

PENFIELD, w. and T. RASMUSSEN (1950). The cerebral cortex of man. A clinical study of localization of function. MacMillan, New York.

RANSON, S. W., H. KABAT and H. W. MAGOUN (1935). Autonomic responses to electrical stimulation of hypothalamus, preoptic region and septum. Arch. Neurol. Psychiat., 33, 467-477.

REICHERT, F. L. and E. J. POTH (I933). Pathways for the secretory fibres of the salivary glands in man. Proc. Soc. exp. Biol., N.Y., 30, 973977. 
RIOCH, D. and C. BRENNER (I938). Experiments on the corpus striatum and rhinencephalon. $\mathcal{F}$. comp. Neurol., 68, 491-507.

RothmanN, H. (1923). Zusammenfassender Bericht über den Rothmannschen grosshirnlosen Hund nach klinischer und anatomischer Untersuchung. Z. ges. Neurol. Psychiat., 87, 247-313.

rothmann, M. (1910). Der Hund ohne Grosshirn. Dtsch. Z. Nervenheilk., $38,267-269$.

SACHS, E., S. J. BRENDLER and J. F. FULTON (I949). The orbital gyri. Brain, 72, 227-240.

SCHALTENBRAND, G. and S. СОвB (1930). Clinical and anatomical studies on two cats without neocortex. Brain, 53, 449-488.

SCHNEYER, L. H., W. PIGMAN, L. HANAHAN and R. W. GILMORE (1956). Rate of flow of human parotid, sublingual, and submaxillary secretions during sleep. $\mathcal{F}$. dent. Res., 35, ro9-1 14.

SHEALY, C. N. and T. L. PEELE (1957). Studies on amygdaloid nucleus of cat. F. Neurophysiol., 20, $125^{-1} 39$.

solomowicz, J. (i9o8). Vom Centrum der Submaxillardrüse. Neurol. Centralblatt, 27, 724-727.

STAVRAKY, G. W. (1936). Response of cerebral blood vessels to electric stimulation of the thalamus and hypothalamic regions. Arch. Neurol. Psychiat., 35, 1002-1028.

STRONGIN, E. I. and L. E. HINSIE (I938). Parotid secretory rate in schizophrenic patients. F. Nerv. Ment. Dis., 87, 7 I 5-724.

WALKER, A. E. and H. D. GREEN (1938). Electrical excitability of the motor face area; a comparative study in primates. $\mathcal{F}$. Neurophysiol., I, I 52I 65.

WANG, S. C. (I943). Localization of the salivatory center in the medulla of the cat. F. Neurophysiol., 6, I 95-202.

wolfF, H. G. (I 937). Die bedingte Reaktion. In Handbuch der Neurologie, Vol. 2, ed. Bumke \& Foerster. Springer, Berlin.

YAGITA, K. (I9I0). Weitere Untersuchungen über das Speichelzentrum. Anat. Anz., 35, 70-75.

YAGITA, K. and S. HAYAMA (I909). Ueber das Speichelsekretionscentrum. Neurol. Centralblatt, 28, 738-753.

zIEHEN, T. (1 899). Ein Beitrag zur Lehre von den Beziehungen zwischen Lage und Function im Bereich der motorischen Region der Grosshirnrinde mit specieller Rücksicht auf das Rindenfeld des Orbicularis oculi. Arch. Anat. Physiol., Physiol Abtheil., 23, I 58-173. 


\section{CHAP'TER XIII \\ THE PHYSIOLOGICAL ROLE OF SALIVA}

The main functions of saliva are to aid in the digestion of food and in the protection of the entrance to the alimentary tract. In addition, various other functions can be attributed to saliva, some of which only belong to certain species. The present chapter deals with the role of saliva in mammals, and, particularly, in humans; the comparative physiology of salivary secretion is reviewed in Chapter XIV.

Although saliva has important functions, it is generally not essential to life. Death occurs in sheep in which saliva is drained off through fistulae of the parotid ducts, but seems to be due to severe loss of electrolytes rather than to loss of a juice with a vital function. Plagge (1938) removed the submaxillary and sublingual glands in new-born rats or ligated the ducts of these glands. The animals died from inanition within five days if not forcibly fed with cow's milk. When the glands were removed after ten days of age the rats could survive but growth was retarded; when the operation was made after twenty days or more, development was normal. Lack of saliva is, however, not without effects in full grown individuals. Many investigations indicate that the incidence of dental caries is increased in "desalivated" animals (for references see Schwartz and Shaw, 1955), illustrating the importance of the protective functions of saliva. The effect of loss of a digestive action of saliva may be exemplified by an oft-quoted observation of Claude Bernard; a horse, supplied with fistulae of both the parotid ducts, had great difficulty in chewing and swallowing its dry food and lost its appetite.

In humans xerostomia may exist because of congenital hypoplasia or absence of the salivary glands or may be due to loss of gland substance after surgical operation or x-ray treatment. Cases have also been described in which the glands are present but for unknown reasons unable to secrete reflexly or in response to injected drugs (Hadden, I 889). Such a patient has been observed to secrete reflexly during pregnancy only (Waldenström, personal communication). In cases of aptyalism, mastication and swallowing 
can be facilitated by sipping fluid frequently; the loss of the protective action of saliva manifests itself, however, in dental caries.

Reflecting the different functions of saliva, a great variety of stimuli can elicit salivary secretion. Whereas the unconditioned reflex secretion of gastric juice is evoked essentially by food in the mouth, such secretion of saliva can be produced both by edible and rejectable substances; flow of saliva, contrary to flow of gastric juice, can be elicited not only by agents acting on the taste buds, but by tactile and nociceptive stimuli as well. The remarkable adaptability of salivation to requirements in a seemingly purposeful way has attracted great attention ever since it was first described by Pavlov; among more recent investigations in this field those by Baxter (I933) and by Montgomery and Stuart (1936) may be mentioned. Not only is the quantity of saliva varied in an apparently useful way, so that dry material causes a more lively flow than does moist food, and water in itself no flow at all, but the composition of the saliva secreted is well suited to the situation. Edible substances, for instance, cause a secretion of saliva rich in mucin which facilitates swallowing, whereas rejectable agents such as alkali or sand stimulate a lively flow of thin saliva poor in mucin, so-called cleansing saliva. It is easily understandable that the composition of saliva can be varied over a wide range. The saliva produced by one gland, for instance the parotid, differs greatly from that of another, e.g. the sublingual gland, and the contributions of all the glands which together form the mixed saliva may vary considerably with the stimulus. Furthermore, a single gland such as the submaxillary is obviously not uniform but composed of different types of secretory cells and their relative contributions to the saliva may vary. Even in a seemingly uniform gland, such as the parotid, the composition of saliva is greatly variable with the intensity and nature of the stimulus. It is equally comprehensible that these great varitions can be brought about from the other end of the reflex arc, the receptors, since the salivary glands can be excited not only from different taste receptors but from touch and pain receptors also. The more precise mechanism through which the adaptation of the secretion to the quality of the stimulus takes place is unknown. The explanation is clearly not to be found in the fact that the gland cells are supplied both with parasympathetic and sympathetic secretory fibres, since the composition of the saliva is adapted to the stimulus even when the sympathetic has been cut. 


\section{DIGESTIVE FUNCTIONS}

Saliva is of importance for the mechanical disintegration of the food by mastication, for the transport of the food through the first part of the digestive tract, for dissolving the food, and for its chemical breakdown.

By moistening dry foodstuffs and the oral mucosa the salira facilitates chewing. From the food imbibed with saliva a bolus can be formed and rendered slippery by the salivary mucin; swallowing is furthered thereby. Mucin plays an important role by its lubricant action on the mucosa and the food.

Water-soluble components of the food can be dissolved in saliva and thus prepared for chemical treatment and eventual absorption. Saliva is, however, of special importance as a solvent because sapid substances can be brought to act on the taste buds only when dissolved; therefore, appetite and secretory and motor activity in the alimentary canal are to some extent indirectly dependent on salivary secretion. The small salivary glands of the tongue probably play a role in the mechanism of taste; their saliva may remove sapid substances from the taste buds, leaving the receptors prepared to receive another stimulus. Some substances are said to give rise to a more persistent taste sensation, for instance iodides and saccharine. This may be due to the fact that they are excreted in the saliva.

'The composition of the saliva itself is of interest in this connection. It is remarkable, for instance, that saliva contains no glucose; the blood sugar has to be elevated to a very high level before glucose appears in saliva or adrenaline has to be injected (Hebb and Stavraky, I936; Langstroth, McRae and Stavraky, I938; Langley, Gunthorpe and Beall, I958). The absence of glucose in normal saliva must be of significance for the perception of sweet. Similarly, the content of sodium in saliva is low, always considerably below the plasma level (Thaysen, Thorn and Schwartz, I954). The concentration of potassium of saliva, it is true, is relatively high and often given as approximately four times that of plasma; but potassium has less effect on the salt receptors than sodium (Öhrwall, r 89r). The threshold for salt taste given by most authors seems to be above the sodium concentration of saliva (particularly if the taste buds have not been washed with distilled water before the estimation). Solutions with less sodium than saliva 
may have a "water taste" (Zotterman, I949; Liljestrand and Zotterman, 1954; Cohen, Hagiwara and Zotterman, i 955; Zotterman, $\left.195^{6}\right)$.

For the chemical breakdown of food by saliva $\alpha$-amylase or ptyalin is mainly responsible. According to Bernfeld, Staub and Fischer (1948) all the amylolytic activity of human saliva is due to $\alpha$-amylase. Most investigations dealing with the activity of this enzyme have been carried out on saliva from human beings. 'The saliva from some of the common experimental animals has, in fact, a very low amylolytic power or none at all (see page 178 ). In most experiments on humans and animals mixed saliva has been used but in some investigations parotid saliva has been collected separately and found to have a much greater activity, sometimes four to eight times greater than the mixed sample (Evans, 1913; Fischl and Kahn, I930; Basir and Ramabhadran, I937; Schneyer, 1956).

Ptyalin can be demonstrated in saliva from infants; the activity is low, however, but increases during the first year to the level found in saliva of adults (Nicory, 1922). In old age the activity is much reduced. Meyer, Golden, Steiner and Necheles (1937) compared the amylolytic power of saliva from a group with an average age of 81 years with that of a group aged 25 years. The activity was found to be about 30 times greater in the younger than in the older group. The authors conclude that in old age the pancreas is mainly responsible for the first steps in the hydrolysis of carbohydrates.

What is the importance of the salivary amylase particularly in relationship to pancreatic amylase? In a patient with an oesophageal stricture Bonsdorff (I93I) investigated the absorption and utilization of food rich in carbohydrates introduced through a gastric fistula; he found it to be unimpaired by the absence of saliva and assumed this to be due to a compensatory hyperactivity of the pancreas. Conversely, it has been stated that the amylolytic activity of human parotid saliva may increase when the pancreatic function is disturbed (Molnár and Ungár, I93I). In dogs it has been found that ligation of the pancreatic ducts is followed by the appearance of amylase in saliva, even when the amylase level of the blood is not raised (Maj and Bonora, I943). It is not known how these adjustments are brought about. 'The mechanism may be the same as that responsible for the adaptation of the salivary amylase concentration to the diet which is assumed by many investigators to occur. 
Neilson, Lewis and Terry (1906, I908) found the amylolytic power of human saliva to increase markedly when the diet was rich in carbohydrate; they even reported similar observations in dogs. Mendel and Underhill (1907) were unable to reproduce these findings on dogs; Samytschkina (1932), however, noticed amylase activity in saliva of dogs fed for some days on a carbohydrate diet. Further experiments in this field seem desirable.

The fact that the food remains in the mouth for a short period only, might seem to reduce the importance of the salivary amylase. As is well known, however, the splitting of polysaccharides under the influence of saliva continues in the stomach. The fundamental experiments by Cannon ( 1898$)$ in which the alimentary canal was made visible on the $\mathrm{x}$-ray screen by means of a bismuth preparation, revealed that the fundus of the stomach is relatively quiescent, whereas the pyloric region is active. Cannon concluded "that the fundus acts as a reservoir for the food, in which the digestion of sugars and starches may take place". That the contents of the fundus is only slowly mixed with acid gastric juice was proved in the following experiment: "A cat which had been without food for fifteen hours was given eighteen grams of mushy bread made slightly alkaline with sodium carbonate. One hour and a half after the cat had finished eating, she was killed and the stomach laid bare by opening the abdomen. A very small hole was then made through the wall in the fundus region, and another similar hole was made into the antrum. By means of a glass pipette food was extracted first from the periphery of the fundus; this food was slightly acid. The cleaned pipette was then introduced two and a half centimetres into the fundus contents and the food thus extracted gave the original alkaline reaction. Specimens of the liquid contents of the antral and middle regions, taken from various depths, were all strongly acid."

Grützner (1905) fed rats on three successive portions of bread differently coloured; the animals were then killed, the stomachs extirpated, frozen and cut through. The different portions of food could be distinctly separated from each other, the food given last being close to the oesophagus and surrounded by the second portion; the first portion was nearest to the wall of the stomach. Enzymatic studies showed that an amylolytic activity could exist in the part of the stomach near the oesophagus simultaneously with a peptic activity in the pyloric region. This fact has been 
demonstrated in many experimental animals (Grützner, I905; Scheunert, 1906; Ellenberger, 1906) and in man (Prym, I907; Sick, I907).

In the fundus, therefore, acid gastric juice penetrates only slowly into the bolus. A slight increase in acidity is actually assumed to increase the activity of the salivary amylase and a rise in the concentration of chloride could do the same (Clifford, I 925; Ninomiya, I940; Bernfeld, Staub and Fischer, 1948). The amylolytic action of saliva has been shown to continue for 15 to 30 minutes in the human stomach (Bergeim, 1926; Beazell, I941). During this period a considerable breakdown of polysaccharides occurs. In a series of experiments on healthy men receiving a test meal Bergeim (I926) found that on the average 76 per cent of the starch of mashed potatoes and 59 per cent of the starch of bread had been converted to maltose, an additional percentage being changed to dextrins. Eventually the concentration of gastric juice becomes so high as to inhibit the ptyalin. Strong acid and pepsin destroy the enzyme (Gewiss, Rasp and Schwarz, I926; Ninomiya, I940). Salivary amylase can therefore function in the intestine only provided that it escapes the gastric juice, for instance in achylia.

Numerous other enzymes, apart from ptyalin, have been found in saliva; in most instances mixed saliva has been used. Only a few examples, and a very restricted number of references, may be given. A lipolytic activity of saliva was observed by Scheer (1928), Peluffo (I929), Katzenstein (I930) and many later investigators. Esterase (Mahler and Chauncey, I957), maltase (Hartles and Wasdell, I954), phosphatases (Giri, I936; Glock, Murray and Pincus, I938), hyaluronidase (Lisanti, I950; Gibian, I952), catalase and peroxidase (Nickerson, Kraus and Perry, I957; Wolfe and Turner, I 957), mucolytic enzymes (Knox, I953), etc., have been detected in saliva. It seems very unlikely that these enzymes contribute to the digestive functions of saliva. In many cases the enzymes originate from the oral bacterial flora (see, e.g., Chauncey, Lionetti, Winer and Lisanti, I954; Hartles and Wasdell, 1954). In other instances they belong to the corpuscular elements of the saliva. This is well illustrated by the early experiments in this field carried out by Willstätter, Bamann and Rohdewald (I929). 'These investigators found that the amylolytic activity of saliva was not measurably reduced when cells and bacteria were removed by centrifugation. The tryptic activity of saliva, on the other hand, was diminished 
by 85 per cent by this procedure; the remaining activity was assumed to be due to enzyme from already disintegrated cells.

The role played by some other enzymes found in saliva, such as lysozyme and kallikrein, will be discussed later in this chapter.

\section{PROTECTIVE FUNCTIONS}

The importance of protective functions of saliva for the health of the teeth has already been mentioned. The oral mucosa is likewise dependent on an adequate flow of saliva. The stomatitis which may appear during fevers is generally assumed to be related to a reduced salivary secretion. There is some experimental evidence to show that salivation may be diminished in fevers. Barbour and Freedman (I92I) found that fever, brought about by injection of coli vaccine in dogs, reduced the salivary response to pilocarpine. Koropow (1934) produced fever in dogs by injecting turpentine and found the conditioned salivary reflex to diminish markedly; the unconditioned reflex and the response to pilocarpine were not affected. To a great extent the protective action of saliva is no doubt simply due to the fact that the mucosa is kept moist and lubricated and the mouth continuously rinsed by a permanent stream of saliva, for even between the meals saliva is flowing slowly. During sleep the secretion may be very small and possibly confined to a spontaneous activity in some glands. When food is eaten the rate of flow increases enormously. This is, of course, connected with the digestive functions of saliva; but an increased protective action must also be required during a meal. Excessively hot food is diluted and cooled by saliva, irritating or injurious agents diluted, acids or alkali dealt with by the buffers of saliva (see Sellman, i 949).

The protective actions of saliva are also apparent during vomiting. In the stage of nausea, which usually precedes the emptying of the stomach, salivary secretion is very pronounced, as can be concluded from the frequent swallowing. When the gastric contents are expelled, saliva protects the mucous membranes.

Much attention has been paid to the antibacterial action of saliva. Many investigators have assumed that saliva acts not only by washing away bacteria, and food particles and desquamated cells which could serve as substrates, but that saliva in addition possesses specific bacteriostatic or bactericid properties. A great variety of possible mechanisms has been proposed. The thiocyanate of saliva 
which has always attracted great attention was at an early stage supposed to have an antibacterial function; the evidence in favour of this view does not seem convincing. The bacterial flora of the saliva in the mouth has been assumed to exert an antagonistic action against pathogens. According to Björnesjö (I950) this is connected with a competition between the salivary bacteria and pathogens for essential growth factors in the saliva. Other investigators have assumed the oral flora to produce agents which inhibit some other bacteria. Such an agent which has been discussed is hydrogen of peroxide (Hegemann, I950; Bethge, Soehring and Tschesche, I947). Bacteria producing peroxide have been found to be present in samples of saliva (Hegemann, I950; Kraus, Nickerson, Perry and Walker, 1957). Since, however, saliva contains peroxidase and catalase (Nickerson, Kraus and Perry, I957; Wolfe and Turner, I957) the role of peroxide as an inhibitory agent has been questioned (Bönicke, Reif and Arndt, 1953). Products from the leucytes of saliva have also been supposed to contribute to the antibacterial action of saliva (Willstätter, Bamann and Rohdewald, I929; Knorr, I94I; Dold, I942). In 1922 Fleming discovered an agent in tissues and secretions capable of dissolving certain bacteria. It behaved like an enzyme and was called lysozyme. The salivary lysozyme is not produced by bacteria but is an original component of saliva (Chauncey and Lisanti, I 953). Its concentration is higher in combined submaxillary and sublingual than in parotid saliva of humans (Hoerman, Englander and Shklair, I 956). Saliva of most animals investigated contains lysozyme(Goldsworthy and Florey, I930).

One complicating factor is that salivary mucin seems to diminish the activity of lysozyme (Simmons, 1952). The virulence enhancing effect of mucins has long been recognized and made use of in experimental bacteriology. Smith (195I) demonstrated that mucin preparations from human saliva increased the virulence of Bact. typhosum in mice, probably by acting on the defence mechanisms of the host. Bacteria and mucin were given intraperitoneally and the experiments were not taken as evidence to show that mucin actually aids pathogens in their attack on mucosal surfaces.

Since saliva has been found to act against some pathogens which are not affected by lysozyme, for instance diphtheria bacilli, many investigators have concluded that other antibacterial agents than lysozyme are present and probably produced by the salivary glands 
(Dold, Lächele and Hsing, 1936; Weigmann and Noeske, 1937; Thompson, 1940, 1941; van Kesteren, Bibby and Berry, 1942).

\section{OTHER FUNCTIONS}

Adequate moistening of the buccal and pharyngeal mucosa is necessary not only for digestive and protective purposes but for articulate speech, as experienced in states of anxiety or fright when the salivary reflex is inhibited.

The role played by saliva in the regulation of the water balance of the body has for a long time been a controversial subject. 'The defenders of the "local dryness" theory assume that water intake is regulated from the mucosa of the mouth and throat, dryness due to inadequate salivation acting as a stimulus. According to this view thirst may be felt and water consumed even with normal stores of water whenever the mucosa becomes dry, for instance, in fear, after injection of atropine, when breathing hot and dry air through the mouth or after ligation of the salivary ducts. In a dehydrated subject, on the other hand, thirst may be alleviated by moistening the mucosa with water, by anaesthetizing the mucosa or by increasing the flow of saliva. This can be achieved by putting some acid substance into the mouth or even by injecting pilocarpine. In order to explain the fact that dehydration gives rise to thirst, Cannon (1918) pointed out that the salivary glands, like other tissues, must suffer when water is lacking in the body; experimentally, he found that the secretion of saliva in response to chewing a tasteless gum, decreased when he reduced his water intake or produced excessive sweating. Similarly, secretion of saliva has been found to diminish after haemorrhage and after a meal when large amounts of fluid are lost temporarily with the digestive juices. Even after intravenous injection of hypertonic sodium chloride solution the salivary flow is reduced. Some of the findings or their interpretations upon which this theory is founded have been disputed. Montgomery ( $193 \mathrm{I} a$ ), for instance, observed no increase of the water intake in dogs after extirpation of the main salivary glands. Gregersen and Cannon (1932) remarked, however, that the secretion from the small salivary glands left in these experiments might be able to keep the mucous membranes adequately moistened under ordinary conditions. They repeated the experiment in hot surroundings which caused the dogs to pant and found this procedure to double the water intake. After injections of atropine 
the dogs did not drink more water than before in Montgomery's experiments $(193 \mathrm{r} b)$. In view of the fact that some glands may secrete spontaneously and therefore even after atropinization, it would be interesting to repeat this experiment also under conditions of increased demands on the salivary secretion, for instance, in panting dogs. An attempt to evaluate the different theories put forward to explain the regulation of the water balance is beyond the scope of this chapter and the competence of its author. The problem has been surveyed by Gregersen (1956), who also gives the literature quoted in this section.

A role just mentioned is that which saliva plays in thermoregulation in some species. 'The salivary glands provide the water which evaporates from the oral mucosa, particularly that of the tongue in the panting dog. When exposed to a warm atmosphere a dog begins to pant and thin watery saliva flows. The secretion is evoked reflexly from the dry mucosa; if the mouth is kept closed or the tongue moistened with water, the salivary flow decreases (Gregersen, I93I). It even seems possible to develop a conditioned reflex with secretion, elicited for thermoregulatory purposes, acting as the unconditioned stimulus.

It could be assumed that the sympathetic system engaged in thermoregulatory reactions by acting on the sweat glands and the blood vessels of the skin would cause the salivary secretion during panting. 'This, however, is not the case. Alexandrov (1939) found that salivation elicited by increasing the body temperature in dogs by means of tetrahydronaphthylamine was abolished by parasympathetic denervation.

It has been mentioned earlier that secretion of saliva is reduced during fever in dogs. There need not be any conflict between this fact and the findings described above. Hypersalivation results from the polypnoea of panting and the consequent dryness of the protruding tongue. There is not necessarily any panting in fever; the reduced salivary responses to various stimuli during fever may be due to a certain degree of dehydration.

The use of saliva for toilet purposes provides a further example of a function of the salivary glands mostly confined to certain species, for example, the cat. The dog's licking of its wounds, supposed to promote healing, may also be mentioned here; Pavlov connected this function with the experimental finding that electrical stimulation of various afferent nerves in dogs causes a flow of 
saliva (Liddell, I936). In cats, spitting is one of the bodily expressions of rage, probably elicited via sympathetic nerves; the llama is said to use saliva for the same purpose. A function of saliva specific to humans although perhaps not foreseen by nature is to aid in the fixation of dentures; the sticky saliva produced by the palatine glands is supposed to be particularly valuable in this respect (Östlund, I953). Dryness of the mouth as a side effect to treatment with ganglionic blocking or parasympatholytic agents in elderly persons with dentures and suffering from hypertension or gastric hypersecretion may therefore be particularly inconvenient. It would be fortunate if the palatine glands were endowed with the ability to secrete spontaneously as assumed by Östlund ( 1953 ).

Specific functions have been attributed to various substances found in saliva. When the vasodilator effect of saliva was discovered it was suggested that saliva might promote digestion in the stomach and intestine by causing hyperaemia there. It was even suggested that the active agent might be absorbed and play a role in the regulation of the blood pressure. The agent responsible for the vasodilatation was identified as kallikrein (Ungar and Parrot, 1936) and found to be an enzyme acting on proteins to form a vasodilator polypeptide; the idea was put forward that this enzyme might act on proteins in the food producing gastrin-releasing material and thus promoting gastric digestion (Hilton and Lewis, 1955). Guimarais and Tavares (1942) found saliva to cause gastric secretion in dogs and assumed this effect to be caused by the hypotensive agent of saliva. Saliva has also been supposed to contain substances which promote the coagulation of blood (see, e.g., Glazko and Greenberg, I 939; Nour-Eldin and Wilkinson, I957). Albrechtsen and Thaysen (I955), on the other hand, found a fibrinolytic activity of human saliva, similar to that of milk, tears and urine; they suggested that the fibrinolytic system of saliva aids in the resolution of fibrin clots which might otherwise obstruct the narrow salivary ducts. Among other interesting agents present in saliva, the blood group substances and enzymes destroying these substances may be mentioned (see Kabat, I956); it is unknown whether these substances have any specific function in saliva.

So far, the role of saliva has been mainly discussed. The salivary glands may have functions other than to produce a fluid with the effects dealt with above. They are usually described as having an 
excretory function. Substances such as iodide, thiocyanate, mercury and lead are known to be secreted in the saliva; the same is true for alkaloids like morphine (Munch, I934) and antibiotics like penicillin, streptomycin, chloramphenicol and aureomycin (Bender, Pressman and Tashman, I953). Ethyl alcohol is eliminated through the salivary glands and its estimation in saliva has been recommended for medico-legal purposes (Linde, I932; Vollenbruck, I937; Friedemann, Motel and Necheles, 1938).

A comprehensive literature deals with the salivary glands as possible endocrine organs. Attention has been paid particularly to actions of the glands on carbohydrate metabolism. A special hormone, parotin, has also been described acting on protein metabolism and promoting the calcification of dentine; it is further said to increase the activity of choline acetylase (Takaoka, Yamaguchi and Kosaka, I952; Takaoka, Yamaguchi, Yamada and Kosaka, I954; Takaoka, Uono, Ninomiya, Yoshikawa, Yamada and Ishikawa, I 955).

The finding that salivary glands, particularly those of humans, are rich in amine oxidase, has led to the hypothesis that the glands might play a role in the destruction of amines in the blood (Strömblad, I959).

\section{REFERENCES}

ALbRECHTSEN, O. K. and J. H. THAYSEN (1955). Fibrinolytic activity in human saliva. Acta physiol. scand., 35, I38-145.

aleXandrov, I. S. (1939). Quoted from Ber. ges. Physiol., i 940, I 18, 576. BARBOUR, H. G. and B. P. FREEDMAN (I92I). Effects of pilocarpine upon salivary secretion in normal and febrile dogs. Amer. F. Physiol., 57, 387-394.

BASIR, M. A. and T. S. RAMABHADRAN (1937). A study of human parotid saliva. Indian $\mathcal{F}$. med. Res., 24, $911-916$.

BAXTER, H. (1933). Variations in the inorganic constituents of mixed and parotid gland saliva activated by reflex stimulation in the dog. F. biol. Chem., 102, 203-217.

BEAZELL, J. M. (I94I). A re-examination of the rôle of the stomach in the digestion of carbohydrate and protein. Amer. F. Physiol., 132, 42-50. Bender, I. B., R. S. Pressian and S. G. TAShman (I953). Studies on excretion of antibiotics in human saliva. Aureomycin. F. dent. Res., 32, $435-439$.

BERGEIM, O. (I 926). Intestinal chemistry. III. Salivary digestion in the human stomach and intestines. Arch. int. Med., 37, I 10-1 17.

BERNFELD, P., A. STALB and E. H. FISCHER (1948). Sur les enzymes amylolytiques. Helv. chim. acta, 31, 2165-2172.

Bethge, J., K. SOEHRing and R. TSChesche (1947). Ueber die Rolle des 
Wasserstoffperoxyds bei der Inhibition nach Dold. Z. Naturf., 2B, I2-I 3 .

BJÖRNESJÖ, K. B. (I950). Studies on the antibacterial factors of human saliva. Acta chem. scand., 4, 835-845.

BÖNICKE, R., W. REIF and J. ARNDT (I953). Ueber die antibakterielle Aktivität des menschlichen Speichels unter besonderer Berücksichtigung der tageszeitlichen Schwankungen. Z. Hyg., 136, 252-264. BONSDORFF, B. (1931). Ueber die Bedeutung des Speichels für die Ausnützung einer kohlenhydratreichen Nahrung. Skand. Arch. Physiol., 62, 282-298.

CANNON, W. B. (1898). The movements of the stomach studied by means of the Röntgen rays. Amer. F. Physiol., I, 359-382.

- (1918). The physiological basis of thirst. Proc. Roy. Soc. B., 90, 283301 .

CHAUNCEY, H. H., F. LIONETTI, R. A. WINER and V. F. LiSANTI (I954). Enzymes of human saliva. I. The determination, distribution and origin of whole saliva enzymes. F. dent. Res., 33, 321-334.

CHAUNCEY, H. H. and V. F. Lisanti (1953). Determination of the enzyme content of whole saliva. F. dent. Res., 32, 642.

CLIFFORD, W. M. (I 925). The effect of halogen salts on salivary digestion. Biochem. F., 19, 21 8-220.

COHEN, M. J., S. HAGIWARA and Y. ZOTTERMAN (1955). The response spectrum of taste fibres in the cat: a single fibre analysis. Acta physiol. scand., 33, 316-332.

DOLD, H. (I942). Die Bakterien-Inhibinwirkung (bakteriostatische Wirkung) sterilen Submaxillaris-Speichels des Hundes. Z. Hyg., 124, 519-530.

DOLD, H., W. LÄCHELE and D. D. HSING (I936). Ueber die Eigenschaften, Wirkungsbreite und Wirkungsart der antibakteriellen Hemmungsstoffe (Inhibine) des menschlichen Speichels. Z. Hyg., I 18, 369-395. ellenberger ( 1 906). Zum Mechanismus der Magenverdauung. Arch. ges. Physiol., I14, 93-107.

Evans, C. L. (1913). Der Einfluss der Nahrung auf den Amylasegehalt des menschlichen Speichels. Biochem. Z., 48, 432-447.

FISCHL, E. and R. H. KAHN (I930). Die amylolytische Wirksamkeit des Kaninchenspeichels. Arch. ges. Physiol., 225, 694-698.

FLEMING, A. (1 922). On a remarkable bacteriolytic element found in tissues and secretions. Proc. Roy. Soc. B., 93, 306-317.

FRIEDEMANN, T. E., W. G. MOTEL and H. NECHELES (I938). The excretion of ingested ethyl alcohol in saliva. F. Lab. clin. Med., 23, 1007-1014. GEWISS, E., F. RASP and C. SCHWARz (1926). Beiträge zur Physiologie der Verdauung, Fermentforschung, 9, 50-57.

Gibian, H. (1952). Ueber einen der Hyaluronidase ähnlichen Faktor im Hundespeichel. Z. phys. Chem., 289, I65-172.

GIRI, K. V. (1936). Ueber Speichel-Phosphatase. Biochem. Z., 285, 3063 I0.

GLAzKo, A. J. and D. M. GREENBERG (I 939). The mechanism of the action of saliva in blood coagulation. Amer. F. Physiol., 125, ro8-1 12.

GLOCK, G. E., M. M. MURRAY and P. PINCUS (1938). The origin and significance of salivary phosphatase. Biochem. F., 32, 2096-2104.

GOLDSWORTHY, N. E. and H. FLOREY (1930). Some properties of mucus, with special reference to its antibacterial functions. Brit. F. exp. Path., II, 192-208. 
GREGERSEN, M. I. (I93I). A method for uniform stimulation of the salivary glands in the unanaesthetized dog by exposure to a warm environment, with some observations on the quantitative changes in salivary flow during dehydration. Amer. F. Physiol., 97, 107-1 16.

- (1956). In Medical physiology, ed. Bard. Ioth ed. Mosby, St. Louis. GREGERSEN, M. I. and W. B. CANNON (1932). Studies on the regulation of water intake. Amer. F. Physiol., ro2, 336-343.

GRÜTZNER, P. (1905). Ein Beitrag zum Mechanismus der Magenverdauung. Arch. ges. Physiol., ro6, 463-522.

GUimarais, J. A. and A. TAVARES (I942). Substances actives salivaires et sécrétion gastrique. Arch. Port. Sci. Biol., 6, 209-2 I 5.

HADDEN, W. B. (I 889). Xerostomia (dry mouth). Brain, Ir, 484-486.

HARTLES, R. L. and M. R. WASDELL (I954). The metabolism of the oral flora. IV. The invertase activity of mixed human saliva. Brit. dent. $\mathcal{F}$., $97,231-235$.

HEBB, C. O. and G. W. Stavraky (1936). The presence of glucose in the salivary secretion after the administration of adrenaline. Quart. $\mathcal{F}$. exp. Physiol., 26, 141-153.

HEGEMANN, F. (I950). Weitere Untersuchungsergebnisse über die Natur des von menschlichen Speichelkokken erzeugten antibakteriellen Stoffes. Z. Hyg., r31, 355-363.

HILTON, S. M. and G. P. LEWIS (1955). The mechanism of the functional hyperaemia in the submandibular salivary gland. F. Physiol., I29, 253-27I.

HOERMAN, K. C., H. R. ENGLANDER and I. L. SHKLAIR (1956). Lysozyme; its characteristics in human parotid and submaxillo-lingual saliva. Proc. Soc. exp. Biol., N.Y., 92, 875-878.

Kabat, E. A. (1956). Blood group substances. Academic Press, New York. KATZENSTEIN, M. (1930). Untersuchungen über Speichellipase. Z. exp. Med., 69, 179-192.

KESTEREN, M. VAN, B. G. BIBBY and G. P. BERRY (I942). Studies on the antibacterial factors of human saliva. F. Bact., 43, 573-583.

KNORR, M. (I94I). Ueber Gewinnung, Wirkung und Herkunft der keimschädigenden Stoffe ("Bakterionoxine") im Mundspeichel. Arch. Hyg., Berl., 126, 59-86.

KNOX, K. W. (I953). Observations on the action of mucolytic enzymes on salivary mucoid. F. dent. Res., 32, 374-378.

Koropow, w. M. (1 934). Ueber die Sekretionstätigkeit der Speicheldrüsen im Fieberzustand. Arch. exp. Path. Pharmak., 175, I56-164.

Kraus, F. W., J. F. Nickerson, W. I. PERRY and A. P. WALKer (1957). Peroxide and peroxidogenic bacteria in human saliva. $\mathcal{F}$. Bact., 73, 727735 .

LANGLEY, L. L., C. H. GUNThORPE and w. A. BEALL (1 958). Salivary glucose threshold. Amer. F. Phy'siol., 192, 482-484.

LANGSTROTH, G. O., D. R. MCRAE and G. W. STAVRAKy (i938). A study of cat's submaxillary saliva obtained under nerve stimulation or adrenaline administration. Arch. int. Pharmacodyn., 58, 61-77.

Liddell, H. S. (1936). Pavlov's contribution to psychology. Psychol. Bulletin, 33, 583-590.

LILJESTRAND, G. and Y. ZOTTERMAN (1954). The water taste in mammals. Acta physiol. scand., 32, 291-303.

LINDE, P. (1932). Der Uebergang des Äthylalkohols in den Parotisspeichel beim Menschen, Arch. exp. Path. Pharmak., 167, 285-291. 
LISANTI, v. F. (1950). Hyaluronidase activity in human saliva. F. dent Res., 29, 392-395.

MAHLER, I. R. and H. H. CHAUNCEY (1957). Lipolytic and esterolytic activity of saliva and salivary organisms. F. dent. Res., 36, 338-342.

MAJ, G. and L. BONORA (1943). Veränderung der amylolytischen Speichelfunktion infolge Stockung der pankreatischen Aussensekretion. Arch. ges. Physiol., 246, 749-756.

MENDEL, L. B. and F. P. UNDERHILL (1907). Is the saliva of the dog amylolytically active? $\mathcal{F}$. biol. Chem., 3, I $35^{-1} 43$.

MEYER, J., J. S. GOLDEN, N. STEINER and H. NECHELES (1937). The ptyalin content of human saliva in old age. Amer. F. Physiol., 119, 600-602.

MOLNÁR, T. and E. UNGÁR (193I). Weitere Beiträge über die Wechselwirkung der diastatischen Fermentproduktion des Pankreas und der Speicheldrüsen. Arch. VerdauKr., 50, 295-300.

MONTGOMERY, M. F. (I931a). The rôle of the salivary glands in the thirst mechanism. Amer. F. Physiol., 96, 22 I-227.

- (193 $b$ ). The influence of atropin and pilocarpin on thirst (voluntary ingestion of water). Amer. F. Physiol., 98, 35-4I.

MONTGOMERY, M. F. and J. S. STUART (1936). Studies upon the secretion of oral and pharyngeal mucus. Amer. F. Physiol., II5, 497-506.

Munch, J. C. (1934). Saliva tests. I. Morphine. F. Amer. pharm. Ass., I15, 766-774.

NEILSON, C. H. and D. H. LEWIS (1908). The effect of diet on the amylolytic power of saliva. F. biol. Chem., 4, 501-506.

NEILSON, C. H. and O. P. TERRY (1906). The adaptation of the salivary secretion to diet. Amer. F. Physiol., 15, 406-41 I.

Nickerson, J. F., F. W. KRAUS and W. I. PERRy (1957). Peroxidase and catalase in saliva. Proc. Soc. exp. Biol., N.Y., 95, 405-408.

NICORY, C. (1922). Salivary secretion in infants. Biochem. F., 16, 387-389. Ninomiya, H. (I940). Beitrag zur Kenntnis der Speichelamylase. I. Mitt. Ueber die Globulinnatur der Speichelamylase. Fap. F. Biochem., 3r, 69-78.

NOUR-ELDIN, F. and J. F. WILKINSON (1957). The blood clotting factors in human saliva. F. Physiol., 136, 324-332.

ÖHRWALl, H. (1891). Untersuchungen über den Geschmackssinn. Skand. Arch. Physiol., 2, I-69.

östlund, s. (1953). Palatine glands and mucin. Odontol. Tidskrift, 62, I-I 28.

Peluffo, A. (1929). Action lipasique de la salive. C.R. Soc. Biol., Paris, I00, I I 5-I 16.

PLAGGE, J. C. (1938). The vital importance of salivary glands to newborn rats. Amer. F. Physiol., 124, 612-619.

PRYM, O. ( 1 907). Die Bedeutung der schichtweisen Auffüllung des Magens für die klinische Diagnostik speziell für die Beurteilung des SahliSeiler'schen Probefrühstücks. Dtsch. Arch. klin. Med., 90, 310-334.

SAmytschina, K. S. (I932). Der Einfluss qualitativ verschiedener Nahrung auf die sekretorische Speicheldrüsenfunktion. Arch. ges. Physiol., 230, 680-688.

SCHEER, K. (1928). Ueber Lipase im Speichel. Klin. Wschr., 7, 163-165. SCHEUNERT, A. (1906). Zum Mechanismus der Magenverdauung. Arch. ges. Physiol., 114, 64-92.

SCHNEYER, L. H. (1956). Amylase content of separate salivary gland secretions of man. F. appl. Physiol., 9, 453-455. 
SCHWARTZ, A. and J. H. SHaw (1955). Studies on the effect of selective desalivation on the dental caries incidence of albino rats. $\mathcal{F}$. dent. Res., 34, 239-247.

SEllman, S. (I 949). The buffer value of saliva and its relation to dental caries. Acta Odont. Scand., 8, 244-268.

SICK, K. (1907). Untersuchungen über die Saftabsonderung und die Bewegungsvorgänge im Fundus- und Pylorusteil des Magens. Dtsch. Arch. klin. Med., 88, 169-223.

SIMmons, N. S. (1952). Studies on the defense mechanisms of the mucous membranes with particular reference to the oral cavity. Oral Surg., Oral Med., Oral Pathol., 5, 513-526.

SMith, H. (195I). The virulence enhancing action of mucins; a survey of human mucins and mucosal extracts for virulence enhancing activity. F. infect. Dis., 88, 207-2 I I.

STRÖMBLAD, B. C. R. (I959). Observations on amine oxidase in human salivary glands. F. Physiol., 147, 639-643.

TAKAOKA, Y., M. UONO, H. NINOMIYA, M. YOSHIKAWA, N. YAMADA and T. ishikawa ( 1 955). Der hormonale Einfluss der Parotisdrüsen auf den Eiweisstoffwechsel. Klin. Wschr., 33, I 56-160.

TAKAOKA, Y., T. YAMAGUCHI and K. KOSAKA (1952). Relation of the parotid gland to serum protein and malnutrition. Tohuku f. exp. Med., 57, 9-15.

TAKAOKA, Y., T. YAMAGUCHI, N. YAMADA and K. KOSAKA (I954). Der hormonale Einfluss der Parotisdrüsen auf den Kohlenhydrat- und Eiweiss-Stoffwechsel. Klin. Wschr., 32, 369-375.

THAYSEN, J. H., N. A. THORN and I. L. SCHWARTZ (1954). Excretion of sodium, potassium, chloride and carbon dioxide in human parotid saliva. Amer. F. Physiol., 178, I 55-1 59.

THOMpson, R. (I940). Lysozyme and its relation to the antibacterial properties of various tissues and secretions. Arch. Pathol., 30, 1096I 134 .

- (I94I). Certain antibacterial properties of saliva and tears not due to lysozyme. F. Bact., 4I, 77.

UNGAR, G. and J.-L. PARROT (1936). Sur la présence de la callicréine dans la salive, et la possibilité de son intervention dans la transmission chimique de l'influx nerveux. C.R. Soc. biol., Paris, 122, 1052-1055. VOLLENBRUCK, H. (I937). Untersuchungen über den Alkoholgehalt im Blut und im Speichel des menschlichen Körpers. Arch. exp. Path. Pharmak., 187, 731-736.

WEIGMANN, F. and H. NOESKE (1937). Untersuchungen über den antibakteriell wirksamen Faktor im menschlichen Speichel. Z. Hyg., II9, 4I3-424.

WILlSTÄTtER, R., E. BAMANN and M. ROHDEWALD (1929). Ueber die Enzyme der Speicheldrüse. Z. phy's. Chem., r86, 85-96.

WOLFE, A. D. and N. C. TURNER (1957). Studies on salivary peroxidatic activity. $\mathcal{F}$. dent. Res., 36, 843-85I.

zotTERMAN, y. (1949). The response of the frog's taste fibres to the application of pure water. Acta physiol. scand., 18, 181-189.

- (1956). Species differences in the water taste. Acta physiol. scand., 37, $60-70$. 


\section{THE COMPARATIVE PHYSIOLOGY OF' THE SALIVARY GLANDS}

While the rest of this book deals exclusively with the salivary glands of mammals, in particular those of man, the cat, dog and rat, in this chapter we will discuss some of the variants in salivary gland function found in other orders. These are of great interest in showing the specialized functions that the glands can undertake, although in most instances little is known of the details of their physiology.

Different classes of insects showed considerable variation in the degree of organization of their salivary glands ranging from quite rudimentary sacs to elaborate organs in many of the higher insects. Baptist (1942) gives a good account of the salivary glands of Heteroptera. In Notonecta glauca L. the glands are characterized by large cells with prominent granules and vacuoles. The glands are innervated by a nervous plexus receiving a glandular nerve from the hypocerebral ganglion of the stomato-gastric system. The gland cells discharge their granules during activity. In other members of the heteroptera, vesicular glands are found. The secretion from the gland cells is discharged into a large central storage cavity. These gland cells contain no zymogen granules but there are small dense masses of "reserve material" in the basal parts of the cells.

The silk glands of lepidoptera larvae are specialized salivary glands; in other orders silk is produced by other glands, for instance in Arachnids by ventral abdominal glands, in Embioptera glands situated in the front feet and in Coleoptera by glands in the Malpighian tube or accessory genital tubes (Lesperon, I937). In Sericaria mori the silk glands are two long tubes that unite in the mouth to form a common tube into which two accessory multilobed glands (the glands of Lyonnet) add their secretion. These secretions are passed along the specialized mouth parts (the silk press) in which the two cylindrical filaments of silk are fabricated into a single plaited ribbon. The tubular silk glands are lined by a single layer of cells which show differences between the most proximal region in which the fibres of silk fibroin are probably made in cells 
with very well developed Golgi apparatus and rich in mitochondria, a second region with an expanded lumen and rather flattened epithelia in which the secretion is stored, and the third in which sericin (the second silk protein) is probably secreted and applied to the fibroin threads. In this latter region the epithelium has a striated appearance not unlike that of the striated duct cells of the mammalian salivary glands. It is thought that the glands of Lyonnet may provide a lubricant for the silk press. The silk organ is comparatively large and would seem to be an admirable object for the study of secretory problems at the cellular level.

In a large number of insects digestive enzymes are found in the salivary glands indicating the role of the glands in digestion. For instance, Wigglesworth $(1927,1956)$ records the presence of an active amylase in cockroaches (Blatella germanica and Periplaneta americana). Its activity was enhanced by halide ions in a similar way to mammalian amylase but its $\mathrm{pH}$ optimum was more acid. Invertase was also present but maltase and lactase were not. Baptist (1942) found amylase in the salivary glands of non-bloodsucking members of the hemiptera and heteroptera. The distribution of digestive enzymes in the salivary glands in various orders of insectivora have been summarized by Wigglesworth (1956) and Roeder (I953).

In blood-sucking insects such as the tsetse fly (Glossina submorsitans and $G l$. tachinoides) there are no digestive enzymes in the saliva which, however, has instead anticoagulant activity (Wigglesworth, 1929). In these species the blood is stored undigested in the crop. Lester and Lloyd (1928) showed that digestion in glossina was not impaired after removal of the salivary glands. Other bloodsucking insects (i.e. Cimex and Stomomys) also secrete an anticoagulant in the saliva. An interesting specialized digestive function of the salivary glands occurs in the larva of Chironomus plumosus L. (Walshe, 1947). This larva first of all makes itself a tubular burrow and then maintaining itself in position by its posterior prolegs performs a number of rotating movements with the anterior part of the body. In this manœuvre as the head describes complete circles of alternating directions around the circumference of the burrow the anterior proleg draws out strands of saliva by rapid approach to and withdrawal from the mouth parts. In this way a loose saucer-shaped sheet of salivary threads is formed. The larva then withdraws a few millimetres down the 
burrow dragging with it a salivary thread from the middle of the sheet which is thus pulled into a conical net. In its new position the larva makes violent movements which draw a current of water through the net, which traps the solid particles. The larva then eats the net and the catch. This process may be repeated every few minutes.

The salivary glands of Drosophila melanogaster have been extensively studied by geneticists because of the large size of the nuclei in the cells and the clarity with which the giant chromosomes can be seen. The glands are simple sacs lined with a single layer of polygonal cells (Bodenstein, 1943). The salivary glands undergo remarkable changes during the insect's development. In the first instar the gland is only about $65 \mu$ long and the nuclei $2.4 \mu$ in diameter, but in the mature third instar the gland is over $\mathrm{I} \mathrm{mm}$ long and the nuclei $20-25 \mu$. In the larvae and adult insects the nuclei are smaller (Ross, 1939).

The blood-sucking leeches (Annelidae) produce an anticoagulant substance from simple salivary sacs that invaginate into the muscle fibres surrounding the oval cavity (Haycroft, I884; Franz, 1903). For many years extracts of the medical leech (Hirudo officinalis) called hirudin were used experimentally as an anticoagulant. With the discovery of heparin, interest in hirudin has waned and much remains to be elucidated on its chemical constitution and mode of action.

The salivary glands of the octopus are highly developed and seem to serve a dual purpose as a digestive organ, providing amylolytic and proteolytic enzymes and a copious amount of mucus, as well as being a source of offensive toxic substances (Ghiretti, I950; Buddenbrock, 1956).

Extracts of the octopian posterior salivary gland are very toxic and there seems little doubt that the secretion is used to immobilize and kill crabs which are the main food of the octopodes. The pharmacology of octopus saliva is very complicated; originally it was thought that the main toxic constituents were histamine and tyramine which are certainly present in high concentration, but in addition there are large amounts of 5-hydroxytryptamine (first isolated from octopus salivary glands by Erspamer), acetylcholine, and murexin (urocanylcholine) as well as toxic proteins. The reason for the presence of so many toxic substances in this secretion is not clear. 
The venom glands of snakes are modified salivary glands. Leydig noted a resemblance to the mammalian parotid glands, although in most respects the structure seems closer to the salivary glands of birds in that they have a loculated structure. The salivary duct opens at the base of a grooved tooth which is the injection device; the exact anatomical arrangement varies in different species. Expulsion of preformed secretion from the gland occurs as a result of contraction of the gland or contraction of surrounding muscles.

Snake venoms contain a great many enzymes (Zeller, I948) some of which are concerned with their toxicity. Phospholipase A (lecithinase) seems to be the main heat-stable toxic factor in the venom of water mocassins (Agkistrodon piscivorus) and rattlesnakes (Crotalus terrificus). The rate of absorption of the toxin from the site of injection is increased by the high concentration of hyaluronidase present. Especially high concentration of this enzyme is present in the venom of vipers (V.aspis, V. russelli, Echis carinata) and the krait (Bungarus coeruleus) (Deutsch and Diniz, 1956; Hadidian, 1956; Jaques, 1956).

Deutsch and Diniz (1956) point out that the venom from a variety of snakes will form bradykinin from a serum globulin, in the same way that saliva from many mammalian species will (page 180). Viper venom also has prothrombin-like activity (Devi, Bose and Sarkar, 1956) whereas cobra venom in the presence of a plasma cofactor is an inhibitor of the conversion of prothrombin to thrombin (Devi, Mitra and Sarkar, 1956). These also are rather similar to the findings in mammalian saliva.

The parotid glands of the toad have long been esteemed in China under the name of Ch'an Su as a valuable ingredient of the pharmacopoeia, used in many diseases but especially in cardiac failure. Chen and his co-workers (Chen, Jensen and Chen, 193I) have systematically studied the pharmacologically active materials in toad glands (these have recently been reviewed by Jensen and Westphal, 1956). These glands have as rich a collection of pharmacologically active substances as the octopus salivary gland. Considerable amounts of adrenaline and noradrenaline are present as well as the indolalkylamines, bufotenine (N-dimethyl- 5 hydroxytryptamine), bufotenidine (N-trimethyl-5 hydroxytryptamine), dehydrobufotenine (3-dimethylvinyl, 5 hydroxyindole) and bufothionine (5-sulphatotryptamine). However, the most fascinating substances present are a group of steroid glycosides with a highly 
active cardiotonic effect. 'These fall into two classes, the free glycosides with a six-membered lactone ring (identical to that in scillaridin A) called Bufogenins, and conjugates of these substances with suberylarginine called Bufotoxins. The lethal dose in the cat of bufalin is $137 \mu \mathrm{g} / \mathrm{kg}$; this compares favourably in toxicity and cardiotonic activity with the best of the plant glycosides. Chen found similar activity in all species of Bufo although the chemistry of the substances present is not identical. The function of these substances is unexplained, but they are unlikely to be the source of an internal secretion, since toads thrive after removal of the parotid glands. It is possible that they are used offensively since the material is toxic to a wide range of animals, but it is difficult to see how they can constitute an effective venom in the absence of an injection device.

Birds have an elaborate system of salivary glands. Histologically these glands are septate (Calhoun, 1932). There is a paucity of physiological data on bird saliva, but presumably it has a lubricative and digestive function. It is also used in nest building. The oriental delicacy, birds' nest soup, is made from dried salivary mucin obtained from the nest of the Borneo swift.

\section{REFERENCES}

BAPTIST, B. A. (1942). The morphology and physiology of the salivary glands of hemiptera-heteroptera. Quart. F. micr. sci., N.S. 83, 9I-I 39. BODENSTEIN, D. (1943). Factors influencing growth and metamorphosis of the salivary gland in Drosophila. Biol. Bull., 84, 12-33.

BUdDENBRock, w. (1956). Vergleichende Physiologie, Bd. 3. Birkhäuser, Basel.

CALhoun, M. L. (1932). The microscopic anatomy of the digestive tract of Gallus domesticus. Iowa F. Science, 7, 261-381.

CHEN, K. K., H. JENSEN and A. L. CHEN (I93I). Ch'an Su, the dried venom of the Chinese toad, the pharmacological action of principles isolated from it. F. Pharm. Ther., 43, I3-50.

Deutsch, H. F. and C. R. DINIZ (1956). In The venoms. American Assoc. Adv. Science, Washington.

DEVI, A., A. K. BOSE and N. K. SARKAR (1956). In The venoms. American Assoc. Adv. Science, Washington.

DEVI, A., S. N. MITRA and N. K. SARKAR (1956). In The venoms. American Assoc. Adv. Science, Washington.

ERspamer, v. (I 954). Pharmacology of indolealkylamines. Pharmacol. Rev., 6, 425-487.

FRANZ, F. (1903). Über den die Blutgerinnung aufhebenden Bestandtheil des medicinischen Blutegels. Arch. exp. Path. Physiol., 49, 342-366. 
GHIRETTI, F. (I950). Enzima della ghiandole salivari posteriori dei cefalopodi. Boll. Soc. ital. Biol. sper., 26, 776-780.

Hadidian, z. (I956). In The venoms. American Assoc. Adv. Science, Washington.

HAYCROFT, J. B. (I 884). Über die Einwirkung eines Secretes des officinellen Blutegels auf die Gerinnbarkeit des Blutes. Arch. exp. Path. Pharmak., I8, 209-2I7.

JAQues, R. (1956). In The venoms. American Assoc. Adv. Science, Washington.

Jensen, H. and U. Westphal (1956). In The venoms. American Assoc: Adv. Science, Washington.

LESPERON, L. (I 937). Recherches cytologiques et expérimentales sur la sécrétion de la soie. Arch. Zool. exper. et gen., 79, I-I 56.

LESTER, H. M. O. and L. LLOYD (I 928). Notes on the process of digestion in the tsetse flies. Bull. Ent. Res., I9, 39-60.

ROEDER, K. D. (I953). Insect physiology. Riley, New York.

WALSHE, B. M. (1947). Feeding mechanisms in chironomus larvae. Nature, I60, $474-475$.

Wigglesworth, v. B. ( 1927 ). Digestion in the cockroach. II. Digestion of carbohydrates. Biochem. F., 21, 797-8 I I.

- (1929). Digestion in the tsetse fly: a study of structure and function. Parasitology, 21, 288-32 I.

- (1959). Insect physiology. Methuen, London.

ZELLER, E. A. (I948). Enzymes of snake venoms and their biological significance. Advanc. Enzymol., 8, 459-496. 


\section{INDEX}

Acetamide, 188

Acetazoleamide, I47, I 54

Acetylcholine, content of gland, 43, Io6; in octopus, 269

effect on amylase secretion, $5^{8}$ on blood vessels, 40, 78-9, 126,

I 33

on metabolism, 58, 79, 230, 232

on phosphorus turnover, 58 , 232

electrogram, 46,78

in paroxysmal secretion, I 17

leakage, $6 \mathrm{I}, 63-4,80$, I08, I Iо

release by nerve impulses, $43^{-4}$, 46,129

by potassium, 85

from degenerating nerves, 63 , I 6 6-I 7

secretory effect, 40-I, 46-7, $77-8$

in man, 76,79

supersensitivity, $58,64,108-9$

Acini, electrical responses, 199

embryology, 3 I

histology, 10, 20

in immature dogs, 218-19

innervation, 42

protein secretion, 183,233

role in secretion, 9, I4I, I95, $217,223-4,226$

Adrenal corticoids, effect on salivary chloride, 154

on potassium, I $5 \mathrm{I}, 220$

on saliva of sheep, I 63

on sodium, 152,220

Adrenaline, content of gland, Io6 in toads, 270

effect on amylase secretion, $5^{8}$

on blood vessels, 84 , I09, I 35

on glucose in saliva, 83,187 ,

253

on metabolism, $58,135,230$

on myoepithelial cells, 49,85

on phosphorus turnover, 58 , 232

P.S.G. - T on sodium and chloride in saliva, I47, I 54, 2 I 9

electrogram, 6o, 83

in antilytic secretion, I I 5

in paralytic secretion, I I $2-14$

release, 60, 85-6, I I 3, I I 5, 237 , 243

secretory effect, $58,8_{3}$

in man, $6 \mathrm{I}, 83$

supersensitivity, 58,63 , Io6-9, I $12-13$

Afferent nerves, of the gland, 66 of the salivary reflex, 24I effect of section, I09, II 3

Alcohol excretion, 262

Amine oxidase, activity in glands, 60-I

after denervation, I 05, I I I

function, 262

Amino-acids in saliva, 174,185 , 215,219

after arterial injection, 215

Amino glutamate, I 85

peptidase, 30

Amphetamine, 83

Amylase, in gland, 32, 106, 269

of cockroaches, 268

in saliva, $171-2,178-9,254^{-6}$

synthesis, 233

Antibacterial action of saliva, I79, 257

Antibiotics, excretion, 189, 262

Anticholinesterases, secretory effect, $42,44,62,80$, I I I, I 40 after denervation, 62, 108

Antihistamines, 82

Antilytic secretion, I I 5

Apomorphine, 75

Aptyalism, 25 I

Arginase, 32

Arteries of glands, 15

Arteriovenous anastomoses, 17, I9, I 22

Ascorbic acid in saliva, 187

Atrophy of glands, 3I-2, $103-7$, 232 
Atropine, effect on paroxysmal secretion, I I 7

phosphorus turnover, 232

secretion caused by acetylcholine and parasympathetic nerves, 51, 59, 66, $72,79,81,125,129,134$, 229

by anticholinesterases, 62 , 80

by barium, 72,85

by histamine, 72,86

by mercury, 86

by nitrogen mustards, 72 , 86

vasodilatation, $51,73, \mathrm{I} 23$, I $28-9,133-4,230$

ganglion blocking action, $8 \mathrm{I}$

secretory effect, 74,76

sympathetic blocking action, 8I

tolerance, $8 \mathrm{I}$

treatment, effect on enzymes, I I I

on histological picture, I04-5

on sensitivity to drugs, 63 , I09, II 3

Augmented secretion, 49, 51-2, 54, 59,78

Banthine, 76,82

Barbiturates, 82

Barium, 72, 85

Bicarbonate, in saliva, $144^{-6}, 212$, 22 I

of puppies, I 47,218

after arterial injection, 215 parotid, of sheep, 162

effect of acetazoleamide, 147

of hyperventilation, 146,219

of metabolism, 148

on chloride in saliva, 154,218

219

Bicarnesine, 79

Blood flow, determination by iodicle clearance, I 22, 224

effect of acetylcholine, $40,78-9$, 1 26, 129

of adrenaline, $84,109,135$

of bleeding, 55

of bradykinin, 79, I 80

of chlorpromazine, I23, 135

of chorda stimulation $122-3$, I 25, 127-9 of priscol, 123, 135

of sympathetic stimulation, I 22-3

on secretion, 39, 4I, 6I, I2I, I 23-4

Blood, supply of glands, 15, I21, 224-5

group substances, $174,176-7$, I 96,26 I

Botulinum toxin, $13 \mathrm{I}$

Bradykinin, 79, 106, 1 32-3, г 36, I 80,270

Bretylium, 66, 85

Bromide in saliva, $154,21_{4}^{-1} 5$

effect on secretion, 203

Bulbocapnine, 74

Butyramide, 188

Calcium in saliva, $145,16 \mathrm{I}$

Carbachol, secretory effect, 8I, roy on phosphorus turnover, 232

Carbon dioxide in saliva, 144

Caries, 1 54, 25 1-2

Chloride, in gland, 205

in saliva, $145,153,155,203,212$, 22 I

after arterial injection, 215

adrenaline, $147,154,219$

of puppies, 218

of sheep, I 62

effect of adrenal corticoids, 154 on amylase, $178,256,268$

Chloroform, 74

Chlorpromazine, on phosphorus turnover, 232

sympatholytic effect, $53,67,123$, I 35

Cholinesterase, in glands, 29, 43, 47 after denervation, I05, I I I-12 in duct cells, 29, 38

in saliva, 48

inhibitors, $42,44,80,108,140$

Chorda tympani syndrome, 46

Cisternae, 23-4, 26

Coagulation of blood, effect of saliva, 108, 261, 268-70

Cocaine, effect on secretion, 60,75 , 84

paralytic, I I 3

paroxysmal, i I 7

Coramin, 75

Corbasil, I I 2 
Creatine phosphate, I 88,23 I

Creatinine, 219, 221

Crotonic betaine, 79

Curarine, 76,78

Cyanide, effect on chloride in saliva, I 54

on lactate formation, $23 \mathrm{I}$

on potassium in saliva, $\mathrm{I}_{5} \mathrm{I}$

on protein synthesis, 233

on spontaneous secretion, 97, I I I

Cyclopropane, 74

Decamethonium, 76

Dehydrogenases, 30

Denervation, effect on activity of amine oxidase, I05, I I I of cholinesterase, 44, I05, I I II 12

of respiratory enzymes, 106

content of acetylcholine, 43, I06 of adrenaline, Io6

contralateral gland, 104

function, $64-5,103,112$

metabolism, 23 I

sensitivity to acetylcholine, 58 , I 09

to adrenaline, $58,63,106-7$, I I 2-I 3

to anticholinesterases, 62, 108

to tyramine, 108

structure, $103^{-5}$

Dibenamine, 84,232

Dibutoline, 82

Diencephalic autonomic epilepsy, 242

Digitalis, 75

Dihydroergotamine, 73,84 : I I 4

Dinitrophenol, effect on oxygen consumption, 232

on protein synthesis, 233 secretory effect, 75

Duct cells, blood supply, i 5-16, I 9, $122,195,211,224-6$

content of enzymes, 29-30

effect of adrenal corticoids, 220

of adrenaline, 2 I 9

electrical responses, 20I, 206, 2 I I

embryology, 16

innervation, 25, 38

morphology, 9, 2 1 8

protein secretion, $183,233-4$ reabsorption of water, $143-4,220$ role in secretion, 9, 31, 143, 195 , 211, 217, 219, 226

transfer of bromide and chloride, 2 I 5

of iodide, I 57-8, 2 I 6

of potassium, 2 I I-I 2,2 I 5

of urea, $216,222-3$

Electrical responses, to acetylcholine, 46,78

to adrenaline, 60,83

to chorda stimulation, $4 \mathrm{I}, 46,59$, I 97, I 99-20 I

to sympathetic stimulation, 53, $59^{-60}, 198-201$

as evidence of double innervation, $56,58,206$

Embryology, 30

Endoplasmic reticulum, 23, 25-7, $3 \mathrm{I}, 233$

Ephedrine, 83

Ergotamine, 59, 84, 232, 237

Ergotoxin, I 35

Eserine, effect on secretion, 40, 62, I 26, I 40

caused by barium, 85

by potassium, 85

paroxysmal, I 17

Esterases in gland, 29-30

in saliva, 256

Ether, 74

Excretion in saliva of alcohol, 262 antibiotics, 189,262

bromide, 154,214

glucose, $83, \mathrm{I} 86,253$

iodide, $155,181,196,212,22 \mathrm{I}$, 262

lead, 262

lithium, I 52

mercury, 73, 85, 262

perchlorate, 160

saccharine, 253

sulphonamides, I 88

thiocyanate, I 60, 257

Expulsion of saliva, by adrenaline, 49,85

by histamine, 49

by oxytocin, 49

by sympathetic stimulation, $4^{8-9}$

Fibrinolytic activity of saliva, I 80 , 26 I 
Fluoride, on secretion, I $54-5$ on metabolism, 231

Fucomucins, 173, 176

Functions of saliva, 99, 25 I, 267

Glucogen, content of glands, 29, $23 \mathrm{I}$

effect of amylase, I 79

Glucose, in saliva, $83,186-7,253$

utilization, 128, 23 I-2

Glycerol, I 88, 22 I

Glycine, 185

Golgi, apparatus, 25, 32, 268

Granules, I I, I 4, 23-7, 29, 31, 196, 267

Hexamethonium, 47, 73, 76

Hirudin, 269

Histamine, in glands of octopus, 269

motor effect, $49,85^{-6}$

secretory effect, $72,76,86$

Histidine, in saliva, 185

Hyaluronidase, in glands of snakes, 270

in saliva, 256

Hydroxyproline in saliva, 185

Hydroxytryptamine, in glands of octopus, 269

secretory effect, 76

Indolalkylamines, 270

Inhibition of secretion, by acetylcholine, $40,78,124,126$

adrenaline, 84 anaesthetics, 73,77

ganglion blocking drugs, 77

parasympatholytic drugs, 8 I

sympathetic stimulation, 4I, I24,

242

sympatholytic drugs, 84

Iodacetate, effect on chloride, 154

on lactate, $23 \mathrm{I}$

on potassium, I $5 \mathrm{I}$

on protein synthesis, 233

Iodide, clearance, $155^{-6}, 224^{-5}$

effect on secretion of chloride,

154

of nitrate, 160

of perchlorate, 160

of thiocyanate, 160 on secretion and electrical responses, 204

excretion in saliva, $155^{-60}, 181$, $196,212,221,262$

after arterial injection, $215^{-1} 6$ incorporation in protein, $160,18 \mathrm{I}$ transient, $157,212-13$

Iodotyrosines, I 8 I

Isoleucine in saliva, 185,215

Isoprenaline, 83

Kallidin, see Bradykinin

Kallikrein, 87, I06, I31, I33-4, I 80,26 I

Lactate formation, $23 \mathrm{I}-2$

Lipase in saliva, 256

Lithium, I 53

Lymphatics of glands, 19

Lysozyme, I 72, I79, $25^{8}$

Magnesium in saliva, I45, I6 I

Malonamide, 188

Mannitol, I 88, 22 I

Mercury, 72-3, 85, 262

Metabolism of glands, 229

effect of acetylcholine, 58, 79, 230,232

of adrenaline, 58 r 35,230

of chorda stimulation, 104, I 28, I 30, I 33-4, 230

of cyanide and iodacetate, $23 \mathrm{I}$

of denervation, 106

of dinitrophenol, 232

of noradrenaline, 232

of pilocarpine, 229

of sympathetic stimulation, 230-I

Methacholine, 79, 108

Methionine, 215

Methylscopolamine, 82

Metrazol, 244

Mitochondria, 23-7, 31-2, 196 in silk glands, 268

Morphine, excretion in saliva, 262 effect in antilytic secretion, I I 5

in paralytic secretion, $113^{-1} 5$ secretory effect, 75

Motor nerves, 39-4I, 48-50, 54, 84

Mucoproteins, 169-75, 179

Murexin, 269 
Muscarine, 79-80

Myoepithelial cells, I I , 25, 29, 39$40,49^{-50}$

Neuraminic acid, 175

Nicotine, 73,77 after denervation, 108

Nitrate, I 59, 203-4

Nitrite, 125

Nitrogen mustards, 72, 86-7

Noradrenaline, content of gland, I06

in toads, 270

metabolic effect, 232

release, 60 secretory effect, $60,83,108$

Nucleus salivatorius, 239

Olfactory-parotid reflex, 74

Osmolyte concentration of saliva, I 42, 22 I

effect of adrenaline, 2 I 9

in immature dogs, 2 $18-19$

in parotid saliva of sheep, 162

Oxygen consumption of glands, see Metabolism

Oxytocin, 49

Palatine glands, 4I, 96, 99, I 53

Panting and secretion, $75^{-6}, 259^{-}$ 260

Paralytic secretion, 40, 94, I03, I $12-15$

Paredrinol, 83

Parkinsonism, 242

Parotid gland, arteries, I 5

blood supply, 23

control, 239

embryology, 30

innervation, $9,4 \mathrm{I}, 43,48,50$, $60-1,65$

maximum rate of secretion, 140 , I 82

of man, $98,155,178,180$

of sheep, 49-50, 73, 95, 97-8, 124,162

of toad, 270

paroxysmal secretion, i I6-17

saliva, amylase, i 78

bicarbonate, 145

blood group substances, 177

calcium, I6 I

chloride, 153 iodide, $155^{-6}$

kallikrein, $\mathbf{x} 80$

lysozyme, I 79

osmolyte concentration, I42

$\mathrm{pH}, \mathrm{I} 44$

potassium, I49

protein, I69, I7I, I 82

sodium, 152

Parotin, 262

Paroxysmal secretion, $63,100,103$, I I 2, I I 6-17

PAS-Schiff reaction, 29

Perchlorate, effect on chloride, I 54 on iodide, 159

excretion, I6o

$\mathrm{pH}$ of saliva, $\mathrm{I} 44$

Phloridzin on glucose in saliva, 187

Phosphatases, in gland, 29, 32, 106

in saliva, 185,256

Phosphate in saliva, 145, 16 I

Phosphoethanolamine, 162,185

Phospholipid turnover, 162, 232

Picrotoxin, 74, 244

Pilocarpine, secretory effect, 76, $80-1,97$

in man, $75,79,82$

supersensitivity, I08, I I 2

treatment of denervated glands, effect on activity of enzymes, I 05, II I

on atrophy, I04

on histological picture, I05, I I I

on paralytic secretion, I I 3

on supersensitivity, 100, I09, I I I

Pinocytosis, 28

Pituitrin, 75

Potassium, content of saliva, I45, I $47^{-8}, 206$

after adrenaline, 147, 219

adrenal corticoids, I 5 I, 163 , 220-I

arterial injection, 2II, 215216

in saliva of sheep, 163

of puppies, I 5 I

in salivary glands, 205, 208

effect on maximum rate of secretion, 140

secretory effect, 72,85

transient, I 50-I, I63, 206-I2,

217 
Priscol, 54, 58, 61, 85, I23, I 36

Privine, 86

Proline in saliva, 185

Propionamide, I 88

Protease, 32, I06

Protein, in saliva, $\mathrm{I} 69, \mathrm{I} 8 \mathrm{I}-2$

dependence of secretory rate, I $82-3,22$ I

synthesis, I $82,185,233-4$

Pyridin, 75

\section{Quinidine, 75}

Regitine, 73

Resting potential of gland cells, I 99-206 secretion, 98, 142

Ribonucleic acid, 23-5, 234

Scopolamine, 82

Sialic acid, 174-5, 177

Sialomucins, I73, 176, I79

Silk glands, 267

Snake venom, 270

Sodium, content of saliva, 145, I 52 , 212,253

after adrenal corticoids, 152 , 163,220

adrenaline, 147, 219

arterial injection $214-17$

content of glands, 205, 208

transient, 2 I 2

Spontaneous secretion, $38,49,52$,

$94,96,103-4$, I 1 2, 257, 26 I

effect of cyanide, 97, I0 I

of vasoconstriction, 124

on sensitivity to drugs, 100 ,

I I I

function, 99

mechanism, 99

Stilboestrol, 3 I

Striated ducts, 10, 22-3, 196

Sublingual gland, arteries, I 5

electrogram, 58, 199

embryology, 30

innervation, 4I, I95

isolated preparation, 96

maximum rate of secretion, 140

paralytic secretion, I 33

saliva, bicarbonate, $145^{-6}$

chloride, 153

iodide, 156 osmolyte concentration, 142

$\mathrm{pH}, \mathrm{I} 44$

potassium, I 50

sodium, I 52

spontaneous secretion, 95

Submaxillary gland, antilytic secretion, I I 5

arteries, I 5

control, I3 I, 239

electrogram, 4I, 199

embryology, 30-I

glucose utilization, I28, 23 I

innervation, $42,48,50,6 \mathrm{I}, 64$

maximum rate of secretion, 42 , $55^{-6}, 83,106,140$

oxygen consumption, I 34,229

paralytic secretion, I I $2-13$

saliva, amylase, 178

bicarbonate, $145^{-7}$

blood group substances, 176

calcium, I6 I

chloride, I 53 , I 55

iodide, ${ }_{5} 6$, I $_{59}$

kallikrein, I 80

lysozyme, 179

magnesium, I6 I

osmolyte concentration, 142

$\mathrm{pH}, \mathrm{I} 44$

potassium, 149-50

protein, I69-7I, I 84

spontaneous secretion, 96

supersensitivity, 107

Sucrose, 219

Sulphate, 2 I 5

Sulphonamides, I 88

Supersensitivity, caused by denervation, $47,54,55^{8-9}, 62$, I o6-9, I I 2

by ganglion blocking drugs, 109-10

by parasympatholytic drugs, 63-4, 81, I09

in human glands, 65

of salivary ganglion, 108

Sympathectomy, effect on activity of amine oxidase, 60,105

of cholinesterase, I 12

on content of adrenaline, 106

on sensitivity to drugs, 54,59 ,

64,84, 106-I 3

on structure, 104

pain during meals, 66

Synephrin, 83 
Taurine in saliva, 185

Testosterone on gland, $31-2$

Tetrahydronaphthylamine, 75,260

Tetramethylammonium, 72, 77, 79

Thermoregulation, $75,99,260$

Thiocyanate, effect on secretion of chloride, 154 of iodide, I 59

and electrical responses, 204

excretion, I60, 257

Thirst, 259

Throttle veins, 18

Thyroid hormones on gland, $3 I^{-2}$

Tyramine, in gland of octopus, 269 secretory effect, 84, I 08

Tyrosine in saliva, 185,215

Ultrastructure of glands, 20
Urea in saliva, I44, I 88, 219, 22 I after arterial injection, $215-16$, 222

Valine, 2 I 5

Vasoconstrictor nerves, 39-40, 53, $60,12 \mathrm{I}-2$

activation by bleeding, 55

effect on secretion, 39, 4I, 6I, I 2 I, I 23-4, I 37

parasympathetic, 40, 125

tone, 54,66 , I 27

Vasodilator nerves, 39-40, 66, I 2 I, I 27-30, I 35

Veratrum, 75

Vitamins, I 87, I 89

Xerostomia, 72, 77, 25I 



$$
\text { . }
$$

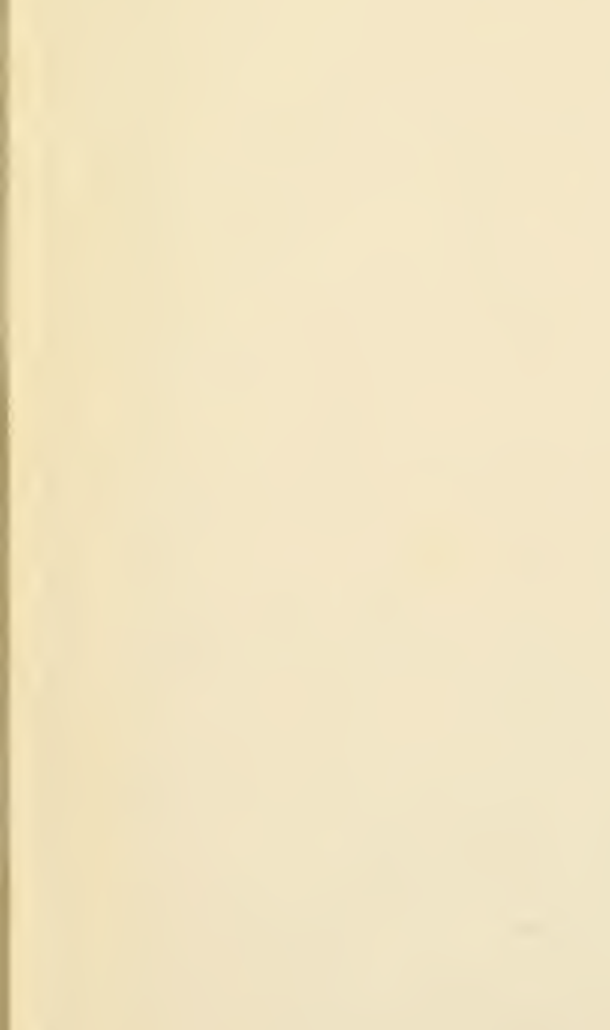


